THE CONTEMPORARY

\title{
SCIENCE SERIES
}

\section{THE History OF THE European Fauna}


LIBRARY

OF THE

UNIVERSITY OF CALIFORNIA. GIFT OF

Uu. Plaso f logo.

\section{BIOLOEY}

LIBRARY

G 




\section{The Contemporary Science Series. Edited by Havelock Ellis.}

\section{The EVOLUtion OF SEX. By Prof. Patrick Geddes and J. A. Thomson. With 90 Illustrations. Third Edition. 3s. 6d.}

"The anthors have brought to the task-as indeed their names guarantee-a wealth of knowledge, a lucid and attractive method of treatment, and a rich vein of picturesque language."-Nature.

II. ELECTRICITY IN MODERN LIFE. By G. W. DE TunZelmann. With 88 Illustrations. 3s. $6 \mathrm{~d}$.

"A clearly-written and connected sketch of what is known about electricity and magnetism, the more prominent modern applications, and the principles on which they are based."-Saturday Review.

III. THE ORIGIN OF THE ARYANS. By Dr. ISAAC TAYLOR. Illustrated. Second Edition. 3s.6d.

"Canon Taylor is probably the most encyclopædic all-round scholar now living. His new volume on the Origin of the Aryans is a first-rate example of the excellent account to which he can turn his exceptionally wide and varied information. . . Masterly and exhaustive."-Pall Mall Gazette.

IV. PHYSIOGNOMY AND EXPRESSION. By P. MANTEGAzzA. Illustrated. Second Edition. 3s. 6d.

"Brings this highly interesting subject even with the latest researches. . . Professor Mantegazza is a writer full of life and spirit, and the natural attractiveness of his subject is not destroyed by his scientific handling of it." - Literary World (Boston).

V. EVOLUTION AND DISEASE. By J. B. Sutton, F.R.C.S. With I 35 Illustrations. 3s. $6 \mathrm{~d}$.

"The book is as interesting as a novel, without sacritice of accuracy or system, and is calculated to give an appreciation of the fundamentals of pathology to the lay reader, while forming a useful collection of illustrations of disease for medical reference."-Journal of Mental Science.

\section{THE VIllage COMMUNity. By G. L. Gomme. Illustrated. 3s. 6d.}

"His book will probably remain for some time the best work of reference for facts bearing on those traces of the village community which have not been effaced by conquest, encroachment, and the heavy hand of Roman law."-Scottish Leader.

VII. THE CRIMINAL. By HAvelock Ellis. Illustrated. Second Edition. 3s. 6d.

"The sociologist, the philosopher, the philanthropist, the novelist-all, indeed, for whom the study of human nature has any attraction-will find Mr. Ellis full of interest and suggestiveness."-Academy.

\section{SANITY AND INSANITY. By Dr. Charles Mercier. Illustrated. 3 s. $6 \mathrm{~d}$.}

"Taken as a whole, it is the brightest book on the physical side of mental science published in our time."-Pall Mall Giazette. 
IX. HYPNOTism. By Dr. Albert Moll. Fourth Edition, Revised and Enlarged. 3s. 6d.

"Marks a step of some importance in the study of some difficult physiological and psychological problems which have not yet received much attention in the scientific world of England."-Nature.

X. MANUAL TRAINING. By Dr. C. M. Woodward, Director of the Manual Training School, St. Louis. Illustrated. 3s. 6d.

"There is no greater authority on the subject than Professor Woodward." -Manchester Guardian.

XI. THE SCIENCE OF FAIRY TALES. By E. Sidney HaRTLAND. 3s. $6 \mathrm{~d}$.

"Mr. Hartland's book will win the sympathy of all earnest students, both by the knowledge it displays, and by a thorough love and appreciation of his subject, which is evident throughout."-Spectator.

XII. PRIMItive FOLK. By Elie Reclus. 3s. 6d.

"An attractive and useful introduction to the study of some aspects of ethnography." - Nature.

XIII. THE EVOLUTION OF MARRIAGE. By Professor Letourneau. Second Edition. 3s. 6d.

"Among the distinguished French students of sociology, Professor Letourneau has long stood in the first rank. He approaches the great study of man free from bias and shy of generalisations. To collect, scrutinise, and appraise facts is his chief business. In the volume before us he shows these qualities in an admirable degree." -Science.

XIV. BACTERIA AND THEIR PRODUCTS. By Dr. G. Sims WoOdHEAD. Illustrated. Third Edition. 3s. 6d.

"An excellent summary of the present state of knowledge of the subject."-Lancet. XV. EDUCATION AND Heredity. By J. M. Guyau. 3s. $6 \mathrm{~d}$.

"It is at once a treatise on sociology, ethics, and pædagogics. It is doubtful whether among all the ardent evolutionists who have had their say on the moral and the educational question any one has carried forward the new doctrine so boldly to its extreme logical consequence."-Professor SuLLY in Mind.

XVI. THE MAN OF GENIUS. By Prof. Lombroso. Illustrated. $35.6 \mathrm{~d}$.

"By far the most comprehensive and fascinating collection of facts and generalisations concerning genius which has yet been brought together."-Journal of Mental Science.

XVII. THE HISTORY OF THE EUROPEAN FAUNA. By R. F. ScharfF, B.SC., Ph.D., F.Z.S. 6s.

XVIII. PROPERTY: ITS ORIGIN AND DEVELOPMENT. By Сh. Letourneau, General Secretary to the Anthropological Society, Paris, and Professor in the School of Anthropology, Paris. 3s. 6 d.

"M. Letourneau has read a great deal, and he seems to us to have selected and interpreted his facts with considerable judgment and learning."-Westminster Review. 
XIX. VOLCANOES, PAST AND PRESENT. By Prof. Edvard Hull, L.L.D., F.R.S. 3s. 6 d.

"A rery readable account of the phenomena of volcanoes and earthquakes." -Nature.

XX. PUBLIC HEALTH. By Dr. J. F. J. Sykes. With numerous Illustrations. 3s. $6 \mathrm{~d}$.

"Not by any means a mere compilation or a dry record of details and statistics, but it takes up essential points in evolution, environment, prophylaxis, and sanitation bearing upon the preservation of public health."-Lancet.

XXI. MODERN METEOROLOGY. AN ACCOUNT OF THE Growth and PRESENT Condition of SOME Branches of Meteorological Science. By Frank Waldo, Ph.D., Member of the German and Austrian Meteorological Societies, etc.; late Junior Professor, Signal Service, U.S.A. With II2 Illustrations. 3s. 6d.

"The present volume is the best on the subject for general use that we have seen." - Daily Telegraph (London).

XXII. THE GERM-PLASM : A THEORY OF HEREDITY. By August Weismann, Professor in the University of Freiburg-inBreisgau. With 24 Illustrations. 6s.

"There has been no work published since Darwin's own books which has so thoronghly handled the matter treated by him, or has done so much to place in order and clearness the immense complexity of the factors of heredity, or, lastly, has brought to light so many new facts and considerations bearing on the subject."British Medical Journal.

XXIII. INDUSTRIES OF ANIMALS. By F. Houssay. With numerous Illustrations. 3s. 6d.

"His accuracy is undoubted, yet his facts out-marvel all romance. These facts are here made use of as materials wherewith to form the mighty fabric of evolution." -Manchester Guardian.

XXIV, MAN AND WOMAN. By Havelock Ellis. Illustrated. Second Edition. 6s.

"Mr. Havelock Ellis belongs, in some measure, to the continental school of anthropologists; but while equally methodical in the collection of facts, he is far more cautious in the invention of theories, and he has the further distinction of being not only able to think, but able to write. His book is a sane and impartial consideration, from a psychological and anthropological point of view, of a subject which is certainly of primary interest."-Athenceum.

XXV. THE EVOLUTION OF MODERN CAPITALISM. By John A. Hobson, M.A. 3s. $6 \mathrm{~d}$.

"Every page affords evidence of wide and minute study, a weighing of facts as conscientious as it is acute, a keen sense of the importance of certain points as to which economists of all schools have hitherto been confused and careless, and an impartiality generally so great as to give no indication of his [Mr. Hobson's] personal sympathies."-Pall MIall Gazette.

XXVI. APPARITIONSANDTHOUGHT-TRANSFERENCE.

By Frank PODMORE, M.A. 3s. 6d.

"A very sober and interesting little book. ... That thought-transference is a real thing, though not perhaps a very common thing, he certainly shows."-Spectator.

XXVII. AN INTRODUCTION TO COMPARATIVE PSYCHOLOGY. By Professor C. Li.oyd Morgan, F.R.S. With Diagrams. 6s.

"A strong and complete exposition of Psychology, as it takes shape in a mind previously informed with biological science. ... Well written, extremely entertaining, and intrinsically valuable." - Saturday Review. 
XXVIII. THE ORIGINS OF INVENTION : A STUDY of Industry among Primitive Peoples. By Otis T. Mason, Curator of the Department of Ethnology in the United States National Museum. 3s. 6d.

"A valuable history of the development of the inventive faculty."-Nature.

XXIX. THE GROWTH OF THE BRAIN: A STUDY OF the Nervous System in Relation to Education. By Henry Herbert Donaldson, Professor of Neurology in the University of Chicago. 3s. 6d.

"We can say with confidence that Professor Donaldson has executed his work with much care, judgment, and discrimination." - The Lancet.

XXX. EVOLUTION IN ART: As Illustrated BY THE Life-Histories of Designs. By Professor Alfred C. Haddon, F.R.S. With I30 Illustrations. 6s.

"It is impossible to speak too highly of this most unassuming and invaluable book."-Journal Anthropological Institute.

XXXI. THE PSYCHOLOGY OF THE EMOTIONS. By Tн. Riвот, Professor at the College of France, Editor of the Revice Philosophique. 6s.

"Charmingly written, and full of lucid explanation and brilliant comparison. A masterly exposition."-British Medical Journal.

XXXII. HALLUCINATIONS AND ILLUSIONS: A STUdY

of the Faliacies of Perception. By Edmund Parish. $6 \mathrm{~s}$.

"The most comprehensive and most scientific work on false perception that has up till now been written in any language."-Journal of Mental Science.

XXXIII. THE NEW PSYCHOLOGY. By E. W. Scripture, Ph.D. (Leipzig). With I24 Illustrations. 6s.

"We have at present no work in English which gives in so compact a form so comprehensive a view of the subject."-Liverpool Post.

XXXIV. SLEEP : Its Physiology, Pathology, Hygiene, and

Psychology. By Marie de Manacéine (St. Petersburg). Illus-

trated. 3s. 6d.

"The book is a complete and wonderfully interesting exposition, and as such ought to receive a hearty welcome." - Scotsman.

XXXV. THE NATURAL HISTORY OF DIGESTION. By A. Lockhart Gillespie, M.D., F.R.C.P. Ed., F.R.S. ED.

With a large number of Illustrations and Diagrams. $6 \mathrm{~s}$.

"Dr. Gillespie's work is one that has been greatly needed. No comprehensive collation of this kind exists in recent English literature. All the important wol $k$ that has appeared within the past few years is discussed so far as the limits of the book allow of discussion, and extremely little of value has been omitted. Nut least interesting are the accounts of the author's own original work."-A merican Journat of the Medical Sciences.

XXXVI. DEGENERACY : Its Causes, Signs, and Results. By Professor Eugene S. Talbot, M.D., Chicago. With Illustrations. 6s.

"The author is bold, original, and suggestive, and his work is a contribution of real and indeed great value, more so on the whole than anything that has yet appeared in this country." - American Journal of Psychology.

XXXVII. THE RACES OF MAN. By J. Deniker. 6 s.

XXXVIII. THE PSYCHOLOGY OF RELIGION. AN

Empirical Study of the Growth of Religious ConsciousNess. By Edwin Diller Starbuck, Ph.D., Assistant Professor of Education, Leland Stanford Junior University. 6 s. 
THE CONTEMPORARY SCIENCE SERIES.

EDITED BY HAVELOCK ELLIS.

THE HISTORY OF THE EUROPEAN FAUNA 


\section{THE HISTORY OF THE EUROPEAN FAUNA}

BY

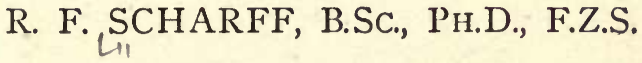

Keeper of the Natural History Collections, Science and Art Museum, Dublin; Member of the Royal Irish Academy; Corresponding Member of the Senckenbergische Naturforschende Gesellschaft.

WITH ILLUSTRATIONS.

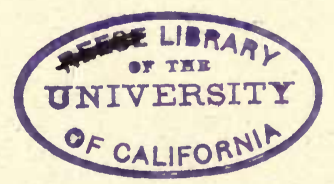

LONDON

WALTER SCOTT, LIMITED

PATERNOSTER SQUARE 1899 
QL 253
534

BIOLOEY LIBRARY G 


\section{CONTENTS.}

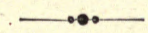

CHAPTER I.

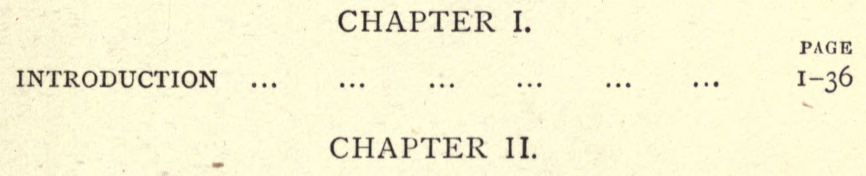

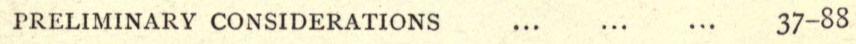

CHAPTER III. THE FAUNA OF BRITAIN $\begin{array}{lllll}\cdots & \cdots & \cdots & \ldots & 89-\mathrm{I} 3 \mathrm{I}\end{array}$

CHAPTER IV.

THE ARCTIC FAUNA ... $\quad$... 132-188

CHAPTER V.

THE SIBERIAN MIGRATION

$\begin{array}{lll}\ldots & \ldots & 189-244\end{array}$

CHAPTER VI.

THE ORIENTAL MIGRATION

CHAPTER VII.

THE LUSITANIAN FAUNA

$$
\begin{array}{llllll}
\ldots & \ldots & \ldots & \ldots & 287-308
\end{array}
$$

CHAPTER VIII.

THE ALPINE FAUNA

BIBLIOGRAPHY INDEX

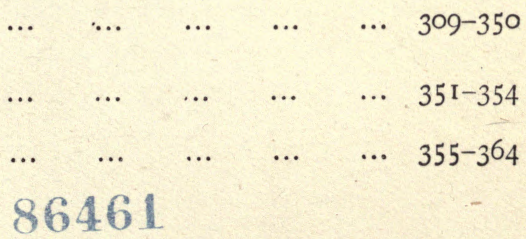





\section{PREFACE.}

OUR knowledge of the present and past fauna of Europe is as yet insufficient to indicate with precision the original homes of its component elements, but I hope that the lines of research laid down here, and the method of treatment adopted, will aid zoologists and geologists in collecting materials for a more com. prehensive study of the history of our animals. I trust also that a fresh impulse will be given by the publication of this book to the study of the Geographical Distribution of Species. Collectors of Beetles, Butterflies, Shells, and Fossils may derive some useful hints by its perusal and thus direct their studies, so as to add, by accuracy in observation, to our knowledge of the former geographical revolutions which have moulded our islands and continents. To geographers, a survey of some of the more important changes in the distribution of land and water in past times-based upon the composition of our fauna-will be interesting. The subject, however, is a complex one. I have ventured to indicate a suitable method of treatment, and as such this attempt to elucidate the history of the European fauna should be received. 
This work was written as the outcome of a paper published in the Proceedings of the Royal Irish Academy (3rd series, vol. iv., I897), "On the Origin of the European Fauna." A summary of that paper appeared in Nature (vol. lvi., I 897), and fuller extracts of more important parts, with some criticisms, in the Geological Magazine (N.S., sec. iv., vol. iv., I897). I freely acknowledge the value of these criticisms, which have largely assisted me to amplify and to improve upon the ideas laid down in the paper.

I have found that it greatly facilitates comprehension of the arguments used, to give a few maps indicating in a general way the extent of former seas and continents. I may in this way, as Mr. Kendall has pointed out, have submerged many square miles of land which had never been covered by the sea,-at least not within recent geological times,but the maps were intended as illustrations of my views in a broad spirit only.

Some zoologists may be surprised that, in some cases, I have not followed the latest views in revised nomenclature. I felt that in a work of this kind it was of supreme importance to employ names still current in our leading text-books, such as Lepus variabilis for the Mountain Hare, instead of Lepus timidus. After each chapter I have endeavoured to give a short summary of contents, while a bibliography of the principal works and papers consulted will be found at the end. I should also acknowledge the aid which I have received from such excellent 
works of reference as the British Museum Catalogues of Birds, by Dr. Bowdler Sharpe, and those of Reptiles, Amphibia, and Fishes, by Dr. Günther and Dr. Boulenger. The valuable works on Mammalia by Sir W. Flower, Mr. Lydekker, Mr. Grevé, and Dr. Trouessart, were indispensable to me.

To Sir William Flower, Mr. Lydekker, Professor Sars, and Professor Smitt, I am especially indebted for allowing me to reproduce drawings from their works, and to my friend Mr. Welch for some beautiful photographs. The Council of the Royal Irish Academy also kindly gave me permission to reprint the maps used in illustration of my paper. Professor Haddon first suggested my writing this book, and gave me many useful hints; and great assistance was rendered me by my colleague, Mr. G. H. Carpenter, in revising the proofs. To both of these kind friends I desire to acknowledge my deep sense of gratitude.

R. F. SCHARFF.

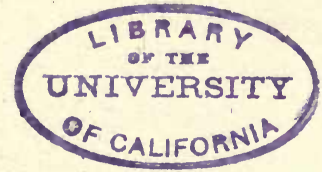





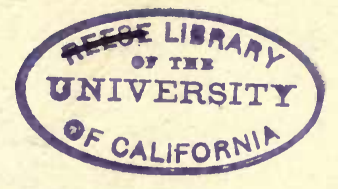

\section{THE HISTORY OF THE EUROPEAN FAUNA.}

\section{CHAPTER I.}

INTRODUCTION.

C. EVERY student of natural history, whether he be interested in birds, butterflies, or shells, contributes his share of facts which help to show how the fauna of his country has originated. The capture of a Swallow-tail or of a Marbled White Butterfly in England at once furnishes material for reflection as to the reason of its absence from Scotland and Ireland. Why should the Nightingale allow its beautiful song to be heard in England, and never stray across the Channel to the sister isle or cross the borders of North Britain? Lovers of bird-life and sportsmen, who have observed the habits of the Ptarmigan in the wild mountain recesses of Scotland, are aware that nowhere else in the British Islands do we meet with this interesting member of the grouse family, and many no doubt have allowed their minds to dwell upon the causes of its singularly local distribution. 
All these animals have a wide range in other parts of the world. In past times, before man began to make observations on the geographical distribution of birds and butterflies, or even before the appearance of man in Northern Europe, they may have lived all over the British Islands. For some reason or other they are perhaps dying out or withdrawing towards their original home, which may either be northward, or to the east or south. If we had some clue as to their former history from fossil evidence-or, in other words, if their remains had been preserved to us in geological deposits,-we should have less difficulty in deciding this problem. But butterflies are scarcely ever preserved in a fossil state, and birds very rarely. We know little or nothing, therefore, of their past history from direct evidence, and are obliged to trust to indirect methods of research which will be indicated later on.

Mammals and Snails tell us their story more plainly. The bones of the former and the shells of snails are easily preserved, and thus furnish us with the necessary data as to their past history, for we find them abundantly in most of the recent geological deposits. Among the mammals of the British Islands there. are some instances of distribution which much resemble those I have quoted. Thus the Arctic Hare (Lepus variabilis) is in the British Islands confined to Ireland and to the mountains of Scotland; and if it were not for the fact that its bones have been discovered in a cave in the south-west of England, we 
should perhaps never have known that, formerly, it must have inhabited that country as well. Of other mammals we possess fossil and also historical evidence of their having once lived in these islands. Such are the Wolf and the Wild Boar, both of which were abundant in Great Britain and Ireland. The latter is a distinctly southern species. We assume this, because its remains have never been found in high northern latitudes; nor does it now occur in Northern Europe or Northern Asia, whilst all its nearest relatives live in sub-tropical or tropical climates. The Arctic Hare, on the contrary, has probably come to us from the north. Its remains are unknown even in Southern Europe, and the more we approach the Arctic Regions, the more abundant it becomes. Thus we have here two instances of British mammals, one of which, the Wild Boar, has died out-as it were in a southerly direction; whilst the other, the Arctic Hare, is apparently retreating towards the north.

There are also some British mammals of which we have no fossil history, at least of which no remains have as yet been found in these islands. Such a one is the Harvest Mouse (Mus minutus). It has a somewhat restricted range in England, and only just crosses the Scottish border in the east. From the rest of Scotland and from the whole of Ireland it is absent. To judge from this distribution, in connection with the fact of its being unknown as a British fossil species, it is probably a late immigrant 
to England, and has not had time to spread, throughout Scotland at any rate. But it is also absent from Scandinavia, from the Spanish peninsula, from almost the whole of Italy and the Alps, as also from the Mediterranean Islands, whilst the little mouse occurs abundantly right across Siberia. We shall learn more about centres of dispersion later on; meanwhile I should mention that such a distribution indicates that the Harvest Mouse has most likely originated in the east, and has spread from there westward in recent geological times.

Conchologists have long ago been acquainted with the fact that many molluscs, for example the so-called "Stone-cutter" Snail (Helix lapicida) and the "Cheese Snail" (Helix obvoluta), have a very restricted range in the British Islands. Both are entirely absent from Scotland and Ireland, the Cheese Snail being confined to South-eastern England. The Stonecutter has rather a wider range, is even known from a Welsh locality, and is met with as far north as Yorkshire. Their distribution would indicate, therefore, that while both are recent immigrants, the Cheese Snail is probably the last comer. This supposition is in so far supported by fossil evidence, as the latter is unknown in the fossil state, whilst the Stone-cutter has been described by Messrs. Kennard and Woodward (p. 243) ${ }^{1}$ as occurring in the cave deposit known as the Ichtham fissure, and also from

1 The numbers in brackets throughout this work refer to the pagenumber in the Bibliography at the end. 
several English pleistocene and holocene deposits. The Stone-cutter can scarcely be looked upon as a very recent immigrant in the light of this evidence, though we have no proof of its having ever had a much wider range in the British Islands than it has to-day.

Among the lichens, which so abundantly cover the rocks and trees in South-western Ireland, and which impart such a characteristic feature to the scenery, we find a beautifully spotted slug (Geomalacus maculosus). ${ }^{1}$ It is a stranger to the rest of the British Islands, and indeed occurs nowhere else in Northern Europe. We have to travel as far as Northern Portugal before we again meet with it, and it is there also that its nearest relations live.

Many more similar examples might be quoted, but enough, I think, has been said to show that the British fauna is made up of several elements whose original homes may lie widely apart and in different directions. We have fossil evidence that some of the northern species, and also a few of the southern ones, have become extinct within comparatively recent times; others are apparently on the verge of extinction, whilst many not only maintain their position in the constant struggle for existence, but are even extending their range.

The problem of tracing the origin of the British fauna, or at least that of some of the more characteristic members of every.section or element,

${ }^{1}$ A map giving its exact distribution in Ireland will be found on p. 300 , and a figure of the slug on p. 298. 
appears at first a somewhat difficult task. Indeed, the means of dispersal of the various groups of animals are so different that it occurred to me it might be better to deal with the mammals, the birds, the reptiles, and so forth, all separately. This idea I have attempted to follow to some extent, with most satisfactory results. The British fauna of the present day is no doubt complex, but no more so than the fauna of the most recent of our geological deposits-the Pleistocene. However, when we go back still further and look at the earlier Tertiary remains, we find the fauna becoming less complex. Northern species disappear, and the strata are entirely filled with the remains of southern animals and plants. Geologists indeed are quite unanimous in their belief, that the fauna of the British Islands during the earlier epochs of the Tertiary Era was a southern one; that it then gradually became more temperate, until at last, in more recent times, decidedly northern forms invaded the country. These seem to have driven out-to some extent at least-the southern species; but more recently again, the southerners, reinforced by an eastern contingent, appear to have gained territory and are advancing into the area held by the northerners. The eastern invasion does not seem to have affected Ireland at all, and we find the country there divided between the southern and northęrn animals. We can thus roughly construct a map as I have done here, showing, by means of horizontal and sloping lines, the principal 
areas inhabited at the present time by the species of northern, southern, and eastern origin (Fig. I).

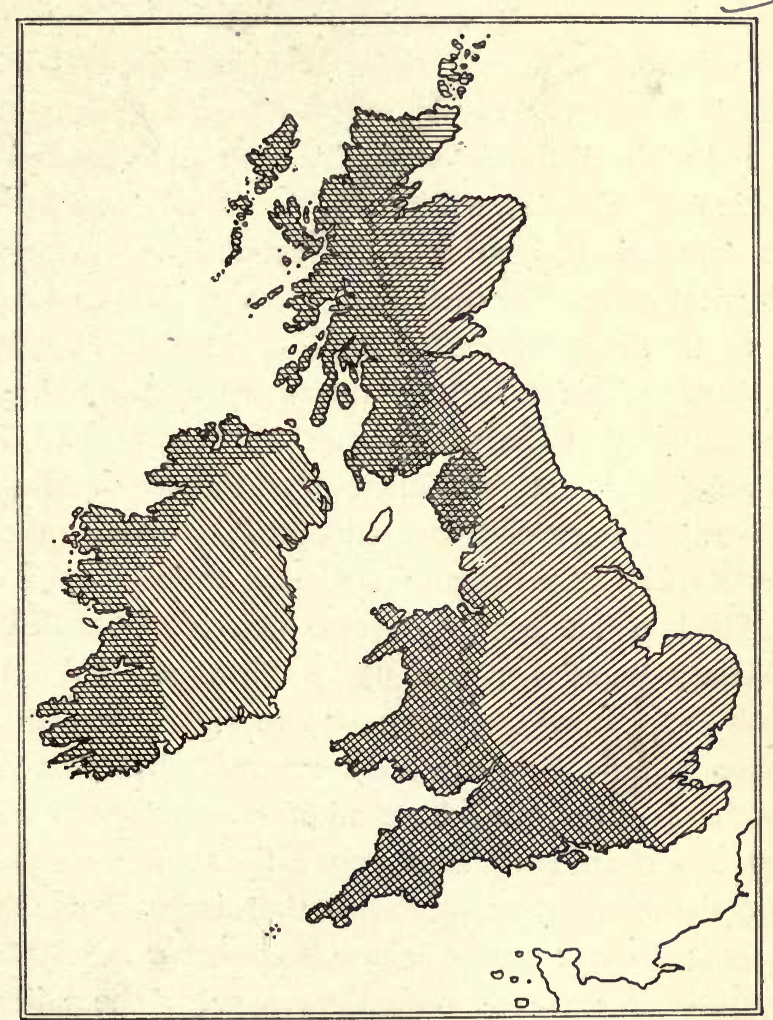

FIG. I. - Map of the British Islands, indicating approximately the areas inhabited by the northern, southern, and eastern animals. The horizontal lines represent the areas of northern species, the sloping lines those of southern and eastern ones.

In the problems which are being discussed in this work I have o?ten found it of advantage, in order to 
facilitate the comprehension of the arguments used, to give maps. Some of these represent the geographical conditions at the particular epoch referred to in the text, but they merely claim to give a general idea. There was never any intention to make them correspond with all the data of which we have geological evidence. They arc what I might call "diagrammatic." In comparing them with reconstructions of former physical geography such as have been attempted from time to time, I hope geologists will therefore deal leniently with the faults I may have committed, and remember that the maps are "impressions," or "diagrams," and not faithful representations of all the geographical revolutions witnessed by some of our remote forefathers at any particular period.

The knowledge we gain from a study of the British Tertiary deposits enables us to affirm positively that both the eastern and the northern species arrived in these islands comparatively recently, but that the southern forms must have migrated northward from the Continent long ages ago. Since the northern and the eastern migrations-that is to say, those coming from the north and east-were the last to arrive in Northern Europe, the remains of the animals contained in the most recent deposits of that portion of our continent will furnish us with a clue as to the extent of the area inhabited by them. This is not all, however. It is also possible to discover from these remains the direction which the animals that they belonged to came from. As we shall learn later on, 
a migration on a vast scale entered Europe during the Pleistocene epoch-the most recent of the geological epochs, during which great extensions of glaciers occurred in the mountainous regions of Europe. The latter period is known to us as the Ice Age or Glacial period. This will be described more fully in Chapter II., meanwhile I may mention that we presume that this migration came from the east, because no remains of the members of that particular fauna are known from Spain, Southern Italy, Scandinavia, Ireland, or from the Balkan peninsula. The number of species evidently belonging to this same migration, moreover, become fewer as we proceed westward, and a large proportion of them still inhabit Northern Asia, though most of them are now extinct in Europe. After having thoroughly studied such a recent geological migration, we learn to understand others better, though the more ancient they are, the fewer are the traces and the more difficult are they to follow.

Then again we have to take into consideration the fact, that whilst mammals, particularly the larger herbivores, are forced to migrate frequently owing to scarcity of food or temporary changes of climate, many of the invertebrates remain practically unaffected by either. Most of our land mollusca, for instance, are satisfied with meagre provender, and stand extremes of climate well, as long as there is sufficient moisture. As a result of their peculiar disposition, many of them, no doubt, have survived through 
several geological epochs, and have witnessed vast geographical revolutions in their immediate surroundings, whilst mammals are comparatively short-lived. Being driven from one country to another, and exposed to innumerable enemies, new types appear and old ones rapidly vanish; in fact, there are almost constant changes in the mammalian fauna as we pass from one epoch to another.

I have until now referred more particularly to the British fauna and the North European in general, because the history of our own animals interests us all more than those of any other European area. It is, moreover, preferable to commence our investigations into the origin of the European fauna by the study of a small district. This should, if possible, be an island. If we took a slice of the continent like France or Germany, we should find the problem more complex. Instead of choosing the British Islands, we might, however, take an island like Corsica or Sardinia. In either of these we should discover peculiarities in the composition of their fauna precisely similar to those which I have indicated to be present in the British fauna. We should find probably a more striking endemic ${ }^{1}$ element, which

1 The term endernic will be employed throughout this work as applied to species peculiar to a country and not found elsewhere. Autochthonous will be used in speaking of a species which has originated in a country to which, however, it is not peculiar; e.g., the Chamois is an autochthonous Alpine species, but occurs also in the Pyrenees and Caucasus. An indigenous species is one native to a country, as opposed to the term "introduced," and is applicable to all species which have reached it loy ordinary migration. 
with us is so meagre that it can almost be left unnoticed; the main features, however, remain nearly the same. The fauna of both of these islands is composed of a strong southern element, of an eastern and a northern one, and in addition we have here species whose ancestors lived in Western Europe.

Before investigating more minutely the problems suggested by the composition of the faunas of these insular and also of some continental areas, it is necessary that we should thoroughly understand all about the migrations of animals. One of the principal objects of this work is to show how the autochthonous animals of Europe, i.e., those which have originated there, may be distinguished from the immigrants, and to trace the latter to the home of their ancestors. But in doing so, it is necessary to refer to the many important geographical changes which have occurred in Europe during the latest geological epochs. The study of the geographical distribution of the European fauna, as expounded in this work, will in many instances confirm the theories as to geographical changes based upon geological foundations. But in every case the views herein advocated are founded upon the geographical distribution of living and extinct organisms alone.

A terrestrial mammal like the deer can, under ordinary circumstances, only reach one part of a country from another by walking or running to it; but a beetle, such as the cockchafer, has two different 
modes of progression. It may walk or fly. In both, however, there is a third mode of transport-an involuntary one. The deer may be suddenly seized by a flood whilst crossing a river, and carried far away without necessarily coming to grief. The beetle in a similar manner could be transported to a distant country, or it might be caught in a whirlwind and blown hundreds of miles off.

We may thus distinguish between the natural or active and the accidental or passive means of distribution of animals. The active mode of dispersal again may be only migratory, as in most animals, or periodic and migratory, as in some birds and fishes. It is of course the tendency of every species to spread in all directions from its original home, provided it does not encounter obstacles, such as want of food, unsuitability of climate or soil, or barriers such as mountains, rivers, or the sea. Birds might be thought to be little interfered with by any of these barriers, but, as Dr. Wallace has shown, they are almost as much affected by them in their distribution as mammals are.

This then is the ordinary migratory distribution. Periodic distribution obtains with migratory birds and fishes. The annual flight of swallows to their northern summer residence comes under the heading of periodic migration or distribution, but apart from this, the swallow must seek to extend its range by the ordinary method, like every other animal. Similarly, the herring migrates periodically into shallow water to spawn, only to return again to its 
decper home, where, as its numbers increase, there must be a tendency to spread. We have in these cases, therefore, both a periodic and an ordinary movement of migration.

Now, in studying the composition of a fauna, and especially its origin, it is of the utmost importance to be able to determine approximately the percentage of accidental arrivals and of the ordinary migrantsthat is to say, of those which have reached the country owing to accidental distribution, and of animals which have adopted the usual course of migration. It is of all the more import to review this subject of accidental, or, as Darwin called it, "the occasional means" of distribution, as both he and Dr. Wallace have, I venture to think, somewhat overestimated its significance. No one doubts that accidental transportal takes place, but the question is whether the accidentally transported animals arrive living and reach a spot where suitable food is procurable, and whether they are able to propagate their own species in the new locality. For it must be clear to anybody that the accidental transportal of a beetle or of a snail to a new country cannot affect its fauna or add one permanent member to it unless all these conditions are fulfilled. As a matter of fact, only exceedingly few instances are on record of man having witnessed, for example, the accidental transportal across the sea to an island of a live animal.

To mention an example, Colonel Feilden informs 
us (Zoologist, I 888) that, when living on the island of Barbadoes, an alligator arrived one day on the shore, and at the same time a tree measuring 40 feet in length, which was recognised as a Demerara species, was likewise stranded. He thinks that there can be no doubt that the alligator, which was alive when it reached Barbadoes, was transported by the tree, thus covering a distance of 250 miles from the nearest land. Numerous observations on the accidental transportal of seeds and tree-trunks from one island to another, and from a continent to an island, have been recorded, and even on our own shores we may witness the occasional arrival of such vegetable products from a far distant land. On the west coast of Ireland it not unfrequently happens that large West Indian beans are stranded, and in this as wcll as in many other similar cases the seeds have often proved none the worse for their prolonged immersion in seawater. That locusts are sometimes blown to great distances from the land is not so surprising, since their power of steering through the air is very limited. Darwin mentions (p. 327) having caught one 370 miles from the coast of Africa, and that swarms of them sometimes visited Madeira. Sir Charles Lyell relates that green rafts composed of canes and brushwood are occasionally carried down the Parana River in South America by inundations, bearing on them the tiger, cayman, squirrels, and other quadrupeds.

But though actual observations of such abnormal instances of the dispersal of animals are few, many 
experiments have been made to demonstrate the possibility of a passive transportal of species over wide distances. It was especially Darwin who gave a great stimulus by setting the example to those interested in natural history in the conduct of such researches. He was struck by the fact that, though landshells and their eggs are easily killed by sea-water, almost all oceanic islands, even the smallest and most isolated, are inhabited by them, and felt that there must be some unknown but occasionally efficient means for their transportal (p. 353). To quote his words: "It occurred to me that land-shells, when hibernating and having a membranous diaphragm over the mouth of the shell, might be floated in chinks of drifted timber across moderately wide arms of the sea. And I find that several species in this state withstand uninjured an immersion in sea-water during seven days: one shell, the Helix pomatia, after having been thus treated and again hibernating, was put into sea-water for twenty days, and perfectly recovered. During this length of time the shell might have been carried by a marine current of average swiftness to a distance of 660 geographical miles. As this Helix has a thick calcareous operculum, I removed it, and when it had formed a new membranous one, I again immersed it for fourteen days in sea-water, and again it recovered and crawled away. Baron Aucapitaine has since tried similar experiments: he placed one hundred land-shells, belonging to ten species, in a box pierced with holes, and immersed it for a 
fortnight in the sea. Out of the hundred shells, twenty-seven recovered. The presence of an operculum seems to have been of importance, as out of twelve specimens of Cyclostoma elegans which it thus furnished, eleven revived. It is remarkable, seeing how well the Helix pomatia resisted with me the saltwater, that not one of fifty-four specimens belonging to four other species of Helix tried by Aucapitaine, recovered. It is, however, not at all probable that land-shells have often been thus transported; the feet of birds offer a more probablc method."

We have here positive evidence that such shells as Helix pomatia and Cyclostoma elegans might easily be transported to an island from the mainland. The former occurs in France, Holland, and England, and the latter all along western continental Europe and England. And yet neither of these species inhabits the Canary Islands, Madeira, or Ireland, none of which are at too great a distance from Europe to be within easy reach for a floating object. The fact that Cyclostoma elegans does not live in Ireland is of particular interest in connection with the floating-theory just quoted, as on all sides of Ireland dead specimens have been picked up on the shore, showing that marine currents carry specimens and have thus transported them for countless centuries. Nevertheless the species has not established itself in Ireland. If such a fate meets a land-shell of the type of Cyclostoma elegans, it may be asked, with some justification, what chance slugs or the smaller non-operculated species would have to 
reach an island like Ireland alive from the mainland, and to colonise it successfully.

Both slugs and their eggs are killed by a short immersion in sea-water, as I have proved experimentally. I have also subjected slugs, in the act of crawling on twigs, to an artificial spray of sea-water. This seemed to irritate their tender skins to such an extent that they curled themselves up, released their hold on the twig and let themselves drop to the ground. If we supposed, therefore, that a slug had successfully reached the sea, transported on a treetrunk, the moisture would tend to lure it forth from its hiding-place under the bark, whilst the mere spray would prove fatal to its existence. Those species of snails and slugs which iead an underground existence, rarely venturing above ground, such as Testacella and Coecilianella, would have even less chance of being accidentally carried to some distant island.

The suggestion advanced by Darwin (p. 353), that young snails just hatched might sometimes adhere to the feet of birds roosting on the ground and thus be transported, appears to me so extremely improbable as to be scarcely worth serious consideration. Indeed, as Darwin himself acknowledged later on, it does not help us very much to suggest possible modes of transport. What we require is direct evidence. How far we are, however, from obtaining it, may be inferred from Mr. Kew's remark (p. I I9), that "we have little or no actual evidence of precise modes of dispersal even for short distances on land." 
A very curious statement was made by a wellknown French conchologist, the late M. Bourguignat, with regard to introductions of mollusca. Whether he had any actual facts collected in support of it, I cannot say, but he maintained that species accidentally transported, with the exception of those under maritime influence, can only be acclimatised from north to south, and not from south to north-from east to west, but not from west to east (p. 353).

The whole theory of the accidental or abnormal dispersal of mollusca appears to have been originated by Darwin, in order to account for their presence on socalled Oceanic islands. His views were strongly supported by Wallace, who defines these islands (p. 243) as those which are of volcanic or coralline formation usually far from continents, entirely without indigenous land mammals or amphibians, but with a fair number of birds and insects, and usually with some reptiles.

I do not wish it to be understood that I am in any way undervaluing the great works of these distinguished naturalists. Darwin's views have had more influence in advancing Zoology than those of any man, and his fame is unassailable. Nevertheless, I feel that his theories regarding the origin of the faunas of oceanic islands require revision.

The formerly prevalent belief of the permanence of ocean basins has been shaken by the utterances of some of the greatest geologists of our day, whilst many positive'y assert that what is now deep sea 
of more than 1000 fathoms was dry land within comparatively recent geological epochs. Thus the Azores are classed by Darwin and Wallace among the oceanic islands-that is to say, among such as have received their fauna and flora by flotsam and jetsam. But Professor Neumayr believes, on geological grounds, that the Old and New Worlds were connected by a land-bridge during Tertiary times right across the Atlantic, and that the Canary Islands, Madeira, and Azores (p. 547) are the last remnants of this continent. This meets with the entire approbation of Dr. von Ihering, who has recently re-investigated the subject from a faunistic point of view (p. 135). Take another instance of one of Wallace's most typical oceanic islands, the Galapagos Group. Their fauna and flora have recently been most thoroughly re-explored by an American expedition, the result of which, according to Dr Baur, goes to show that these islands must have formed part of the mainland of South America at no distant date. The fauna and flora are therefore to be regarded as having reached them in the normal mode, viz., by migration on land. According to Mr. Beddard (p. 138), it is difficult to see how earthworms could be transported across the sea. Floating tree-trunks have been observed far out at sea, but unless the water remained absolutely calm during the long period necessary for the drifting by currents so that no splashing occurred, the worms would probably be killed. Yet earthworms 
do occur on oceanic islands. It is indeed quite possible that our views with regard to the origin of the remainder of the Pacific Islands may change very materially, and once more revert to what Dr. Gould expressed nearly fifty years ago in the following words : "From a consideration of the land-shells on the Pacific Islands, it seems possible to draw some fair inferences as to the relations of the lands which once occupied the area of the Pacific Ocean, and whose mountain peaks evidently now indicate or constitute the islands with which it is now studded." Indeed Dr. von Ihering goes so far as to positively state that in his opinion the Polynesian Islands are not volcanic eruptions of the sea floor, which being without life were successively peopled from Australia and the neighbouring islands, but the remains of a great Pacific continent, which was in early mesozoic times connected with other continental land masses ( $a$, p. 425).

Before coming to a decision on the part played by flotsam and jetsam in the constitution of an island fauna, those who have studied the problem on the spot should, however, have a voice in the matter. And though, from my experience in northern latitudes, I feel sure that island faunas there are but slightly affected by occasional dispersal of species, $\mathrm{Mr}$. Hedley, who has made the fauna of the Pacific Islands his special study, assures me that drift migration plays an important rôle in that region. I hope we may soon have a more detailed account 
of his particular observation bearing on this interesting subject.

On the other hand, Mr. Simpson, who has gained considerable experience of oceanic dispersal in the West Indian region, though he acknowledges having often noticed bamboo rafts, which would be suitable in the transportal of invertebrates, nevertheless does not attach much importance to this means of distribution. "The fact," he remarks, "that the operculates (operculate land-shells) form so large a proportion of the Antillean land-snail fauna, that a majority of the genera are found on two or more of the islands and the mainland, while nearly every species is absolutely restricted to a single island, appears to me to be very strong testimony in favour of a former general land connection" (p. 428).

Amphibians are affected in the same manner by sea-water as slugs are. The accidental transportal of an amphibian from the mainland to an island is therefore almost inconceivable. And the presence of frogs, toads, and newts in the British Islands, in Corsica and Sardinia, indicates, if nothing else did, that all these islands were at no distant date united with the continent of Europe.

As regards the terrestrial reptiles, the case is somewhat different. Many of them readily take to the sea, and, as probably all snakes and some lizards are able to swim, it is possible that sometimes, though very rarely, they might reach islands if not too far from a continent. Instances of accidental transportal 
of land-reptiles to islands have actually been observed. But the fact of the occurrence of such instances by no means proves that reptiles thus conveyed are able to establish themselves permanently in their new home. Sir Charles Lyell records in his Principles of Geology that a large boa-constrictor was once seen floating to the island of St. Vincent, twisted round the trunk of a tree. It appeared so little injured by its long voyage from South America, that it captured some sheep before it was killed.

Mammals might be accidentally conveyed to islands on such rafts as have been described by Sir Charles Lyell, and there are instances on record of their having crossed short distances of sea by swimming. Elephants and also deer and pigs are good swimmers, the former having been known to swim for six hours at a stretch. "But," remarks Mr. Lydekker (p. I3), "it may be assumed that about twenty miles is the utmost limit which mammals are likely to cross by swimming, even when favoured by currents. Such passages as these must, however, be of very rare oscurrence, for a terrestrial mammal is not likely to take it into its head to swim straight out to sea in an unknown direction. Moreover, supposing a mammal, near to a particular island, to have arrived there by swimming, unless it happen to be a pregnant female, or unless another individual of the same species but of the opposite sex should arrive soon after (a most unlikely event), it would in due course die without being able to propagate its kind." 
All zoologists, indeed, are quite in accord with Dr. Wallace's view as expressed in Island Life (p. 74). "Whenever we find that a considerable number of the mammals of two countries exhibit distinct marks of relationship, we may be sure that an actual landconnection, or at all events an approach to within a very few miles of each other, has at one time existed." As all the European islands come under this category, their mammals exhibiting distinct rclationship with those on the European continent, they all have been connected with it formerly.

Perhaps the most powerful of all agents in the transportal of species by accidental means is man. But his actions may be accidental as well as intentional. We have therefore to distinguish between the animals disseminated all over the world by pure chance, and those which have been introduced into new countries purposely. Invertebrates, such as snails, centipedes, woodlice, beetles, and cockroaches, are constantly being unintentionally carried with vegetables, fruit, trees, and with timber from one country to another. Earthworms are sometimes transported in the balls of earth in which the roots of trees are enveloped. As regards molluscs, Mr. Kew believes (p. 178) that during the last three centuries at least, human agency has influenced their disposal more than all other causes taken together. A large number of species of invertebrates in America are said to owe their existence in that country to accidental introduction by man. In 
most cases, however, no particular reason can be assigned why they should have been thus introduced, and as a matter of fact there are always individual differences of opinion as to the precise number of such. Certain it is, that though the number of supposed introductions from Europe to America is very large, those which have been carried from America to Europe is exceedingly small. In fact, I remember only two instances of accidental animal importations from America which have firmly established themselves in Europe, viz., a small fresh-water mollusc, Planorbis dilatatus, and the much-dreaded vine-pest, Phylloxera vastatrix.

As a rule the animals die out very shortly after their arrival on foreign soil. Many instances, nevertheless, are on record, especially in the case of molluscs, where snails thus transported have not only survived but are apparently in a flourishing condition and spreading. Helix aspersa, for example, our large garden snail, has been naturalised in many foreign countries by French and Portuguese sailors, who had taken them on board their ships as food.

It certainly cannot be denied that a number of species among almost all groups of invertebrates have been unintentionally conveyed by man from Europe into foreign countries. It has been proposed by Dr. von Ihering to apply the term "cenocosmic" to those species which have become spread all over the world through artificial means, and thus to distinguish them from cosmopolitan ones which have attained a 
similar range naturally. The latter he calls "palincosmic" species ( $a$, p. 422). Many so-called cenocosmic ants are believed by Dr. von Ihering to be palincosmic. We are altogether too apt to regard cosmopolitan as synonymous with introduced, and we should hesitate before concluding that because one of our common European species occurs in Australia or South America, it must have been transported there recently by human agency. Some of our widelydistributed forms are probably of very great antiquity, and may have spread to distant lands in early Tertiary times, when a different state of the geographical conditions enabled them to do so.

I cannot quote a more appropriate instance than the molluscan fauna of Madeira. No less than thirteen of the Madeiran snails are looked upon as having been introduced from Europe by human agency, on the sole evidence that these happen to be common European species. Yet the correctness of this supposition must be questioned in face of the interesting observation made by Darwin (p. 357), "that Madeira and the adjoining islet of Porto Santo possess many distinct but representative species of land-shells, some of which live in crevices of stone; and although large quantities of stone are annually transported from Porto Santo to Madeira, yet this latter island has not become colonised by the Porto Santo species. Nevertheless, both islands have been colonised by European land-shells, which no doubt had some advantage 
over the indigenous species." Darwin, therefore, meets the evident anomaly by suggesting that the European species are supposed to possess some advantages as colonisers. But the true explanation appears to me to lie in the supposition that the European land-shells found in the Madeiran Islands are all, or for the greater part, ancient forms which survived both there and on the continent, whilst the remainder of the forms inhabiting these islands are either such as are now extinct in Europe, or have become modified since their arrival there from the continent at a time when extensive land-connections allowed a free migration by land.

The theory of accidental introductions is an extremely popular one. It allows free scope to a host of speculations, and once the idea has taken firm root that a certain species is introduced, especially among the class of naturalists who by way of experiment are wont to create new centres of dispersion in their own neighbourhood, evidence to the contrary must be of the most convincing nature to shake the popular belief. Thus, it is almost regarded as an established fact by conchologists and others, that the fresh-water mussel (Dreyssensia polymorpha) was introduced into England at the beginning of this century. Though it has been proved that this species is quite unable to live in pure sea-water, yet the view that it has been carried from the Black Sea ports to this country attached to the bottom of ships is maintained by many, whilst others incline to the theory that the 
shell came with timber. But Dreyssensia polymorpha was by no means always confined to the Caspian and Black Sea areas; it occurs abundantly in the lower continental boulder-clay (see p. 230), and no doubt it had at one time a much wider geographical distribution. It appears to me possible, that it was able to maintain itself in certain fresh-water lakes and slow-flowing rivers in Northern Europe, from which it might have spread since the introduction of canals into Europe at the beginning of the century. As the larva of this fresh-water mussel is free-swimming, its propagation is much favoured by canals. Quickly-flowing rivers are fatal to its existence, since the delicate larvæ are swept out to sea and perish. Such an hypothesis as this is strengthened by the fact of its recent discovery in a sandy layer fifteen feet below the present surface under the streets of London in a deposit which probably, as Mr. Woodward remarks (p. 8), was accumulated in the early days of the city's existence. In spite of Mr. Woodward's interesting find, and Dr. Jeffreys' opinion, who always maintained that this shell was indigenous to England, popular belief still clings tenaciously to the introduction theory.

Among man's intentional introductions into a new country, no instance is better known than that of the rabbit to Australia. Rabbits are entirely confined to Europe. In their transplantation to Australia they were carried to a country with a different climate and among new surroundings. Yet the rabbits flourished, and within comparatively few years increased to such 
an extent as to become a burden and pest to the country. It may be remembered though, that, owing to the complete absence of small carnivores, which act with us as a check upon the too rapid increase of this rodent, the speed with which it established itself in the new surroundings is not so very surprising.

Many of the English settlers in the New World felt that America lacked the presence of our familiar birds. The homely sparrow was therefore brought over, with the result that the Agricultural Department of the United States is now devising means for its destruction, so rapid has been its increase.

Similarly, the inhabitants of Jamaica, annoyed by the great profusion of rats in their island, sent over to India for a number of mongoose. These have decimated the rats since their arrival, but they have multiplied to such an extent as to be a serious menace to the native fauna.

To give an instance nearer home, the Capercaillie (Tetrao urogallus) was successfully introduced into Scotland in 1837. From its different centres of distribution it is spreading in all directions where sufficient cover is obtainable. But this case differs from the others very materially, in so far as this bird was formerly a native of Scotland, and only became extinct during the last century.

However, although there are many examples of undoubtedly successful introductions by human agency, quite as many, or perhaps more, unsuccessful ones might be quoted. In fact, it is by no means easy to 
establish a species in any new locality. Frequently it happens that the species seems to be on the increase at first, but then there is a decline, and after a few years the new plantation has entirely vanished. In other cases, the species disappears immediately after the introduction takes place, or lingers on for many years if it receives special and uninterrupted protection.

It may not be generally known that the English Hare (Lepus Europaus) is not found in Ireland, where the Mountain Hare (Lepus variabilis) alone occurs. Attempts to acclimatise the English species have been made in a number of places in Ireland, but many of them have been failures, and not one of them has been a signal success. ${ }^{1}$ Similarly, the endeavour to introduce the French or Red-legged Partridge (Caccabis rufa) into Ireland has met with a like result. According to Dr. Day, it was tried during the summer of 1869 to naturalise the Sterlet (Acipenser ruthenus) from Russian waters into the Duke of Sutherland's River Fleet by importing artificially impregnated ova. From one hundred and fifty to two hundred lively young sterlets are said to have been turned out, but nevertheless the experiment met with no success. Several fortunately abortive efforts were also made in British rivers to establish Silurus glanis, a hideous monster of a fish, and quite unpalatable.

1 I might refer any one more specially interested in these introductions to an article on this subject in the Irish Naturalist of March I898, by Mr. Barrett-Hamilton. 
The Natterjack Toad (Bufo calamita) has a very local distribution in the British Islands. In Ireland it is found only along the coast of Dingle Bay in County Kerry, where it is known among the peasantry as the Black Frog. There is no doubt about its being indigenous there, and though it has not spread beyond the very limited area of its habitat, the Irish climate cannot be said to be unsuited to its existence. Yet it seems to be extremely difficult to acclimatise it elsewhere, for though no less than sixty specimens were turned out in Phœnix Park, Dublin, about forty years ago, none of them were ever seen afterwards. They were placed in the vicinity of one of the lakes, so as to give them ample scope for breeding and developing the young, and in surroundings which were considered eminently suitable at the time.

It has occasionally happened, too, that animals are introduced by kindly-disposed persons with the view of adding a species to their fauna, in complete ignorance of their previous existence in the country where they wished to naturalise them. Thus we are told that in the year 1699 one of the Fellows of Trinity College, Dublin, procured Frog's spawn from England in order to add that amphibian to the Irish fauna. It was placed in a ditch in the College Park, whence the species is supposed to have gradually spread all over the island. This story is quoted by many writers as the true history of the Frog in Ireland, and is given as an example of the rapidity 
with which animals spread. Unfortunately the wouldbe introducer seemed unaware that, according to Stuart's History of Armagh, the first Frog which was ever seen in Ireland made its appearance in a pasture field near Waterford about the year I630, that is to say, seventy years before its introduction in Dublin. ${ }^{1}$ But even Stuart was mistaken in supposing that no Frog had ever been seen in Ireland before, since Giraldus Cambrensis, in his Topography of Ireland, mentions that a Frog was found in a meadow near Waterford in the year I 87.

Certain British species of vertebrates are generally looked upon as introduced species, though we cannot trace any record of their first establishment, and it is quite possible that, though there was local extinction and subsequent local re-introduction, they are truly indigenous and may never have become totally cxtinct. Such are, for instance, the Rabbit (Lepus cuniculus) and the Pheasant (Phasianus colchicus). The latter certainly had become naturalised in England before the Norman invasion.

But cases of introduction such as those above referred to are by no means confined to the vertebrates, similar instances among invertebrates being numerous enough. I am sure every naturalist is personally acquainted with a good number, and it is hardly necessary that I should quote in any detail after

1 I should recommend those who are particularly interested in the full history of the Irish frog to read the notes on this subject contained in vol, ii. of the Irish Naturalist. 
what has been said on the subject generally. The two species of snails, Helix pomatia and Cyclostoma elegans, both of which occur in England, and which I had occasion to mention among those experimented on by Darwin, were turned out in several suitable localities in Ireland by Thompson, but failed to establish themselves. The former, according to Mr. Kew, was also introduced into Scotland and Norway, whilst fifty or sixty specimens were brought to Petersfield in England, but none of these trials at acclimatisation were successful. As among vertebrates, a large number of the so-called successful introductions rest upon insufficient evidence.

When we once more carefully review the evidence as to the undoubted difficulty attendant on intentional introduction of animals by human agency, placed as they often were in most suitable localities, we must feel that accidental introduction cannot play an important rôle in the making of the fauna of any country. Especially is this the case with an island fauna. Vertebrates are almost altogether excluded, and invertebrates must arrive singly as a rule, often stranded on an inhospitable and unsuitable shore. Their chances of surviving a passage by sea, of finding suitable food and shelter and a mate in order to procreate their species, appear to me infinitesimally small. Yet there may be some such cases. However, I quite agree with Mr. Andrew Murray-a high authority on geographical distribution-that "colonisation or occasional dispersal is insufficient to account for the 
character of the faunas and floras of oceanic islands; and I believe that the normal mode in which islands have been peopled, has been by direct continuity with the land at some former period, or by contiguity so close as to be equivalent to junction" (p. 15). "That a slight intermixture," he continues, "due to Mr. Darwin's colonisation, occurs in many (probably in all) I am ready to admit; and from instances to be afterwards noticed, I am disposed to reckon the proportions of such intermixtures in the flora, in the most favourable circumstances, at not more than two per cent. In the fauna I think it must be much less."

Mr. Murray's views, though they relate only to oceanic islands, are likewise applicable to continental islands such as our own. I think we might take the admixture in the British fauna due to occasional, including human introduction, as amounting to five per cent. It is better to take a high estimate, so as to include all the species about whose native land there might be some reasonable doubt. Now of what importance, after all, is this five per cent.? The remaining ninety-five per cent. of the species of animals belonging to the British fauna undoubtedly migrated to these islands in the normal way by land.

It is of grcat importance, in dealing with the question of the origin of the British fauna, to thoroughly grasp this conclusion-that ninety-five per cent. of the animals have reached us by land. We can afford in fact to ignore the five per cent. altogether. It is an insignificant factor. As rcgards 
the botanical aspect of the question, botanists are quite in accord with the zoologists, and entirely share their view's in the belief of a former landcontinuity between the British Islands and the Continent. "It cannot be denied," says Professor Blytt (p. 32), "that a plant of one or another species may, in an exceptional case, migrate, without human assistance, all at once, across large tracts of land and sea, and that such migration, if operating during geological periods, might introduce a number of species even into distant oceanic islands; but when the question is of whole communities of plants, such as the above enumerated elements in our flora, then such an accidental and sudden transport across large tracts can only be conceived to be at all probable in the case of Arctic plants carried by drifting ice to a bare country without native flora; as to the other species, we must imagine that the migration during the gradual change of climate has proceeded slowly and step by step across connected tracts of country. In that manner we may assume that our country has in the course of time obtained its present covering of plants. Each of the abovenamed elements in our flora has doubtless its corresponding element in our fauna. The fauna and flora of a region stand in relation of complicated dependence to each other. The animals live on the plants. The fecundation of the plants takes place in a great degree by means of insects; their seeds are often scattered by resident birds and 
quadrupeds. Everything indicates that conveyance to small distances is the rule, and that sudden and long migration is the exception."

The conviction which has been gained by zoologists and botanists, that the British Islands once formed part of the Continent, is based on the present British fauna and flora. The remains, however, of animals which used formerly to live in these countries, such as the Mammoth, the Irish Elk, the Cave Bear, and many others, tell us the same tale. They could not have peopled England by swimming across the Channel, or even by walking across solid ice, as has once been suggested. Nothing but a land-connection induced them to explore this country more closely, and finally to decide on settling there.

The origin of the British fauna will be discussed more in detail in the third chapter. The methods of investigation adopted, along with a general scheme of this book, will be found in the next.

The manner in which the origin of the fauna of any particular continental area can be traced is very similar to that adopted in the case of an island. Portions of the continent of Europe can be shown to have been islands in former times. Thus the Crimea, now a peninsula united to the mainland by the narrow isthmus of Perekop, must have been an island in comparatively recent times. The absence of a number of striking and familiar South Russian species of mammals and reptiles prcves this to have been the case. It was probably long after the apper $r$ - 
ance of man, though before historic times, that these changes took place.

We shall learn in the subsequent chapters, that by a careful study of the fauna and flora the fact can be established, not only of the former connection of an island with a continent, but also whether such union existed (geologically speaking) within recent or more remote times. The better the fauna is known, both recent and fossil, the more precisely can the period of connection be indicated, and its duration determined. 


\section{CHAPTER II.}

\section{PRELIMINARY CONSIDERATIONS.}

I INTEND to give in this chapter a general outline of the subject which will be discussed in the subsequent ones. This will include a brief history of the great events, in recent geological times, which have modified the evolution of the European fauna by the influence which they have exerted on the course of the successive streams of migration.

The composition of the European fauna is the first item which will have to be taken into consideration. But not only must the existing species of animals be dealt with: the extinct ones, too, at least those which have lived in Europe during late Tertiary times, will be useful for our inquiries. A knowledge of the past faunas is a most important factor in tracing the original home of the European animals.

Wherc a species first originated, whether this was in one or several places, or, in other words, where it first had its home, cannot be determined with absolute certainty in the present state of our knowledge, but as a rule it can be indicated approximately with a fair amount of precision. In 
a few instances, species may possibly have had a dual origin. The majority of naturalists doubt that there are any such, but it seems to me that almost the same forces may have acted in different localities on certain forms so as to produce, in very cxceptional circumstances, similar species. The vast majority of animals, however, have no doubt originated in one locality; or, we might say, almost all species have but one home.

We may assume that every animal gradually extends its range by migration, as the result of the natural increase of the species necessitating a search for fresh feeding grounds. Every species thus tends to slowly take possession of all the habitable parts of the globe to which it has access. They would all naturally spread from their original homes in every direction, unless prevented by an impassable barrier. We have already learned that to all land animals, the sea acts as such a barrier. Mountains and rivers act also in a similar way, but not to the same extent. It is not difficult to understand also that a forest may be a formidable barrier to a typical inhabitant of the open country and vice vers $\hat{x}$, whilst a desert is impassable to almost all terrestrial organisms. Some species are scarcely affected by climate, and flourish equally well in the tropics and in temperate or cold countrics; the majority, however, are greatly influenced by it. "No more striking illustration," remarks Merriam (p. 38), "could be desired of the potency of climate compared with 
the inefficiency of physical barriers, than is presented by the almost total dissimilarity of the North American Tropical and Sonoran Regions, though in direct contact, contrasted with the great similarity of the Boreal Regions of North America and Eurasia, now separated by broad oceans, though formerly united, doubtless, in the region of Behring Sea."

To return to the composition of the European fauna, we now know positively that a number of the mammals and birds inhabiting Central and Eastern Europe are of Siberian origin. How they came, and when, will form the subject for discussion in Chapter V. At present it will suffice to mention that in the superficial deposits belonging to the Pleistocene series of the North European p'ain have been discovered the remains of many typical members of the Siberian Steppe-fauna. Some of these, such as the Saiga-Antelope (Saiga tartarica), Fig. 2, still inhabit portions of Eastern Europe, whilst others have retreated to their native land. But it might be asked, how is it known that these species did not originate in Europe, and thence migrate to Siberia? Because if they had originated on our contillent, they would have spread there. They would have invaded Northern and Southern Europe, and they would probably have left some remains in Spain, Italy, or Greece. They would also have left some of their rclations in Europe; but all their nearest allies, too, are Asiatic. Moreover,-and this completes, I think, the proof of their Siberian origin,- the Pleisto- 
4O HISTORY OF THE EUROPEAN FAUNA.

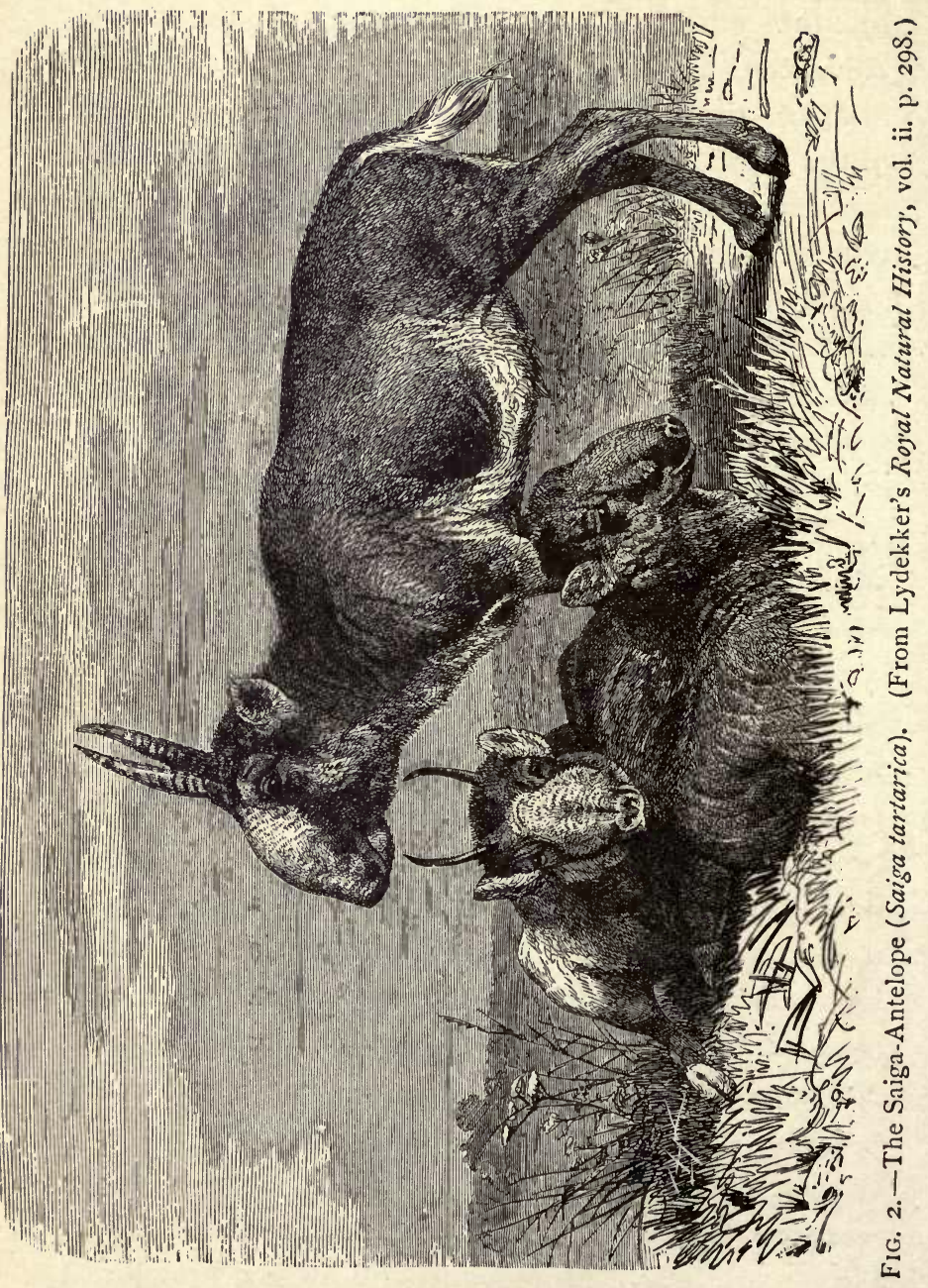


cene remains of these animals in Europe become less abundant, and the number of species likewise decreases, as we proceed from east to west. With these remains of Steppe animals are generally associated those of others, which we must also look upon as Siberian emigrants, such as the Pikas or tailless Hares belonging to the genus Lagomys, the pouched Marmots (Spermophilus), and others. Some of them, as I have mentioned, still inhabit Central and Eastern Europe, whilst others have a wider distribution on our continent.

This migration must have been an unusually large one. It has been suggested that the Glacial period had some connection with it, and there can be little doubt, as we shall see later on, that a change of climate probably brought about this great Siberian invasion of Europe. But other causes might tend in the same direction, such as want of sufficient food after a few years of great increase of any particular species. It is not known to what we owe the periodic visits of the Central Asiatic Sandgrouse (Syrrhaptes paradoxus), Fig. 3, but certain it is that immense flocks of these birds invade Europe from timc to time at the present day, just as those mammals may have done in past ages.

The Siberian migrations will be spoken of in the subsequent pages, as the Siberian element of the European fauna. These migrations, however, are not the only ones which reached Europe from Asia. The sixth chapter deals with migrations which have 
influenced our fauna far more than the Siberian. The latter did not last long, nor did they affect the whole of Europe. But what I may call the Oriental migrations spread to every corner of Europe and certainly lasted throughout the whole of the Tertiary Era. The Oricntal element came probably from Central and

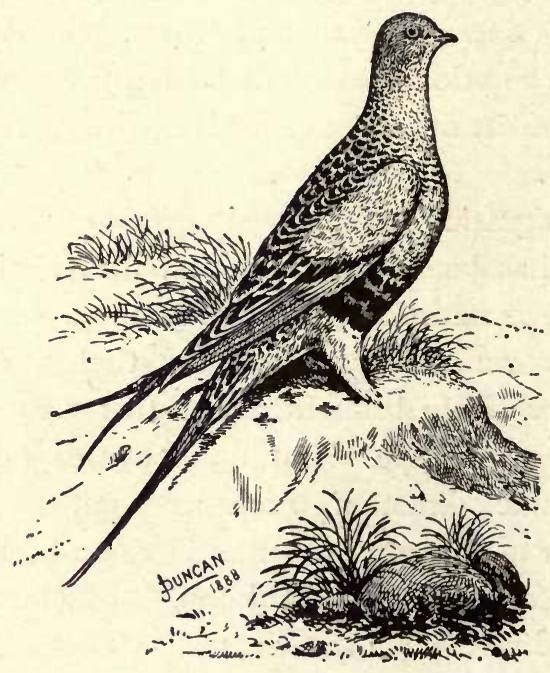

FIG. 3-Central Asiatic Sandgrouse (Syrrhaftes faradoxus).

Southern Asia, and in its march to Northern Europe it was joined by local European migrations. For on our continent, too, animals originated and spread in all directions from their centres of dispersal. A separate chapter has been given to the Alpine fauna, and another to that of South-western Europe, which will be known by the name of the Lusitanian element. 
Finally, animals have also reached us from the north, and in the fourth chapter the history of that remarkable migration will be fully discussed under the title of the Arctic element of the European fauna.

It is generally believed that Africa played an important rôle in the feopling of our continent, but this is quite a mistake. The eminent Swiss palæontologist Rütimeyer was quite right in saying (p. 42) that it is much more probable that Morocco, Algeria, and Tunis were stocked with animals by way of Gibraltar, and perhaps also by Sicily and Malta, from Europe, than the South of Europe from Africa.

I have already referred to what are known as "centres of dispersion" of animals, but before continuing to explain the general outline of this book, it will be necessary to make a few additional remarks on the subject.

Since every animal naturally tends to spread in every direction from its original home-that is to say, from the place of its origin-the latter should correspond with the centre of its range. And in any particular group of animals the maximum number of species should be formed in the area or zone which is the centre of its distribution. In the great majority of instances this is probably the case, in the higher animals perhaps less so than in the lower; still the rule must hold good that the original home of a species is generally indicated by the centre of its geographical distribution.

Take for example our familiar Badger (Meles tarus). 
It inhabits Europe and Northern Asia. It is absent apparently from many parts of Central Asia, but it appears again farther south in Palestine, Syria, Persia, Turkestan, and Tibet. West Central Asia would be about the centre of its range. That this corresponds to its place of origin is indicated by the fact that the only three other Badgers known-viz., M. anakuma, $M$. leucurus, and M. albogularis-are confined to Asia. If we examine the fossil history of the genus, we find that the two most ancient instances of the existence of Badgers have been discovered in Persia, where $M$. Polaki and $M$. maraghanus occur in miocene deposits. The latter had migrated as far west as Greece in miocene times; no other trace of the Badger, however, is known from Europe until we come to the pleistocene beds. There are a good many cases known among mammals where the centre of dispersion would indicate to us a similar origin. On the other hand, there may be no fossil evidence of the occurrence of a species, or of its ancestors, in Asia, whilst such has been discovered in Europe. I think, however, that the present range of a species forms a safer criterion for the determination of its original home, as the Asiatic continent is still practically unworked from a palæontological point of view. In a letter which I received from Professor Charles Depéret, he advocates the view that the wild Boar (Sus scrofa) is probably of European, and not, as I maintained ( $c$, p. 455), of Asiatic origin; because there seemed to be a direct descent from Hyotherium of the middle miccene of 
Europe, through the upper miocene Pig of the Mount Lebéron (Sus major) and of Eppelsheim (Sus antiquus), and the pliocenc Pigs of Montpellier (Sus provincialis) and of the Auvergne (Sus arvernensis). No doubt this appears rather a strong case in favour of the European origin of the wild Boar, but although the Tertiary strata of Asia, as I remarked, are as yet little known, a number of fossil pigs are known from India, Persia, and China, the oldest being the upper miocene Persian Pig (Sus maraghanus). Pigs are therefore as old in Asia as in Europe, and as a direct intercourse between the two continents probably never ceased since miocene times, it is not surprising that this genus should occur in both. Even if the genus had its origin in Europe, it is quite possible that in later Tertiary times, the active centre of origin was shifted to the neighbouring continent, and that henceforth many new species issued forth from Asia, some of which may subsequently have been modified on reaching our continent. The wild Boar (Sus scrofa), however, to judge from its general range, I must look upon as merely an immigrant in Europe. I have no doubt that it originated somewhere in Asia, probably in the south.

The view I take of the origin of our European Boar is also supported by Dr. Forsyth Major's recent researches. He was led to a re-investigation of the history of the Pig while examining a large number of fossil skulls in the Museum at Florence, and came to the conclusion that only threc or four species of 
recent wild pigs can be clearly distinguished (b, p. 298). One of these, viz., Sus vittatus, he thinks, is traceable in slight modifications from Sardinia to New Guinea and from Japan to South Africa. The centre of distribution of this species lies in Southern Asia. Of the three remaining species, two, viz., Sus verrucosus and $S$. barbarus, are entirely confined to the great islands which form part of the Malay Archipelago. Finally, Sus scrofa, our Central European wild Boar, is so closely related to $S$. vittatus that the Sardinian Boar might be looked upon as a variety of either the one or the other. At any rate, Dr. Major recognises clearly in Sus vittatus the representative of the ancestral stock of which Sus scrofa is a somewhat modified offshoot.

The fauna of Europe consists, as I have mentioned, to a large extent of immigrants from the neighbouring continents. This is especially noticeable among the higher animals. When we come to the lower, such as the amphibia, we find a larger percentage, and among the land mollusca the great majority, to be of European origin. The foreigners are, as we learned, called Orientals, Siberians, and Arctics. For the sake of convenience, only two of the great European centres of origin have a chapter devoted to themselves, namely, the Alpine and the Lusitanian centres. There is another,-however, of almost equal importance which lies in the east.

In the British Islands there is only an exceedingly small and insignificant group of species which are 
peculiar, and which we may consider to have had their origin there. Almost the whole of the British fauna is composed of streams of migrants which came from the north, south, and east, though many of these immigrant species have since their arrival been more or less distinctly modified into varieties or local races.

The eminent French conchologist Bourguignat ( $a, \mathrm{p}$. 352) was of opinion that, as far as terrestrial mollusca were concerned, there are in Europe three principal centres of creation or dispersion-all situated in mountainous countrics and not in the plains. He distinguished the Spanish, Alpine, and Tauric centres, and believed that almost all species known from Europe had originated in one of these three, and that each of them possessed quite a distinct type of its own. This theory seems to agree very well with the facts of distribution. Let us take, for instance, the genus Clausilia, a pretty turret-shaped snail, which abounds on old ruined walls. Only two species, viz., Cl. laminata and Cl. bidentata, are met with in Ireland. In England we find the same species with the addition of two others, Cl. biplicata and Cl. Rolphii. Crossing over the Channel to Belgium, these four species occur again, and also several others not known in England. In Germany the list of Clausilice mounts up to twentyfive species, including all those found in the British Islands. As we proceed eastward the number of species of this genus increases steadily, and when we reach the Caucasus or the Balkan Peninsula the con- 
chologist is able to make a collection of several hundred different kinds, whilst farther east again they diminish. This clearly indicates there is in SouthEastern Europe a powerful centre of creation of Clausilice, from which the species have spread all over Europe. But it is by no means certain that this centre was always in our continent, for in SouthEastern Asia and the Malay Archipelago Clausilice increase once more. It is interesting to note, however, that almost all these eastern forms belong to the subgenus Phadusa (vide Boettger), which had only been known as a fossil genus from a few species in the Eocene and Oligocene of Southern Europe. The first centre of origin, therefore, may possibly have been in Southern Asia, and in these early Tertiary times a second centre may have become established in Southern Europe from which the sub-genus Garnieria went eastward, Macroptychia southward, and Nenia westward across the Atlantis to South America. Only a few remnants of these primitive Clausilice are now left in Europe, such as the interesting $\mathrm{Cl}$. (Laminifera) Pauli.

As an example of a genus which has its centre of distribution in South-Western Europe we might take that to which our common brown garden slug belongs, viz., Arion. Dr. Simroth, who was the first to point out that the species of Arion had spread over our continent from South-Western Europe (p. 5), is inclined to the belief that the Arionida had originated on the old land-bridge between Europe and North America. 
which is generally known by the name of "Atlantis." From this a branch went westward to the New World and another eastward as far as Southern Asia, - but Arion and a number of other genera are more or less confined to South-Western Europe. Only a few species of Arion have a wide range in Europe, one of them, $A$. subfuscus, crossing the borders of our continent into Siberia. In the British Islands and in Western Germany, which are about equi-distant from the supposed creative centre of the genus, there are found five species. In France six or seven species are met with, and in Spain and Portugal about ten. Towards the east, Arions diminish in number. This genus, therefore, forms part of a migration which I have designated as "Lusitanian" from Lusitania, the name applied by the Romans to what we now call Portugal. Another genus of slugs, Geomalacus, is interesting from the fact that one species occurs in the British Islands, being otherwise confined to the Lusitanian province. Parmacella, a sluglike animal bearing a tiny shell at the extremity of its tail, has probably likewise had its origin in this part of Europe. All this, however, will be more fully referred to in the seventh chapter, which deals with the Lusitanian fauna.

As regards the Alpine centre of origin, Dr. Kobelt considers three groups of mollusca as especially characteristic of the Alps, viz., the sub-genus Campylaea of the great and widely-spread genus Helix, and the genera Pomatias and Zoniles. The latter, which is not 
to be confounded with our British Hyalinia (formerly united with Zonites), does not extend very far south or north of the Alps. There may be others too, wnich owe their origin to these mountains, but most of the terrestrial mollusca are exceedingly ancient, and many genera have existed long before the Alps had made their appearance above the surface of the early Tertiary seas. It should be remembered that $H^{\prime} a-$ linia and $P u p a$, both British genera, are known from carboniferous deposits in forms which closely approach those living at the present day, and in these and a great number of other instances, it is quite impossible to determine the original home of the genus.

This little digression on centres of dispersion will help us to understand in what manner the indigenous clement of the European fauna joined in with the alien members as they arrived in our continent. The species confined to South-Eastern England need not necessarily have come to us from Eastern Europe or Siberia. Alpine species spread northward probably at the same time as the Siberian animals went westward. An Alpine form may therefore have joined a batch of the latter and entered England with them. Even a Lusitanian animal may have mingled with these migrants, so that all three elements may occur together in one locality.

But these are exceptions. The migrations have, as a rule, not joined to any great extent; indeed, all those naturalists who have carefully examined the problem of the origin of the European fauna, have felt 
that it was composed of elements which arrived at different times.

The great Russian naturalist, the late Professor Brandt, distinguished five phases in the history of the Eurasian mammalian fauna (pp. 249-254). During the first phase - an uncertain period of long duration - the mammals held intact their position in the northern half of Asia. The Mammoth, the Hairy Rhinoceros, Bison, Musk Ox, Wild Sheep, Reindeer, and perhaps Tigers, Hyænas, etc., lived then, with numerous peculiar Rodents, under such climatic conditions, according to Brandt, that they were able to extend their range along with tree vegetation to the extreme north of the Asiatic continent. This, he thinks, seems to have been the case especially with the Reindeer, Mammoth, Rhinoceros, and Musk Ox. The second phase was characterised by the dispersion of the Northern Asiatic mammalian fauna towards Central, Southern, and Western Europe, and this period lasted until the complete extermination of the Mammoth. The third phase dates from the time when the Mammoth and the Hairy Rhinoceros had become extinct, whilst the fourth commenced with the disappearance of the Reindeer in Europe, and terminated when the Wild $\mathrm{Ox}$ in the feral state had become unknown. Finally, the last phase constitutes the present time. Lartet held similar views, and also believed that Europe was peopled by successive migrations from Asia.

Botanists have worked at the problem of the 
European flora much more systematically, and our knowledge of the origin of that flora has been greatly increased within the last twenty years, chiefly by the researches of Professor Engler. More recently, detailed studies have been made in Scandinavia by Professor Blytt, in the Alps by Dr. Christ and Mr. Ball, in Germany by Professor Drude, Dr. Schulz, and many others. Dr. Schulz (p. I) is of opinion that the great majority of the European plants have either migrated to or have originated in our continent since the beginning of the Pliocene epoch, and that the original home of the immigrants must be looked for in Asia and in Arctic America. From the latter an almost uninterrupted migration must have taken place during the greater part of Tertiary times up to the commencement of the Pliocene epoch, partly over a direct land-connection with Europe by way of Greenland, Iceland, and the Faroes, and also vici Spitsbergen, Franz Josef Land and Novaya Zemlya, and partly by an indirect one across the Behring Straits between Alaska and Kamtchatka.

A good deal of work still requires to be done before zoologists have acquired the same intimacy with the European fauna as botanists have with the flora. However, the view that our animals all come from Asia, as was long ago believed, has been abandoned for some time. The first to bring under the notice of naturalists the hypothesis, that there must have been two distinct migrations of northern animals to Central Europe-one from the north, and another 
from the cast-was the late Mr. Bogdanov. The Arctic species, of which remains have been discovered in the Pyrenees-namely, the Reindeer, Arctic Hare, Willow Grouse, etc., he thought had nothing to do with those which invaded Europe from Siberia during the Glacial period. He maintained that the former had quite a distinct origin, and came from Scandinavia (p. 26).

As I shall deal with this problem more fully in a subsequent chapter, I need only mention that I fully agree with the view expressed by Mr. Bogdanov that two distinct migrations of northern species to Central Europe can be traced.

No one, I think, has done more in fostering a careful study of the migrations of animals than our distinguished geologist Professor Boyd Dawkins. He did not follow Bogdanov in distinguishing two Arctic migrations; however, he did more in constructing a very ingenious chart $(a, \mathrm{p}$. I I I) representing the geography of Europe during the last and most recent geological epoch-the Pleistocene-and indicating on it the probable extent, during that time, of an eastern and a southern migration of mammals. The map is very instructive, and is the first ever published giving a clear idea of a southern and an eastern migration to Europe. He believed that the migration of the southern mammals northward, took place conjunctly with the westward movement of the eastern species. Having once reached Europe, the southern species are supposed to have passed northward in summer 
time, whilst the eastern forms (he calls them northern) would swing southwards. The two migrations wou'd thus occupy, at different times of the year, the same tract of ground ( $a$, p. I I 3 ). From the mingling of the remains of the Hyæna with those of the Reindeer and Hippopotamus in the Kirkdale Cavern, he infers that the former preyed upon the Reindecr at one time of the year, and on the Hippopotamus at another. He argues that in such a manner might be explained the curious mixture of northern and southern types which we find in the British pleistocene and in cave deposits.

Besides mammals, the only European animals which have received some attention with a view to a study of their origin, are the Butterflies and the LandSnails. The entomologists who have taken up the problem have in so far scarcely produced satisfactory results, as they all seemed to be bound down to the hypothesis that practically all the butterflies had been destroyed in Europe during the Glacial period. Hofman, in his interesting little work, comes to the conclusion (p. 50), that only in Greece and Spain could a small remnant of the butterflies have survived the extreme rigours of climate. Greece was at that time connected with Asia Minor, and Spain with North Africa; and the author supposes that the semialien fauna inhabiting these tracts was mainly responsible for the re-stocking of Southern Europe, but that the main mass of our butterflies are post-glacial Siberian immigrants. 
The work published by Messrs. Speyer deals only with the origin of the Central European Butterflies. The period during which our European species originated is not specified, but the authors believe that they had their home either in Southern Russia or Central Asia. The fact that the number of butterflies decreases very considerably as we proceed north-westward in Europe appears to them to substantiate these views. The apparent dislike evinced by butterflies to the damp Atlantic Coast climate, they think, clearly indicates that they had originated in a dry and more continental climate. The history of the North European Butterflies and Moths has been carefully described by Mr. Petersen. He adopts Hofman's theory as to the almost total cxtinction of the Lepidoptera in Europe during the Glacial period. The chief immigration to Europe after that period is, he thinks, Siberian.

At first there appeared species which belonged to a cold climate, and which now live in elevated regions; then came forms suited to a milder climate, which established themselves on the northeasterly slopes of the Alps. The most recent addition which our continent has received from Siberia is, according to Mr. Petersen, the present Scandinavian fauna. Scandinavia has obtained a larger number of species than the European plain, because to this last migration were added such as prefer a northern or Alpine climate. 
As a contribution to the history and composition of the European fauna, by far the most important work ever published is that of Dr. Kobelt, the eminent German conchologist. Whilst the researches into the origin of the Lepidoptera, above described, have been marred by the prevalent prejudice as to the deleterious effects of a glacial climate on the butterflies, the present author boldly works out the problem on independent lines. He shuns theories and speculations almost altogether. His great work, as yet practically unknown, the result of a lifetime of the most painstaking labour, ranks among the most important contributions to zoogeography. I shall have frequent occasion to refer to it throughout these pages. Meanwhile some of his more remarkable conclusions may be mentioned. "Comparing all classes of animals as to their zoogeographical importance, the highest rank must undoubtedly be accorded to the land-snails" (i., p. 7). "The Pleistocene, and with it the land and fresh-water molluscan fauna of the present day has been gradually evolved from the Tertiary one, and its roots can be traced through the Cretaceous to the Jurassic epoch. During the whole of that time no sudden appearance of a new fauna can be demonstrated. Quite slowly, step by step, the Cretaceous is succeeded by the Tertiary fauna, and one after the other of the characteristic palæarctic genera appear-first the fresh-water, then the land forms" (p. 14I). "The division of the North Alpine from the South Alpine fauna must be older than the 
Glacial period; and the present Central European fauna had already become developed from the Pliocone in all its details of form and distribution before the commencement of the Ice Age" (p. 162). "We must draw the conclusion from the preceding remarks, that the present (palæarctic) molluscan fauna in its distribution is older than the Glacial period, and that the latter produced merely a retreat of the fauna from the most inhospitable regions of Europe with a subsequent re-immigration, but did not cause its destruction" (i., p. I69).

A few attempts have also been made by naturalists to trace the origin of the fauna of some smaller European areas. Thus Ruitimeyer, in dealing with the mammalian fauna of Switzerland, remarks (p. 3I) "that it seems certain that, in spite of many local disturbances, the continuity of generations was never interrupted throughout the whole of the Tertiary period until the present day."

An even more interesting memoir is that of $\mathrm{Mr}$. Köppen on the origin of the Crimean fauna. It is only recently, according to this author, that this peninsula has become connected with Southern Russia. And it is for this reason that the Squirrel and a number of other animals, and also plants, present in Russia, are absent from the Crimea. Originally the latter probably formed a westward continuation of the Caucasus, and at that time it was surrounded by the sea on all other sides. "Much later," he continues, "after and in consequence of a local subsidence, the country 
between the Caucasus and the Crimea became interrupted. The latter existed for a long time as an island, and only much later, in recent geological times, did it become united with Southern Russia by means of the isthmus of Perekop."

There is, on the whole, a great diversity of opinion as to how the European fauna has originated; however, except in Dr. Kobelt's work, no attempt has hitherto been made to collect together all the available information, and to include in the inquiry more than one class of animals. The little work which I venture to bring before the public will not by any means exhaust the subject, nor is our knowledge of the European fauna sufficient to give more than a mere sketch of many of the animal groups mentioned. As we have learned in the introduction, different classes of animals are not all of equal importance in indicating the changes which have taken place in the distribution of land and water. While Dr. Kobelt is of opinion that the land-snails are by far the most important in such an inquiry, Mr. Lydekker believes that mammals afford the safest and truest indications of such changes. Mr. Beddard puts in a claim for earthworms, as even a narrow strait of sea-water forms an insuperable barrier to their dispersion. Dr. Wallace agrees with Mr. Lydekker, and goes so far as to say (p. 74) that "whenever we find that a considerable number of the mammals of two countries exhibit distinct marks of relationship, we may be sure that an actual land-connection, or at 
all events an approach to within a very feiv miles of each other, has at one time existed." Besides the groups referred to, I claim that particular attention should be devoted to Amphibia, which, contrary to Wallace, I hold do not possess special facilities for dispe:sal; and also to spiders and to all wingless animals leading a subterranean life, such as some of the wood-lice, planarian worms and apterous bcetles.

A thorough knowledge of the changes in the distribution of land and water is desirable in order to appreciate the extent and variations of former migrations. A study of the British fauna, for example, teaches us that the British Islands were once connected with one another and with the continent of Europe between England and France. It was Professor James Geikic, I believe, who first pointed out, many years ago, that the area now covered by the Irish Sea was formerly in all probability a freshwater lake. This had its outlet at the southern extremity in the form of a stream into which most likely flowed the smaller rivers from the south-east of Ireland, and which was joined from the east by the Severn, and finally debouched into the Atlantic (Fig. 4). The range in the British Islands of those species which have migrated to them from the south, indicates that whilst the Atlantic Ocean had gradually crept up and flooded the area between Ireland and Wales, and had turned the fresh-water lake into a bay, communication between Scotland and Ireland was 
still possible. The occurrence of many Scandinavian species in Scotland which are absent on the continent

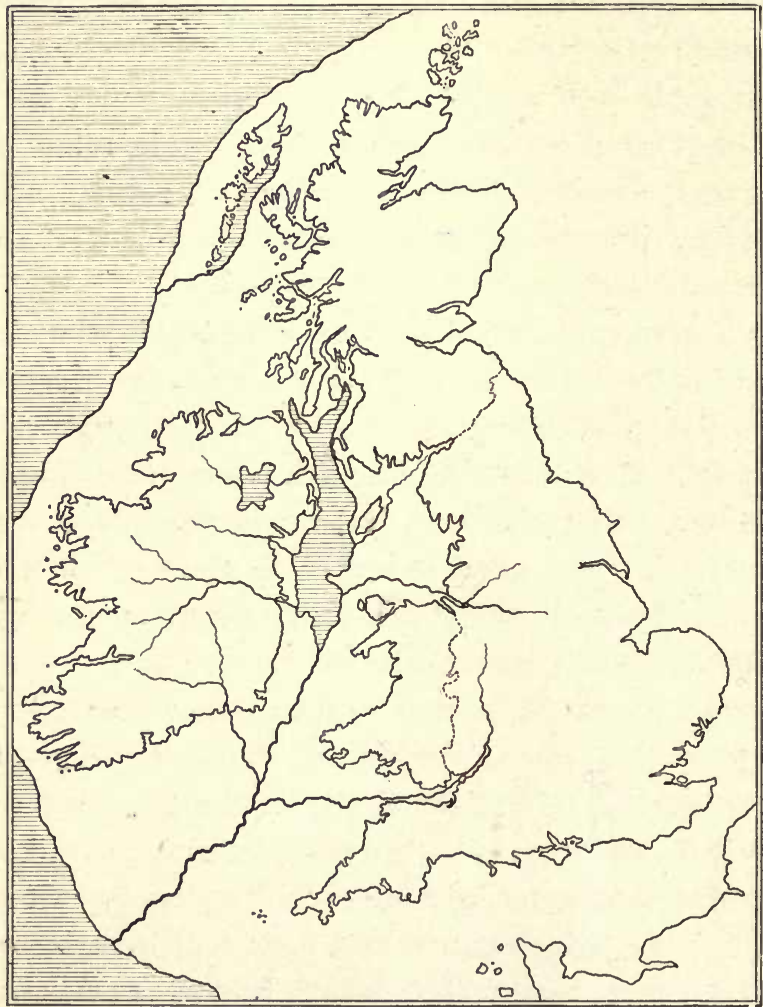

FIG. 4. - Map of the British Islands and surrounding area at a time when the earlier members of the southern migration reached England. (Only some of the rivers have been indicated. The shaded parts represent water, the light land.)

of Europe, indicates that these two countries also were united formerly. Most geologists hold that such 
a connection, if it existed, must have broken down in Pliocene times. Professor Judd, however, has expressed his belief (p. 1008) that it still existed until after the appearance of man in Northern Europe, and that our forefathers might have been able to walk dry foot from Scotland to Norway.

I shall also show on distributional evidence, in the fourth chapter, that until recent geological times Scandinavia was continued northward, by way of Bear Island, with Spitsbergen and probably Franz Josef Land, which islands again were joined with North Greenland and Arctic North America, and that the polar fauna and flora were able to spread on this land-connection to both America and Europe.

That Gibraltar was connected with Morocco, and Sicily with Southern Italy and Greece on the one hand, and with Tunis on the other, is more generally recognised; whilst Professor Suess has shown (vol. i., p. 442), on purely geological grounds, that the Egean Sea was dry land up till quite recentlycertainly, he thinks, till after the appearance of man. This supposition enables us to understand, as will be more fully discussed in the sixth chapter, how the Oriental fauna entered Europe. Such minor zoogeographical problems as the occurrence of the Wild Goat of Asia Minor (Capra agagrus) on the islands of Crete and on some of the Cyclades now almost explain themselves. The Sea of Marmora is probably a modern formation, so that Asia Minor extencled not long ago beyond the Turkish capital, but 
Dr. Kobelt believes that an arm of the Black Sea communicated up till recent times along the lower course of the Maritza with the Gulf of Saros. It can be shown also that Sardinia and Corsica formed part of the continent of Europe, and that their present fauna and flora reached them by migration on land.

The Russian naturalists, Brandt and Köppen, believed that at no very distant date a sea extended right across Eastern Russia from the Caspian to the Arctic Occan, whilst Professor Boyd Dawkins expressed himself in very similar language as follows (c, p. 35): "Before the lowering of the temperature in Central Europe the sea had already rolled through the low country of Russia, from the Caspian to the White Sea and the Baltic, and formed a barrier to westcrn migration to the Arctic mammals of Asia." These naturalists based their opinions on distributional evidence, but additional facts will be brought forward in the fifth chapter to substantiate these views.

These are some of the more important geographical events which will be dealt with in detail in the subsequent chapters in connection with the history of the migrations of the European fauna.

A separate chapter has been devoted to the British fauna and its origin, since it plays a very important part in the evolution of that of our continent. So essential is a thorough knowledge of this fauna, that I think it would be difficult to understand, without 
it, the main features of the great migrations; and I have before now expressed the opinion that the British fauna forms the key to the solution of the problem of the origin of European animals. We know that our British species came to us by land -at least the bulk of them. But we want to know what direction they came from, and at what time they arrived. When Ireland became disconnected from Great Britain, and the latter from Scandinavia and France, is another interesting problem. Professor Boyd Dawkins has indicated to us a method of the special line of research to meet such inquiries. "The absence," he says ( $b$, p. xxix), "of the beaver and the dormouse from Ireland must be due to the existence of some barrier to their westward migration from the adjacent mainland, and the fact that the Alpine hare is indigenous, while the common hare is absent, implies that, so far as relates to the former animal, the barrier did not exist."

Many members of the great Siberian invasion reached England, but Ireland remained entirely free from these migrants. The assumption therefore seems not unreasonable, that the latter country at the time of their arrival was no longer joined to England. The great bulk of the Irish fauna is composed of Lusitanian, Alpine, and Oriental immigrants, and there is besides a distinctly Arctic or North American element. All these, of course, must have established themselves in Ireland before the 
Siberian fauna set foot in England, since it has been shown that a continuous land-surface was necessary for their migration. Owing to the perfect preservation of the remains of the Siberian migrants in recent continental deposits, the history of that migration can be clearly followed, and it is possible even to determine the date of its arrival in England-in geological language at any rate. The time of the colonisation of Ireland can be thus approximately fixed as having taken place at a period prior to the arrival of the Siberian migrants in England.

All those who have seriously studied the problems presented by our British fauna-notably the late Professor Forbes, and more recently Mr. Carpenter and myself-are agreed that the Lusitanian element is the oldest, and that the newest is that which has come to us from the east.

The sequence of events in the British Islands was probably as follows:-The first comers were the members of that fauna which issued from Southwestern Europe; then came the Alpine, and at the same time probably the Arctic and the Oriental; and finally the Eastern or Siberian. The migrations of all but the last continued, uninterruptedly, for very long periods.

The study of these migrations has convinced me that, though climate was a powerful factor in the evolution or history of the European fauna, the geographical changes which took place on our continent in later Tertiary times exerted a yet stronger 
influence. The principal climatic disturbance is generally supposed to have been the so-called "Ice Age." So firmly rooted is the conviction, among naturalists of the present day, of the enormous destruction which this period produced on our European fauna, so that all animal life practically disappeared from large areas of our continent, that it is desirable that we should now shortly review the history of that remarkable period in order to ascertain in how far these views are corroborated by facts. Frequent reference, moreover, will be made throughout this work to the theories connected with the Glacial period:

It has been stated by an eminent geologist that during part of the Glacial period the climate was such that neither plants nor animals could have existed in the British Islands. If that had been so, it is evident that very few organisms could have even survived in France, though a number of Arctic species might have dragged on an existence in Southern Europe. At any rate, on the return of more genial conditions, the Arctic species would undoubtedly have been the first to gain admission to the British Islands, to re-people the arid wastes. Our supposition that the Lusitanian element in the British fauna is the oldest would therefore be wrong. From early Tertiary times onward, the climate of Europe, which was then semi-tropical, gradually became more and more temperate; until finally the Ice Age or Glacial period arrived, during which, according to Professor 
J. Geikie-one of our highest authorities on this subject-a great part of Northern Europe became practically uninhabitable owing to the severity of the climate.

To enable us to judge better of the true value of the many hypotheses which have been advanced to account for this supposed extraordinary fall of temperature during the "Ice Age," we must compare the views of other authorities with the one just quoted. I do not propose to discuss the causes which have led to the production of the Glacial periodthose interested in these questions should consult the writings of Dr. Croll, Professor J. Geikie, Professor Bonney, Mr. Falsan, and others-but merely to give the climatic aspects from a physical, zoological, and botanical point of view.

According to Professor Penck ( $a$, p. 12), the nature of the glacial climate can be determined by comparing the snow-line of the Glacial period with that of the present day. The position of the snow-line is dependent on two climatic factors-viz., precipitation and temperature. We know the height at which snow must have lain permanently during the Glacial period, or during the maximum phase of glaciation. If the Ice Age had been produced solely by an increase of snowfall, as has been suggested, Professor Penck tells us that then it must have snowed three or four times as much as it does now. But he does not adopt the view that the Ice Age is due to an increase of snowfall alone. His calculations, based upon the 
height of the snow-line, tend to show that a general decrease of temperature to the extent of from 4-5 degrees Centigrade (all other atmospheric conditions remaining the same as now) would be sufficient to give us back the Glacial period.

Professor Neumayr (p. 6I9) adopted a similar principle in determining the temperature which prevailed in Europe during the Glacial period. Snow now lies in the Pyrenees 1000 metres higher than it did then, I,200 metres higher in the Alps, and 800 metres higher in the Tatra mountains. Since the temperature in Central Europe decreases by half a degree Centigrade for every 100 metres of elevation, it follows that if the glacial phenomena had only been brought about by a decrease of temperature without an increase of moisture, we should have had a reduction of temperature during the Glacial period of six degrees Centigrade in the Pyrenees, of seven degrees in the Alps, and of four in the Tatra mountains. The general lowering of the temperature of Europe, says Professor Neumayr, could not have amounted to more than six degrees Centigrade. Moreover, he is of opinion that the very low snow-line in the British Islands proves that even during the Ice Age a comparatively mild climate prevailed there, and that the climatic conditions generally, in the different parts of Europe, were relatively about the same as they are now.

Professor J. Geikie does not give us his views as to the temperature of the Glacial period, but he main- 
tains that a lowering of the temperature is evinced not only by the widespread phenomena of glaciation, but by the former presence in our temperate latitudes of a northern fauna and flora.

Mr. Charles Martins, who based his calculations on the temperature during the Glacial period on the glaciers of Chamounix, concluded that it only needed a lowering of the temperature to the extent of four degrees Centigrade to bring the glaciers down to the plain of Geneva, and in fact give us back the Glacial period. It need not surprise us, therefore, that the French geologist, Mr. Falsan, the author of La periode glacière, is of opinion (p. 230) that the mean annual temperature of France during the Glacial period was approximately from 6-9 degrees Centigrade, perhaps more. Close to the immense glaciers of the Rhone, it might have been about six degrees. This is the actual mean annual temperature of the South-west of Sweden and Norway, or the North of Scotland.

Although all these investigations tend to show that the climate of Europe during the Glacial period was by no means so severe as we are often led to believe, yet there exists also a school of geologists who maintain there was actually a higher temperature than at present. The inconsistency of mentioning heat in connection with ice and snow is more apparent, however, than real, for we must remember Tyndall's original remark on this subject. It is the snow, he says, which feeds the glaciers. But the 
snow comes from the clouds, and these again originate from the vapours which the sun causes to be absorbed from the ocean. Without the sun's heat, we should have no water vapour in the atmosphere; without vapour, no clouds; without clouds, no snow; without snow, no glaciers. The ice of glaciers, therefore, owes its origin indirectly to the sun's heat. It has been supposed that if the sun's heat diminished, larger glaciers would form than those existing to-day, but the diminution of the solar heat would infallibly reduce the amount of water vapour in the air, and would thus stop the very source of glaciers.

Mr. Falsan even admits that without a change of the mean annual temperature (p. 20I) of Europe, the central portions of our continent might at this period have enjoyed an insular climate. This more equable and humid climate could, within certain limits, favour the development of the ancient glaciers by increasing the snowfall and slackening the summer rate of melting.

It seems evident then, according to these views, that with a comparatively slight change of the atmospheric conditions in the British Islands, we might have glaciers back again on all our highest mountain ranges in England, Scotland, and Ireland. But a widespread belief seems to prevail that the presence of glaciers implies a very low temperature. Snow and ice, however, are formed as soon as the tcmperature falls below freezing point; it does not 
matter whether there be I or 20 degrees of cold. Winters with a few degrees of frost will be just as favourable for the growth of glaciers as winters with the most severe cold.

Let us now see what the fauna and flora, as far as we know it, tell us of the climate of the Glacial period. At the very outset of our inquiry we are confronted with one very serious difficulty in the problem, and that is the supposed occurrence of interglacial mild phases alternating with colder ones during the Ice Age. At first, when traces of a temperate flora and fauna were discovered intercalated between two layers of boulder clay, their presence was explained by the supposition of a mild inter-glacial period. The famous Forest-bed on the east coast of England was also pronounced to be an inter-glacial deposit, though not coming precisely under this definition. In a few places one such bed was found, in some two or more, and in others none at all. Professor James Geikie discovered the evidences of no less than five of such inter-glacial epochs (p. 612) in Europe. Lest a reader of that author's remarkable work on the Ice Age might carry with him the idea that his hypotheses had met with general acceptance, a few quotations from almost equally high authorities on glacial matters will be useful. "That the glaciers," remarks Professor Bonney (p. 245), "were liable to important oscillations seems to be proved, but whether the evidence suffices to establish inter-glacial epochs, in the usual sense of the words, is more doubtful. 
When the snow-fields, as in the Alps, were much more extensive than they are at present, the glaciers which radiated from them would be more sensitive to minor climatal change. Even now they oscillate considerably. But during a Glacial epoch, an inch, either more or less, of precipitation might mean a considerable advance or retreat of the ice in the lowlands." French geologists look with even less favour on Professor Geikie's theories. Mr. Falsan (p. 212) says that he agrees with Messrs. Favre, de Saporta, Lory, de Mortillet, Desor, de Lapparent, Lortet, Chantre, Benoit, Fontannes, Depéret, and many other geologists, that there was only a single Glacial period, which, according to each particular region, might be divided into several phases, or into their equivalents-viz., one or more extensions of the ancient glaciers. But, on the whole, the view that there was at least one inter-glacial phase in the Glacial period meets with more general acceptance among geologists, I think, though the other opinion agrees much better with the nature of the fauna and flora as it has been revealed to us from the pleistocene deposits.

The occurrence of the remains of such arctic species of mammals as the Musk-Ox, Arctic Fox, Glutton, Lemming, and many others in these deposits, is frequently held up to us by geologists as a proof of the prevalence of an arctic climate while these beds were laid down. And indeed this appears at first a most satisfactory explanation of the 
phenomenon. But we must not judge the climate of Europe by their presence alone. As I shall explain more fully in Chapter V., these species invaded Europe owing to two circumstances. Firstly, because the climate of Siberia was becoming colder, necessitating a southward movement, with a consequent over-population in a reduced arca; secondly, because a new short route to Europe had been opened up for them about the same time (see p. 221). An invasion of Europe therefore took place from east to west. Similar invasions occur even at the present day, though not caused by a change in our climate, for every now and then immense flocks of the Siberian Sandgrouse emigrate to our continent. The mammalian migrants referred to are not to be looked upon as constituting the whole of our fauna at that time. Europe had a fauna of its own, and these invaders merely mingled with our animals. There was, no doubt, a keen struggle for existence, as the result of which the weaker in many cases succumbed. The hypothesis, however, that these Siberian migrants occupied an empty continent, forsaken by its pre-glacial inhabitants, is not supported by any facts.

All those who have investigated the pleistocene fauna have been struck by the extraordinary mixture of northern and southern types of animals. Professor Dawkins attempted to explain these facts by the supposition (p. I I ) that "in the summer time the southern species would pass northwards, and in the winter 
time the northern would sway southwards, and thus occupy at different times of the year the same tract of ground, as is now the case with the elks and reindeer." "In some of the caverns," he continues (p. II4), "such as that of Kirkdale, the hyæna preyed upon the reindeer at one time of the year, and the hippopotamus at another."

A similar mingling of northern and southern faunas has also been observed in France. $\mathrm{Mr}$. Falsan tells us (p. 236), that the remains of the mammals gathered and determined by Lartet and Gaudry belong partly to species which have been wrongly regarded as indications of a severe climate, and partly to such as are accustomed to a relatively mild temperature. In several localities in France, viz., at Levallois, St. Acheul, and Arcy, the remains of the Hippopotamus have occurred together with those of the Reindeer; whilst, according to Sir H. Howorth, the Lion has been found together with northern Voles at Bicêtre, near Paris. It is stated by the same authority (p. I I5) that much the same conditions exist in Germany. "The lion and the spotted hyæna, the mammoth and rhinoceros, were found with the marmot, the suslik, the lemming, the pica, and the reindeer." At another locality near Thiede, remains of the Mammoth, woolly Rhinoceros, Horse, Ox, Reindeer, Arctic Fox, Lemming, and Pica are met with in the same deposit. In quoting the presence of these northern animals in Europe as evidence of an arctic climate, we commit a fatal mistake. Indeed, 
breeders of animals and those acquainted with zoological gardens know perfectly well that it is much easier to keep a northern species in a southern climate, than a southern species in a northern one. If in a Central European deposit occur a mixture of northern and southern forms of animals, the presence of the latter is more remarkable than that of the former. Logically, we should look upon the occurrence of southern species in the north, therefore, as supporting the view that a mild climate had induced them to travel northward. The only indication, indeed, of the presence of a Monkey in the British Isles in former times comes to us from the very same strata which have also yielded the remains of the Siberian mammals.

Before I conclude the consideration of the pleistocene fauna, it may be of interest to hear what Mr. Lydekker, one of our highest authorities on fossil mammals, has to say on this subject. "The most remarkable feature connected with this fauna is the apparently contradictory evidence which it affords as to the nature of the climate then prevalent. The Glutton, Reindeer, Arctic Fox, and Musk-Ox are strongly indicative of a more or less arctic climate; many of the Voles (Microtus), Picas (Lagomys), and Susliks (Spermophilus), together with the Saiga Antelope, appear to point equally strongly to the prevalence of a Steppe-like condition; while the Hippopotamus and Spotted Hyæna seem as much in favour of a 
sub-tropical state of things. Many attempts have been made to reconcile these apparently contradictory circumstances; one of the older views being that while the tropical types of animals lived during a warm interlude, they migrated southwards with the incoming of colder conditions to the arctic type of fauna. Since, however, it has now been ascertained that the remains of both tropical and arctic forms have been found lying side by side in the same bed, it is perfectly certain that such an explanation will not meet the exigencies of the case" (p. 300).

In Germany the remains of the Siberian mammals occur to a large extent in a pleistocene deposit known as "loess," and the theory has of late years gained ground that the latter is the fine dust-like sand accumulated during an intensely arctic dry climate. That many of the mammals discovered in the "loess" now inhabit the dry steppes of Eastern Europe and North-Western Asia seems to lend support to this supposition; but besides the mammals there are also land and freshwater shells in this deposit. The molluscan fauna certainly indicates no steppe-character, according to Dr. Kobelt (b, i. p. I66).

The attempt to utilise the Siberian migrants to Europe as indicators of a severe climate there, certainly fails to establish conviction. But it may be asked, surely the remains of the Alpine and Arctic plants which have been found in pleistocene deposits must decide this question in favour of one or the other hypothesis? Let us test it. 
Plants being more directly affected than animals by changes of temperature and rainfall, remarks Mr. Clement Reid (p. I85), give evidence of the highest value when we inquire into former climatic conditions. The severity of the climate during the Glacial period is often assumed from the occurrence in pleistocene strata of such plants as Dryas octopetala, some species of willow, the dwarf birch, and others, which are now found in high latitudes and in the Alps, but are, as a rule, absent from the plain of Northern Europe. Professor J. Geikie goes so far as to state (p. 398) that it was unlikely that southern England during the climax of the glacial cold had much if any vegetation to boast of, and continues, "It is certain, however, that it was clothed and peopled by an Arctic flora and fauna when the climatic conditions were somewhat less severe, relics of that flora having been detected at Bovey Tracey." He believes, therefore, that an Arctic flora took possession of England as soon as the climate enabled it to live in the country. Arctic plants, according to this explanation of the sequence of events, were the first immigrants to reconquer the dreary, plantless wastes and make them habitable for mammals.

Fortunately these views do not at all agree with those of many of our leading European botanists and others entitled to have a voice in the matter. Professor Warming is of opinion that the main mass of the present flora of Greenland survived the Glacial period in that country (p. 403); whilst Professor 
Drude has shown (p. 288) that all plant life could not possibly have been destroyed in northern countries. He maintains that the greater part of the Arctic floral elements which unite Greenland and Scandinavia must have survived the Glacial period in these countries in sheltered localities. Indeed, he justly remarks, where at the present moment do we find such plantless wastes? Greenland, Franz-Josef Land, and Grinnell Land, situated in high Arctic latitudes, all have a flora composed of flowering plants and cryptograms. "I cannot understand," he continues (p. 286), "why a flora, possibly mixed with northern forms but in the main points agreeing with our present floral elements, should not have persisted throughout the Ice Age even in the heart of Germany." "To my mind," says Col. Feilden, the well-known Arctic traveller (b, p. $5 \mathrm{I})$, "it seems indisputable that several plants now confined to the polar area must have originated there, and have outlived the period of greatest icedevelopment in that region." The theory in favour of a survival of the pre-glacial flora has been especially strengthened by the late Mr. Ball (than whom probably no botanist possessed a better knowledge of Alpine plants), who was strongly in favour of this view as far as the Alps are concerned. "Is it credible," he says (p. 576), "that in the short interval since the close of the Glacial period hundreds of very distinct species and several genera have been developed on the Alps, and, what is no less 
hard to conceive, that several of these non-Arctic species and genera should still more recently have been distributed at wide intervals throughout a discontinuous mountain chain some I,500 miles in length, from the Pyrenees to the Eastern Carpathians?" Mr. Ball's remarks, indeed, just touch upon a very important characteristic of all the so-called Alpine plants. In Europe they chiefly occur in Scandinavia and the central and southern mountain ranges, whilst they are mostly absent from the intervening lowlands. Again, we find a large number of species in the mountains of Central Asia and in some of the North American mountains. Almost all species of Alpine plants, in fact, are examples of discontinuous distribution; and this, as every naturalist knows, is always, in both animals and plants, a proof of antiquity.

The glacial or Alpine flora is very old, and must have originated long before the Ice Age. But it might be urged, why should these plants be now almost confined to the Arctic regions and the higher mountain ranges, where the temperature undoubtedly is very low, if they had originated during a pre-glacial period probably much milder than the present? The answer can be given by those who have made Alpine plants their special study, and who have attempted to grow them by administering to them a temperature and such climatic conditions as to be most conducive to good health. We should all expect these plants to be very robust, and especially to be able to stand extremely low temperatures. But, 
strange to say, the very opposite is the case. Professor Blytt tells us (p. 19) that "Arctic and Alpine species in the Christiania Botanic Gardens endure the strongest summer heat without injury, while they are often destroyed when not sufficiently covered during winter." The English climate then, one would think, ought to suit these plants, since the winters are not too cold; but we find that at Kew Gardens the large collection of Alpine plants have to be wintered in frames under glass in order to keep them in good health; and Professor Dyer, the Director of the Gardens, thinks they are mostly intolerant of very low temperatures (compare also pp. I6I-I64).

Such being the constitution of Alpine plants, how could they possibly have originated during the Glacial period and wandered from the mountains into the plains, across numbers of formidable barriers, often exposed to icy winds, for thousands of miles? As a matter of fact, Alpine plants have survived in the high North and in the Alps because they are there permanently protected during winter by a covering of snow from very low temperatures, and they are at the same time prevented from drying up. If they are given sufficient moisture and a constant, mild temperature they seem to do very well. Such conditions are afforded them in many parts of the British Islands, and we find indeed the Mountain Avens (Dryas octopetala), one of the most typically Arctic plants, growing wild in profusion on the coast of Galway, in Ireland, at sea- 
level. The winter temperature of that part of Ireland resembles that of southern Europe, being no less than $12^{\circ}$ Fahr. above freezing point. This fact appears to strengthen the view not only that the Alpine flora is of pre-glacial origin, but that the climate of Europe during the Glacial period was mild.

Having now shortly reviewed the state of our knowledge with regard to the former presence in our temperate latitudes of Arctic animals and plants, it still remains for me to give a succinct statement of the light thrown by this fauna and flora on the widespread phenomena of glaciation. It is necessary to do so, because, though the greater development of glaciers on the mountains of Europe in former times does not presuppose the prevalence of an Arctic climate, the survival through the Ice Age of a fauna and flora could not possibly have taken place in northern Europe if the theories of glaciation now so much in vogue are really truc. Professor Geikie reminds us, in speaking of his native country ( $p$. 67), that "we must believe that all the hills and valleys were once swathed in snow and ice; that the who!e of Scotland was at some distant date buried underneath one immense mer de glace, through which peered only the higher mountain tops." That under such conditions no fauna or flora to speak of could have survived in Scotland is evident. Then again he argues (p. 426) that because in the great plain of Europe we meet occasionally with striated rock-surfaces and roches 
moutonnées very similar to those produced by the glaciers of Switzerland, it must have been traversed by "inland ice" flowing from Scandinavia and the Baltic southward. The boulder clay of Germany is supposed to have accumulated underneath this vast "mer de glace," as he calls it. There is no question here of a simple local development of glaciers, such as could have existed under a mild and moist climate; practically all the plants and animals would have been annihilated in northern Europe under such conditions, as there were no areas free from ice. A more vivid idea of the state of Europe during the epoch of maximum glaciation will be obtained by looking at Professor Geikie's map (p. 437). The whole of Scandinavia, Iceland, Scotland, Ireland, and Switzerland is there represented as having been completely enveloped in ice, and also the greater part of Russia, Germany, and England. In speaking of Scandinavia (p. 424) he remarks that "the whole country has been moulded and rubbed and polished by one immense sheet of ice, which in its deeper portions could hardly have been less than 5000 feet or even 6000 feet thick." The greater portion of the area indicated as having been underneath a sheet of ice is thickly covered with superficial accumulations of gravel, sand, and clay. The latter is generally spoken of as "boulder clay," and, with the associated sand and gravel, it may be observed equally well in Russia or Germany, in England or Ireland. As a 
rule these stony clays thicken out as they are traced from the high-lying tracts to the low grounds; and especially near the mountains the rock-surfaces are often polished and striated. "For many years it was believed," continues Professor Geikie (p. 432), "that all those superficial deposits were of iceberg origin. The low grounds of Northern Europe were supposed to have been submerged at a time when numerous icebergs, detached from glaciers in Scandinavia and Finland, sailed across the drowned countries, dropping rock-rubbish on the way. Such was thought to have been the origin of the erratics, stony clay, and other superficial accumulations, and hence they came to be known as the 'great northern drift formation." "But," he adds (p. 433), "when the phenomena came to be studied in greater detail and over a wider area, this explanation did not prove satisfactory. The facts described in the preceding paragraphs-the occurrence of striated surfaces and roches moutonnées, the disturbed appearances associated with the till, and the not infrequent presence of giants' kettles-convinced geologists that all the vast regions over which boulder-clay is distributed were formerly occupied by the 'inland ice' of Scandinavia."

I think Professor Geikie over-estimates the value of the evidences which appear to be in favour of his theory. His treatise on the Ice Age leaves one under the impression that the older view of the marine origin of the boulder-clay is not only 
done with for good and all, but that no geologists nowadays believe in it. If a more careful study of the glacial phenomena has led most geologists to abandon what I might call the "marine view" in favour of the terrestrial one, a more careful study of the fauna and flora will, I venture to think, have the opposite effect. However, it appears that even from a purely geological point of view more can be said in favour of the old theory than Professor Geikie and his school are ready to admit. Thus we are told by Professor Bonney (p. 280), in referring to the boulder-clay, that "the singular mixture and apparent crossing of the paths of boulders are less difficult to explain on the hypothesis of distribution by floating ice than on that of transport by land-ice, because, in the former case, though the drift of winds and currents would be generally in one direction, both might be varied at particular seasons. So far as concerns the distribution and thickness of the glacial deposits, there is not much to choose between either hypothesis; but on that of land-ice it is extremely difficult to explain the intercalation of perfectly stratified sands and gravel and of boulder-clay, as well as the not infrequent signs of bedding in the latter." "Anything," writes Professor Cole (p. 239), "that keeps open the position maintained by Lyell and others, that extensive glaciation is compatible with mild and sheltered nooks and corners, and that much of the distribution of boulder-clay was performed in 
seas and not on land, may be welcomed by rationalists, at any rate until further research has been carried on among the Arctic glaciers. At present every year brings evidence of modern marine boulder-clays in high latitudes, and removes us farther and farther from belief in a moraine profonde." That foraminifera are occasionally found in boulder-clay has been known for a long time, but it is only within recent years that these marine organisms have been shown to occur in so many localities, that Mr. Wright, who examined a large number of samples, says (p. 269), "I am forced to the conclusion that the Scottish as well as the Irish boulder-clay is a true marine sedimentary deposit"

In the fourth and fifth chapters I shall return to this subject again, and mention a number of facts of distribution which appear to me much easier of explanation by means of the marine than by the landice theory. But I do not propose to go into further geological details in this volume, as I think I have clearly conveyed my position in this controversy.

Before concluding this short review of the glacial problem, so far as it affects the origin of the European fauna, I should like to refer to the opinion of one who has devoted years to the study of the glacial phenomena in the Arctic Regions, viz., Col. Feilden. "To a certain extent," he says ( $a$, p. 57), "all boulder clays at home are fragmentary when compared with the boulder-bearing beds of Kolguev, 
which we may safely assume are 50 miles in length by 40 in width, with a thickness of not less than 250 fcet, probably far more, all lying in one undisturbed mass. It is suggestive that all the glacial deposits which I have met with in Arctic and Polar lands, with the exception of the terminal moraines now forming above sea-level in areas so widely separated as Smith's Sound, Grinnell Land, North Greenland, Spitsbergen, Novaya Zemlya, and Arctic Norway, should be glacio-marine beds. Throughout this broad expanse of the Arctic Regions I have come across no beds that could be satisfactorily assigned to the direct action of land-ice; that is to say, beds formed in situ by the grinding force and pressure of an ice-sheet. On the contrary, so far as I can judge, the glacial beds which I have traced over the extensive area mentioned above have all been deposited subaqueously and re-elevated."

One of the strongest arguments that can be used against the view of the marine origin of the glacial phenomena in Northern Europe seems to me the fact that we find polished rock-surfaces far removed from the source of glaciers, and so exactly resembling those produced at the present day by our Alpine glaciers as to appear identical to the experienced eye. Most of such striated and polished rocks occurring in the higher mountain ranges of Scandinavia, and also of the British Islands, have no doubt been actually produced by glaciers, whilst those in the plain, sometimes hundreds of miles away from the mountains, 
must have originated in a similar manner; that is to say, by a heavy mass of material containing stones being slowly dragged over the rock-surfaces. The weight which causes the stones to polish the latter is generally ice, but it is quite conceivable that any other substance, especially if it is in a semi-solid state, must act and operate in much the same way. All polished rock-surfaces are carved by glaciers, because we can see them done by glaciers every day, is the argument commonly used nowadays. It was not so formerly. But Mr. Mallet and his views are almost forgotten now; his name does not even appear in our great modern works on the Ice Age. His argument was that as the land rose out of the glacial sea, the mud which had accumulated round the shore slipped downward in a direction determined by the contour of the surrounding valleys and mountains. The moment the land rose above water-level, the large mass of gravel and mud lying upon it slipped downward. During a steady rising of the land there would therefore be produced a continuous sliding down of this mud-glacier, which would groove and polish the rock underneath it, in the same manner as the iceglaciers do in the Alps (p. 47). Professors Sedgwick and Haughton became strong adherents of $\mathrm{Mr}$. Mallet's theory at the time, but it seems later on to have fallen into disfavour with geologists, who may not even be thankful to have it brought to light again. 


\section{SUMMARY OF CHAPTER II.}

I have endeavoured to show in this chapter how we can determine approximately the original home of an animal. By this means we are able to study the component elements of the European fauna, which is found to consist to a large extent of migrants from the neighbouring continents. There is a Siberian, an Oriental, and an Arctic element in it. The remainder of the fauna is derived from local centres of dispersal. What was formerly believed to have been one great northern migration now resolves itself, on closer study, into two very distinct ones-the Siberian and the Arctic. The mammals have received most attention hitherto, because their remains are so frequently met with, thus enabling us more easily to investigate their past history; but butterflies and snails have not been neglected, and at least one very remarkable work on the latter has been published dealing with their origin in Europe and in the remainder of the Palæarctic region.

The former distribution of land and water is intimately connected with the origin of the European fauna, and the changes which have taken place in this respect may be best traced by the present distribution of mammals, snails, and earthworms. In this manner the British Islands may be shown to have been connected with one another and with the Continent; Spain with Morocco across the Straits of Gibraltar; Greece with Asia Minor, and so forth.

The British fauna has played such an important part in the evolution of the European fauna, that it forms the key to the solution of the wider problem. In it five elements are recognisable, of which the Lusitanian element is the oldest, and the Siberian the most recent. It has been deemed advisable to conclude this chapter with a short review of the 
history of the Glacial period in its climatic effects on the animals and plants of Europe. A number of writers are quoted who have conducted special researches in determining the temperature of our continent at the time. The fauna of Europe is frequently described as having been of an Arctic nature, but as a matter of fact there existed during the Ice Age a striking and most remarkable mingling of a northern and a southern fauna. The presence of Siberian mammals in Europe is said to have been due to the prevalence of a dry steppe climate, but this view is not supported by other evidence. The Alpine flora in a wide sense is probably pre-glacial in origin, and appears to have survived the Ice Age where it is now known to exist. A few words on the phenomena of glaciation are added be?ore bringing the chapter to a close. 


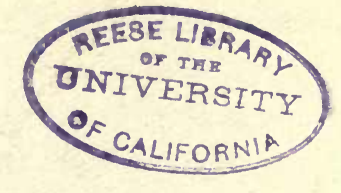

\section{CHAPTER III.}

TIIE FAUNA OF BRITAIN.

The British Islands are, as I have remarked, very suitable as a starting-point for our investigations. Their fauna and flora are fairly well known, and the distribution of the large animals at any rate, which are of course of much importance in these researches, has been as much studied as that of any other area in Europe. We possess in England an abundance of the remains of past animal life, and a combination of the data furnished by both of these important factors will enable us to draw up a history of the origin of the present British fauna.

In the first chapter I indicated that in the fauna of the British Islands three divisions or elements are recognisable-a northern, a southern, and an eastern. These elements correspond to migrations which can be proved to have arrived in this country at different periods in past times. When we investigate these migrations more closely, the eastern is found to be composed partly of European and partly of Siberian species. The southern is made up of European and of Central and Southern Asiatic species. To make matters still more complex, the southern and 
eastern migrations insensibly merge into one another, so that it is often very difficult to determine to which of them an animal may belong. The European species spread principally from three centres over Europe-viz., from the Lusitanian, Alpine, and the Balkan centres. The southern element of the British fauna is therefore composed of animals which have originated in these three centres, and in Central and Southern Asia. The Balkan species have been included with those coming from the latter centre under the term "Oriental" migration. The sixth chapter is devoted to it, whilst the Lusitanian and Alpine migrations have each a chapter to themselves.

The Arctic Hare is, as I have already mentioned, one of the mammals of the northern element of the British fauna. It is now confined to the mountains of Scotland and the plain and mountains of Ireland. But in former times it had a wider range in the British Islands. The Stoat is another distinctly northern mammal. It occurs with us, as Messrs. Thomas and Barrett-Hamilton have pointed out, in two distinct varieties or species, the one being confined to Great Britain, the other to Ireland. As I shall explain more fully later on (p. I35), I have reasons to believe that the Irish Stoat came from the Arctic Regions as a northern migrant, but that the English Stoat, on the other hand, reached England with the Siberian fauna from the east. A third northern animal, now extinct in the British Islands, 
is the Reindeer. It is supposed to have died out in these countries not very many centuries ago, and records have been handed down to us that it still inhabited Scotland as late as the thirteenth century. Like the Stoat, it occurred in two well-known varieties, distinguished from one another by the shape and form of the antlers. In the English pleistocene deposits the remains of both kinds are met with mingled together, whilst in Ireland only one of them has been found. The explanation of this case is similar to that of the two stoats. One of the varieties, which we may call the northern one, came to us from the Arctic Regions; the second wandered to the British Islands at a later period, when Ireland had probably become separated from England. It was therefore unable to penetrate so far west.

One of the most familiar examples of a northern British bird is the Red Grouse (Lagopus scoticus). By most authorities it is looked upon as a species distinct from the Scandinavian Willow Grouse (Lagopus albus), but except in colour it is undistinguishable from it, and the eggs are identical. The whole genus Lagopus is a distinctly Arctic one, and there can be no doubt that the British Grouse belongs to the northern migration, just like the Arctic Hare. The Ptarmigan (Lagopus mutus) and the Snow Bunting are also migrants from the north. Though as resident British birds they are quite confined to Scotland, the remains of the former have been found in a cave in the south of Ireland, showing that its range in the 
British Islands was formerly more extensive. Another bird which probably came to our shores with this same migration, though it is now unfortunately extinct, is the Great Auk (Alca impennis), of which some specimens have luckily been preserved in our museums. From the occurrence of its remains in kitchen-middens and other recent deposits, the Grcat Auk is known to have inhabited the coasts of Scotland, Ireland, and Scandinavia, as well as those of Newfoundland. Mr. Ussher recently found the bones of this bird near Waterford, which, I believe, is the most southern locality known. The manner of their occurrence leaves no doubt that the bird had been used as food by the early races of man. In all probability it originated in the Arctic Regions, and subsequently spread south on either side of the Atlantic. We need not here refer to the many winter visitants, -northern birds which appear regularly, or at more or less long intervals, in these islands,-although in most of the ornithological works they are included under the term "British Birds."

All the British reptiles and amphibia appear to have reached us from the south or east, but among the fishes there are a good many northern forms. The whole salmon family-the Salmonida-are typical northern immigrants. The Stickleback (Gasterosteus aculeatus), too, has undoubtedly come to us from the north. The genus Cottus, like Gasterosteus, is certainly Arctic in origin. Originally freshwater forms, many species are now found between tide- 
marks, and of these a few have migrated southward along the coasts of the great continents. Thus we meet with various species of Cottus as far south as California and Japan, on the American and Asiatic coasts of the Pacific respectively. In Europe, two species, viz., C. scorpio and $C$. bubalis, range as far south as the French coast. Our freshwater Cottus, the Miller's thumb (Cottus gobio), has migrated to us from the north with the Arctic species. All the freshwater forms, indeed, of this genus are typically Arctic.

A large number of land and freshwater invertebrates too have no doubt reached us from the north. Some of them may have originated in Scandinavia or within the Arctic Circle, but others probably came still farther, either from America or even from Asia, and used the Arctic land-connection viâ Greenland in their migration to Europe. As I shall give a number of additional instances of such migrants in the succeeding chapters, I need not, perhaps, dwell upon them now any longer, except to mention a few of the more typical ones. Vertigo alpestris, a minute snail with an amber-coloured shell, and our freshwater pearl-mussel, Unio (Margaritana) margaritifer, belong to this migration. Then among butterflies we may cite the Marsh-ringlet (Coenonympha typhon), and among beetles, Pelophila borealis and Blethisa multipunctata. There are a number of northern spiders, among which a few certainly indicate an Arctic origin, or at any rate, that they have wandered to 
Europe across Greenland and the old Arctic landconnections. Bathyphantes nigrinus, Linyphia insignis, and Drapetisca socialis, for instance, are three British species whose range indicates a northern origin, and which also occur, according to Mr. Carpenter, in North America. Mr. Carpenter also tells me that the Collembolan, Isotoma littoralis, is a typical northern migrant. He has recently discovered it in the west of Ireland, its only station in the British Islands.

Among the crustacea, the genus Apus forms an exccedingly interesting illustration of the northern migration, Apus glacialis having been discovered in a Scottish pleistocene freshwater deposit, whilst it is now almost confined to the Arctic regions.

To the same group of animals also belong the three remarkable species of freshwater sponges, Ephydatia crateriformis, Heteromeyenia Ryderi, and Tubella pensylvanica, which Dr. Hanitsch has described from some lakes in Western Ireland. None of these are known from Great Britain or from the continent of Europe. A few North American plants grow wild in the same district. That any of these should owe their existence in Ireland to accidental introduction appears to me exceedingly improbable. In a former contribution to this subject $(a$, p. 475$)$ I assumed that these American plants and animals had migrated to Europe at the same time as the other northern forms referred to. My friend Mr. Carpenter, however, takcs exception to this (p. 383), and I quite recognise the force of his argument. "Their very 
restricted and discontinuous ranges," he says, "along the extreme western margin of Europe mark them as decidedly older than those northern animals and plants which have a circumpolar distribution." We have indeed quite similar examples in the Oriental migration, of which part is very ancient, surviving here and there and exhibiting discontinuous distribution. We may therefore look upon these American immigrants as among the oldest members of that northern stock which have survived in our islands - probably a mere remnant of a once luxuriant flora and fauna.

In order to show the importance of the Eastern or Siberian element in the English, or, we might say with Dr. Sclater, the Anglo-Scotian mammalian fauna, I herewith give a list of the species of mammals which probably migrated to Great Britain from Siberia. I have marked with an asterisk those which still exist in this country (not in Ireland), or have become extinct within historic times.

Canis lagopus.

Gulo luscus.

* Mustela erminea.

* $"$ putorius.

* , vulgaris.

* Sorex vulgaris.

Lagomys pusillus.

* Castor fiber.

Spermophilus Eversmanni.

erythrogenoides.
* Mus minutus.

* Arvicola agrestis.

* " amphibius.

* $\quad$ " $\quad$ arvalis.

, gregalis.

" ratticeps.

Equus caballus.

Saiga tartarica.

Ovibos moschatus. 
Cricetus songarus.

Myodes lemmus.

Cuniculus torquatus.
Alces latifrons.

" machlis.

Rangifer tarandus.

We have evidence that most of these twenty-six species of mammals came from Eastern Europe, but there is no reason to suppose that they originated therc. On the contrary, it is highly probable, as I said before, that their native home is Siberia, and that they entered Europe to the north of the Caspian. Along with these, vast numbers of other forms of life, and also plants, swarmed into our continent, and as we advance eastward from England we meet with them in increasing numbers to the present day. But not only on the Continent do we find these survivals of the great Siberian migration, which has been so ably described by Professor Nehring; no less than nine species still inhabit Great Britain (if we include the recently extinct Beaver). On the other hand, not more than three have been found fossil in Ireland, and of these only one still survives. This very significant fact will be referred to again more fully on p. I 53 . Meanwhile it should be remembered that these three species, viz., Mustela erminea, Equus caballus, and Rangifer tarandus, occur in Ireland in varieties distinct from those found in Central Europe. It is upon this, and many other circumstances, that I founded my belief that Ireland was already separated from England at the time of the arrival of the Siberian emigrants in the latter country. As 
we shall see, the Irish Stoat, Horse, and Reindeer probably came by a different route from that taken by the English representatives of the same species.

Very few of the lower animals of Sibcrian origin have reached the British Islands. Most of those which were formerly thought to be Siberian are either of East European or of Central and South Asiatic origin, though they probably joined the Siberian migration on their way to England. The Arctic migration brought a greater variety of species to this country than the Siberian, but neither the one nor the other has contributed more than a small percentage to the British fauna. The bulk of that fauna is derived from the various European centres of dispersal, and especially from Central and Southern Asia.

Those animals which have their home in the latter area, I have named Orientals, though it must be remembered that they need not necessarily have come from what is known among zoologists as the "Oriental Region." The terms "Oriental animals" and "Oriental migration" are used here in a wider sense, and include even those species which reached Central and Northern Europe from South-Eastern Europe. It is astonishing, what a vast number of both vertebrate and invertebrate animals can be traced back to this Oriental migration. Great tracts of Europe were repeatedly submerged beneath the sea during Tertiary times, and on their re-appearance were formed into green fields and pastures new for the rich Asiatic fauna, which was ever ready to flood the neighbouring 
continent. This went on, and not for a comparatively short space of time, as in the case of the Siberian invasion; the immeasurable ages which passed, whilst several of the Tertiary epochs dawned upon Europe, witnessed an almost constant stream of Asiatic immigrants pouring in upon us. Europe returned her own products in exchange, but they must have been scanty in comparison to the enormous number of species which have undoubtedly originated in Central and Southern Asia. Very many of the widely distributed forms in the British Islands are of Oriental origin. Among these are also the cosmopolitan species, such as the Barn Owl (Strix flammea) and the Painted Lady Butterfly (Vanessa cardui). A great number of our British Mammals, Birds, Butterflies, and Beetles have come to us with the Oriental migration. But, as I shall explain in the special chapter devoted to it, the earlier migrants from the south-east found their northward progress barred by a great sea which stretched through Central Europe from west to east. The Mediterranean was then divided into two smaller basins. On their arrival in Greece, which was then connected with Asia Minor and Southern Italy, the Oriental migrants seem to have turned westward, skirting the shores of the Mediterranean. When they finally reached Spain, many then changed their course northward (sce Fig. 5, p. II7) and wandered to the British Islands with the Lusitanian animals which came from South-Western Europe. 
Dr. Wallace makes mention of a fairly large number of species and varicties of Lepidoptera, Coleoptera, and land and freshwater Mollusca, supposed to be peculiar to the British Islands. Even if these were all found to be of British origin, most of their nearest relatives are continental species. Many, however, must be looked upon as mere races or sub-species of familiar continental forms. But others, such as Geomalacus maculosus and Asiminea Grayana, are by no means confined to the British Islands. Some of the so-called varieties enumerated by Dr. Wallace are merely slight individual variations in form and colour, which, only by the extraordinary tendency of the variety-monger to advertise himself, have received a distinct Latin denomination. The number of the remaining species, after weeding out the unworthy ones, will be found to be insignificant.

Similarly, the list of seventy-five species and varieties of flowering plants included by Dr. Wallace among the forms peculiar to the British Islands (p. 360) is reduced by Sir Joseph Hooker to twenty. The remainder are to be considered as varietal forms of a very trifling departure from the type, or as hybrids.

Just as we distinguish in the British Islands the parts inhabited by Englishmen, Scotchmen, and Irishmen, so we can recognise three divisions in the animal world, and these roughly correspond to the boundaries of England, Scotland, and Ireland. Most of the eastern species inhabit England, most of the northern 
ones are confined to Scotland, whilst Ireland is occupied chiefly by southern animals. This, however, is only a very rough-and-ready method of sub-dividing the British Islands into their component parts according to the origin of their faunas. On closer study such a division is found to be unsatisfactory. The eastern species do not really stop at the Scottish frontier, they range far into Scotland. Nor are the northern forms confined to the latter country. Many of them range into Ireland, and also into England. I have constructed a map of the British Islands showing approximately the boundaries of the northern, eastern, and southern species (p. 7), but even this may not altogether meet with the views of an ornithologist or conchologist. For every group of animals the boundaries would probably require to be marked differently. There is also a good deal of overlapping, so that the attempt to define the limits of the various elements meets with great difficulties. But the map represents, I think, fairly well the general impression one receives as to the disposition of its component elements, after a careful study of the British fauna as a whole.

The distribution of the British plants has been worked out much more thoroughly than that of the animals. It need not surprise us, therefore, that the first attempt to separate the British Islands into natural divisions was made by a botanist - the late Mr. Watson. As he himself pointed out, in making these divisions he did not take into consideration the 
origin of the British species. They represent merely groups of assemblages of plants of different types of vegetation. Edward Forbes, on the other hand, founded his districts on the origin of plants. His work is not only the first of the kind, but it is a classical essay, and remains one of the most remarkable contributions to the literature on the geographical distribution of living organisms known to science. The vegetation of the British Islands, he informs us (p. 4), presents a union of five well-marked floras, four of which are restricted to definite provinces, whilst the fifth, besides exclusively claiming a great part of the area, overspreads and commingles with all the others. These are-

I. Mountainous districts of South-
west and West of Ireland . $\}$ Lusitanian type.

II. South-west of England, and
South-east of Ireland . . . Gallican type.

III. South-east of England.

IV. Mountains of Scotland, Cumber-
land, and Wales Scandinavian type.

V. General Flora . . . . . Germanic type.

Professor Forbes points out, in connection with the plants of the Germanic type, that the fauna accompanying this flora presents the same peculiarities and diminishes westward and to the north. This type includes, thercfore, almost all the species which can be shown to have come to us directly from the east, few if any of which have penetrated to Ireland.

On a previous occasion, the same author had 
divided the British Islands into ten districts, according to the distribution of their molluscan fauna. These are-

I. The Channel Isles.

II. South-east of England (including Cambridgeshire).

III. South-west of England.

IV. North-east of England.

V. North-west of England (including Isle of Man).

VI. North of Ireland.

VII. South of Ireland.

VIII. South of Scotland.

IX. North of Scotland.

$\mathrm{X}$. Shetland Isles.

In a short paper on this subject $(b, \mathrm{p} .5)$, I have shown that some of these districts are founded on erroneous data; whilst, with the knowledge now at our disposal, others can no longer be maintained as distinct. I thought then that the molluscan fauna warranted a division of the British Islands into the following two provinces:-

I. England and Wales (except the South-west).

II. South-west of England and Wales and the whole of Ireland and Scotland.

The second district contains some species of molluscs which are almost entirely absent from the first, such as Geomalacus maculosus, Testacella Maugei, Helix pisana, Helix revelata, Helix acuta, and Pupa ringens. These are all of Lusitanian origin, and do not occur in Central Europe. Scotland alone cannot 
be classed as a separate province, since it docs not contain a single species peculiar to itself. But, along with Ireland and the South-west of England and Wales, it is distinguished from the remainder of these countries by the almost total absence of what have been called Germanic types.

A French conchologist, the late Dr. Fischer, dealt with the British molluscan fauna in a somewhat similar spirit (p. 57). He divided the British area into two districts, but these differ from mine in so far as the South-west of England and Wales and the West of Ireland form one ; the remainder of England and Ireland as well as the whole of Scotland the other. His classification is of particular intercst, since the first district represents part of a larger Atlantic province, the second a portion of the Germanic province of the European sub-region. The latter he looks upon as one of the sub-regions of the great Palæarctic Region. Attention is thus drawn to the intimate relationship existing between the western parts of the British Islands and the Spanish peninsula on the one hand, and between the eastern portions and Central Europe on the other.

Mr. Jordan's North-Sea-and-Baltic district includes Scotland and the North of Ireland, whilst England joined with the West and South of Ireland forms part of his Celtic province. Both of these districts or provinces belong to Mr. Jordan's greater Germanic Region (p. 302).

In the collection illustrating the geographical dis- 
tribution of animals in the Dublin Muscum, the British species have been grouped into three divisions. One contains those with a wide range over the British Islands, another the characteristic forms of the southeast and lowland districts of Great Britain, and the third the Irish and the western and highland AngloScotian species. Mr. Carpenter has named the last two divisions the "Teutonic" and the "Celtic." More recently, he has recognised that this last division contains two distinct groups; one including animals of northern, the other those of southern origin. $\mathrm{He}$ acknowledges indeed, just as I do, three distinct faunas in the British Islands, with the addition of the group of generally distributed species of undetermined origin.

Many other naturalists have worked in the direction I have indicated-namely, in grouping the British animals into several distinct assemblages, without, however, taking their foreign range into consideration, or their origin. I have already referred to the useful work done by botanists, who have been the pioneers in the science of the geographical distribution of living organisms. Among the British naturalists who have applied the principles of Watson to zoology, A. G. More deserves to be specially mentioned. He was the first to make a serious study of the British fauna on the lines laid down by that distinguished botanist. In conjunction with E. Boyd, he published a valuable essay on the "Distribution of Butterflies in Great Britain," and later on the birds 
were similarly dealt with. All the more important groups of animals are now being studied with a view to determining their exact range in these islands. Mr. Harvie-Brown, Mr. J. W. Taylor, Mr. Eagle Clarke, Mr. Miller Christy, Mr. Ussher, Mr. Barrington, and a number of others have considerably advanced our knowledge in this direction in recent years.

Any such contributions are to be welcomed as furnishing us with the necessary data to solve the problem of the origin of the British fauna. Meanwhile we know enough to enable us to assert positively that the latter has reached us by landconnections from various parts of Europe (cf. p. 35). This statement of course refers to the bulk of the British fauna. The small proportion of indigenous species, or such as have been introduced accidentally, may be left out of consideration when dealing with the great mass of animals which have evidently migrated to the British Islands on land now sunk beneath the sea (see Fig. 4, p. 60). Opinions of zoologists, botanists, and geologists are practically unanimous on this subject; yet there are two other theories, which have from time to time been advanced to account for the origin of the British fauna. Only the first of these, however, can claim the serious attention of those interested in the problem. Its chief contention lies in the oft-asserted dictum of the "imperfection of geological record." It has been suggested, in fact, that the British fauna, instead of having migrated to our islands, might have 
originated there, but that, owing to the fragmentary nature of our Tertiary deposits, all trace of their early history had disappeared. "The origin of European species," remarks Professor Cole (p. 238), "within the area of the British Isles, and their migration outwards when local conditions became less favourable for their multiplication, are possibilities that seem too often disregarded. Yet the geologist must see in the western borderland of modern Europe a diminished continent from which land-animals must have again and again moved eastward." "Hence geologists may fairly be unwilling to look on our isles as barren lands waiting to be peopled in pliocene or later times. Far rather has the breaking up of a broad land-area along the present continental edge sent our land-fauna to the new steppes that opened eastward, leaving us a mere diminished remnant to struggle with the glacial period."

There are in Professor Cole's views many points with which I readily agree. In the first place, he acknowledges that migration has taken place on land, so that we have our land-connection between Great Britain and the Continent whatever theory we accept as to the direction taken by the migrants. That the western borderland of Europe has given rise to many important assemblages of animals in past times, seems to me also exceedingly probable, nor do I look upon the British Islands as "barren lands waiting to be peopled in pliocene or later 
times." On the contrary, I believe an almost uninterrupted stream of migrants poured into the British Isles before pliocene times from the south. But what I thoroughly disagree with, is the remark that our British land-fauna has been sent to the new steppes that opened eastward. These are the more or less arid portions of Eastern Europe. Professor Cole no doubt has in mind those species of mammals which I have included in what I called the Siberian migration, and of which we have fossil evidence in the late Tertiary deposits of Europe. It would be impossible here to discuss this subject fully, especially as I have done so in the subsequent chapters; but, even if we had no geological record whatsoever, the present range of the species in question and their nearest relatives must convince us that they could not have originated in Western Europe. However, on the strength of the geological evidence, Professor Nehring-the only one who has made this fauna his special study-remarks (p. 228), that there seems scarcely any doubt that this steppefauna just referred to had come to us from the east. Professors Boyd Dawkins, Brandt, and Lartet held similar views.

The theory that an ice-sheet stretched across a narrow sea might be the means of aiding a fauna across from the mainland to an island, is particularly inapplicable to the British Islands. Neither $\mathrm{Mr}$. Kinahan nor Mr. Lamplugh, the two supporters of this view, have, however, taken the trouble to apply 
it to more than one species of the British fauna. An ice-bridge, thinks Mr. Kinahan, "could easily have connected Scotland and Ireland, thus giving a land causeway for migration" (p. 3). Mr. Lamplugh throws more light on this interesting speculation by giving us the name of an animal which he believes crossed a narrow sea on a bridge of ice. This animal unfortunately happens to be one whose remains have never been found in high northern latitudes, viz., the Irish elk (Cervus giganteus). And because he is of opinion that this species of extinct deer found its way to the Isle of Man from the mainland on a waning ice-sheet, he sees no reason why certain elements of the Irish fauna should not have been similarly introduced.

It seems of no advantage to begin the discussion on the origin of the British fauna by assuming the former existence of ice-bridges, and the possibility of a migration across them of some of its members. If a glacier connected Scotland and Ireland, the climate of both countries (since they were highlands and acted as the feeders of the ice-sheet) must have been uncomfortable to the majority of the British species. What were the inducements that could have prompted those which had braved the discomforts of Scotland to emigrate to Ireland at such a time? What light does it throw on the origin of the Irish fauna as a whole, to advance the extremely improbable hypothesis that certain elements of it may have reached Ireland by an ice: 
bridge? If any species came to that country in such an unusual manner, surely they must have been Arctic or northern forms. But what about the southern species, which form the bulk of the Irish fauna and also the flora? Even the Arctic element of the British fauna, which probably includes, besides the Reindeer, many hundreds of species, could not, I think, have migrated to these islands on an ice-bridge. Indeed, I agree with most of the writers who have dealt with the subject, in asserting that the northern as well as all the other elements of our fauna utilised for their migration the old land-bridges which connected these islands with one another and with the Continent.

There is a greater diversity of opinion as to the age during which the British fauna arrived in these islands. This is naturally a much more complicated problem, but it is one which I am convinced will ultimately bc solved mainly by means of a study of the geographical distribution of animals and plants. If we can settle the relative ages of the various migrations, we thercby supply an important link in our attempt to reconstruct the past geographical features of the British Islands. The range of the British species will give us all idea of the nature of the land-connections and their gradual changes in course of time. Geological data are exceedingly valuable in these inquiries, but it is a fatal mistake to build our geographical theories and the origin of the British fauna as a whole entirely on the assumptions of a certain school of geologists. Unfortunately, Dr. White's very interest- 
ing remarks on the British fauna for this reason lose much of the value which they might otherwise possess.

In his remarkable essay the late Edward Forbes affirms that the flora peculiar to the west of Ireland, of which the strawberry tree (Arbutus unedo) is the most striking example, and which exhibits such strong southern affinities, is not only much the most ancient of our island floras, but that it is actually of miocene age. It migrated to Ireland from Spain at a very remote period, during which he supposed that a direct land-connection existed between the two countries. The destruction of this old land-bridge, he thinks, must have taken place before the commencement of the Glacial period. Climatal changes during that time destroyed the mass of the southern flora which had thus reached Ireland, the survivors being species such as were most hardy (saxifrages, heaths, etc.), which he considers to be the only relics of this most ancient portion of our flora.

The northern or Arctic fauna and flora, according to the same author, established themselves in the British Isles during the Glacial period-at a time when these were groups of islands in the midst of an ice-bound sea. Finally, the great mass of our animals and plants migrated from the Continent to England after the Glacial period. "The migration of the species," he says, "less speedy of diffusion, which are now peculiar to England was arrested by the breaking up of the land-connection between England 
and Ireland, and thence the famous deficiencies of the sister isle, as, for instance, its freedom from reptiles" (p. 10). He is also of opinion, that the separation between England and the Continent took place at a later date than that between England and Ireland.

According to Dr. A.R.Wallace (p. 338), we possessed just before and during the Glacial period "a fauna almost or quite identical with that of adjacent parts of the Continent, and equally rich in species." But the submersion, he thinks, which is supposed to have occurred during the latter part of the Glacial period, destroyed the greater part of the life of our country. When England again became continental, continues Dr. Wallace, this fauna was succeeded by an assemblage of animals from Central Europe. "But sufficient time does not seem to have elapsed for the migration to have been completed before subsidence again occurred, cutting off the further influx of purely terrestrial animals, and leaving us without the number of species which our favourable climate and varied surface entitle us to." The comparative zoological poverty of Ireland he attributes to the fact that "the depth of the Irish Sea being somewhat greater than that of the German Ocean, the connecting land would there probably be of small extent and of less duration, thus offering an additional barrier to migration."

Dr. Wallace's explanation of the origin of the British fauna is disappointing after Forbes's careful 
study and critical inquiry into its component elements. So great an authority on geographical distribution might have given us more lucid statements of his views on a variety of topics connected with this subject.

In speaking of the fauna of Ireland, Professor Leith Adams, Professor Dawkins, and Mr. Alston are cvidently only thinking of the mammals, which form but a very small proportion of it. The first-mentioned palæontologist held that there was a landcommunication between Scotland and Ireland at the close of the Glacial period, by which the greater portion of the mammals that had found their way to the former country crossed to the latter (p. IOO). And, he continues, the severance between the two countries must have taken place before the slowtravelling Mole, the Beaver, the forest-haunting Elk and the Roebuck had time to arrive.

Much in the same spirit are Mr. Alston's remarks on this subject (p. 5). "The absence from the known fossil fauna of Scotland and Ireland of most of the characteristic post-pliocene English animals, shows that the northward migration of these forms was slow, gradually advancing as the glacial conditions of the northern parts of our islands decreased in intensity. Thus it is not difficult to suppose that the Hedgehog, Ermine, Badger, Squirrel, and Mountain Hare may have found their way through southern Scotland into Ireland long before they were able to penetrate into the still sub-arctic regions of the High- 
lands. Subsequently, when the improvement of the climate had continued, the Shrews and Voles may well have found their way northward along the com. paratively genial coasts, before the larger beasts of prey could find a sufficient stock of game."

That the Bear, Wolf, Stag, Horse, Mammoth, and Reindeer lived in Ireland before the Glacial period is considered highly probable by Professor Boyd Dawkins (a, p. 152).

Only the Butterflies are dealt with in Dr. Buchanan White's clever little essay on distribution. And, as I remarked before, his conclusions are somewhat marred by the unwarrantable assumption that our islands at no distant date were totally destitute of all plant-life, and were therefore uninhabitable by animals. But his paper differs in so far from most of the others, that he has made a thorough study of the one group he deals with. In some respects it may serve as a model to future students in its general treatment of the problem he has set himself to work out. He adopts the principle, even for butterflies, that though it is possible for them to be blown over from the Continent, they have probably migrated with the rest of our indigenous fauna and flora across the dry bed of the German Ocean. His conclusions are that Britain derived its butterfly fauna from continental Europe in post-glacial times, that the Arctic and Alpine species were the first arrivals, and that one part of the Irish species reached Ireland by way of Scotland, another from the south. He assumes, of 
course, that Great Britain and Ireland were connected at that time.

Within the last few years the spell which has bound naturalists to accept the theory of a total destruction of life during the Glacial period is happily vanishing, and more enlightened views are gaining ground. The Lusitanian species of plants in the west of Ireland, which had already furnished Forbes with an argument in favour of survival, are also regarded by Mr. Bulman as the remnants of a pre-glacial flora which was exterminated everywhere else by the cold (p. 265). This view of the survival of a preglacial fauna and flora has since been accepted by Mr. Carpenter, whilst I also have endeavoured to bring fresh evidence into the field in its favour. We both agree with Edward Forbes in considering the Lusitanian element as the oldest section of our fauna and flora, and that it came long before the Glacial period. But we differ somewhat from him, in so far as we do not limit that element to Ireland. It seems also to be represented in South-western England and Wales, though it is there less conspicuous.

This decision as to the relative age of the British South-western fauna has not been arrived at from any geological considerations. The conviction that it must be older than the other sections has been gained solely from a study of the geographical distribution of the species belonging to that fauna. Many of them exhibit what is known as "discontinuous distri- 
bution," which zoologists are agreed to regard as a sign of antiquity. Thus Geomalacus maculosus, the Kerry Slug, is in the British Islands confined to Southwestern Ireland (see Fig. 19, p. 300), and on the Continent it is unknown north of North-western Spain. The Millepede, Polydesmus gailicus, has a wider range in Ireland, and is also known from France and the Azores. Two Earthworms of the Spanish and Mediterranean region, viz., Allolobophora veneta and Georgii, have been discovered in Ireland, but are apparently unknown in England or France; whilst the Weevil, Otiorrhynchus auropunctatus, does not occur north of the Auvergne Mountains in France cxcept in Ireland. A very large number of instances might be mentioned of species found in Southwestern Europe, France, the South-west of England and Ireland. Enough, however, has been said to show the nature of the fauna, and there is, as Forbes has pointed out, a corresponding flora.

A great number of the species belonging to the South-western British element seem to have originated in South-western Europe, or at any rate to have spread over our continent from that part. Their home lay therefore probably in a warm, damp climate, and it secms a reasonable inference to suppose that they spread north at a time when the temperature over the British Islands was much higher than what it is now. Any one familiar with our Bristle fern, or Killarney fern, as it is called in Ircland (Trichomanes radicans), will readily admit that 
it must have come to us at such an epoch. It at once suggests some shady waterfall in a tropical forest, and indeed the home of the genus is South America. It is one of those plants which have evidently migrated to us from South-western Europe, a mere remnant of a once luxuriant flora.

Sir Archibald Geikie tells us (p. 837), and in the main every one agrees with him, that at the beginning of the Tertiary era in which we now live, the climate was of a tropical and subtropical character in Europe. Gradually it became more temperate, and eventually it passed into a phase of extreme cold, but since that time the cold has again gradually diminished. It is quite evident, therefore, that from a purely geological point of view our south-western flora must have migrated northward before the cold came on, and survived in sheltered localities under the influence of the mild coast climate. Some, however, suppose that there occurred a phase of extreme mildness immediately after the Glacial period, and that it was during that time that the Lusitanian fauna and flora became established in the British Islands. To this Professor James Geikie replies (b, p. I69), "there are few points we can be more sure of than this, that since the close of the Glacial epoch-since the deposition of the clays with Arctic shells and the Saxicava sands -there have been no great oscillations, but only a gradual amelioration of climate. It is quite impossible to believe that any warm period could have intervened between the last Arctic and the present temperate 
conditions without leaving some notable evidence in

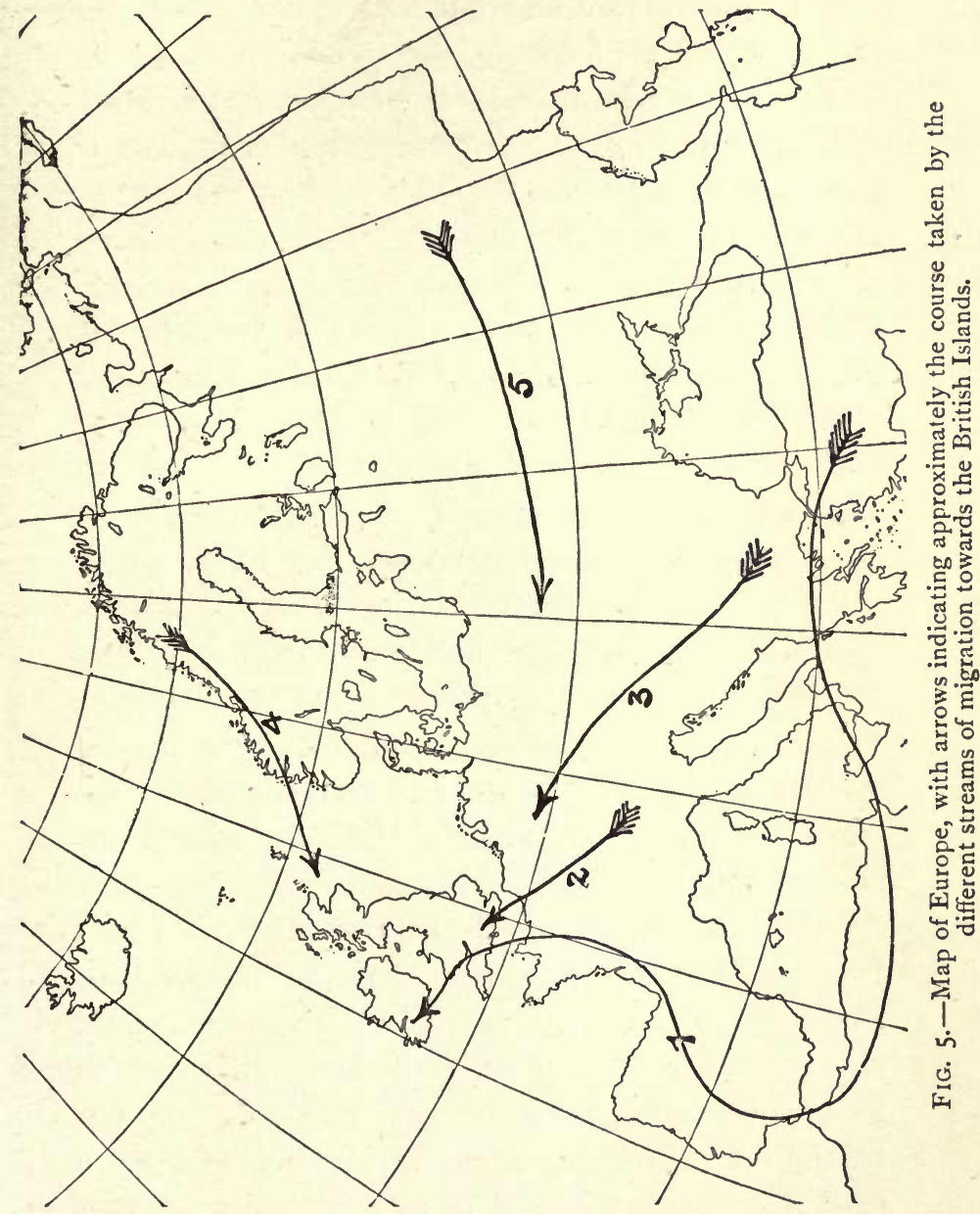

the superficial deposits of Scotland, Scandinavia, and North America." Thus it appears that on the whole 
the assumption that the Lusitanian fauna and flora are very ancient and pre-glacial is also supported on geological evidence.

The course of events in the origin of the British fauna might have been therefore somewhat as follows:-In early Tertiary times, when the climate all over Western Europe was moist and semi-tropical, a migration proceeded northward from the southwestern corner of Europe. This was strengthened by Oriental migrants which had moved westward along the Mediterranean basin (Fig. 5, No. 1). Owing to geographical changes supervening, the Alpine fauna (No. 2) was then enabled to colonise the British Islands, and subsequently another migration had begun to come in from the south-east (No. 3). The climate had meanwhile gradually become more temperate and drier. About the same time, or even earlier, an Arctic migration commenced to pass southward (No. 4), and finally the Siberian animals (No. 5) poured into our continent. The arrows in the map indicate the directions followed by the different migrants as they travelled to the British Islands. The arrows are not meant to represent the whole nor the full extent of the migrations from any particular centre, but only in so far as they affect our islands. Moreover, it would be impossible to indicate on one map the geographical conditions which obtained during the several migrations. It must be remembered that during the time which elapsed while they passed into the British 
Islands, these were joined in the north to Scandinavia and in the south to Belgium and France. The various phases of geographical evolution of Europe will be studied in the subsequent chapters, and maps will then be given to show as far as possible in a general way the leading characteristics of these great changes.

I have now given some reasons for the belief that several different migrations of animals entered the British Islands in later Tertiary times. I have also shown why some of them must be looked upon as being older than others, and in so far we have come to a decision as to their relative ages. It still remains for us, however, to examine how their geological ages can be approximately determined. We require for this purpose palæontological aid.

In the fifth chapter will be found the history of the Siberian migration. And since we possess most valuable records of it in the numerous fossil remains discovered in Central and Western Europe, we are able to trace their progress from the east to the west in a very complete and satisfactory manner. In England their first appearance dates from the ForestBed, for here we find remains of the Glutton (Gulo luscus), Musk-Ox (Ovibos moschatus), and others (see p. 204). It seems reasonable to suppose, therefore, that the first entry of these Siberian mammals into Europe took place at or just before the Forest-Bed period. But Professor Nehring tells us in his remarkable work on the Tundra and Steppes (p. 222), that in 
Germany the remains of the same mammals occur in deposits which are certainly more recent than the lower continental boulder clay; and he is inclined to the belief that they migrated into Europe during the inter-glacial phase which is supposed to have separated the earlier from the later stage of the Glacial period. It is evident that in this case the inter-glacial period in Germany would have corresponded to, and be contemporaneous with, our Forest-Bed period. The deposits immediately preceding the Forest-Bed would also be contemporaneous with the lower continental boulder clay. Although this may seem rather a startling statement to make, from the evidence which will be brought forward in the fourth and fifth chapters I am inclined to the belief that such is probably the case.

Having once arrived at a determination of the exact geological period during which the Siberian mammals invaded our continent, and having also previously determined the relative ages of the various other migrations, we have advanced another step in the direction we are aiming at. Let us suppose that the Siberian migration actually reached the British Islands during the Forest-Bed period. Since the Siberian migration is the most recent of those which entered the British Islands, the others must have commenced their march before the Forest-Bed period. Now it was Professor Boyd Dawkins who first indicated to us, as I have remarked before, the method of research to be adopted in an attempt 
to determine the geological age of the different migrations in so far as they affected the British Islands. I may be excused, therefore, for again quoting the following important passage in one of his works. "The absence," he says ( $b$, p. xxix), "of the beaver and the dormouse from Ireland must be due to the existence of some barrier to their westward migration from the adjacent mainland, and the fact that the Alpine hare is indigenous, while the common hare is absent, implies that, so far as relates to the former animal, the barrier did not exist." The Beaver, Dormouse, and Common Hare are either Siberians or later migrants from elsewhere, and there can be no doubt that at the Forest-Bed period Ireland was already, or was just being, separated from England. All the southern species, that is to say all the Lusitanian, Alpine, and Oriental forms occurring in Ireland, must therefore be older than that period. I have advocated similar views in a former essay on this subject. Mr. Carpenter recently advanced some interesting and valuable criticisms on these views, which we may examine a little more closely (p. 385). "While, then," he remarks, "I find myself in almost complete agreement with Dr. Scharff with regard to the older sections of our fauna, I think that those widespread species which survived the Glacial period must have been confined to the more southern parts of our area, and have only subsequently spread northwards and westwards to Scotland and Ireland." He suggests, in fact, that the widespread British 
species belong to a younger or newer section of our fauna than the local ones. In many cases this may be quite true, but we possess also a large number of common and widely-spread forms which bear the impress of antiquity upon them. We have the most positive proof of the antiquity of the very common small circular Snail (Helix rotundata), since it was found in miocene freshwater deposits near Bordeaux. Many other examples might be mentioned to show that, though discontinuous range is generally a proof of antiquity, continuous range is not always a sign of the opposite. Some species, in fact, appear to be short-lived and disinclined to spread, whilst others multiply rapidly even under a change of temperature and climate, and are to be found almost everywhere. But even if we supposed, with Mr. Carpenter, that these widely-ranging species must have been confined during the Glacial period to the more southern parts of England, the idea that they afterwards made their way northwards along the eastern shore of the Irish Sea and then passed into Ireland, does not appeal to me. Southern England was occupied at that very same time by an assemblage of Siberian mammals. Mr. Carpenter thinks these might have been kept out of Ireland by an arm of the sea until the landconnection with North-western England had broken down. But if an arm of the sea could keep out the Siberian mammals it would also keep out the widelyspread British species of the general fauna. On the other hand, I quite admit that my view of the survival 
in Ireland of the pre-glacial fauna is somcwhat difficult to accept, considering that we have such undoubted cvidence of a very extensive submergence. The case of Isle of Man, quoted by Mr. Carpenter, can be met, I think, by the supposition that it was connected with Cumberland until quite recently, and quite independently of any connection between England and Ireland; that the Isle of Man, in fact, was always a cape or peninsula of the mainland, and only recently became separated by local subsidences or by the action of the sea.

Part of the history of the British fauna will be referred to again in the next chapter, which deals with the Arctic migration. We need not therefore dwell any longer on this subject here. There is one matter, however, which is of importance in connection with the geographical conditions of the British Islands at the time when the greater portion of our fauna arrived from abroad.

On page 60 will be found a map indicating the physical geography of that part of the ancient continent on which what are now the British Islands were situated. Only one large river has been marked on that map, namely, that flowing out of a lake which occupied part of the Irish Sea. Another probably discharged its waters into the Atlantic midway between France and England, whilst the Thames may have been a tributary of the Rhine, as it emptied itself into the sea near our south-east coast. I have shown in a previous essay that the former presence of a fresh- 
water lake between England and Ireland is indicated by the distribution of the Charrs and also by the various species of British Coregonus. There are three British species of Coregonus, viz., C. clupeoides, $C$. vandesius, and $C$. pollan. These are confined to the lakes of North Wales, North-western England, South-western Scotland, and Ireland. All but the latter communicate at present directly with the Irish Sea. The lakes of the latter country, however, must have done so at a time when the west of Ireland stood at a higher level than it does now. The ancestors of the three Coregonus species, and also those of the Charrs, then lived in the large freshwater lake indicated on the map (p. 60), and when the sea gradually crept up the river valley and finally converted the lake into a gulf, the freshwater fish took refuge in the rivers which supplied it with water.

Now as for the continuous sea-shore between the coast of Brittany and the south-west of Ireland, zoological distribution again aids us in proving that such must have actually existed at no very distant geological date. Most of our common shore forms of life migrate along the coast exactly as land animals do-step by step. Their eggs are carefully attached to fixed objects, so as not to be carried away by the waves, whilst the young often remain and grow old in some particular little pool, rarely venturing farther than a few yards from the spot where they first saw the light of day. A number of such shore forms are found on the west coast of France, 
the same species recurring again on the south-west coasts of England and Ireland, thus clearly indicating a former continuity of coast-line between these points, now separated by deep sea. A very familiar example to British zoologists is the purple rock-boring Seaurchin (Strongylocentrotus lividus), but there are a great many others, such as the semi-marine Beetles Octhebius Lejolisii and Appophilus Bonnairei, the Crustaceans Achceus Cranchii, Inachus leptochirus, Gonoplax anrulata, Thia assidua, Callianassa subterranea, the Fishes Blennius galerita and Lepadogaster Decandollii, and the Molluscs Otina otis, Donax politus, and Amphidesma castaneum.

Before concluding this chapter, a few words as to my views on the conditions prevailing during the Glacial period will not be out of place. They do not differ very much from those held formerly by most geologists; and even at present there are, as I have mentioned before, a few upholders of those older views.

The sea, I think, must have gradually crept across England from the east during, or shortly after, the Forest-Bed period, so as to separate the south from the north, whilst Ireland and Scotland were then still connected with one another. At a later stage, the sea also partially invaded Ireland, and this condition is very roughly represented on the accompanying map, Mr. Kendall kindly drew my attention to the fact that several notable areas on which shelly drift has been observed are here placed upon the land; but 


\section{I26 HISTORY OF THE EUROPEAN FAUNA.}

it must be remembered that one stage only can be shown on the map, and that the sea covered more ground a little later. Many of the smaller islands in the glacial sea, too, are not shown. The map, in fact,

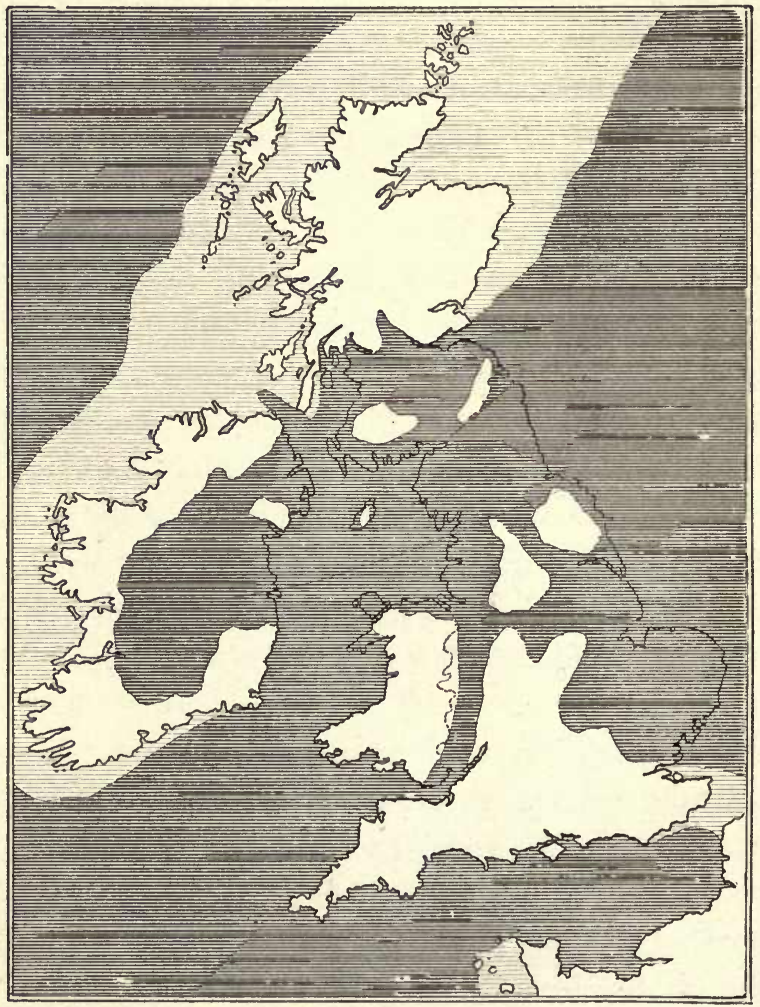

FIG. 6. - Map of the British Islands, showing approximately in what manner the sea may have invaded the country from the east during, or shortly after, the Forest-Bed period. The darkly shaded parts indicate the areas covered by water, and the lightly shaded and white portions what was land at that time. 
is merely meant to give a general idea of the manner in which the great northern sea moved westward and slowly covered a large portion of the British Islands. These peculiar geographical conditions explain, I think, better than anything, the absence from parts of the Midlands and the north of England of such a number of terrestrial invertebrates which are otherwise widely distributed over the British Islands. In spite of the fact that a large portion of the British Islands became submerged, we possessed at that time an extensive arca which has since been claimed by the sea, so that there was ample room for the present fauna to survive the Glacial period. The climate during this period was probably much the same as it is at present, though moister, with cooler summers and milder winters.

It may be asked what proof we have of such an extensive submergence of England and Ireland. My own views are principally based on the general distribution of the fauna in the British Islands, and the belief that nothing but a mild climate during the Glacial period could have brought it about. On purely geological grounds, however, some geologists, notably Mr. Mellard Reade, have come to a similar conclusion. "The whole of Lancashire and Cheshire," he remarks ( $a$, p. 542), "from sea-level up to about 400 fect, and in places 600 fect, is covered by a continuous mantle of boulder-clay and sands." "These clays, as a rule, contain distributed through 
them, in a greater or less degree, fragments of shells and some perfect ones. I myself have recorded forty-four species." Again he continues (pp. 545 and 546): "A large part of Ayrshire is covered with similar shelly boulder-clays from sea-level to $106 \mathrm{I}$ feet at Dippal. These Ayrshire high-level shells have, in the majority of cases, been taken, not from sand and gravel beds, but from boulder-clay, and in that respect they are most important and unique. In Moel Tryfan the shells are found in sands and gravels at 982 feet; on the range of hills from Miaera to Llangollen from I000-I200 feet; also in sands and gravels at Gloppa, near Oswestry, at I 100-1 200 feet; and near Macclesfield at a level of about i 200 feet. In Ireland marine shells can be traced almost from sea-level to a height of over I000 feet."

"Again," continues the same author, "if we look broadly at the distribution of these shelly deposits, we find that they occur all round our maritime coasts in Lancashire, Cheshire, and Wales, in Cumberland and Westmoreland, Wigtonshire and Ayrshire, and along the eastern coast of Ireland. The same is to be said of the eastern coasts of England and Scotland."

That a very considerable change of sea-level has taken place in some parts of the British Islands would appear to a zoologist the most logical conclusion after an examination of these "high-level shelly sands and gravels," but the shells contained in them are now generally supposed to have been carried there frozen 
in the sole of a glacier or pushed up in front of it. The older view, however, which agrees so much better with the facts of distribution, fortunately has not disappeared among geologists. "When we call up," says Mr. Mellard Reade (b, p. 435), "before our mental vision the simple and well-known facts of nature which suffice to explain the marine drifts on the theory of submergence, it seems unnecessary to resort to the ingenious and artificial system of physics elaborated to explain the phenomena of land-ice."

"When we have more knowledge of the glaciers of the Arctic Regions, and facts, in place of ingenious suppositions, to base our reasoning upon, we may possibly have to revise all our glacial conceptions. In the meantime, the submergence theory of the origin of high-level shelly gravels and sands seems to me by far the simpler of the two theories, and the most consistent with the facts and phenomena which the labours of a succession of enthusiastic geologists have made us acquainted with."

Among those geologists, and they form the majority, who hold that Ireland was covered by land-ice, there is a great diversity of opinion as to its extent. Messrs. Close, Kinahan, J. Geikie, and others believe that the ice covered practically everything, whilst others who claim to have examined the ground with equal care, such as Professor Carvill Lewis, were led to believe that the south of Ireland, with the exception of a few local glaciers, was free from ice. The glacial 
phenomena of the country can therefore be interpreted in different ways, even by those who are convinced that they are due to land-ice and not to icebergs or mud-glaciers.

\section{SUMMARY OF CHAPTER III.}

The history of the British fauna is not only of interest to us from a sentimental point of view, it is a convenient startingpoint in the study of the larger European problem. The fauna, broadly speaking, is composed of three foreign elements, viz., the northern, eastern, and southern, to which may be added a small endemic one. Examples are given of the more noteworthy forms belonging to each of these. This leads us to the subject of the natural divisions of the British Islands according to their animal inhabitants. Zoologists attempted at first to subdivide these countries, on the lines laid down by botanists, into a large number of provinces. Forbes proposed ten such divisions for mollusca, and subsequently five, which were ultimately reduced by others to two or three.

The opinions of biologists are almost unanimous in attributing the bulk of the British fauna and flora to migrations by land from the Continent, but two other theories, viz., those of Professor Cole and Messrs. Kinahan and Lamplugh, are also referred to. The first believes in a possible migration eastward from Western Europe, and the latter support the view of the former existence of ice-bridges to assist the fauna in their migrations.

An endeavour is next made to determine at what geological periods the various migrations entered the British Islands. There is considerable difference of opınion on this subject. Some believe that the British fauna is altogether post-glacial; a few think that it is partly so and the remainder glacial; 
others again hold that a portion is pre-glacial and the rest glacial and post-glacial. Those who have studied the subject most closely feel convinced that the south-western or Lusitanian fauna, and also the flora, must have arrived before the Glacial period and survived the latter in these Islands. It seems reasonable to suppose, therefore, that the climate cannot have been very severe during the so-called Ice-Age. This Lusitanian fauna must be looked upon as the oldest portion of the British fauna. The Alpine and Oriental migrations arrived next. After these came the Arctic, and finally the Eastern or Siberian. As the fossil evidence is most complete with regard to the last, we are able to determine with precision not only the direction whence this migration came, but approximately its geological age. It arrived in Germany from the east after the deposition of the lower boulder-clay. Since the boulder-clay is looked upon as a glacial deposit, the Siberian migration reached Central Europe after the first portion of the Glacial period had passed. In England it makes its first appearance in the Forest-Bed, which would therefore correspond to the "Loess" formation of Central Europe. All the other migrations are older than the Siberian. They must therefore have come to Great Britain during the earlier part of the Glacial period or before it.

The chapter concludes with a short statement on the physical geography of the British Islands during the time when these migrations entered them. That there existed a continuous coast-line between France and Ireland is proved by the occurrence of a considerable number of identical shore species, whilst the former existence of a freshwater lake on the site of the present Irish Sea is indicated by the distribution of some freshwater fishes. 


\section{CHAPTER IV.}

\section{THE ARCTIC FAUNA.}

THE lands lying within the Polar Circle are inhabited by an assemblage of animals and plants, many of which are peculiar to those regions. They are mostly adapted to the abnormal conditions of life prevailing in the high latitudes of our globe-the long, dark winters, and the short summers of one long day. Though the numbers of species and of individuals are few, there is a keen struggle for existence in those regions. The prevailing colour of the ground is white, and since a resemblance in the colour of an animal to the ground it lives on acts as a protection to weak ones, and also enables Carnivores to approach their prey with greater facility, it is not surprising that we should find the majority of polar animals coloured white. As I remarked, the polar area contains a very distinct set of species; most of them, however, range beyond the confines of the Arctic Circle. It is therefore scarcely justifiable to raise this Arctic area into a distinct zoological region equivalent to the great zoogeographic regions, which have been established by Sclater and Wallace, though we might, with Dr. Brauer, look upon it as a sub-region. 
There are six typical Polar Land-mammats, one of which, the Polar Bear, is semi-aquatic. The Reindeer (Rangifer tarandus) occurs upon almost all the polar lands, and it has often been a source of speculation in what manner it has reached such remote islands as Spitsbergen and Novaya Zemlya-the former of the two being so remote from a continent. There is no doubt that Reindeer are great wanderers, owing to the difficulty of finding sufficient food-supply for the large herds in which they are accustomed to travel; and for this reason they can cross, and have been known to cross, distances of from ten to twenty miles on ice. The Behring Straits, when frozen over in winter, is frequently traversed by them. But I quite agree with Dr. Brauer (p. 260) that it is impossible to account for their presence in Spitsbergen by an immigration from either Novaya Zemlya, Greenland, or Scandinavia, under the present geographical conditions. The seas between the former island and the other land-masses referred to are rarely entirely frozen over. Even if this should occur, the distances between Spitsbergen and Greenland, Novaya Zemlya, or Scandinavia are so great, that a migration across ice is quite excluded from the range of possibilities, since Reindeer could not subsist without food during the time it would take to travel from one to the other. The manner in which it did reach Spitsbergen and Greenland will be discussed more fully below, and I will therefore proceed to mention the other Arctic mammals. 
One of the most important and most typical species is the Polar Bear (Ursus maritimus), the greater part of whose life is spent on the ice and in the sea. The fact that its favourite nourishment consists of seals proves its excellent and keen faculties of sight and hearing, and its facility in swimming. But it is not a

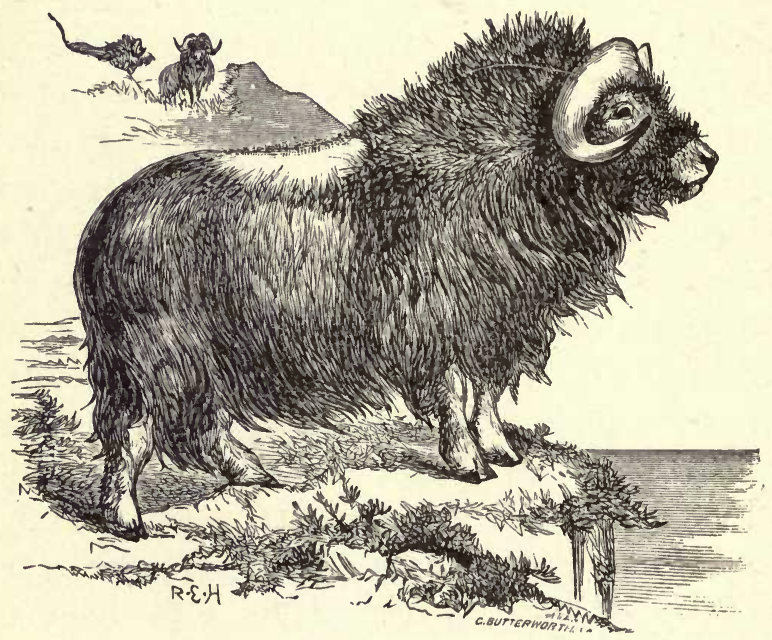

FIG. 7. -The Musk-Ox (Ovibos moschatus). (From Flower \& Lydekker's Mammals, p. 358. London: Adam \& Chas. Black.)

dainty feeder, and lives upon almost all animals which come within its reach; birds, land-mammals, or fish are not despised in times of scarcity. Its fur throughout the year is coloured white, though in old bears it assumes a more yellowish hue.

Another large mammal, perhaps less well known, is the Musk-Ox (Ovibos moschatus, Fig. 7), which 
resembles in size the smaller varieties of Oxen, but in structure and habits is closely allied to the Sheep. As is implied by the specific name, it exhales a musky odour; this does not, however, appear to be due to the secretion of a special gland, as is the case in other animals with a similar smell. The skin is covered with long brown thickly-matted hair, interspersed with white. It is confined to the most northerly parts of North America and the American Arctic islands, and to North Greenland. Though not now living in the Old World, it seems formerly to have been abundant in Siberia, and, as we shall learn later on, it was one of the species which took part in the great Siberian invasion of Europe. Its remains have been found not only in Germany and France, but also in the south of England.

The Polar Fox (Canis lagopus) occurs throughout the Polar Regions, and on islands where even the Reindeer and the Musk-Ox are unknown. Beyond the Polar Circle, its range extends into Northern Asia, to the extreme north of North America, and the mountains of Scandinavia. Like its congeners, it had in pleistocene times a more southerly extension, and fossil remains have been met with in various parts of continental Europe and in England.

The Stoat (Mustela erminea), which is known and much valued in commerce under the name of Ermine, was formerly believed to occur only in Arctic America and the northern parts of the Old World, but in more recent years it has been discovered in a number of 
the northern islands, such as Saghalien, in the islands of the Behring Straits, the Aleutian islands, and also in Greenland and Spitsbergen. In Europe, it is found as far south as the Arctic Hare, or perhaps even farther, and it flourishes in the Alps up to a height of 9000 feet. It offers a parallel to the Arctic Hare in the fact that in some countries, such as Ireland, it only rarely turns white in winter. The Irish form of the Stoat differs so much from the English, that Messrs. Thomas and Barrett-Hamilton are of opinion that it is specifically distinct, as I mentioned in speaking of the divisions of the British fauna (p. 90).

The Arctic Hare (Lepus variabilis) is almost the only one of the typical Arctic mammals which still inhabits the British Islands, and for that reason it is to most of us more familiar than any of the preceding species. Hares have been described from Greenland by the name of Lepus glacialis, from the European Alps as Lepus alpinus, and under other names from Arctic North America; but though slight differences in the fur and even in the skull can be pointed out, there is no doubt that all these are only varieties or races of what, in the British Islands, is known as the Irish or the Scotch Mountain Hare, Lepus variabilis. In the Arctic Regions this Hare remains white throughout the year, but in Scandinavia and some other parts its fur becomes brown in the summer, and in Ireland it frequently remains entirely brown during the whole year, and never, or 
only in very rare cases, becomes entirely white in winter. Besides Scandinavia, Scotland, and Ireland, it is found in Northern Russia, and also in the Pyrenees, the Alps, and the Caucasus. In Asia it occurs not only on the mainland of Siberia, but it has

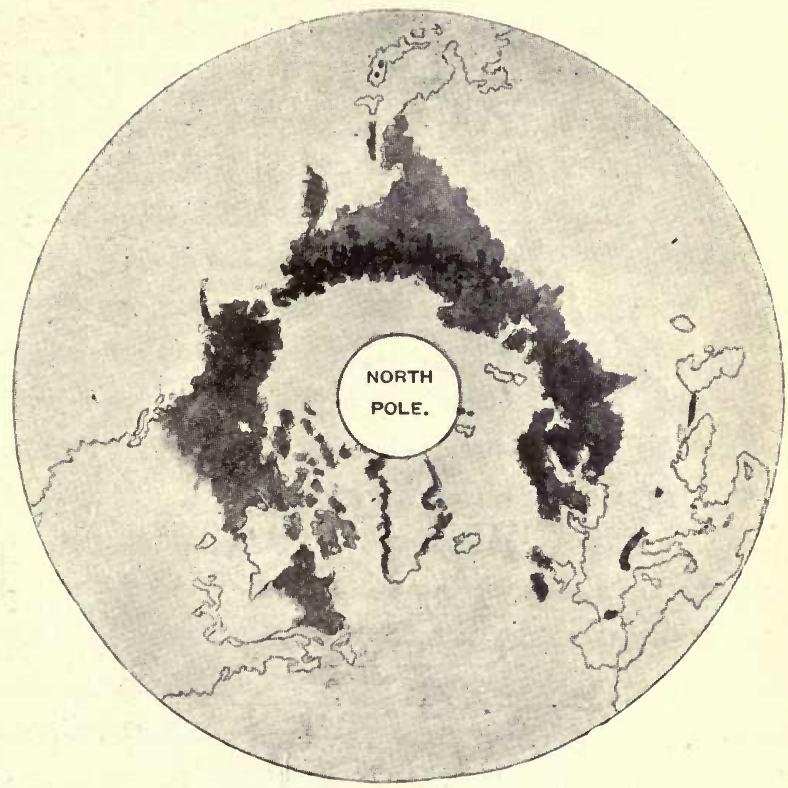

Fig. 8.-Map of the northern hemisphere, to show the geographical distribution of the Arctic Hare (Lepus variabilis) indicated in black.

bcen obtained on the Akita Mountains in Japan and on the Mioko San Mountain, and also on the island of Saghalien. It had in former times a more extensive range, and its remains have been discovered in 
England and in a number of places on the continent of Europe. The peculiarity of its range, which will be explained more fully directly, lies in the fact of the occurrence of isolated colonies in the mountains of Europe, in Ireland and Scotland, and in the mountains of Japan (Fig. 8). From a distributional point of view, it is one of the most interesting species of mammals, and its history throws a flood of light on the geographical changes which have occurred in former times.

One more species must be mentioned, and that is the Banded Lemming (Cuniculus torquatus), which occurs chiefly in Arctic America, Northern Siberia, and Greenland. Though frequently mistaken for the Scandinavian Lemming, there is a striking difference in the character of the teeth, which has induced zoologists to put them into distinct genera. The Arctic Lemming, moreover, is distinguished from the Scandinavian by the absence of external ears, the densely furred feet, and by the great length of the two middle claws in the fore-feet. There are two species of the true Lemming, namely, the one just referred to, Myodus lemmus, and Myodus obensis. These may be looked upon as more or less Arctic species, since they occur within the Polar Circle, but they are not so exclusively confined to that region as the Banded Lemming (Cuniculus torquatus). The remains of both Cuniculus torquatus and of Myodus lemmus have been found in British pleistocene deposits.

Until recently no Lemming remains had been found 
to the south of France, but Mr. Barrett-Hamilton announced to us a short time since that Dr. Gadow had discovered some skeletons with their skins still preserved in a cave in Northern Portugal. These were found to belong to the Scandinavian Lemming (M. lemmus), and the author incidentally expressed the opinion that there was some possibility of this species still inhabiting the mountains of Spain.

The Lemming multiplies with great rapidity under favourable conditions. In speaking of his experiences in Siberia Dr. Brehm says (p. 79): "All the young of the first litter of the various Lemming females thrive, and six weeks later at the most these also multiply. Meanwhile the parents have brought forth a second and a third litter, and these in their turn bring forth young. Within three months the heights and low grounds of the tundra teem with lemmings, just as our fields do with mice under similar circumstances. Whichever way we turn we see the busy little creatures, dozens at a single glance, thousands in the course of an hour. But the countless and still increasing numbers prove their own destruction. Soon the lean tundra ceases to afford employment enough for their greedy teeth. Famine threatens, perhaps actually sets in. The anxious animals crowd together and begin their march, hundreds join with hundreds, thousands with other thousands, the troops become swarms, the swarms armies. They travel in a definite direction, at first following old tracks, but soon striking out new ones; in unending files-defying all computation 
-they hasten onwards; over the cliffs they plunge into the watcr. Thousands fall victims to want and hunger; the army bchind streams on ovcr their corpses; hundreds of thousands are drowned in the water or are shattered at the foot of the cliffs; the remainder speed on; other hundreds and thousands fall victims to the voracity of Arctic and red foxes, wolves and gluttons, rough-legged buzzards and ravens, owls and skuas which have followed them; the survivors pay no heed. Where these go, how they end, none can say; but certain it is, that the tundra behind them is as if dead, that a number of years pass ere the few who have remained behind and have managed to survive slowly multiply and visibly repeople their native fields." This eloquent passage reminds us of the manner in which migrations of all kinds of animals have taken place in former times, and are still taking place. It is principally want of food which compels them to search for new homes.

On page 9I I have referred to some birds which have come to us from the north. One of these, the Snow Bunting (Plectrophenax nivalis), is a typically Arctic species. In summer it is widely distributed, and is found in Spitsbergen, Novaya Zemlya, Siberia, and the Arctic Regions generally. In winter it migrates down into North America, into Japan, Northern China, Turkestan, Southern Russia, and occasionally even across Europe into North Africa. Very characteristic Arctic birds are the Eider Ducks 
belonging to the genus Somateria. Three species have visited the British Islands. The common Eider Duck (S. mollissima), which is of such high commercial value, is abundant in Norway and northward,

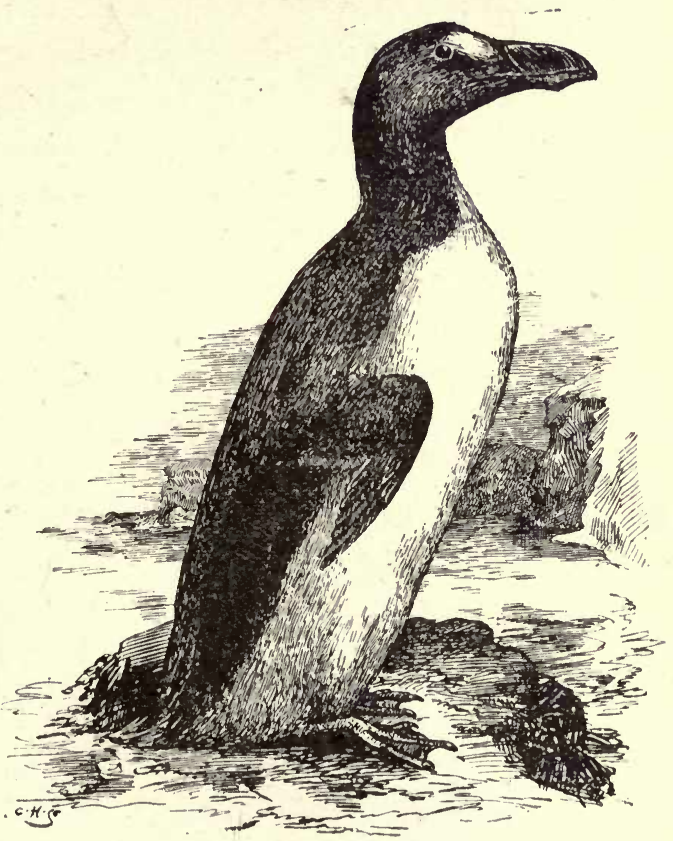

FIG. 9. -The Great Auk (Alca impennis).

throughout the Polar Regions. The appearance of the King Eider (S. spectabilis) on our coasts is an extremely rare occurrence, and even in Norway it is only known as a visitor, but on Novaya Zemlya and along the Arctic shores of Siberia, in Greenland and 
Arctic North America, it is known to breed. The third species, Steller's Eider (S. Stelleri), seems to be still rarer, and only in the Aleutian islands and in the north of Alaska can it be said to be at all abundant. It is probable that the famous Great Auk (Alca impennis, Fig. 9) also was a typical Arctic species. Its range extended to both sides of the Atlantic. In Newfoundland and on the coast of Iceland it is known to have been met with in considerable numbers within historic times; and no doubt, like all Arctic species, it extended farther southwards at a more remote period.

The members of the genus Lagopus, including the various species of Grouse, are likewise of northern origin. The British Red Grouse (L. scoticus), which may be looked upon as a form of the Scandinavian Willow Grouse (L. albus) (compare p. 9I), constitutes in some respects a curious case of parallelism with the Arctic Hare, since the latter, in its more southern station, generally retains the summer fur throughout the year. The allied Ptarmigan (L. mutus) inhabits Scandinavia, the Ural Mountains, and some of the Asiatic mountain ranges. It is also found in the European Alps and in the Pyrenees. The North European range of the Ptarmigan suggests that we are dealing with an ancient species which came south from the Arctic Regions at about the same time as the Arctic Hare; but it is more probable, as I have shown in a subsequent chapter (p. 334), that this species has entered Europe more recently 
with the Siberian migrants from Central Asia, where indeed the genus had its original home. The Black Cock (Tetrao tetrix) and the Capercaillie (Tetrao urogallus) have also come to us from the east, and have even penetrated into Ireland. They are therefore some of the few instances of members of the Siberian invasion having become temporarily established there.

Reptiles and amphibia are altogether unknown in the Polar Regions, but a large number of fish, chiefly marine, have taken their origin there. The Salmon family are of Arctic origin, as also are the Sticklebacks and the Perches, many of the Cod family, the Herrings, and several of the Flat fish.

It would lead me too far to refer to the invertebrate fauna of the Polar Regions, but a few remarks on the Arctic plants may not be out of place.

The principal Arctic genera are Salix, Ranunculus, Draba, Pedicularis, Potentilla, Saxifraga, Carex, Juncus, Luzula, Eriophorum, and others.

Among the most characteristic Arctic plants may be mentioned Dryas octopetala, to which I have already referred as occurring in the west of Ireland; Saxifraga oppositifolia, another British species, occurs in the higher mountains of Scotland, Ireland, and Wales; Braya alpina, Papaver nudicaule, Lychnis apetala, Diapensia lapponica, and Lobelia Dortmanna, which is found in the lakes of Scotland and Ireland. The dwarf birch (Betula nana) also, which still occurs in Scotland and the North of England, and which 
had formerly a wider range in the British Islands, should be included among these; but there are other plants probably of Arctic origin, though not now occurring in the Arctic Regions, and to these may be classed the so-called American species of plants which are found on the northern and western coasts of Ireland, in the Hebrides, in Scotland, and in North America. These are no doubt the relics of an Arctic flora which flourished in high latitudes in past times when the climate there was more temperate A list of these species will be found on page 166 .

As none of them occur in Siberia, they must either have found their way to North America and to Europe from the Arctic Regions, or have travelled from North America across the latter to Europe. In any case a former land-connection between the two continents must have existed. This becomes the more evident when we examine the remarkable results obtained by the late Professor Heer, who first described the Tertiary plant-beds in North Greenland. No less than 282 species of plants have been described by this eminent botanist from these deposits. A large number of the plants found were trees belonging to the genus Sequoia, Thujopsis, and Salisburia, besides beeches, oaks, planes, poplars, limes, and magnolias. That they grew on the spot is proved by the fruits, which have been obtained from these beds in various stages of growth.

From a similar deposit in Spitsbergen a large number of fossil plants have also been brought to 
light, many of which are identical with those found in Greenland; and some of the Greenland forms (such as Taxodium distichum and Sequoia Langsdorfii) have been found too in Alaska, showing that there was probably a continuity of land between Spitsbergen and North America by way of Greenland. Two species of Sequoias, namely, S. sempervirens and $S$. gigantea, the well-known Californian giant trees, are very closely allied to the Greenland forms discovered by Professor Heer.

Heer assigned the Arctic plant-bearing beds to the Miocene epoch, but doubts have been recently thrown upon this opinion by Mr. Starkie Gardner, who brought forward arguments in support of his theory of their being of the Eocene age. Professor Heer, however, was able to meet these criticisms, and he is ably supported in his views by Professor Engler and other eminent continental botanists.

It is evident that under the present conditions of temperature none of those plants could have flourished in Greenland. The climatc must have been much milder than it is at present. Professor Heer estimated from the general aspect of the fossil flora that the mean annual temperature of North Greenland was at least nine degrees centigrade, and that the mean winter temperature was not below zero.

It will hardly be necessary for me to review here the various theories which have been advanced by geologists and botanists to account for this remarkably high temperature in such northern latitudes 
Any one who has read the writings of the late Dr. Croll cannot help being struck by the facts he adduces to show the importance of ocean currents in relation to the distribution of heat over the globe, and it seems to me that the view which attributes the mild climate prevailing in former times in Greenland to warm ocean currents reaching the Polar Circle is the one least open to serious objections. If we suppose that the North Atlantic Ocean was bridged by a land-connection between Scandinavia and Greenland by way of Spitsbergen, and between Greenland and North America, the Polar Ocean would be practically a closed sea. If, then, a wide passage existed somewhere about Behring Straits to allow a warm current to enter and circulate within the Arctic Seas, we should have the southern shores of Greenland washed by the warm Atlantic current and the northern shores by a warm Pacific current, which combination would undoubtedly produce the effect of raising the temperature throughout the Polar Regions very considerably; and especially would that be the case with regard to Greenland and the neighbouring islands.

It might be urged that the constant darkness during winter must have had an injurious action upon the flora, but it is found that in countries such as Northern Russia, where southern plants are housed during winter in greenhouses, the light being almost entirely excluded by a covering of straw, no serious damage is done thereby to the plants. 
It seems probable that a similar gradual refrigeration of climate in northern latitudes has taken place after Miocene times as has been proved to have occurred in Europe.

Some years ago Dr. Haacke propounded the hypothesis that the centre of creation of all the larger groups of animals was situated in the region of the North Pole, and that the newly originated groups must always push the older ones farther and farther south into the most remote corners of the earth. As instances of the correctness of his view he quotes the fact that the more ancient mammals, such as Monotremes, Marsupials, Lemurs, Edentates, and Insectivores, all inhabit the more southerly parts of the world. The Apteryx, Moa, Rhea, and the Ostrich, as well as Epyornis, which is only recently extinct, are found in the same regions. But we have no palæontological evidence in favour of these extravagant views. Fossil Edentates and Marsupials are almost entirely confined to the Southern Hemisphere, and the supposition that because these primitive mammals inhabit the extreme south of our great continental land-masses, they therefore came from the north, cannot be said to be an argument. Nevertheless, I am quite with Dr. Haacke in considering that the North Pole, or, we might say, the lands within the Arctic Circle, have been the place of origin of some of our European mammals, and there can be no doubt that certain species in other groups, among invertebrates and also plants, have originated 
in the Polar Regions. The facts of geographical distribution teach us that in these regions there has been a centre of origin within comparatively recent geological times. I have on a previous occasion drawn attention to the range of the Reindeer: that it lives almost throughout the Polar lands, and that it spreads into North America, Northern Europe, and Northern Asia. We have, again, fossil proof that its range extended down to the Pyrenees in Europe in pleistocene times. But there is not a scrap of evidence that it ever during any time occurred farther south, either in Europe, Asia, or North America. Its original home must therefore have been in the Polar Regions, for if it had originated either in Central Europe, Asia, or America, there is no reason why it should not, in the natural course of cvents, have extended its range to the south as well as to the north.

The Arctic Hare presents us with a very similar case of distribution. Like the Reindeer, it inhabits, as we have learned, the Polar Regions and the northerly parts of the Old World and the New; but while we have only fossil evidence of the former, more southerly, extension of the range of the Reindeer, the Arctic Hare furnishes us with a still stronger proof of its past southward range in the survival of small isolated colonies in some of the southern mountain ranges of Europe and Asia. It is generally believed that the occurrence of the Arctic Hare in these southern mountains is a standing testimony to the severity of the 
climate at the time when it commenced its southerly increase of range, but I have already shown that the climate of Europe at that time was not necessarily colder than it is at present, but that it may have been somewhat milder (p. 80). I think that a vast increase of ice in the Polar Regions has taken place only at, a comparatively recent date, and that both the Reindeer and the Arctic Hare originated there during a much more temperate climate than obtains at present. A great sensation was produced among European zoologists and anthropologists when the discovery was first announced that the remains of the Reindeer had been found in the Pyrenees, and it naturally gave rise to many speculations as to the nature of the climate at the time when its range extended so far south. $^{1}$ The greater number of our best authorities are still of opinion that the existence of the Reindeer in Southern Europe points to the prevalence of an arctic climate in that region. It is generally overlooked, however, that the Reindeer-remains occur in company with many typically southern animals, which,

1 A very interesting piece of information has been given us, recently, by Mr. Barrett-Hamilton on the Arctic Fox of Spitsbergen. In comparing the skulls of Spitsbergen Foxes with those of Europe, he found that the former are much smaller, and represent a distinct race or subspecies. This small race he believes to be confined to Greenland, Iceland, Spitsbergen, and Novaya Zemlya, whilst the larger one occurs in Europe, Asia, and on the Commander Islands. This fact favours the view which I have advocated in Chapter V., that the Arctic Fox in Europe is a Siberian migrant, and did not come from the north with the Reindeer and Arctic Hare. 
if they had been found alone, would have been held to be a certain indication of a warm climate. The French geologist Professor Lartet, indeed, was of opinion that the temperature during the time when the Reindeer lived in the Pyrenees must have been rather milder than it is at present (compare pp. 7I-75). Similarly, Mr. Harlé argues, that the extremely cold climate probably did not extend to Southwestern France, since that area only received occasional visits from some of the representatives of the Arctic fauna.

Long ago North American zoologists recognised the existence in their country of two well-marked races of the Reindeer (Caribou) - a smaller one with rounded antlers (Fig. IO), and a larger one in which the antlers are more or less flattened out (Fig. I I). Two somewhat similar races can also be traced in the fossil remains of the Reindeer in Europe. It was, I think, Gervais who first pointed out that the Reindeer remains from the north of France differed from those found in the south; and Lartet referred to the fact that the southern remains were more like what, in America, is called the Barren-ground. Caribou, while those from Central European deposits all belonged to the Siberian variety, which is more like the Woodland Caribou of North America. In Ireland, Professor Leith Adams also drew attention to the curious fact that all the Irish Reindeer remains resemble the Norwegian varicty rather than the Siberian; and Mr. Murray was so much struck by 


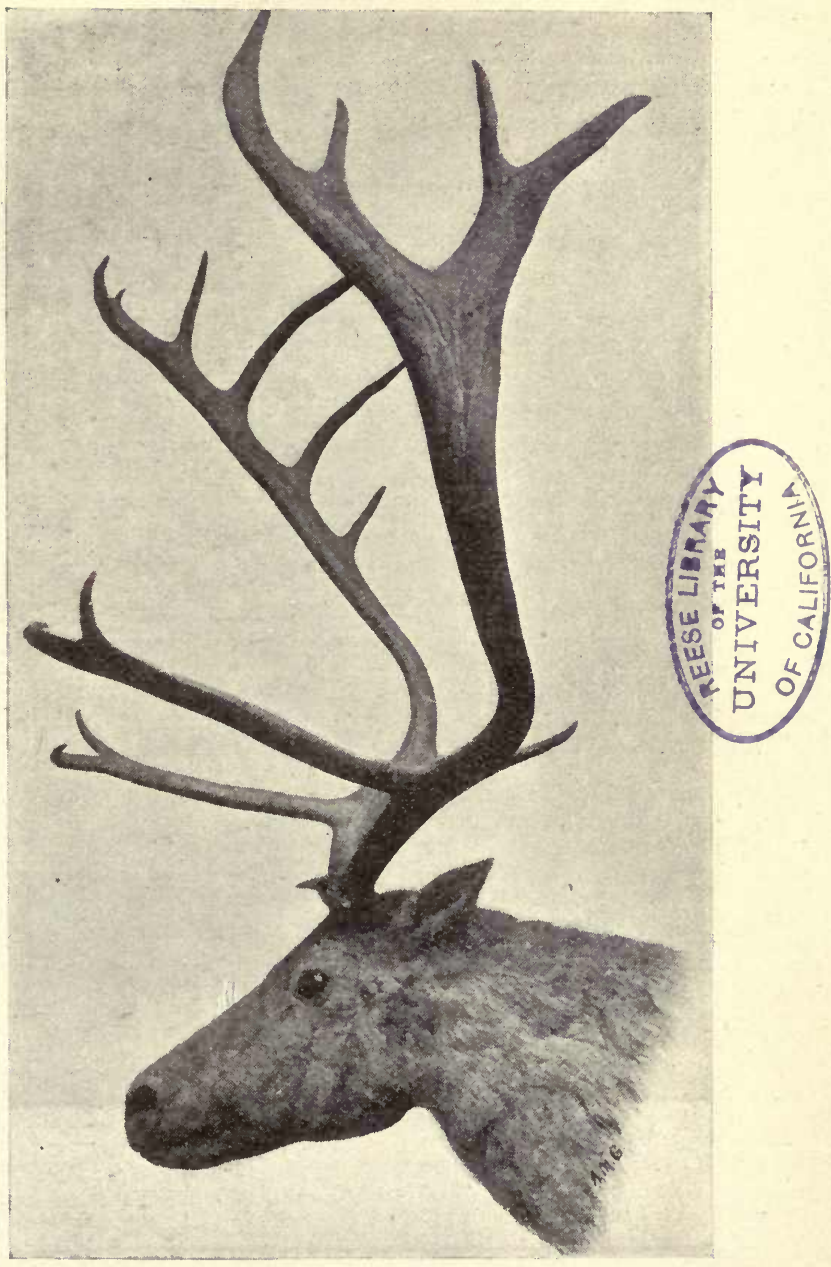

FIG. 10-IIead of a Barren-ground Reindeer in the Dublin Museum (photographed by Mr. McGoogan). 
I52 HISTORY OF THE EUROPEAN FAUNA.

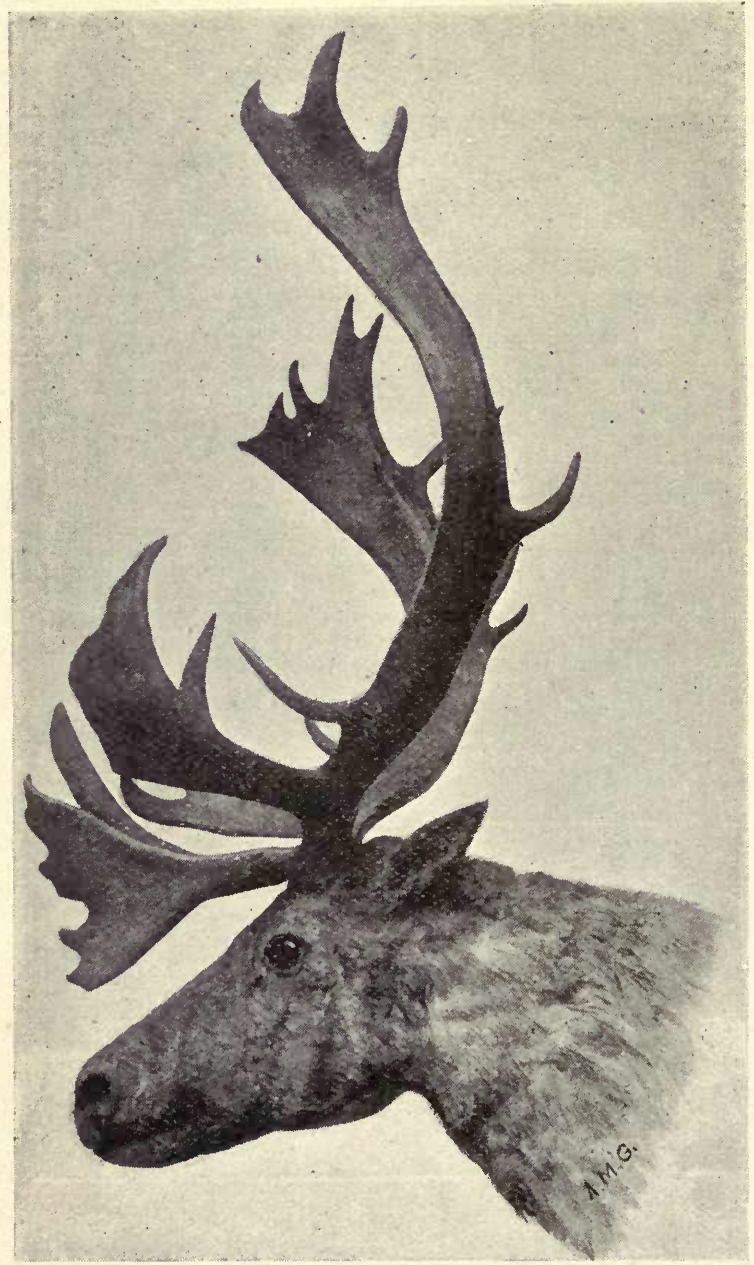

FIG. I1.-Head of a Woodland Reindeer in the Dublin Museum (photographed by Mr. McGoogan). 
the close resemblance between the Spitsbergen and Greenland forms with the Barren-ground Caribou, that he based some speculations on a former land-connection between these countries on this circumstance.

We have, therefore, records of the present or the former existence of a Reindeer resembling the North American Barren-ground form in Greenland, Spitsbergen, Scandinavia, Ireland, and the South of France. In England the remains of the two forms occur mixed, but I do not know in how far either the one or the other predominates. The Barren-ground Reindeer is in Europe altogether confined to the west; the most easterly locality that I am acquainted with bcing Rixdorf, near Berlin. The majority of the European remains of the Reindeer scem to belong to the Siberian or Woodland variety, and it would appear as if some intercrossing between the two forms had occurred in Lapland, since it is stated that in that country the Reindeer is somewhat intermediate between the two. All the Asiatic remains also resemble the Woodland variety.

As far as I know, no explanation has been attempted to account for this peculiar range in Europe of the two forms of Reindeer. But if we look more closely into the mode of occurrence of the Reindecr remains, we find that the Barren-ground form, seems to have existed in Western Europe long before the other variety made its appearance there. It was pointed out by Struckmann that the Reindeer in Southern Europe occurs in older deposits than in 
the north. In speaking of the northern ones, he had of course chiefly the German deposits in view. It is in one of the oldest pleistocene deposits in Germany that the isolated instance, referred to above, of the occurrence of the Barren-ground Reindeer, near Berlin, has been noted.

There is still a further point which illustrates the supposition that the Barren-ground Reindeer was a more ancient inhabitant of Europe than the Woodland one. The latter in all Central European stations (in fact almost wherever it occurs fossil) is associated with the remains of the typical inhabitants of Siberia, such as the Glutton, Sousliks, Lemmings, and others; but in the deposits in which the Barrenground Reindeer have been found in South-western France, no other Arctic mammal finds a place. Again, in Irish deposits none of the Siberian migrants are found. The only explanation of this remarkable fact is that the two varieties of the Reindeer have come to Europe by different routes. We have learned already from the observations of Mr. Murray that there are evidences of the existence of a former land-connection between North America, Greenland, and Spitsbergen. Professor Petersen tells us that, according to recent surveys, a high submarine plateau with a sharp fall of 1000 fathoms towards the Atlantic Ocean begins from Northern Norway and is continued as far as Spitsbergen. Several islands, such as Bear Island, King Charles Land, and others, arise from this plateau, and these 
must be looked upon as the remains of a sunken land (Fig. I2).

From Arctic America, thinks Professor Schulz (p. I), we probably have had an uninterrupted migration during the greater part of later Tertiary times up to the commencement of the Pliocene epoch - partly over a direct land-connection between Greenland, Iceland, and the Faroes, and also between Arctic America, Spitsbergen, Franz Josef Land, ctc. There was also a connection between Asia and Alaska.

The distribution of the Barren-ground Reindeer in Europe seems to warrant the belief that, at the time it began its southward wanderings from the Polar area, Northern Norway must have been connected with Greenland in the manner just indicated, but, as I shall explain later on, Russian Lapland and part of Northern Russia, or the land between the White Sea and the Baltic, must at that time have been submerged by the sea. The greater part of Denmark and the lowlands of Sweden were likewise submerged, but Scandinavia extended south as far as Scotland, while Scotland was connected with Ireland, and the latter with England and France. The Reindeer migrating south into Scandinavia could only reach the continent of Europe by way of the British Islands. It appeared there in the west and gradually cxtended its range east, wherc, as I mentioned above, it has occurred in a few isolated localities.

The advent of the Woodland form of the Reindeer in Europe took place at a much later stage. It came, 
I56 HISTORY OF THE EUROPEAN FAUNA.

as I indicated, with the hordes of Siberian migrants which invaded Europe during what is known as the Inter-glacial phase of the Glacial period. Scan-

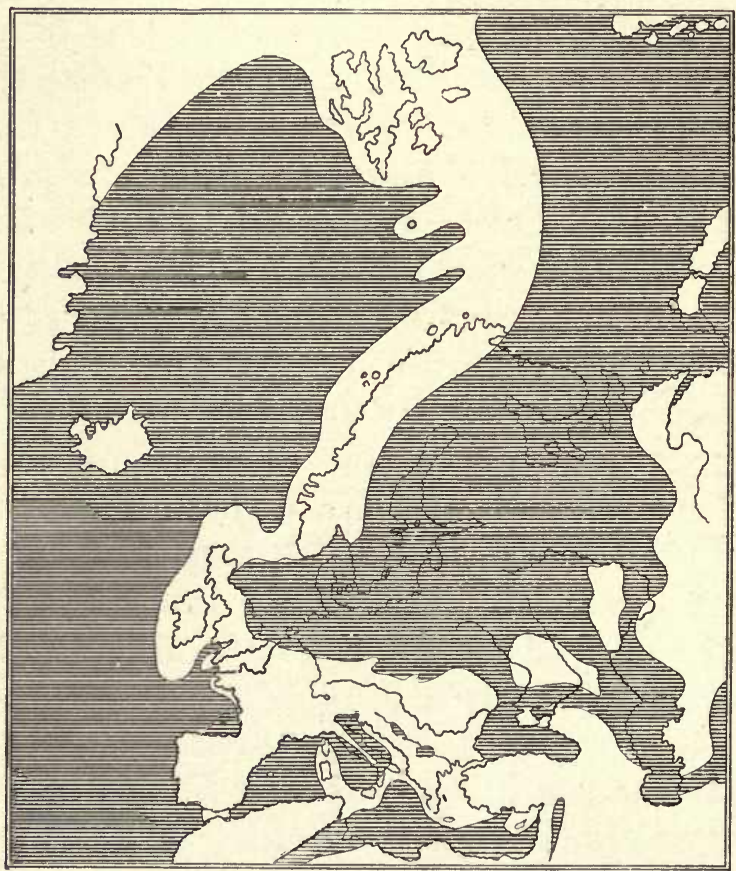

FIG. 12. - Map of Europe, indicating the parts which were probably submerged (shaded) at the commencement of the Glacial period. The light portions represent, approximately, the extent of the land at that time.

dinavia, not being then directly connected with continental Europe, was not accessible to it; neither was Ireland, which had by that time become dis- 
connected from Great Britain. None of the Siberian migrants seem to have been able to cross the River Garonne, and we therefore find neither the Woodland Reindeer nor any of the typical Siberian species represented in the Pyrenean deposits.

The Woodland Reindeer persisted in continental Europe until comparatively recent times, and it has since made its way into Scandinavia across Northern Russia, and probably mingled with the older stock of the Barren-ground form. In the same way, it may have come about that in the English pleistocene deposits the remains of the two races occur.

In a recent contribution to our knowledge of the deer tribe ( $c$, p. 88), Mr. Lydekker suggests that the former division of the Reindeer races into the two forms of Woodland and Barren-ground Caribou, no longer holds good. He now recognises no less than six races, as follows :-

I. Rangifer tarandus typicus.

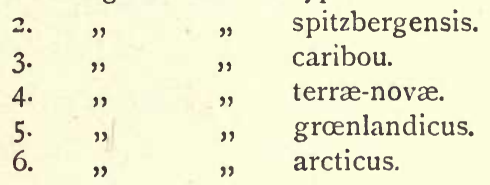

I hardly think these can be considered of equal value; indeed, though there may be differences between $R$. gronlandicus, typicus, arcticus, and spitsbergensis, the antlers exhibit a certain much closcr relationship among one another than to $R$. terrenove and caribou. But the whole subject is by no 
means as well known as could be wished, and a very careful comparative study of recent and fossil remains of the Reindeer from various parts of the Old and New Worlds is much needed to put our views on a firmer basis.

The presence of the Arctic Hare in Ireland and the absence of the common European Hare (Lepus europaus) can be explained in a somewhat similar manner. The Arctic Hare is the older of the two species-corresponding with the Barren-ground Reindeer-and the European Hare the newer one, associating, like the Woodland Reindeer, in its westward migration with Siberian animals, though probably of Oriental origin.

Let us once more refer back again to the map on page I 37 indicating the geographical distribution of the Arctic Hare. Its discontinuous range and its isolated position in the Alps, Pyrenees, and the Japanese mountains, all tend to show that it is an ancient species. Moreover, its presence in Ireland in the plain as well as in the mountains, clearly points to the fact that, in the British Islands at any rate, the Arctic Hare was the first comer, and that subsequently the European Hare invaded these countries. It probably found Ireland then no longer accessible, having since become separated from England. Again and again do we find the statement repeated, that the presence of the Arctic Hare in Europe is a clear proof of the former prevalence in our continent of an Arctic climate. But if so, why should this Hare at present live and 
thrive in Ireland, which has a particularly mild climate in winter, and be absent from so many continental stations where the temperature more resembles that of its native home? If we suppose that the European Hare migrated to Europe from the east, after the Arctic Hare had become established in Western Europe, and drove the latter into the mountains or northward whenever the two came into contact, we should have, it seems to me, a better explanation of the range presented by the two species. I was formerly of opinion that the European Hare had come with the Siberian animals from Siberia, but it appears to me more likely now, that it reached our continent with the Oriental migrants, and only then joined the Siberians in Eastern Europe.

The evidence in favour of a former land-connection between Scandinavia and Greenland, rests on many other facts besides those already brought forward. That some form of land-connection formerly existed between Europe and Greenland is now indeed almost universally accepted. That it was situated more to the south between Scotland and Greenland is a supposition which has been actively supported by many leading authorities, but it seems to me that if such a land-bridge existed, it must have been in very early Tertiary times, whilst the northern one, such as I have indicated, may have originated later and persisted until a recent geological date.

The distribution of few groups of animals is now better known than that of the larger butterflies and 
moths (Macro-lepidoptera); even those of Siberia have been fairly well investigated. The interesting facts obtainable from their distribution are therefore of special value. No less than 243 species of Lepidoptera are mentioned by Möschler as being common to North America and Europe. It is extremely probable that a fair number of these have either migrated direct from America to Europe or vice versâ, though many may be of Asiatic origin, and have wandered east and west from their original home. The following twelve species are mentioned by Petersen (p. 38) as occurring in Arctic Europe and also in Arctic North America, but not in Asia:-Colias nastes, Colias hecla, Syrichthus centaurea, Pachnobia carnea, Plusia parilis, Anarta Richardsoni, Anarta Schönherri, Anarta lapponica, Anarta Zetterstedti, Cidaria frigidaria, Cidaria polata, Eupithecia hyperboreata; and these, as he remarks, point to the possibility of a former direct land-connection between Europe and North America.

Mr. Petersen believes that the chief immigration into the Arctic area of Europe is post-glacial and took place from Siberia, since the majority of the species are still to be found in that country at the present day (p. 57). He also draws particular attention to a fact,- - which I shall discuss more fully in the next chapter,-namely, that the most characteristically Arctic forms of Northern Europe, which also partly occur in the Alps, are entirely absent from the Caucasus. 
Adopting the glacial views of some of our leading geologists, Petersen comes to the logical conclusion that Central Europe could not have possessed any butterflies during the height of the Glacial period, but since all evidences seem to point to the chief migration from Siberia having taken place after the Glacial period, he concludes that they must have survived the severe cold of that time in Central Asia. He leaves us, however, to imagine under what possible geographical conditions the climate in Europe could be too severe for a lepidopterous fauna, while at the same time Central Asia could maintain an abundant one.

In a suggestive note on the origin of European and North American Ants, Professor Emery states (p. 399) that a great number of North American ants are specifically identical with European ones; whilst Dr. Hamilton tells us (p. 89), as an instance, that specimens of the beetle Loricera coru'escens from Lake Superior and from Scotland do not seem to vary to the extent of a hair on the antennæe. He enumerates $4 \mathrm{~S} 7$ species of Coleoptera as being common to North America, Northern Asia, and Europc, many of which no doubt have migrated by the Americo-European land-connection.

Arctic Scandinavia or Lapland, according to Sir Joseph Hooker, contains three-fourths of the entire number of specics of plants known from the whole circumpolar area. His view, that the Greenland flora is almost exclusively Lapponian,-having only 
an extremely slight admixture of American or Asiatic types,-again points to a former more intimate connection between North America and Arctic Europe, and indeed he remarks (p. 252), "It is inconceivable to me that so many Scandinavian plants should, under existing conditions of sea, land, and temperature, have not only found their way to Greenland by migration across the Atlantic, but should have stopped short on its western coast and not crossed to America."

Hooker's view, that the Scandinavian flora is of great antiquity, that, at the advent of the Glacial period, it was everywhere driven southwards, and that during the succoeding warm epoch the surviving species returned north, has been adopted by the great majority of naturalists.

The natural corollary of this theory is that there must have been, between the beginning of the Glacial period and the present time, either two independent land-connections between the Polar Regions and Northern Europe at different epochs to enable animals and plants to travel southwards and once more to regain their former northern home, or, that during the whole of the Glacial period the Polar Regions were uninterruptedly connected with Northcrn Europe, until the fauna and flora had once more reached their northern goal, after the Polar lands had been desolated by the supposed rigours of that period.

In following the history of the Arctic migration to 
Europe, it is of great importance to determine the nature and the time of duration of these landconnections. The Greenland flora is a very instructive one in helping us to understand many of the problems connected with the origin of the European plants and animals. To judge from the remarks of Professor James Geikie and Mr. Clement Reid, no flowering plants could have existed in the British Islands during the height of the Glacial period, and one would suppose that the cold in Greenland at that time must have been far more intense than in England. If no flowering plants could exist in the latter country, then very surely none could in Greenland, where the climate was of necessity by far more rigorous. It will be a surprise, therefore, to those who are acquainted only with Professor Geikie's views of the nature of the Glacial period, that two of the most eminent Swedish botanists, who have made a special study of the flora of Greenland, have come to the conclusion that a survival of flowering plants has taken place in Greenland itself from pre-glacial times. According to Professor Nathorst (p. 200), only a few plants could have survived the Glacial period in Greenland. The species now peculiar to that country may perhaps, he thinks, be the remnants of those which existed in pre-glacial times. Mr. Warming, on the other hand, is of opinion that the main mass of Greenland's present flora survived the Glacial period there (p. 403), and that the remainder was carried from Europe and North America by 
occasional means of distribution of the nature indicated by Darwin.

Very similar views on the origin of the present Polar flora are expressed by Colonel Feilden, who says, "To my mind it seems indisputable that several plants now confined to the Polar area must have originated there and have outlived the period of greatest ice-development in that region" ( $b$, p. 50). No land-connection at all need be supposed to have existed in recent geological times, that is to say, during the Glacial period or after, if Mr. Warming's and Colonel Feilden's views be adopted. A pre-glacial connection would be sufficient to explain the general features of distribution. An admission is thus obtained from these two independent authoritics that the climate during the Glacial period must have been vastly less severe in the Polar Regions than is generally conceded. I am of opinion that not only the whole of the present flora, but also the fauna of Greenland survived the Glacial period in that country.

If we suppose that an extensive centre of origin existed in the Polar area, or we may say in Greenland, both animals and plants would have been able to spread from it into Northern Europe and North America by means of the land-connections which are generally supposed to have existed in pliocene times, that is to say, just before the commencement of the Glacial period. There must have been at this time a connection too between Scotland and Scandinavia, 
which will be dealt with more fully presently. The important point is to consider what light the Greenland flora and fauna will throw upon the problem of the continuity of the aforesaid land-connection during the Glacial period. We have seen that the Barren-ground Reindeer, a typically Polar species, penetrated as far south as the Pyrenees, the Arctic Hare went as far, while a number of other species of Polar animals and also of plants occur in the Alps. Of these it remains to be seen how many have come direct by way of Northern Europe or from the Polar Regions by way of Asia. At any rate, as the origin of the Alpine animals and plants will be discussed in another chapter, there is no need to dwell on this subject at present.

From the nature of the distribution in Ireland of Arctic plants and animals, which occur mostly on the north and west coasts, it would seem that a stream of migration entered from Scotland, and I have no doubt that that same migration came into Scotland directly from Scandinavia by a route over which now roll the waves of the North Sea. There is, moreover, as I already mentioned on p. 94, a very interesting so-called American element in the north-western European flora, that is to say, plants now found in North-west Europe and North America without occurring in Greenland or any of the islands which might have formed the former highway between the Old World and the New. These are probably some of the more ancient Polar plants which have become extinct in 
the Arctic Regions and survive in isolated patches in favourable localities. We find seven species of these American plants in Ireland, almost entirely confined to the north and west coasts. These are Spiranthes Romanzoviana, Sisyrinchium anceps, Naias flexilis, Eriocaulon septangulare, Juncus tenuis, and Polygonum sagittifolium. To them must be added another plant recently discovered by the Rev. Mr. Marshall in the south of Ireland, namely Sisyrinchium californicum. As I have mentioned in former writings, there are three species of North American freshwater-sponges in Ireland which have not hitherto been discovered elsewhere in Europe or in Asia. These, namely Ephydatia crateriformis, Heteromeyenia Ryderi, and Tubella pennsylvanica, all occur in some of the lakes near the western coast of Ireland.

There are in all groups of animals instances of species which are confined to Europe and North America, while unknown from the Asiatic continent, but none, as far as is known, have such a very discontinuous range as that of the animals and plants just referred to. In some cases the species still occur in Greenland, and in this way make it still clearer that their migration in former times took place from one continent to the other by way of that country. As an interesting instance of such distribution may be mentioned the Common Stickleback (Gasterosteus aculeatus); which is found in Greenland, North America, and Europe, but is quite absent from Asia. Then again, the Ninespined Stickleback (Gasterosteus pungitius) is confined 
to Western Europe and North America, though an allied species, Gasterosteus sinensis, lives in China and has probably penetrated there from the New World across the old Behring Straits land-connection.

The Coleoptera Diachila arctica, Elaphrus lapponicus, and Blethisa multipunctala are good instances of species which have come to us from North America by way of Greenland. I have alrcady referred to the Lepidoptera, but might add that eleven species of Anarta occur in Scandinavia, eight of which reappear again in Labrador, none of them, however, being met with in Siberia. Then again, take the interesting Crustacean Lepidurus (Apus) glacialis. It is found in Greenland, Spitsbergen, Lapland, and Norway; and formerly, as we know from fossil evidence, it ranged into Scotland. Another Phyllopod, viz., Branchinecta paludosa, inhabits Greenland, Lapland, and Norway. Mr. Kennard suggests that the freshwater Snail Planorbis glaber might also belong to the same migration. And there are no doubt large numbers of others.

Professor Emery mentions that Northern Europe possesses one peculiar genus of Ant, viz., Anergates. This is closely allied to Epoccus, another genus confined to North America. It seems probable, therefore, that both of these have sprung from an Arctic genus which sent two branches southward into the two continents without there being any migration through Asia.

The general range of the Arctic plants and animals 
gives no reason to suppose that the Greenland fauna and flora of the present day were exterminated by the Glacial period and then reintroduced into that country. Nor have we any evidence that such a fauna and flora migrated across the British Islands northward. The Greenland animals and plants too are altogether much more like the Lapland ones than those of Scotland. It will also become evident to the reader of this work that no very extensive migrations could have taken place during the post-glacial period, and that almost everything points to a survival of both fauna and flora in northern latitudes throughout the Glacial period.

If we take into consideration the palæontological evidence of the two races of Reindeer in Europe, one of which came to us from the north, and that the Arctic Hare and one of the races of the Stoat entered our continent from the same direction-when we, moreover, carefully review the numerous other instances quoted of plants and animals which could only have reached us from the north, the irresistible conclusion is forced upon us that a land-connection existed at no very distant period between Northern Europe and the Arctic Regions of North America. This is not a new hypothesis. Many geologists are of opinion that a land-passage did exist within comparatively recent times, uniting Europe, Greenland, and North America. But the position of this old land-bridge, as I have mentioned, has been generally placed somewhat farther south than I should feel inclined to put it. 
The fact that very extensive glaciers formerly covered the mountains of Scandinavia on the eastern side, whilst they scarcely reached the sea on the west (Feilden, a, p. 72I), seems to favour the view of a warm current having washed the western shores. As I shall attempt to show later on (p. I79), the Arctic Ocean extended across Northern Russia at that time from the White Sea to the Baltic-that is to say, to the eastern shores of Scandinavia, which country was then joined to the north of Scotland. The predisposing agents to a copious snowfall existed in Scandinavia, viz., an excessive evaporation of the warm Atlantic waters and unusual precipitation in the form of snow owing to the cold given off by the Arctic waters on the east side of the mountains. It is therefore probable that the land-connection which united Europe and North America was farther north than has been supposed.

If we sail straight across from Northern Scandinavia to Greenland, we traverse an exceedingly dcep marine basin; but if we examine the sub-marine bank which runs all along the coast of the former country from south to north, we find that it does not end when the extreme north of the land is reached. The bank extends much farther north, and is continued as far as Spitsbergen. As I have said before, the latter, as well as Bear Island, must be looked upon as the remains of a large mass of sunken land-the ancient Scandinavia stretching far into the Arctic Circle. Professor Nathorst speaks of Spitsbergen as a northern 
continuation of Europe, not only geographically, but a!so botanically and geologically. However, this northern land must have stretched even farther-not

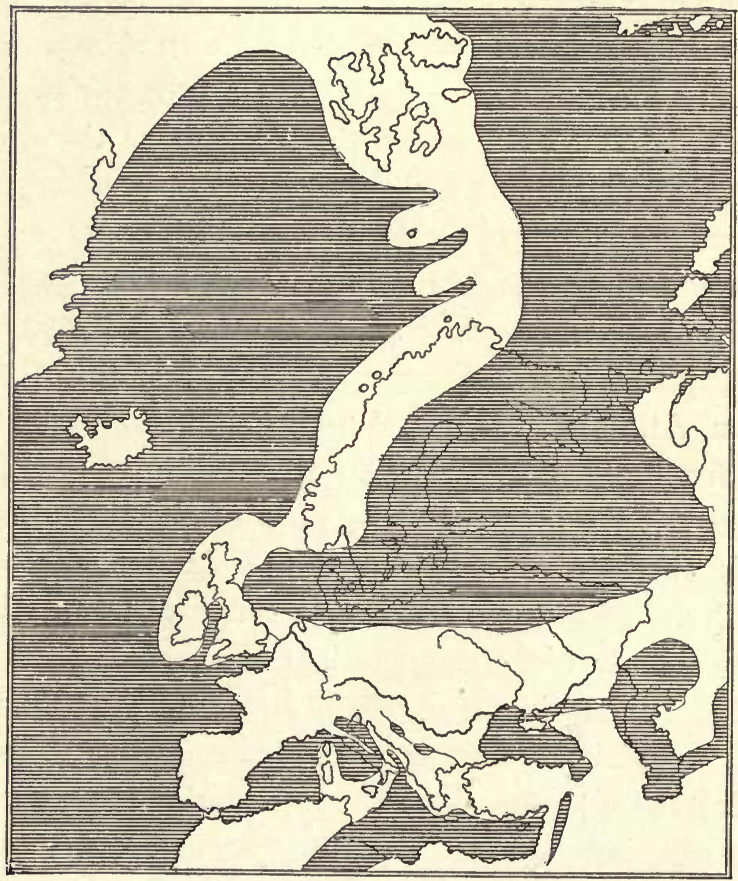

FIG. I3 - Map of Europe, indicating approximately the distribution of land and water during the earlier stages of the Glacial periodshortly after the period represented in Fig. 12, p. I56. The darkly shaded parts indicate the areas covered by water, and the white portions what was land at the time.

perhaps farther north, but farther west. Here lay the old land-connection between Scandinavia, Greenland, and North America (Fig. I3). One of the highest 
authorities on the geographical distribution of plants, Professor Engler, maintains that the arguments in favour of this Arctic connection of America with Europe are more weighty than those for a land-bridge between Greenland, Iceland, the Faroes, and Great Britain. Moreover, he is of opinion that a certain number of species of plants belonging to the Alpine flora of Arctic Siberia have travelled from Scandinavia viâ Greenland and North America to Eastern Asia, and not direct from Scandinavia to Siberia (p. I43).

That this ancient Arctic land-connection existed almost throughout the Glacial period appears to me probable. It has often been suggested that such a land-barrier was one of the principal causes of the production of the glacial phenomena in Europe, and as such it must have existed intact certainly during the earlier stages of the Glacial period. The barrier must then have gradually subsided in one or two places; and once a breach was formed, the complete union between the Atlantic and the Arctic Oceans could not have been long delayed.

The terrestrial fauna and flora, as we have seen, lend strong support to the view of the former connection between Scandinavia and Greenland, but many other facts point in the same direction. It was Edward Forbes who first drew attention to the presence of a number of species of littoral molluscs on the coast of Finmark which also occur on the coast of Greenland, and he expressed the firm conviction that 
they indicated by their existence on both sides of the Atlantic some ancient continuity of the coast-line. He held that the line of migration of these mollusca was probably from west to east, and that it must have taken place during physical conditions entirely different from those prevailing at present. If Forbes's view is correct, a current must have existed from the north coast of North America along the northern shore of the ancient land which stretched east as far as Europe. We have also some palæontological evidence bearing on the existence of such a current (p. I73).

As we shall learn presently, the early stages of the Glacial period were accompanied by a marine transgression over Northern Russia and Germanyan overflow, as it were, of the waters of the Arctic Ocean covering a great part of Northern Europe, with the exception of Norway. One continuous ocean ultimately extended from the east coast of England across Holland, Northern Germany, and Russia to the White Sea (Fig. 12, p. 156). The south of England being at that time joined to France, and Scotland to Scandinavia, there was no direct communication between this large North European Sea and the Atlantic. The glaciers which took their origin in the Scandinavian Mountains discharged icebergs into this sea, and many of them no doubt were stranded on the east coast of England. The boulders of Scandinavian origin which have been discovered in recent geological deposits on 
that coast have generally been traced to the action of land-ice, but the supposition that they have been carried by icebergs-the older theory-appears to me the more probable one. Such boulders begin to make their first appearance in the Red Crag, a deposit which is now looked upon as belonging to the newer pliocene series. But whether we call it pliocene or pleistocene really matters little. The important fact is, that glacial phenomena, consisting of the appearance of boulders foreign to the country together with an invasion of Arctic shells, are now ushered in upon a coast which shortly before teemed with the southern life of a Mediterranean character. Among the new arrivals in these English crags there are no less than eighteen species of North American marine mollusca. Since the German Ocean had then no direct communication with the Atlantic, these mollusca could only have come from the White Sea, and Forbes's Arctic current would offer an explanation of the manner in which they were enabled to migrate there from their original home.

It might be urged that we have no grounds for the supposition that the German Ocean was practically a closed basin; and that these American species probably inhabited at that time the whole of the North Atlantic Ocean. But if such had been the case, we ought to have evidence of the occurrence of some of these species in the newer Tertiary deposits along the west coasts of the British Islands. Such 
beds exist; there is, however, not a trace in any of them of any American mollusca. In examining the marine deposits of St. Erth, on the coast of Cornwall, which are believed to be of about the same age as the newer crags, Messrs. Kendall and Bell were much struck by the absence of the species characteristic of the latter. The St. Erth fauna led them to believe that the Arctic Ocean could not then have opened into the Atlantic, but that a landcommunication had existed between Europe and North America, so as to form a barrier of separation between the two oceans. This again perfectly harmonises with the views I have expressed, and supports them.

Let us now look a little more closely at the history and the fauna of the Baltic and the adjoining lakes, in order to gain additional information as to the geographical changes which have had such lasting influence on the peninsula of Scandinavia. The Baltic is a shallow sea covering an area of 184,496 square miles, and its waters are decidedly brackish. The fauna is a poor one, being too salt for the purely freshwater species and not salt enough for the typical marine forms. The absence of some animals which we should expect to find there is one of the remarkable features about the Baltic, but, on the other hand, some species occur which are altogether strangers to the fauna. And these, moreover, are confined to the extreme northern end of the sea. I need only refer to the Arctic Seal (Phoca annelata), which is confined 
to the Gulf of Bothnia, and to the four-horned stingfish (Cottus quadricornis, Fig. I4, p. I78), neither of which occur on the west coast of Scandinavia. But there are others which point in an equally unmistakable manner to the former existence of a marine connection between the Baltic and the southward prolongation of the Arctic Ocean-known as the White Sea. It is generally admitted now that such a union between these two seas, viz., the Baltic and the White Sea, occurred in recent geological times, but opinions differ as to the duration of this connection. I adhere to the view expressed by Murchison and others, that the boulder-clay is a marine deposit. I am also convinced that the Arctic Ocean, as I hare already mentioned, transgressed over the lowlands of Northern Russia at about the time when the newer crags were being deposited on the east coast of England; that the same large sea also covered Northern Germany, Denmark, Holland, and the lowlands of Sweden, and laid down the lower continental boulder-clay which is spread over such vast tracts of land in those countries. I shall have occasion to refer to this again more fully in the next chapter; meanwhile, it should be remembered that this stage was followed by a partial retreat of the northern sea, though Scandinavia did not become joined to the Continent. The date of this retreat of the sea, represented in Fig. I3, corresponds probably to what is know as the inter-glacial phase of the Glacial period, and I think it must have been during this time that 
the Forest-Bed on the coast of Norfolk was laid down. ${ }^{1}$

None of the Siberian mammals apparently eritered Scandinavia at the time when they invaded Central Europe and penetrated as far west as England and Western France. Nor did the great Oriental mammals, like the Mammoth and others, reach Scandinavia; and Professor Pohlig argued, on the strength of these facts, that the latter country was either for a very short time only free from ice, or that it had defective land-communication with the Continent during inter-glacial times. This seems to me scarcely to explain the facts of distribution and account satisfactorily for the absentees. Nor does it, of course, harmonise with the vicws that I have announced above. Professor Engler's remark (p. I3I), that Scandinavia probably projected above the glacial sea as an island, is more in accordance with these views, though the tcrm island is scarcely applicable to that country, since it was always, as I said, indirectly joined to the Continent (vide Fig. I3, p. I70). The fauna of Scandinavia, both fossil and recent, points to a direct isolation of that country from the continent of Europe during a considerable period.

Another proof that Northern Russia and the lowlands of Sweden were covered by the sea comes to us from a study of the fauna of the relict lakes-the "Reliktenseen" of Leuckart. This name was first applied by Leuckart to lakes containing marinc

1 I have already expressed this view on p. I 20. 
organisms, which are supposed to have been flooded by, or to have been in close communication with the sea at some former period, like the lakes Ladoga and Onega in Russia. His views have been worked out subsequently in greater detail by Lovén and $\mathrm{O}$. Peschel, who gave them their strong adherence. Many leading zoologists, such as Professor Sars and others, have since adopted them, and though discredited by Professor Credner, the theory still offers the best explanation for the origin of marine animals in freshwater lakes.

Professor Credner's contention, that marine mollusca are always absent from these relict lakes, seems at first sight a stumbling-block to the theory. But the explanation is really simple enough. It is to Dr. Sollas that we owe a very ingenious explanation of the origin of freshwater faunas. He showed that all freshwater organisms in their early stages of development are provided either with some process enabling them to attach themselves to a foreign object, or that they pass this period within the body of the parent. This is a provision of nature to prevent freshwater organisms from being floated out to sea, where they would perish, until they reach maturity and can cope with floods and currents. Had Professor Credner been aware of Dr. Sollas's vicws, no doubt he would have modified his criticisms, for, as most marine mollusca have free-swimming larvæ, they wou!d have little chance of becoming permanent residents of lakes. During their larval stage, marine molluscs are quite a 
prey to the currents of the sea. They have practically no swimming organs, and only move by lashing to and fro the tender cilia with which they are provided:

This disposes, therefore, of Professor Credner's main criticisms. As for the fauna of the relict lakes, we are now only concerned with those of Northern Russia, Finland, and Sweden. In the lakes Wetter and Wener in the latter country occurs the four-horned sting-fish (Cottus quadricornis,

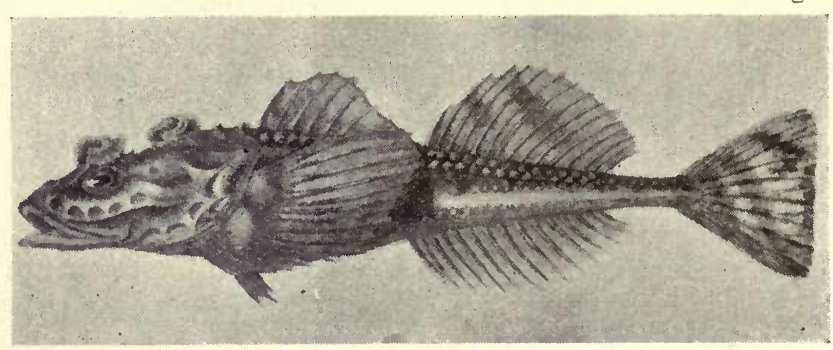

FIG. I4. - The Four-horned Sting-fish (Cottus quadricornis), reduced from Professor Smitt's figure in the Fishes of Scandinavia.

Fig. 14), which, as we have learned, also inhabits the northern part of the Baltic, and, as was suggested, migrated there at a time when the latter was connected with the White Sea. The principal food of this little fish consists in a marine Crustacean called Idotea entomon, an animal allied to our common woodlouse. This is a typical marine species, but it occurs also in the relict lakes of the countries mentioned above, as well as in the Baltic and the Caspian. Perhaps the best known 
form with a similar range is the Schizopod crustacean $M y^{\prime}$ sis relicta ${ }^{1}$ (Fig. I 5), which is clearly a descendant of the Arctic marine Mysis oculata, of which it was formerly considered a mere variety. The two Amphipods Gammaracanthus relictus and Pontoporeia affinis, and the Copepod Limnocalanus macrurus, are three additional well-known Arctic crustaceans whose range differs but little from those above-mentioned. ${ }^{2}$

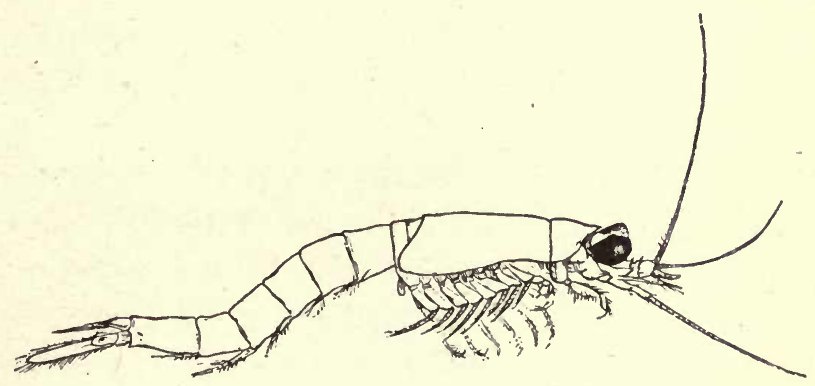

FIG. I5.-Mysis relicta, a small shrimp-like Crustacean, after Sars (enlarged).

These facts all go to prove that the sea formerly covered the lowlands of Sweden, Finland, and Northern Russia. The fauna of Scandinavia, as we have seen, indicates that during the greater part of the Glacial period the country was not directly connected with continental Europe as it is now. It seems that the barrier of separation probably con-

1 The occurrence of this species in Lough Neagh in Ireland, pointing to a connection between the Irish Sea and the Baltic, will be referred to later on; as also that of two allied forms in the Caspian Sea.

${ }^{2}$ For additional species with a similar range, vide Nordquist. 
sisted of a broad expanse of ocean on which floated numerous icebergs, which originated from the Scandinavian glaciers as they reached the sea. This was a cold sea, whilst Western Scandinavia was washed by the Gulf Stream (vide Fig. I2, p. I56). We might look upon the boulder-clay which covers such vast tracts of country in Northern Germany, Russia, and Holland as deposits formed by this sea rather than the ground-moraine of a huge Scandinavian glacier. I shall refer to this subject again in the next chapter; meanwhile it may be remembered that the boulder-clay of Northern Europe exactly resembles in all important particulars the similar accumulations met with in the British Islands. They resemble one another also in the occasional occurrence of sea-shells, the frequent appearance of bedded deposits, and the often inexplicable course taken by boulders from their source of origin. There occurs often a singular mixture and an apparent crossing of the paths of boulders in the boulderclay. Professor Bonney remarks (p. 280) that these are less difficult to explain on the hypothesis of distribution by floating ice than on that of transport by land-ice, because, in the former case, though the drift of winds and currents would be generally in one direction, both might be varied at particular seasons. So far as concerns the distribution and thickness of the glacial deposits, he says there is not much to choose between either hypothesis; but on that of land-ice it is extremely difficult to explain the 
intercalation of perfectly stratified sands and gravels and of boulder-clay, as well as the not infrequent signs of bedding in the latter. Two divisions are generally recognisable in the continental boulder-clay -a lower and an upper. An inter-glacial phase characterised by a less severe climate is assumed to have intervened between the deposition of the two. In Russia no such division can as a rule be made out, and sea-shells are either entirely absent or extremely scarce. It has been pointed out by Professor J. Geikie that the erratics-a name applied to boulders in boulder-clay-in the upper division have travelled in a different direction from those contained in the lower. Taking for granted that the boulderclay is a marine deposit, this phenomenon seems to indicate that the current which prevailed during the early part of the Glacial period in this North European ocean was different from the prevailing current during the latter part. I have attempted to explain this circumstance by the supposition that during the early part of the Glacial period the Northern Sea had a connection with the PontoCaspian Sea-a sea formed by the junction of the Black Sea and the Caspian (Fig. 12, p. 156). There is geological evidence, as will be explained in the following chapter, that the area of these two seas was considerably larger in glacial times than it is now, and that they were joined across the valley of the Manytch. After the inter-glacial phase of the Glacial period, the North European Ocean became connected 
with the Atlantic Ocean across the north of England (Fig. 6, p. 126), the junction between the former and the Ponto-Caspian having meanwhile become dry land (Fig. I3, p. I70). A fresh current, now flowing westward, was set up in the North European Ocean, which accounts for the fact just cited that the erratics in the upper continental boulderclay have travelled in a different direction from those in the lower. The boulder-clay laid down by the sea on the midland and northern counties of England, just as was the case with the similar deposit on the Continent, is generally accredited to the action of land-ice. It is by most geologists looked upon as the ground-moraine, partly of the huge Scandinavian glacier which is supposed to have impinged upon the English coast, partly of local British glaciers.

But renewed geological investigations on this point throw doubts upon these theories. Thus Mr. Harmer remarks in a recent contribution to glacial literature (p. 775), that "it is difficult to see how the Baltic glacier could have reached East Anglia, though icefloes with Scandinavian boulders might easily have done so, while had the Norwegian icc filled the North Sea and overflowed the county of Norfolk, some evidence of its presence ought to be found in the glacial beds of Holland."

All the phenomena of distribution of the British fauna and flora are, as we have seen, much more easily explained by the supposition of a damp, temperate 
climate, such as might have been produced by the proximity of a cold sea on one side and of a warm one at the other, than by invokirg an arctic climate with enormous glaciers. Most of the living animals and plants would have been exterminated under the latter conditions. Palæontological evidence in Great Britain clearly indicates that southern species migrated first to these islands, that Arctic species were then driven south from their native lands,-_probably owing to insufficient food-supply and climatic changes in the north,- - that finally eastern species invaded the country-all this without the annual temperature of Europe being apparently much affected. For we find in the British pleistocene deposits-and $\mathrm{Mr}$. Lydekker draws particular attention to this remarkable fact-a curious intermingling of southern and northern mammals, which undoubtedly lived side by side. Everybody knows that northern and Arctic species can live perfectly well in a temperate climate, but that it is almost impossible to acclimatise southern animals in an Arctic or even temperate one. We have in this circumstance almost a proof, therefore, that the climate cannot have been very cold. Though a cold sea bathed the shores of Eastern England, and even eventually invaded a portion of Northern England, the warm ocean on the west must have effectually prevented any great lowering of temperature.

At the time when the North European Sea flooded a portion of England, Scandinavia was still connected 
I84 HiSTORY OF THE EUROPEAN FAUNA.

with Scotland, and the latter with Ireland (Fig. 6, p. I26). There is no doubt that the food-supply in the Arctic Regions was decreasing with an increase of snowfall and with the gradual lowering of the land, which reduced also the habitable area. Arctic species therefore were driven south in search of fresh pastures. But it need not be supposed that anything like a vast destruction of the fauna of the Arctic Regions took place. Only fewer mammals were able to find food in a given space than heretofore. This southward migration may have commenced, in the case of plants and the invertebrates, at a much earlier time, -during the Miocene or Pliocene Epochs,-but it is doubtful whether the mammals and birds which we find in our pleistocene and recent deposits began to travel south much before the commencement of the Glacial period. The beginning of the Glacial period in England, I think, is indicated by the deposition of the Red Crag, though the latter is generally regarded as belonging to the pliocene series. Much of the northward migration from the British Islands of Lusitanian and other forms had then ceased, but we have in Scandinavia, just as in these islands, a southern relict fauna and flora, plants and animals which had wandered across what is now the German Ocean from Scotland to Scandinavia, and have never become extinct in that country to the present day. I need only mention the Red Deer, the Badger, and Slugs of the genus Arion. 
Professor Blytt directs attention to some such southern relict species of plants now only found in the extreme south-west of Scandinavia, such as Asplenium marinum, Hymenophyllum Wilsoni, Carex binevvis, Scilla verna, Erica cinerea, Conopodium denudatum, Meum athamanticum, and Rosa involuta (p. 28).

The Arctic fauna and flora in Scandinavia-that is to say, the descendants of those species which migrated direct from Greenland and Spitsbergen, as we have seen, are numerous. They of course persisted throughout the Glacial period in the country, and are now in many localities being exterminated partly by change of climate, partly by a keen competition with more vigorous rivals which have come to Scandinavia from the east. It is a curious circumstance, as pointed out by Professor Blytt, that the Arctic plants in the Botanic Gardens at Christiania are able to stand almost any amount of sunshine, but are very liable to be injured by the frost, and have to be covered in the winter. A similar observation has been made in the case of the Alpine plants at Kew Gardens, which have to be wintered in frames, though their homes are either in the high Alps-among the everlasting snows-or in the intensely cold climate of Greenland. Many of the Scandinavian plants exhibit instances of discontinuous distribution, thus showing their ancient origin; and there is altogether nothing in the fauna and flora of that country which might lead us to believe that these were exterminated during the Glacial period and reintroduced subse- 
quently. The climate during that period in Scandinavia was probably more equable and moister,with a greater snowfall in winter and with less sun to melt the snow during summer,-so that the development of glaciers took more formidable dimensions, chiefly on the east side. The lowlands of Sweden were covered by the sea, whilst many of the valleys were choked with great glaciers, which cast off portions of ice as they reached the sea, just as the Greenland and other northern glaciers do (vide p. 237). A country which at the present day probably somewhat resembles the former Scandinavia climatically is Tierra del Fuego, in the extreme south of South America. Though there is an abundant snowfall, so that glaciers reach the sea in many parts of the country, the flora has been described by travellers as luxuriant; and it appears that the fauna also is richer than might be expected from the cheerless climate.

Towards the latter part of the Glacial period the land-connection between Scandinavia, Spitsbergen, and Greenland broke down, and the waters of the Arctic and Atlantic Oceans joined. Whether it was at this time or later that the other land-connection between Scandinavia and Scotland collapsed is difficult to determine; but it is certain, I think, that Scotland was still united with Ireland even after these two great land-bridges ceased to exist. 


\section{SUMMARY OF CHAPTER IV.}

The fauna of the Arctic Regions is much pcorer than that of the other regions which are dealt with in this work. In some groups, such as Reptiles and Amphibia, there are no representatives at all, but no doubt a larger number of species existed there in earlier Tertiary times. At least we have fossil evidence that during the Miocene Epoch plants of many families flourished in Greenland of which no vestige is now left in the Polar area. Climatic conditions must therefore have changed, as in Europe. A gradual refrigeration took place, owing probably to the slow withdrawal of the current which supplied the Arctic Sea with warmth. Greenland and Europe were then connected, and the Arctic Ocean was separated from the Atlantic. This landconnection is supposed to have lain far north between Scandinavia, Spitsbergen, and Greenland, and must have persisted until towards the end of the Glacial period.

As the temperature decreased and the land-area available in the north diminished, the surplus population, consisting of animals and plants, and possibly also of human beings, moved southward. We have traces in Europe, and especially in the British Islands, of a very early migration from the north in the so-called American plants and in the freshwater sponges. The geographical distribution of some of the Arctic species of mammals is referred to in greater detail, to show how the relative age of their entry into Europe can be determined. Two forms of Reindeer, resembling the Barren-ground and Woodland varieties, have been met with in European deposits, but only the former occurs in Ireland and the south of France, whilst eastward the other becomes more common, and finally is the only one found. It is believed that the Barren-ground is the older form as far as Europe is concerned, and that it came to us with the Arctic migration, and that the other Reindeer reached Europe much later from Siberia, when Ireland had already become detached from England. The range of the 
Arctic Hare is equally instructive. It must have been a native of Europe since early glacial or pre-glacial times-before the common English Hare had made its appearance in Central Europe. Along with other Arctic forms, it entered Northern Europe directly from the Arctic Regions, by means of the former land-connection which joined, as I remarked, Lapland with Spitsbergen, Greenland, and North America. There need not have been a post-glacial connection between Europe and Greenland; the present flora of that country may have survived the Glacial period in the Arctic Regions, as has been maintained by some botanists and other authorities. Professor Forbes argued from the occurrence of the same species of shore mollusca on the coast of Finmark and Greenland that these two countries were not long ago joined, so that a slow migration from west to east along an ancient coast-line could have taken place. That such a migration actually occurred is further made probable, judging from the presence of American mollusca in the Crag deposits on the east coast of England. These came into the North Sea in the first place direct from the Arctic Ocean at a time when the two oceans freely communicated with one another across the lowlands of Northern Russia, Northern Germany, and Holland. Arctic shells are also found below the boulder-clay on the Baltic coast, and a free communication such as indicated is generally held to have taken place at no very distant date. The so-called "relict species" -marine animals left in freshwater lakes in districts formerly covered by this sea-lend some support to this view. But the view that the continental boulder-clay is a marine deposit is not now held except by a few, though I here bring it forward again, as it seems to me to fit in so much better with the known facts of distribution. The sea just referred to probably existed throughout the greater part of the Glacial period; and icebergs, which originated from the Scandinavian glaciers, would have brought detritus and boulders to the lowlands. Scandinavia was then connected with Scotland, and England with France. 


\section{CHAPTER V.}

\section{THE SIBERIAN MIGRATION.}

IN dealing with the British fauna in particular, I have drawn attention to the fact that it is chiefly in the south of England that we find fossil remains of eastern species of mammals in recent geological deposits. We can actually trace the remains of these species and their course of migration across part of the Continent towards Eastern Europe, and as none of their bones have been discovered in the southern or northern parts of our Continent, it must be assumed that their home lay in Siberia, where many still exist to the present day, and where closely allied forms also are found. Some of these Siberian migrants have remained in England and on the Continent to the present day. Many lave become extinct. But the animals forming this eastern migration did not all originate in Siberia, though I have sometimes spoken of them collectively as Siberian migrants. There must have been other centres of dispersion of species in Europe. We know that a very active centre of development-at any rate for land-mollusca-lay in South-eastern Europe, either in the Caucasus or in the Balkan peninsula, or more 
probably in both. The Alps no doubt produced a number of species which have spread north and south, and may in their wanderings have joined the Siberian migrants in their western course, and thus have reached the British Islands. Nevertheless, the majority of the mammals belonging to the eastern element of the British fauna (vide p. 95) have undoubtedly originated in Siberia. The Polecat (Mustela putorius) and the Harvest Mouse (Mus minutus), for instance, are members of that eastern migration. Both occur throughout Central Europe and a large portion of Siberia, but are absent from the extreme north and south of Europe and also from all the Mediterranean Islands. A Siberian species, which has never penetrated so far west as the British Islands, nor even so far north as Scandinavia or south to Italy, is what is known in Germany as the "Hamster" (Cricetus frumentarius), a little Rodent which spends the winter asleep in its burrows, and surrounds itself with a great accumulation of foodmaterial carried there during autumn. The common English Hare, which I formerly regarded as an instance of a Siberian mammal, must now find a place among the Oriental migrants. Its history is very instructive, and I shall have an opportunity later on to refer to it again. Meanwhile, it may be mentioned that though this Hare inhabits Europe in two varieties or races, one of which, Lepus mediterraneus, is confined to Southern Europe, the latter owes its origin to an earlier migration from Asia. 
When we come to consider the eastern birds, we have to distinguish between resident species and migratory ones. The Black-throated Thrush (Turdus atrigularis), which has been twice obtained in the British Islands, is a mere straggler to Europe, and is not known to breed there at all. Better known bircis, perhaps, are the Golden Thrush (Turdus varius), which has even occurred as far west as Ireland, the Rock-Thrush (Monticola saxatilis) and the Scarlet Grosbeak (Carpodacus erythrinus), which breed in Eastern Europe, but are known only as occasional visitors in the west.

To judge by their distribution, the Bullfinches (Pyrrhula) are of Asiatic origin, for seven species out of ten are confined to that continent. Our common Bullfinch ( $P$. europea) probably came with the Oriental migrants, or perhaps its ancestors did. But the larger Northern or Russian Bullfinch (P. major) has no doubt entered our Continent directly from the east. We have in many groups similar instances of closely allied species or varieties, one of which, originating at a somewhat later stage than the other, took a different route of migration from that followed by its near relative.

The Pine-Grosbeak (Pinicola enucleator) is only known to British ornithologists as an exceedingly rare visitor. Its real home lies in the northern parts of Europe, Asia, and North America, and it is one of the most typical of the Siberian migrants.

But there are a number of other species of birds, which, though probably not of Siberian origin, 
only migrated westward recently, and have either not yet reached the British Islands, or which lead one to suppose, from their British range, that they are eastern forms.

Such, for instance, is the Nightingale (Daulias luscinia), which is probably of Oriental origin, but only visits England regularly in spring. There is no authenticated record of its ever having migrated either to Scotland or Ireland.

The Bearded Titmouse (Panurus biarmicus) is one of the eastern birds still resident in England, though unfortunately it seems to be on the verge of extinction. It is unknown in Scotland and Ireland. Another resident eastern species is the Nuthatch (Sitta casia), but neither of these is probably of Siberian origin.

The majority of the European Reptiles are probably of eastern origin. Among our British species, the Common Viper (Pelias berus), for example, is a typically eastern form. It is almost unknown in Southern Europe proper-that is to say, in Italy, the Balkan peninsula, and the Mediterranean Islands, but its range extends in the west as far as Spain, and in the east right across the Asiatic continent to Japan. It is well known that the Viper occurs in Scotland, and that neither it nor any other snake is found in Ircland. There is a legend, indecd, that snakes did once exist in Ireland and were banished from the island by St. Patrick, but unfortunately we have no historical evidence that such an 
interesting event actually took place. The SandLizard (Lacerta agilis), another British species, may be looked upon as an eastern form. It is quite absent from Italy, the Balkan peninsula, and the Mediterranean Islands, but extends throughout Central Europe to the east.

Among the species of eastern Reptiles which have a mere local range in Europe might be mentioned the two Lizards, Phrynocephalus auritus and Agama sanguinolenta. They belong to the family Iguanida, which includes some very large species. Both of them are Asiatic forms, which have only just penetrated across the eastern steppes into Europe, where they inhabit the arid regions between the Caspian and the River Don in Southern Russia.

The species of Mammals living in Europe at the present day have, with few exceptions, migrated to our continent from other parts of the world. With regard to the Birds, it is possible that a somewhat larger number proportionally may be of European origin. Still, the great majority are, I think, to be regarded as immigrants. The autochthones are about equal to the immigrant reptiles, but many of the European Amphibians and the majority of the Fishes have probably originated on our continent. Some of the European Amphibiaespecially among the tailless forms-appear to be immigrants from Asia. Thus the distribution of Rana arvalis in Europe is remarkably like that of a Siberian migrant. This frog occurs in Siberia, 
ranging southward as far as Persia and parts of Asia Minor. Crossing the European border, we find it in Russia, Upper Hungary, North and Central Germany,-being rarer in the south,-Denmark, and Scandinavia. According to Bedriaga, it crosses the Rhine only in Alsace, but occurs no farther west. It only just enters Holland. If we suppose the species to have originated in Central Europe, we should expect to find it in Switzerland, France, and perhaps England. If it had its ancestral home in Eastern Europe, we might expect it to occur on the Balkan peninsula. It seems to me more probable, therefore, that Rana arvalis came with the Siberian migration. This need not cause surprise, as the genus Rana is certainly not European. Out of about I IO species, only four are peculiar to Europe, the rest are scattered over all parts of the globe. Moreover, the fact that these four species are confined to Southern Europe would seem to indicate that the first species entered from the south, and there either became modified or spread over nearly the whole continent, as did, for instance, Rana esculenta and R. temporaria. Neither of these is by any means confined to Europe. $R$. esculenta ranges right across the Asiatic continent to Japan, and also enters North Africa, while the other has a wide distribution in northern and temperate Asia.

The various groups of Vertebrates are not dependent on each other in their migrations. Mammals and Birds extend their range with so much greater facility than 
Reptiles and Amphibians, that the surplus population of our neighbouring continents readily poured into Europe when-owing to changes of climate perhapsthey forsook their original homes.

We observe much the same differences of origin in the various groups of European Invertebrates. The Central European Molluscan fauna, remarks Dr. Kobelt, had already developed from the pliocene -in almost all its details, as regards formation of species and distribution-when. the Ice-Age commenced ( $b$, i. p. 162). Certain very interesting dislocations, however, in the range of land mollusca can be proved to have taken place about that time. Thus, as Dr. Kobelt has pointed out, the genus Zonites, which is now almost confined to the south-east of Europe, occurs in inter-glacial deposits in the valley of the Neckar, and even as far west as the Seine. If we might judge from this single instance, a molluscan migration from the east to the west seems to have occurred either in early or pre-glacial times. That Helix pomatia has migrated only comparatively recently from the East to Western Europe is rendered probable by its general range in northern and western Europe, but I cannot agree with Dr. Kobelt in the belief that Helix aspersa is of an equally recent origin in the North. No matter whether it has been found fossil or no, its range in the British Islands points to its having penetrated to Ireland when the latter was still connected with the Continent by way of England. Its migration from 
the Mediterranean dates therefore from early pleistocene or late pliocene times.

In referring to the sixty-five species of Land and Freshwater Mollusca which have been described from the continental "Loess," Dr. Kobelt states (p. 166) that this fauna has certainly not a steppe-character. It does not therefore strengthen Professor Nehring's view that Europe during the deposition of the loess had a climate comparable to that of the Siberian steppes. The Glacial period had hardly any effect on the molluscan fauna of Europe. Dr. Kobelt believes in a certain movement of that fauna from the least favourable areas, with a subsequent re-immigration; but even that could not have taken place on a large scale. Nothing like a destruction of the fauna occurred, as far as we know from fossil evidence.

Not a single species of land or freshwater mollusc can be quoted as having migrated to Europe from Siberia in recent geological times. The molluscan fauna of the latter country is so closely connected with that of Europe, that it is quite impossible to elevate it to the rank of a sub-region of the Holarctic Region. Dr. Kobelt insists that Siberia cannot even claim to be placed into a distinct province. According to the same authority, we find no species in the whole Siberian molluscan fauna which we might regard as having immigrated since the close of the Glacial period. Even to attempt the location of the original homes of many of the species which 
Siberia has in common with Europe, seems hopeless. Such forms as Arion hortensis, which has been obtained in Siberia, and which, as we have seen, must have originated in Western Europe, migrated in pliocene or miocene times, possibly along the shores of the Mediterranean and across Asia Minor. We have evidence, therefore, of an eastward migration among the land and freshwater mollusca in later Tertiary times, but not of a westward one from Siberia.

A very different view is presented to us by the coleopterous fauna of Europe. Many of our European Beetles are Siberian migrants. Let us take, for instance, the Tiger Beetles (Cicindelida). Thcre are over forty species of the genus Cicindela in Europe, five of which reach the British Islands. This seems a large number; but there are altogether no less than $6 c 0$ species of the genus scattered over the greater part of the world, many of them being Asiatic. The genus is certainly not of European origin, for not only are most of the European species confined to the Caucasus and the south-east generally, but no Cicindelide whatsoever occur, for example, in Madeira or the Canaries, where we should expect some to have persisted if the genus had originated on our continent. Moreover, of the five tribes into which the large family of Cicindelide can be subdivided, only two range to Europe, and one of them is represented by only a single species on our continent. 
Some of the Cicindelas may have come with the Oriental migration. I think this was the case with the only Irish species of the genus, $C$. campestris. It occurs all over continental Europe and Northern Asia, and varicties of the species are known from Corsica, Sicily, Crete, the Cyclades, Sardinia, Asia Minor, Greece, and Spain. Five species of Cicindela, as I said, are known from England, of which $C$. silvatica and $C$. maritima are certainly Siberian migrants, and perhaps $C$. hybrida too. Neither of the two first species is found in Southern Europe or in Spain, where we should expect them to occur had they originated on our continent. C. silvatica and maritima have no doubt entered Europe from Siberia in recent geological times, probably soon after a way was opened up across the Tchornosjem district of Southern Russia-that is to say, in inter-glacial times. The former spread along the Central European plain as far west as the south-east of England when Great Britain still formed part of France. C. maritima, which preferred the proximity of the sea, migratcd along the shores of the Caspian and then across Russia to the shores of the Baltic and North Sea, and has penetrated a little farther north and west in England than its near relative. C. litterata has a very similar distribution and origin, but instead of wandering so far west as the British Islands, it seems to have preferred extending its range southward, and has just reached Northern Italy. 
The closely allied Ground-beetles (Carabida) furnish us with equally interesting and instructive proofs of a migration from Asia. Over 300 species of Carabus are known to science. The number of species inhabiting Asia and Europe are about equal. But the genus does not extend its range to Southern Asia or to South America or Australia. Very few species enter Africa, and only nine North America, of which three also occur in Siberia. The genus is unknown in Madeira, and only represented by three species in the Canary Islands. To judge from its distribution, it has probably originated in Western Asia. Probably some Carabi of European origin have spread into Asia, but the Asiatic-or we might say the Siberian-origin and subsequent migration westward of a number of well-known forms appears to me evident. Such forms as C. clathratus, C. gramulatus, and $C$. cancellatus are no doubt of European origin, and have only in recent geological times extended their range across Northern Asia, whilst $C$. marginalis, coming fiom Siberia, can hardly be said to have invaded Europe, since it has never been met with farther west than the eastern provinces of Prussia.

Among the Carabidae there are altogether very many examples pointing to a migration from Asia to Europe, but I do not wish here to give a list of all such cases, and only refer to a few of the more remarkable ones. One of the European species of Demetrias (D. unipunctatus), known to English ento- 
mologists as a south-eastern form, seems to have arrived with the Siberian migration, whilst the closely allied $D$. atricapillus, which has been able to reach Ireland, has a wider range and came earlier with the Orientals.

Messrs. Speyer state (p. 68) that almost all those species of Central European Butterflies whose northern limit is deflected southward as we approach the west coast of Europe, inhabit also the Volga country and the adjoining parts of Asia. Many of them are much commoner there than in Central Europe, and it appears probable to the authors of the Geographical Distribution of Butterflies that these species came from the east. Asia and Central Europe have, according to Messrs. Speyer, no fewer than 156 species in common. Mr. Petersen estimates that no less than 9I per cent. of the ArcticEuropean Butterflies also occur in Siberia. He made a special study of the Arctic Macro-lepidoptera, and came to the conclusion that Central Asia, not having been glaciated in the Ice-Age, offered a possibility of existence to both animals and plants. Here, he thinks, was the principal centre to which Europe owed its re-population in post-glacial times. Mr. Petersen is of opinion (p. 40) that the Arctic-European Lepidoptera are composed of two elements - the pliocene relics which persisted in Europe during the Glacial period, and the now immigrants from Siberia.

No doubt Siberia supplied Europe with a number 
of species of Butterflies and Moths in recent geological times, but we need not necessarily suppose that these arrived only after the Glacial period. Even the most extreme glacialists admit that large areas on our continent were free from ice at the height of the Ice-Age, Siberia had therefore no particular advantage over Europe in giving an asylum to Butterflies and Moths which were escaping from the rigours of a supposed arctic climate. But we have already learned (p. 8o) that the climate during the Glacial period probably differed but little from that which we enjoy at the present day, and we may assume, therefore, that the Lepidoptera of Siberia migrated during that time or even earlier to Europe.

Let us for a moment reconsider some instances of mammalian migration from Siberia, with a view to studying more closely the nature of these great events. I mentioned the fact that some of the Siberian migrants have remained in England, that more have settled down permanently on our continent, but that many others have either become entirely extinct or do not live any longer in Europe.

Of the mammals which made their appearance in Great Britain in recent geological times, i.e., during and since the deposition of the Forest-Bed for cxample, the following species probably came direct from Siberia across the plains of Europe, as already mentioned (p. 95):- 
Canis lagopus.

Gulo luscus.

* Mustela erminea.

* " putorius.

*,$\quad$ vulgaris.

* Sorex vulgaris.

Lagomys pusillus.

* Castor fiber.

Spermophilus Eversmanni.

erythrogenoides.

Cricetus songarus.

Myodes lemmus.

Cuniculus torquatus.
* Mus minutus.

* Arvicola agrestis.

* " amphibius.

" arvalis.

* „ glareolus.

" gregalis.

"ratticeps.

Equus caballus.

Saiga tartarica.

Ovibos moschatus.

Alces latifrons.

" machlis.

Rangifer tarandus.

* Those marked with an asterisk still inhabit Great Britain, or did so within historic times.

Of the arrival of many of these in Europe we have geological proof, as they have left their boncs in recent pleistocene deposits, and are unknown from older European strata. The remote ancestors of others, such as Sorex and Lagomys, no doubt lived in Europe, but the recent species probably had their original homes in Asia. It is evident that in recent geological times there existed no active centre of origin for mammals in Europe, and that our continent was largely dependent on the neighbouring one for the supply of its mammalian fauna. A shifting of the centre of development from Europe to Asia appears to have taken place occasionally, as already mentioned (p. 45). Mr. Lydekker has drawn attention to the fact that though the remote ancestors of the Elephantide resided in Europe, neither the latter 
continent nor North America was the home of the direct ancestor of any of the true Elephants. Similarly, though we have had our Sorex in Europe from the Upper Eocene and Lagomy's from the Middle Miocene, the geographical distribution of Sorex vulgaris and Lagomys pusillus does not support the view that they are of European origin and have migrated to Asia. Their absence from most of the European islands indicates either an extremely recent origin or a recent immigration from Asia, and the latter view secms to me much the more probable.

No less than twenty-six species of the Siberian mammals penetrated as far west as the British Islands, and nine of these still inhabit Great Britain. Some of the remaining seventeen species probably lived only for a very short time in England, and the rest gradually became extinct one by one. This process of extinction of the aliens still continues. The Beaver (Castor fiber) has died out within recent historic times. We possess legends and uncertain historic records pointing to the existence of the Reindeer in Scotland as recently as about seven centuries ago. But much the same state of things has happened on the Continent. The Glutton (Gulo luscus), which still lived in Northern Germany last century, has now entirely vanished from that country, as also the Reindeer. The Lemmings have found an asylum in Scandinavia. The Musk-Ox (Ovibos moschatus) has disappeared not only from Europe but also from Asia, and is now 
confined to Arctic America and Greenland. The Horse no longer occurs in Europe in the wild state, and the Saiga Antelope (Saiga tartarica) has retreated to the Steppes of Eastern Europe and Western Siberia.

As we proceed more and more eastward across Central Europe, we find that a larger and larger percentage of the Siberian migrants have adopted the new country as their permanent home, though in France and Germany, as well as in Austria, we have evidence that a great number of Siberian species, which formerly lived there, have either become entirely extinct, or have retreated towards the land of their origin. There is a prevalent belief that these migrants have taken refuge on the higher European mountain ranges, but this idea is altogether erroneous, as will be shown in the chapter dealing with the origin of the Alpine fauna.

One of the Jerboas (Alactaga jaculus) occurs fossil as far west as Western Germany, but it is now confined to Russia and Western Siberia. The Bobak marmot (Arctomys bobak), which has a similar range now, probably inhabited France in former times. A Siberian species which has retrcated but little is the Hamster (Cricetus vulgaris). Its fossil remains have been found in Central France, but it does not now occur west of the Vosges Mountains.

It appears, therefore, as if a wave of migration had swept over Central Europe from east to west, that those species which were able to adapt themselves to 
the new surroundings had remained, and as if the rest had died out or were gradually retreating to the east.

Ornithologists are well acquainted with the fact that in some years there is an unusually large exodus from Eastern Europe and Siberia of birds; and that species like the Waxwing (Ampelis garrulus) then appear in great numbers. But the appearance of this bird in Western Europe is not looked upon as so remarkable as that of Pallas's Sandgrouse (Syrrhaptes paradoxus, Fig. 3, p. 42), a typical inhabitant and resident of the Arctic Steppes. The last great irruption took place in 1888 , and many birds reached even the extreme west of Ireland in May and June of that year. A few weeks before, it had been announced to the German papers that large flocks of this peculiar pigeon-like bird had arrived in the eastern provinces; and though the vast majority vanished as quickly as they had come, a certain number remained for a year or so in the newly visited countries, and some even bred in England.

Twenty-five years before, in 1863 , a similar migration had occurred, though not perhaps on quite such a vast scale, and a few small flocks had made their appearance in Western Europe on several occasions between these dates.

It may not be generaliy known that no other bird has been honoured by our Government in a like manner, for it is the only animal for whose protection a separate Act of Parliament has been passed. 
In spite of this unusual precaution, the species has not survived to add another member to the resident British fauna. The wave of migration from the east has come and vanished again just like so many others with which history is familiar.

These migrations from the east occurring at the present day give us some idea of those of which we have fossil evidence, and which all had their origin in Central and Northern Asia. Almost all the species of mammals to which I have referred as being of Siberian origin have been found in the fossil state in comparatively recent geological deposits within a certain very limited area. None of the typical species have ever been found in Southern Europe proper, including the Mediterranean islands. It must be remembered that though the Reindeer is a Siberian migrant, the form of the Reindeer which was found in the Pyrenees belonged to a distinct variety - in fact, to a much earlier migration which issued from the Arctic European Regions, and to which I have referred in detail (pp. 150-158). Curiously enough, no deposits of these typical Siberian mammals have ever been obtained in Scandinavia-only in Russia, Austria, Switzerland (the lowlands), Germany, Belgium, France, and England. To facilitate a study of the extent of these migrations, I have constructed a map on which the probable course taken across Central Europe is roughly indicated by dots (Fig. I6).

In the migrations of to-day we perceive the same 
tendency as in the older ones of which we have fossil evidence, viz., generally a spreading of species on a large scale over new territory, and then a gradual

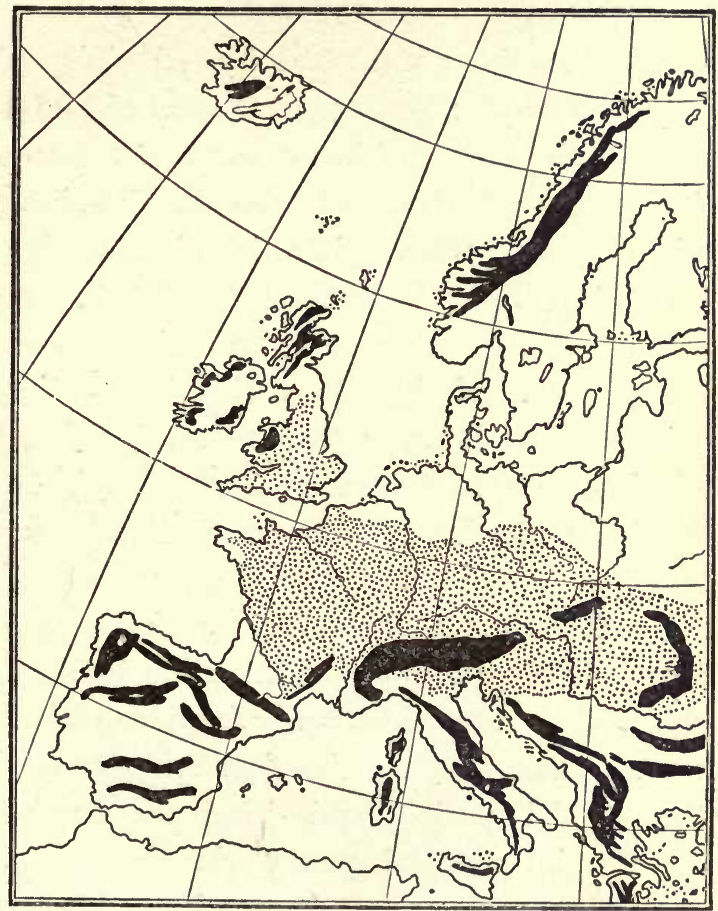

FIG. I6.-Map of Europe. The dotted portions represent, approximately, the course of migration of the Siberian mammals. The principal mountain ranges are roughly indicated in black.

shrinkage towards their original home, with an occasional survival of small colonics in the invaded part. It must not be supposed that this observation applies 
alone to the Siberian migration. In the case of the Arctic one, precisely the same thing has happened, and we shall see that the Southern (migration from the south) agrees in this respect with the others.

As for the immediate cause of these migrations, it is to be looked for either in the scarcity of food dependent upon a temporary or permanent change of climate, or in an excessive increase in numbers of a particular species. I do not propose to trace back migrations beyond the Pliocene Epoch, or indeed much beyond the beginning of the Glacial period, which is regarded as a phase of the most recent geological epoch, viz., the Pleistocene. During the period in question, we have indirect evidence of one vast migration from Siberia into Europe across the lowlands lying to the north of the Caspian and to the south of the Ural Mountains. There is a general consensus of opinion that this migration took place in Pleistocene times. Professor Nehring thinks that there can be no doubt (p. 222) that the Siberian migrants arrived in Northern Germany after the first stage or division of the Glacial period, and lived there probably during the inter-glacial phase which occurred between the first and second stages-if indeed we look upon this period as being divisible into two distinct stages.

Judging from the evidence of distribution of mammals in pleistocene Europe, Professor Boyd Dawkins came to the conclusion (p. I I3) that the climate of our continent "was severe in the north 
and warm in the south, while in the middle zone, comprising France, Germany, and the greater part of Britain, the winters were cold and the summers warm, as in Middle Asia and North America." "In the summer time the southern species would pass northwards, and in the winter time the northern would swing southwards, and thus occupy at different times of the year the same tract of ground, as is now the case with the Elks and Reindeer." Very different are the views of Professor Nehring on this subject. According to him, the climate in Germany must have been extremely cold and damp, resembling that of Greenland, though perhaps not quite so arctic. Professor Nehring does not at all believe that southern and northern species of mammals could have lived in Central or Northern Europe at the same time; though of this we have undoubted geological evidence (pp. 72-75). He thinks that the supposed commingling of southern and northern types, which has actually been shown by Professor Dawkins to occur, is either due to careless observation or to the fact that some of the species need not necessarily have lived where their bones were found (p. 133).

The most reliable conclusions as regards former conditions of vegetation and climate can be drawn, according to Professor Nehring, from the smaller burrowing mammals, such as the marmots, sousliks, etc. $\mathrm{He}$ is of opinion that a great portion of Northern Europe, where their remains have been 
discovered, must have possessed tundras and steppes, as we find them nowadays in Siberia, and a climate similar to that of Northern Asia. It is presumed that the climate, after the maximum cold of the first stage of the Ice-Age, ameliorated so far as to permit these mammals to exist in Europe.

The natural question, however, which is forced upon us in reading Professor Nehring's interesting and suggestive work is, where did all these steppe animals live during the earlier part of the Ice-Age? No traces of their remains have been discovered in Southern Europe, and it can therefore certainly be affirmed that they could not have lived there. If Central and Northern Europe were uninhabitable for mammals, Central and Northern Asia must have been even more so, and we have to fall back upon the Oriental Region as a possible home of these species during the assumed maximum cold of the Glacial period. In invading Europe from the Oriental Region these Siberian mammals would have taken the shorter route by Asia Minor and Greece, which was open to them. This they certainly did not do, which proves that they came directly from Siberia to Europe without retreating first to Southern Asia.

But it seems to me that there is no necessity for assuming such drastic changes of climate to have taken place at all (compare pp. 75-80). We really have no idea under what precise climatic conditions the Siberian mammals lived in their original home. The only thing we can be certain of is that the 
smaller burrowing mammals would not have chosen a wood to live in, if they could possibly help it. Prairies, or sand-dunes with short grass or shrubs, such as abound in Europe near the sea-coast, would suit these species perfectly. If we suppose Northern Germany to have been covered by sea (p. 156) during part of the Pleistocene Epoch, forests would probably not have grown there for a very considerable time afterwards, owing to the excessive salinity of the soil, but a tract of sandy country would have been left on the retreat of the sea. Possibly a slight change of climate in the original home of these steppe-species may have reduced their habitable area, and thus caused their migration into Europe.

But this migration problem cannot be solved without tracing the mammals to their place of origin and investigating their early history. This I shall attempt to do presently; meanwhile, it would be interesting to note whether other groups of animals support Professor Nehring's steppe-theory.

Among groups other than mammals, the most important, for the purpose of drawing conclusions as to former physical conditions and climate, are the mollusca. Their remains have been well preserved, and are easily identified. Though Professor Nehring argues that the molluscs found along with the small mammals harmonise perfectly with the assumption of a steppe-climate (p. 2I2), I cannot at all agree with him. He enumerates the following sixteen species as having been discovered by him:- 
I. Pupa muscorum.

2. Chondrula tridens.

3. Cionella lubrica.

4. Patula ruderata.

5. Do. rotundata.

6. Helix striata.

7. Do. hispidia.

8. Do. tenuilabris.
9. Helix pulchella.

10. Do. hortensis.

II. Do. obvoluta.

12. Hyalinia radiatula.

13. Succinea oblonga.

I4. Limnæa peregra.

I5. Clausilia sp.

16. Pisidium pusillum.

Only two of these can be looked upon as typically northern species, viz., Patula ruderata and Helix tenuilabris, though both of them are still found living locally in Germany. Some of the others are decidedly southern species, like Chondrula tridens, Helix obvoluta, $H$. rotundata, and $H$. striata. All the rcst live and flourish, for example, in Ireland at the present day, where, as we all know, anything but a dry steppe-climate prevails.

Dr. Kobelt quite agrees with me in thinking that the remains of the mollusca found along with the so-called "steppe-mammals" afford no proof of a steppe-character of the country at the time when they were alive (p. 166). Nor do the mollusca which have been found in England in the Forest-Bed and the succeeding pleistocene strata support such a view. The Forest-Bed, generally regarded as belonging to the Upper Pliocene, I believe to be an interglacial pleistocene deposit-contemporancous with the loess formation in Germany. Of fifty-nine species of land and freshwater mollusca which have been discovered in this bed, forty-eight species, according 
to Mr. Clement Reid (p. I 86), are at present living in Norfolk, six are extinct, two are continental forms living in the same latitudes as Norfolk, and the other three are all southern forms. Not a single species has a particularly northern range. Of the land and freshwatcr mollusca of the South of England in the succeeding pleistocene deposits, six species are now no longer living in the British Islands, but only one (Helix ruderata) can be looked upon as an Arctic or Alpine form. After this short digression on the mollusca, I will briefly recapitulate what is known about the early history of the Siberian mammals, which will assist us in tracing the cause of their migration to Europe.

-We have in Siberia problems quite as difficult of solution as the European ones. Volumes have been written to explain the former presence of Arctic mammals like the Reindeer in Southern Europe, and the most extraordinary demands on the credulity of the public have been made by some geologists in their attempts to account for this comparatively simple problem. In Northern Asia a somewhat similar phenomenon, but much more difficult of explanation, has taken place. Mammals have been found fossil in recent geological deposits in localities where they do not now occur, and apparently the Siberian and the European deposits are of about the same age. Now, however, comes the extraordinary difference. In Europe the Arctic mammals went southward, but in Siberia the Southern ones went northward. Not 
only do we find the Saiga-Antelope, Tiger, Wild Horse, European Bison, Mammoth, and Rhinoceros in the extreme north of the mainland of Siberia; their remains have even been obtained in the New Siberian Islands. As these islands are situated in the same latitude as the northern part of Novaya Zemlya,indeed, not far south of the latitude of Spitsbergen, - the fact of such huge mammals having been able to find subsistence there at apparently quite a recent geological period seems an astounding fact. It may be urged that their bones might have been carried so far north by ice, or by some other equally powerful agency. But Tcherski and all other palæontologists who have examined these northern deposits are unanimous in the belief that these herbivores and carnivores lived and died where their remains are now found. "It is evident," says Tcherski (p. 45 I), "that these large animals could only have lived in those extremely northern latitudes under correspondingly favourable conditions of the vegetation, viz., during the existence of forests, meadows, and steppes." He also is of opinion that the moist climate which evidently prevailed in Europe during Posttertiary (Pleistocene) times must have modified the Siberian climate in so far as to render it milder. The existence of the Aralo-Caspian basin (Fig. I2, p. I 56) must also have tended in the same direction. It appears then that, at the time when plants and animals are believed to have retired southward in Europe before the supposed advancing Scandinavian 
ice-sheet, no agency existed in North Siberia which was able to suppress and to annihilate the forest and meadow vegetation, and drive away the fauna connected with it. We know, continues Tcherski, that such genera as Bison, Colus (Saiga), Rhinoceros, Elephas, and Equus are met with in all horizons of the diluvium of West Siberia. He therefore comes to the conclusion (p. 474), that these and other facts imply that the retreat of the North Asiatic fauna commenced about the end of the Tertiary Era (Pliocene), and that it was continued very slowly throughout the Post-tertiary (Pleistocene) Epoch, without any visible changes in its southward direction, even during the time of the most important glacial developments in Northern Europe. Only after the conditions disappeared which had produced the augmentation of an atmospheric moisture, did the climate of North Siberia become deadly to a temperate fauna and flora. Tundras then spread over the meadow-lands and remnants of forests, whilst arctic animals replaced the large ungulates and carnivores which had wandered far away from their native southern home.

This is Tcherski's explanation of the extraordinary events which he has chronicled, after years of the most arduous labour and under conditions of peculiar hardship. And though his work cannot be overestimated, and his opinions should receive the most careful consideration, yet I fear the explanation will not be looked upon as entirely satisfactory. Every one 
will agree with him that the climate of Siberia must have been greatly moister in pliocene and pleistocene times than it is now. The Aralo-Caspian covered a vast area of South-western Siberia. Freshwater basins existed along the east of the Ural Mountains, while Central Asia was studded over with a number of large lakes, which have now almost entirely vanished. But that the generally assumed refrigeration of Europe must have had a chilling effect on the Siberian atmosphere seems to me evident. That the whole of Northern Europe should have been made uninhabitable owing to the advance of the Scandinavian ice-sheet, while North Siberia at the same time supported forests, meadows, and a temperate fauna, is incredible. At the approach of winter, at any rate, the animals would have been driven southward for thousands of miles to seek shelter from the snows and cold and to obtain nourishment, and it would scarcely have been possible for them to undertake such vast migrations at every season. Professor James Geikie's suggestion (p. 706), that the Mammoth and Woolly Rhinoceros could have survived the Pleistocene Epoch in Southern Siberia, does not appear to solve the problem, as that part of Asia must have participated in the great cold which is said to have prevailed all over Europe.

Let us now concede, for the sake of argument, that the current views regarding the pleistocene climate of Europe are correct. We are told by Professor Geikie that the climate of Scotland during 
part of the Pleistocene Epoch was so cold, that the whole country was buried underneath one immense mer de glace, through which peered only the higher mountain-tops (p. 67). If this was the state of climate in close proximity to the Atlantic, it must probably have been still more severe on the European continent. Now at the present time Siberia has the reputation of being the coldest country in the world, and the mercury of the thermometer is said to remain frozen for weeks during winter, even in the south.

With the prevailing dampness in pleistocene times the snowfall throughout Siberia would have been much heavier than at present, though it would have modified the temperature to some extent. Under such circumstances Southern Siberia could not have been a desirable place of residence for large mammals. It would have been necessary for the Mammoth and the other species referred to, to wander farther into the extreme south of Asia or Europe to find a suitable refuge during the arctic conditions which are supposed to have prevailed in Northern Europe. To quote Professor J. Geikie's own words (p. 706): "They (Mammoth, etc.) would seem to have lived in Southern Siberia throughout the whole Pleistocene period, from which region doubtless they originally invaded our Continent. But with the approach of our genial forest-epoch (penultimate inter-glacial stage) they gradually vanished from Europe, to linger for a long time in Siberia before they finally died out." It is suggested, therefore, by the author that the 
Mammoth and the other mammals whose remains have been discovered on the New Siberian Islands found their way there during one of the late interglacial stages of the Ice-Age. But there is no astonishment expressed by Professor Geikie at the extraordinary change of climate which must have occurred in Siberia to allow of such migrations. I can find no very definite statement in this author's work as to the nature of the climate in Europe during those inter-glacial phases, but he remarks (p. 129) " that the evidence of the Scottish inter-glacial beds, so far as it went, did not entitle us to infer that during their accumulation local glaciers may not have existed in the Highland valleys." There is no evidence, in other words, of the existence in Europe of a milder climate than that prevailing at present. Still less can there be any ground for the supposition that the climate of the whole of Siberia ameliorated to such an extent that forests and meadows could develop as far north as the New Siberian Islands; for if the temperature in Europe was then about the same as now, that of Siberia could not have been vastly higher than it is at present.

It is highly improbable, therefore, that a sufficiently mild climate prevailed in the extreme north of Siberia during the so-called later inter-glacial periods to induce the mammals to which I have referred to seek fresh pastures there.

The late Professor Brandt, one of the highest. zoological authorities in Russia, was of opinion that 
at the commencement of the Glacial period the great mammals of Northern Siberia either perished or migrated southward. From there they gradually penetrated into European Russia. He believed that before the Glacial period a connection existed between the Aralo-Caspian Sea and the Arctic Ocean, carrying warm water northward. The gradual disappearance of this marine channel caused a decrease of warmth in Northern Asia, so that large accumulations of frozen soil and ice were formed, which still more depressed the temperature. This, he suggested, probably took place at the time when the Glacial period commenced in North-western Europe.

It has been urged against these views of Tcherski and Brandt, that the bone beds in the Liakov Islands (New Siberian Islands) rest partly upon a solid layer of ice of nearly seventy feet thick. This mass of ice, it was thought, must have accumulated during the Glacial period. As the bones rest upon it, the mammals could only have lived in those islands in more recent times, after the Ice-Age had passed away. Nothing, apparently, can be clearer, and yet in the face of this seeming proof one feels, as I have mentioned before, that if such an extraordinary revolution of climate as is implied by this admission had taken place, we should be able to perceive the traces throughout the northern hemisphere. In this dilemma, a suggestion made by Dr. Bunge, who visited the New Siberian Islands recently at the instance of 
the Imperial Academy of St. Petersburg, helps us out of the difficulty. He found that, as a rule, these so-called fossil glaciers contain seams of mud and sand, and he argued that the ice had formed, and is still forming at the present day, in fissures of the earth. I entirely concur with this view. Neither palæontology nor the geographical distribution of animals lend any support to the other theory, and I think we may conclude that Brandt's view in the main is probably the correct explanation of the phenomena which we have discussed. Some important facts of distribution are more easily explicable on this assumption. Why, for instance, should the Siberian fauna of pliocene times have remained in Siberia and not have migrated to Europe at that time? The pliocene mammals of Siberia are mostly of southern origin. Their range increased enormously during the epoch throughout Northern Asia. We should expect them, therefore, to have crossed the Caspian plains, or even the low-lying Ural Mountains, to pour into the neighbouring continent. But Professor Brandt explained how they were prevented from spreading west. An arm of the sea strctched from the Aralo-Caspian to the Arctic Ocean, thus raising an effectual barrier between the two continents. There is some evidence for the belief, as we shall learn presently, that this marine barrier existed also during the early part of the pleistocene epoch. After having greatly expanded during pliocene times, the fauna of Siberia gradually withdrew from the 
northern regions during the earlier portion of the succeeding epoch. It was only after the marine connection above referred to ceased to exist, or became disconnected, that an entry into Europe was possible.

A fauna, to some extent composed of species now inhabiting the steppes of Eastern Europe and Siberia, poured into the neighbouring continent. On p. 95 I have given a list of those which reached as far west as the British Islands, but, as I mentioned, many other species came from the east about this time. With regard to the early history of the Siberian mammals, I favour a view somewhat between that of Tcherski and that of Brandt. The outpouring of the fauna into Europe seems to me to indicate that there was a sudden change of climate in Siberia. This was produced, perhaps, by the rupture of the marine connection between the Arctic Ocean and the Aralo-Caspian. Such an event would not only have caused the sudden shrinkage of the area available for food-supply by lowering the temperature in Siberia, it would have acted also as a means in assisting the fauna to enter a new continent where an inconsiderable number of mammals, already established, were mostly dispossessed of their homes by the advancing eastern host.

Brandt's theory, however, of a marine connection between the Arctic Ocean and the Aralo-Caspian is by no means generally accepted. That the Caspian Sea was at that time greatly larger than it is at 
present, and joined to the Sea of Aral and the Black Sea, is acknowledged by everybody. That the deposits laid down by this huge inland sea reach as far north as the shores of the river Kama, in Central Russia, is also well known to geologists. But what comes rather as a surprise, is that Professor Karpinski, whom we must take as one of the highest authorities on the geology of Russia, asserts that this Aralo-Caspian Sea was probably joined by a system of lakes or channels to the Arctic Ocean (p. I83). He was by no means the first, though, to put forward such a theory. We have already learned that Professor Brandt held a somewhat similar view, though he believed in something more than a connection by mere channels, and Mr. Köppen, and also the Russian traveller Mr. Kessler, agreed with him. So much was Professor Boyd Dawkins impressed with their arguments at the time, that he wrote (c, p. I48): "Before the lowering of the temperature in Central Europe, the sea had already rolled through the low country of Russia, from the Caspian to the White Sea and the Baltic, and formed a barrier to western migration to the Arctic mammals of Asia."

In one particular Professor Dawkins's views differ from those of almost all the previous writers. His connection between the Caspian and the Arctic Ocean is placed to the west of the Ural Mountains, while it had always been assumed by the Russian writers to have lain on the eastern or Asiatic side of that mountain range. Thus, when Tcherski in recent 
years announced that the tract on this eastern side of the mountains was covered by freshwater deposits, his discovery seemed once for all to settle the problem of the arctic marine connection in the negative. As Professor Dawkins's theory has, however, received much additional affirmative evidence by current faunal researches, a connection between the Caspian (or Aralo-Caspian) and the Arctic Ocean (White Sea) may have actually existed within recent geological times.

What relict lakes are, has already been explained (p. I76), and their fauna will again be referred to in a subsequent chapter. I might perhaps be allowed to repeat that such lakes are supposed to have been flooded by, or to have been in close connection with, the sea at some former period. Many of the Swedish lakes are spoken of as relict lakes (Reliktenseen), because they contain a number of marine species of animals which have now become adapted to live in fresh water, but all of whose nearest relatives inhabit the sea. One of these, the schizopod crustacean Mysis relicta,-a shrimp-like creature,-which was formerly believed to inhabit also the Caspian, is of particular interest. More recently, the occurrence of this Mysis in the Caspian was denied, but though this denial has been confirmed by Professor Sars in his memoir on the crustaceans of the great Russian inland sea, he has been enabled to add two new species of Mysis to the list of those already known to science. These are $M$. caspia and $M$. micropthalma, and both are 
closely related to the arctic marine Mysis oculata. According to Professor Sars, the genus Mysis as a whole may be regarded as arctic in character. The occurrence of these two species, therefore, in his opinion, points to a recent connection of the Caspian with the Glacial Sea.

A large number of other crustaceans have been described by the same author from the Caspian. Of the order Cumacea, which is exclusively marine, ten species are mentioned, but none of these seems to range beyond the Caspian. Among the smaller species of crustaceans, a minute pelagic copepod (Limnocalanus grimaldii) also inhabits the Baltic and the Arctic Ocean. The marine isopod Idotea entomon, related to the common wood-louse, has a similar distribution.

Genuine Arctic species of Fishes do not seem to occur in the Caspian, though some, viz., Clupea caspia, Atherina pontica, Clupionella Grimmi, and Syngnathus bucculentus, are almost certainly the descendants of marine forms.

The Seal of the Caspian (Phoca caspica) is closely allied to the Arctic Seal, and its presence alone in that sea indicates that at no very distant date-at any rate since pliocene times-a closer connection with the Arctic Ocean existed than at present.

I am sure it will be readily granted that there is zoological evidence for the belief of such a connection or union between the two great seas. However, it may be urged that owing to the presence of an ice- 
sheet in Northern Europe during the Glacial period, such a connection must either have been pre-glacial or have existed after that period. But the connection must have occurred at a time when the Caspian

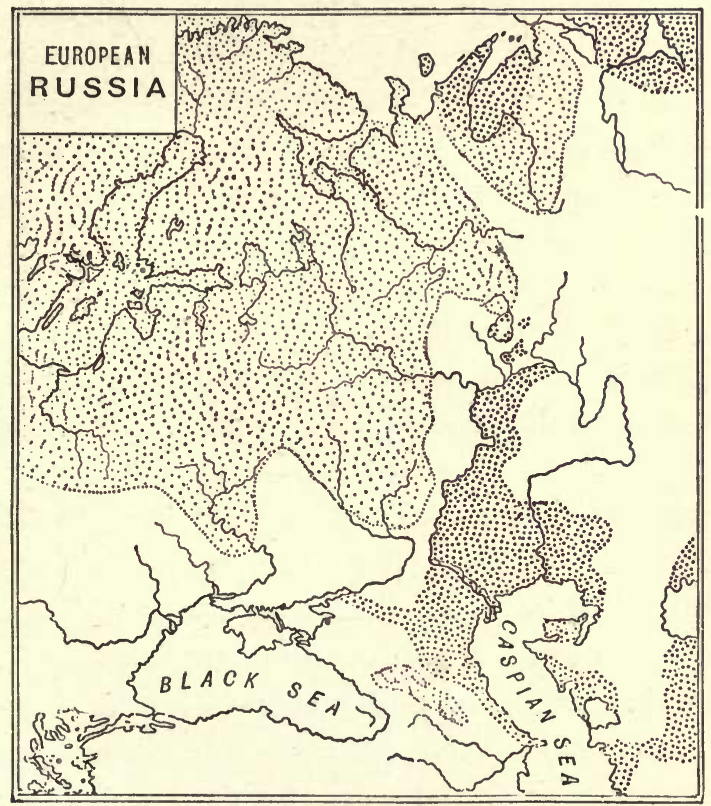

FIG. 17.-Map of European Russia (after Karpinski). The faintly dotted parts indicate the areas covered by bou'der-clay, the strongly dotted ones those exhibiting Aralo-Caspian and other post-pliocene deposits.

extended far to the north-when indeed the so-called post-tertiary Caspian deposits were laid down (Fig. I7). Since the boulder-clay which covers the plain of Northern Russia is assumed to be the ground- 
moraine of the great northern ice-sheet, we might expect to find that the Caspian deposits were not contemporaneous with it. Curiously enough, it has been shown by Mr. Sjögren that all observations have pointed to the fact that these two deposits do not overlie one another, but occur side by side, and are therefore contemporaneous. This seems to warrant our belief, that while the boulder-clay was being laid down in Northern Europe, the AraloCaspian Sea had some communication with the White Sea.

The boulder-clay of Northern Continental Europe, as already stated, is now generally recognised to be the product of a huge ice-sheet which invaded the lowlands of Continental Europe from the Scandinavian mountains. Though Alpine glaciers at the present day produce little or no ground moraine, these ancient larger ice-sheets, or "mers-de-glace," are believed to have deposited immense layers of mud containing scratched and polished stones. Many of the latter have been carried great distances from their source of origin. The Scandinavian ice-shcet is supposed to have advanced as far south as the line indicated on the map, after which it gradually retreated. On this point, however, as in almost every detail connected with the Glacial period, geologists are at variance. Professor James Geikie maintains, that there were no less than four Glacial periods, separated from one another by milder inter-glacial phases. On the Continent the view of two Glacial 
and one inter-glacial period is, I think, more generally adopted. Professor Geikie's four periods seem to me to have originated in a desire to correlate the British pleistocene deposits with the continental ones, and at the same time to retain the old view of the inter-glacial position of the Forest-Bed. The two theories agree in so far as that in both the glacial conditions culminate in a maximum glaciation, followed by a more temperate phase of climate, with conscquent retreat of the ice-sheets, and finally by a renewed advance of the glaciers.

We are told that there is not the slightest doubt about it that a marked but gradual decrease of temperature took place all over Europe either during the beginning of the Pleistocene or towards the end of the Pliocene Epoch.

We might reasonably suppose, then, that a similar climatic effect was produced in Siberia, in consequence of which the fauna would have been obliged to retreat from the extreme northern latitudes southward. No doubt great efforts would have been made by the members of the Siberian fauna-at any rate by those possessing strong power of locomotion-to extend their range in other directions. But we have no evidence that a migration from Siberia came to Eastern Europe at that time. It seems, therefore, as if the barrier referred to by Brandt, Köppen, Boyd Dawkins, and others (p. 222), had existed at this time. This would have effectually prevented an overflow of 
the fauna from Siberia. Only in deposits later than the lower continental boulder-clay do we find traces of a Siberian migration. The time of maximum glaciation had then passed away; the great glacier which was believed to have invaded the lowlands of Northern Europe had again retreated, before the Siberian mammals made their appearance in Germany.

It has been stated above (p. 226) that while the Russian boulder-clay was being laid down, the AraloCaspian probably had some communication with the White Sea.

But how can this view be reconciled with the existence of a huge mer de glace in the northern plains of Russia? The existence of the ice-sheet has been conjured up in order to explain the presence of the boulder-clay. But not long ago a very different interpretation of the origin of this clay was given; and one, I may say, which explains the history of the Siberian and the European fauna in a more satisfactory manner than is done by the icesheet hypothesis. It is that the boulder-clay is not the product of land-ice, but has been deposited by a sea with floating icebergs. 'Thus the latter hypothesis does not deny the existence of glaciers, but allows the mud to be deposited on the floor of a turbid sea, instead of beneath an immense mer de glace. I need hardly mention that this view, which was formerly universally accepted by geologists, is now scouted by almost every authority, both British and 
Continental. I should scarcely venture the attempt to revive old memories and stir up again long forgotten controversies, were it not for the fact that many new points have arisen in the course of the above inquiries, which appear to me so very difficult to explain by the land-ice hypothesis, while they are comparatively easy to understand when we adopt the old theory of the marine origin of the boulderclay. But a few geologists even at the present day, while believing in the land-ice thcory, recognise that the marine hypothesis should have some consideration shown to it. I need only remind glacialists of the work recently published by Professor Bonney. "The singular mixture," he remarks (p. 280), " and apparent crossing of the paths of boulders, as already stated, are less difficult to explain on the hypothesis of distribution by floating ice than on that of transport by land-ice, because, in the former case, though the drift of winds and currents would be generally in one direction, both might be varied at particular seasons. So far as concerns the distribution and thickness of the glacial deposits, there is not much to choose between either hypothesis; but on that of land-ice it is extremely difficult to explain the intercalation of perfectly stratified sands and gravels and of boulderclay, as well as the not infrequent signs of bedding in the latter."

Now with regard to the land-ice theory, several serious difficulties present themselves in connection with the origin of the European fauna. In the first 
place, as the climate renders Northern Siberia almost uninhabitable for mammals at the present day, how much more severe must it have been during the time of the maximum glaciation in Europe. As the then existing fauna was not driven into Europe, where could it possibly have survived? Secondly, how can we reconcile the contemporaneous existence of a great inland sea (the Aralo-Caspian) containing survivals of mild Sarmatic times with an immense glacier almost touching it on its northern shores? How did one of the most characteristic species of that sea, Dreyssensia polymorpha, come to make its appearance in the lower boulder-clay of Prussia and then disappear in the upper? And finally, how are we to explain the sudden appearance of a Siberian fauna after the deposition of the lower boulder-clay, except by the removal of a barrier which had prevented their egress from Siberia?

If we assume that the continental boulder-clay of Russia has been formed in the manner so ably explained by Murchison, de Verneuil, and von Keyserling, viz., by a sea with floating icebergs, the temperature of Siberia might have been higher than at present, and have supported a fauna in more northern latitudes.

The contemporaneousness of the deposits of this sea with those of the Aralo-Caspian is also rendered more intelligible. If we suppose, moreover, the connection between the Aralo-Caspian and the White 
Sea (Fig. I2, p. I 56) to have existed at this time, we possess an explanation of the method of migration of the Arctic marine species into the Southern and of the Caspian species (Dreyssensia) into the Northern Sea.

An inter-glacial phase is believed to have supervened after the deposition of the lower boulder-clay, and it is during this period that the Siberian species first appeared in Central Europe. If we assume then that the retreat of the Northern Sea (Fig. I 3, p. I70) opened up a passage for the Sibcrian fauna, we have in this very fact also an explanation of the extraordinarily large exodus of Asiatic mammals, because the great reduction of the marine area in Northern Europe would have had an important influence in lowering the temperature in Asia. Only a sudden change of climate in Siberia could have brought about the migration of the vast hordes of Asiatic mammals whose remains we find in Central and Western Europe in deposits of that period.

Throughout this work we are made acquainted with facts which bear out the view that the climate during the greater part of the Glacial period was mild rather than intenscly arctic in Europe. That a huge ice-sheet could have covered Northern Europe under such conditions appears to me very doubtful. No one can deny, however, that glaciers must have existed during the Glacial period in all the mountainous regions of Central and Northern Europe, though their existence is not incompatible 
with a mild climate. Tree-ferns and other tropical vegetation grow at the foot of glaciers in New Zealand. We need not even go so far afield, for in Switzerland grapes ripen and an abundant fauna and flora thrive in close proximity to some of the wellknown glaciers.

One matter of importance still remains to be considered before concluding this chapter, viz., the fauna contained in the English geological deposit known as the "Forest-Bed." This interesting deposit is exposed at the base of a range of cliffs on the coast of Norfolk. It is composed of beds of estuarine and marine origin. The tree-stumps formerly believed to be the remains of trees in situ have, after more careful examination, proved to be in all cases drifted specimens. A portion of the "Forest-Bed" no doubt was laid down in close proximity to a large river, and subject to being periodically flooded by it. It is not absolutely certain, therefore, that all the mammals whose remains occur in this deposit lived in England or whether only on the banks of the river farther south. Nevertheless, we may take for granted that some of them did. England was at the time connected with France and Belgium, and for our purpose it matters little whether they had crossed the Channel or inhabited those parts of the Continent through which the great river flowed which sent its alluvial detritus as far as the plains of Norfolk. All we have to remember is that certain mammals, which appear to have 
originated in Siberia, and of which we have some evidence that they crossed Central Europe in their westward course, had now reached the great river just alluded to, which some geologists believe to have been the Rhine.

I have had occasion to refer to a number of British mammals (p. 202) - some of which are now extinctwhich I believe to have migrated across the plains of continental Europe direct from Siberia. There were twenty-six species of these Siberian mammals; and no less than ten of these occur in the Forest-Bed. None appear in any older British deposit. It is perfectly clear, therefore, that the Forest-Bed must have been laid down after their immigration into Europe. They probably wandered to Western Europe very soon after crossing the eastern boundaries of our continent; the deposits in which they are found are therefore contemporaneous. But we have learned above (p. 208), that the beds in Eastern Europe in which the Siberian mammal-remains are found are more recent than the lower boulder-clay. As already stated, the Forest-Bed must also be more recent than the lower continental boulder-clay, and should be included in the pleistocene series.

That the Forest-Bed is an inter-glacial deposit has been urged long ago by various writers. Professor Geikie regards it as stratigraphically contemporaneous with the peat and freshwater beds below the lower diluvium of Western and Middle Germany, and as having been laid down during the first Inter-glacial 
Epoch of the great Ice-Age. The fact that no boulder-clay underlies the Forest-Bed seems rather a strong argument against the view of its being an inter-glacial deposit. It lies directly on what is known as the Newer Pliocene Crags. If the ForestBed is included in the pleistocene series, as I suggested it should, the crags, or a portion of them, would therefore be equivalent as regards time of deposition to the lower continental boulder-clay. And again, if the lower continental boulder-clay is contemporaneous with the Newer Crags, the latter should also be classed with the pleistocene strata. I can scarcely hope that geologists will be ready to admit such a sweeping change of nomenclature without a protest. I venture, therefore, to explain more fully my reasons for adhering to these unorthodox views.

Let us look once more at the map which I constructed (Fig. 12, p. 156) to elucidate the migration of the Arctic terrestrial species to the British Islands. It will be noticed that one continuous ocean extends from the east coast of England across Holland, Northern Germany, and Russia to the White Sea. At the same time Greenland and Northern Scandinavia, Scotland and Southern Scandinavia, are united by a narrow strip of land, and so are England and France. The waters of the Atlantic and this North Europcan Sea do not therefore intermingle at any point, the two seas being absolutely independent of one anothcr. 
Such I assume to have been the geographical condition of Northern Europe during the deposition of the Red Crag. Arctic mollusca were then brought to the east coast of England, and boulders were scattered through the beds laid down on that coast by icebergs which had been cast off by Scandinavian glaciers on reaching the sea. Bedded clays which have yielded arctic shells lie beneath the lower continental boulder-clay on the Baltic coast-lands and on the coast of the White Sea. According to Professor Geikie, marine clays on the same geological horizon reach an elevation of some 230 feet. "It would seem, then," he says, "that before the deposition of the lower boulder-clay of those regions the Baltic Sea had open communication with the German Ocean" (p. 442). All these clays are evidently deposits of the same sea. But apart from the fact that the Red Crag and these Baltic deposits are the oldest of the upper Tertiary beds containing arctic shells, there is no evidence that they are contemporaneous.

Overlying the same Baltic deposits comes the lower boulder-clay, reaching a thickness of several hundred feet in some parts of Germany. It presents, like the upper clay, frequent interstratification with wellbedded deposits of sand and gravel. The scarcity of marine mollusca, the occurrence of striated surfaces, and the occasional presence of so-called giants' kettles, appear to favour the view, which at present is generally adopted by both British and Continental geologists, that the boulder-clay owes its origin to 
land-ice. I have stated on several occasions that the view of the marine origin of the boulder-clay agrees best with the known facts of distribution, and with the history of the European fauna (pp. 80-86, and p. I29). It may be urged that if the lower boulderclay were contemporaneous with the British Crags which succeeded the Red Crag, how can we explain the fact that these crags contain plenty of shells, while in the lower continental boulder-clay there are scarcely any?

But as yet our knowledge of the conditions of life of the marine mollusca and of their distribution is extremely scanty. We are apt to imagine that the bottom of the sea is covered by a more or less uniform thick layer of shells; but whenever a careful survey of the nature of the deposits now forming there has been made, such is by no means found to be the case. Some of the best results obtained by that useful body, the Liverpool Marine Biological Committee, have been precisely in this direction. A most interesting account has been published by Professor Herdman and Mr. Lomas on the floor deposits of the Irish Sea, in which the authors state (p. 217), that "a place may be swarming with life and yet leave no trace of anything capable of being preserved in the fossil state, whereas in other places, barren of living things, banks of drifted and dead shells may be found, and remain as a permanent deposit on the ocean floor."

Owing to the fact of the peculiar geographical 
position of Scandinavia at this time-an isthmus of land with a high mountain range lying between the warm Atlantic and the cold Arctic Sea-the snowfall must have been excessive, and large glaciers were evidently forming. These produced icebergs as soon as the lower parts had advanced to the Baltic coastland and deposited their detritus in the sea. Immense masses of mud and stones were thus cast to the bottom of the sea, and under these circumstances no delicate mollusca or other marine life probably could have developed within a considerable distance from the shore. To judge from the direction pursued by the majority of the boulders from their source of origin, the prevailing current during the deposition of the lower boulder-clay was from north-west to southeast. It is possible that little marine life, except frec-swimming forms, would have been able to live within the Russian area of this sea. But the freeswimming larvæ of molluscs and other surface species were not prevented from passing from the White Sea south-westward, and in sheltered localities where little or no mud deposition was going on, these no doubt might have developed into adults on the sea-floor. It is quite conceivable, therefore, that in one portion of the North European Sea, which was fully exposed to the destructive influences of the iceberg action, the fauna was scanty or totally absent, while in another part there lived a fairly abundant one. The unfossiliferous state of the lower continental boulder-clay does not, therefore, offer any serious 
difficulty to the supposition that some of the socalled Newer Pliocene Crags of the east coast of England were laid down at the same time by the same sea.

This would also explain how the Arctic species come to inhabit the Caspian, as the old Aralo-Caspian Sea could have had some communication (Fig. I2, p. 156 ) with the North European Sea. And this again offers an explanation of the otherwise mysterious occurrence of the Caspian Dreyssensia polymorpha in the lower continental boulder-clay.

The climatic reasons for the supposition that the boulder-clay is a marine deposit have already been given (p. 66). However, it may be asked what about the glacial flora which has been proved to have existed all over the plains of Northern Europe ?-what about the relics of this same flora which still linger on in a few localities to the great delight of the systematic botanist? They have been spoken of as indications of a former Arctic climate in Europe. The presence of an Arctic species such as Dryas octopetala in any of the pleistocene deposits is often looked upon as an absolute proof of a very severe climate having prevailed at the time they were laid down. Professor Gcikie tells us that the South of England was clothed with an Arctic flora, when the climate became somewhat less severe than it had been during the climax of the glacial cold (p. 398). Relics of such a flora have been detected at Bovey Tracey, in Devonshire, the Arctic plants found comprising 
Betula nana and B. alba, Salix cinerea and Arctostaphylos uva-ursi.

Now three of these four species of plants are still natives in the British Islands, and all are forms which probably came to us with the Arctic migration which I described in Chapter IV. They travelled south with the reindeer, or before it, and may have covered large tracts of country at the time. With the increased struggle for existence on the arrival of the Siberian and Oriental migrants, they have probably been evicted by these more powerful rivals. A discovery of their remains does not necessarily indicate that a great change of climate has taken place since they lived in the country. And certainly these Arctic plants cannot be taken as indicating a low temperature, for it has been shown that Alpine plants are mostly intolerant of very low temperatures. "Arctic and Alpine species in the Botanical Gardens at Christiania," says Professor Blytt (p. I9), "endure the strongest summer heat without injury, while they are often destroyed when not sufficiently covered during the winter." Similar observations have been made in other countries. For this reason they have to be generally wintered in frames in the Botanic Gardens at Kew and Dublin, and are thus exposed to higher temperatures than at present obtain in the British Islands. This fact suggests that the Alpine and Arctic plants really did not originate in countries with cold temperatures. They probably made their first appearance long before the Glacial period- 
perhaps in early Tertiary times-chiefly in the Arctic Regions, which at that time had a mild climate. They have since become adapted to live in cold countries where they flourish, provided they receive sufficient moisture in the summer, and are protected from severe frost in the winter by a covering of snow.

When we carefully examine the present range of Arctic plants in the British Islands, a curious fact presents itself which no doubt has frequently been noted by botanists, viz., that some of the most characteristically Arctic species, and some which are often quoted by glacialists in support of their theories, flourish at the present moment in very mild situations. I have already referred to the fact that the Mountain Avens (Dryas octopetala) abounds in the west of Ireland (County Galway) down to sealevel. Now it is well known that the mean winter temperature of that part of Ireland resembles that of Southern Europe, being no less than $12^{\circ} \mathrm{F}$. $\left(=7^{\circ}\right.$ Cent.) above freezing point. The plant, of course, is here a native, and not introduced. This instance shows clearly, that as long as more vigorous competitors are absent, and as long as it is not exposed to severe frost or undue dryness, this and allied species do just as well in a mild climate as in their native Arctic home.

In his interesting essay on the distribution of the Arctic plants in Europe during the Glacial period, Professor Nathorst adduces the fact that all the localities but one, in which remains of such plants 
have been discovered, lie either within or close to the limits of the maximum extension of the supposed northern ice-sheet, or within those of the former Aipine glaciers. Whether we look upon the boulderclay as a marine or a terrestrial product, it is quite conceivable that, in many instances, the remains of the Arctic plants may have been carried by ice to great distances from where they grew. The probability, however, is in favour of most of them having lived where their remains are now found. Now, it is a remarkable fact, that the single instance in Europe of a deposit of Arctic plants having been found far removed from the maximum extension of the northern ice-sheet is the one quoted above, viz., at Bovey Tracey, in Devonshire. Even up to recent times Arctic plants may have persisted at Bovey Tracey just as they do in Galway under the influence of a mild coast climate. Similar circumstances may have led to their survival along the shores of the sea which deposited the North European boulder-clay, while they moved northward from the Alps along with the glaciers, which always supplied them with an abundance of moisture. Alpine plants probably became exterminated in the plain of Central Europe at a much earlier period.

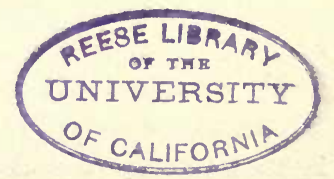




\section{SUMMARY OF CHAPTER V.}

What has been spoken of in the earlier parts of this book as the eastern migration, refers in a general way to the animals which have come to England from the east. But these are by no means natives of one country alone. We can trace a number of the British mammals to a Siberian origin, and also some birds; among many of the lower vertebrates and invertebrates, however, there are few species which have reached us from Siberia. They may have had their original homes in the Alps, in Eastern Europe, or in Central and Southern Asia, and have joined in their westward course the later, more quickly travelling mammals. Many instances are given from all the more important groups of animals to show how we may proceed in approximately identifying the home of a species.

The periodical invasion into our continent of Pallas's Sandgrouse and other birds, suggests an explanation as to the cause of the great westward migration in former times of the Siberian mammals. Since a considerable amount of fossil evidence is available to show the path of migration pursued by these mammals, other important problems, such as the time of their arrival in Europe and the geographical conditions surrounding them, may perhaps be approximately ascertained, and thus throw much light on the general features of the European fauna. It has been proved by Professor Nehring that the Siberian mammals arrived in Eastern Europe after the deposition of the lower continental boulder-clay. He believes that the climate of Germany at that time had ameliorated so far, after the maximum cold of the Glacial period, that steppes with a Siberian fauna could exist. Other groups, such as the Mollusca, however, do not support Professor Nehring's theory, and in order to arrive at an independent solution of this and the other problems referred to, a short history is given of the Siberian 
fauna. Recent geological ages have witnessed the arrival in Southern Europe of mammals now almost confined to the arctic and subarctic regions. In Siberia, on the other hand, many southern species penetrated, apparently about the same time, to the extreme northern limits of that country. The greatest authority on the Siberian fossil fauna, Tcherski, believes that this took place in pliocene times, the gradual retreat occupying the whole of the Glacial period. If this were correct, the retreat from the Arctic Regions would have occurred at the same time when, according to our European authorities, Professors Nehring and Geikie, the much more southern parts of our continent were already uninhabitable. But - Siberia could not have supported the large mammals at all at a time when Europe was uninhabitable, as it would be difficult to conceive under what geographical conditions the climate of the latter was arctic and that of the former temperate. If the whole fauna was driven into Southern Asia, how is it that the Siberian invasion of Europe occurred immediately after the deposition of the lower boulder-clay, that is to say, after the earlier part of the Glacial period? The difficulty can be met by the supposition that both Europe and Siberia had a temperate climate at that time. This view is supported by certain evidences, fully described, of a connection between the Caspian and the White Sea, which would have had the effect of influencing the climate. The Siberian fauna would thus have been prevented from spreading westward in Pliocene and early Glacial times. But on the disappearance of the marine connection, a way would have been opened into our continent, which again had an effect on the climate. The latter would have become sensibly colder and thus have reduced the habitable area of the Siberian fauna.

Such geographical conditions would have been incompatible with a great northern mer de glace, and the boulder-clay in Northern Europe could not have represented a ground moraine but is a marine deposit. The sea is supposed to have covered 
the Northern Russian and German plains, and into it icebergs discharged the detritus which had accumulated on them when they were still Scandinavian glaciers.

As regards the time of the arrival of the Siberian migrants in Europe, the English Forest-Bed gives us an additional clue to its determination. Since Siberian migrants are unknown from earlier deposits than this, it is reasonable to suppose that they arrived in England about the time when it was laid down. But since they appear in Germany in the inter-glacial beds subsequent to the deposition of the lower boulder-clay, the former are probably contemporaneous with the Forest-Bed. Some of the deposits generally regarded as upper pliocene by British geologists would therefore have to be classed with the lower continental boulder-clay as lower pleistocene. In connection with this theory some interesting faunistic data are given which seem to support it.

In conclusion, the former presence of Arctic plants in Central Europe and their bearing on the climatic problems are discussed. 


\section{CHAPTER VI.}

TIIE ORIENTAL MIGRATION.

THE Oriental migration is closely related to the Siberian. Both have originated within the Asiatic continent, and in many respects a strict linc cannot be drawn between them. There can be no doubt that some of the species which we regard as Siberian migrants had their original home in more southern latitudes, and thus may have formed part of the older Oriental migration. The home of that migration I take to be Central and Southern Asia, that is to say, everything south of the Altai Mountains and the Caucasus. Its members have reached Europe across an old land-connection which united Turkey, Greece, and Syria, while the Siberian animals invaded our continent to the north of the Caspian and Caucasus.

The Siberian immigrants into Europe on the whole are not very numerous, but it is different with those from the more southern parts of the Asiatic contincnt. The members of the Oriental migration form a very large percentage of the European fauna. No other migration has affected our continent so powerfully, because it continued uninterruptedly for 
a very long time. Hence its results can be traced from one corner of Europe to the other. We have seen that the Siberian migration only commenced after the first portion of the Glacial period had passed away. The Oriental, however, persisted throughout, or at any rate for the greater part of that period. It commenced ages before it, in miocene times, or even earlier. And as the Egean Sea, which broke up the highway of the Oriental migrants, is only of recent formation, there was a steady westward march for a very considerable time. No doubt the migration was also favoured by the fact that scarcely any formidable barriers had to be crossed.

Many instances might be quoted of the same species forming part of the Oriental and also of the Siberian migration, but as a rule the Siberian migrant belongs to a distinct variety, or has such wellmarked racial characters as to be at once detected from its more southern relative. Among the examples of Oriental migrants which I have occasion to bring forward, such instances will be specially dealt with.

In its wild state the Red Deer (Cervus elaphus) is almost extinct in the British Islands, though it still occurs in the moorlands of Devonshire and Somersetshire in England, in the south-west of Ireland, and in some localities in Scotland. Fifty years ago it was also found wild in several other of the Irish western counties; and in the seventeenth century it was common in most of the mountainous districts of 
Ireland. Its remains have been found fossil in the marls and caves of Ireland, and in the Forest-Bed, as well as in a large number of caves in England. The history of the Red Deer in other countries is very similar. In Scandinavia it flourished as far north as the sixty-eighth degree of latitude, whereas it is now quite extinct on the mainland, though still lingering on in some of the western islands. Denmark and Switzerland know it no more, and it is almost extinct in Belgium. Nearly throughout Europe where it occurs, its numbers are diminishing, greatly owing, perhaps, to the relentless persecution by man, but its gradual disappearance must likewise be partly due to other causes. Formerly it inhabited every country of Europe and all the larger islands. It still exists in Corsica and Sardinia, and at an earlier period it was also met with on the island of Malta. The Red Deer found in Corsica and Sardinia is smaller than that inhabiting Central Europe, and is by some authorities regarded as a distinct species, which has been named Cervus corsicanus. But Sir Victor Brooke has pointed out that the antlers of some of the Scotch Deer agree in every point with those of the Sardinian species. Indeed, the West European Red Deer altogether is a smallantlered form, compared with the Eastern one. This character, however, is only a racial one, and not of specific value. In the pleistocene deposits of Eastern and Central Europe, a very large-antlered race has 
been discovered, and identified by Professor Nehring with Cerous canadensis-the Canadian Red Deer. Tcherski, the Siberian traveller, believed that Cervus canadensis was identical with, or a variety of, the Asiatic species of Deer, Cervus eustephanus, Cervus xanthopygus, and Cervus maral. Some authorities -and to these belong Mr. Lydekker - think that we ought perhaps to regard the whole number of Red Deer-like forms as local varieties of one widelyspread species. Besides the deer already referred to, the following belong to this same group:-Cervus cashmirianus, Cervus affinis, Cervus Roosvelti, from North America, and the North African Cervus barbarus.

The question now is, where have these varieties originated? Or, if we go to the root of the matter, where is the original home of their ancestors? Considering that so many Cervida have been found in French and English pliocene deposits, and that remains of the Red Deer occur not only in the English Forest-Bed, but have been found associated with those of the Pigmy Hippopotamus in Malta, it would only be reasonable to suppose that the genus Cervus had originated in Europe. It might also be argued with equal force that the Red Deer had its birthplace in our continent. But when we carefully study its present range this verdict cannot be accepted. The view of the Asiatic origin of the Red Deer, so ably maintained by Köppen, corresponds far better with its present distribution, 
especially if we look upon the Asiatic, North American, and North African forms as varieties of the same species.

If the Red Deer were of European origin, it must have come into existence at a time when Malta was part of the mainland, when North Africa and the British Islands were connected with the continent of Europe, and of course before the deposition of the Forest-Bed. Such land-connections existed probably during the Pliocene Epoch. Migrants would have wandered from Europe into Asia. These would have developed into larger races, which again furnished emigrants for North America. The latter crossed by the old land-connection which once joined America and Asia at Behring's Straits. During pleistocene times the large Siberian race would now have re-migrated to the home of its ancestors in Europe, for we find the remains only in Central and Eastern Europe, indicating that an invasion of the Red Deer from Asia must then have taken place.

Against this view of the European origin of the Red Deer, it may be urged that deer are known from Indian as well as from European pliocene deposits, and that a migration could have taken place from the Oriental Region to Europe just as easily as from the latter to Asia. The majority of the species of the genus Cervus (in a wide sense), moreover, are Asiatic, ranging to Borneo, Sumatra, and the Philippine Islands, all of which islands have been 
separated from the mainland for a considerable time. Finally, the original home of a species, as we have learned, generally corresponds with the centre of its geographical range, and this lies in the case of the Red Deer in Central Asia.

One of the highest authorities on the deer family, Sir Victor Brooke, also was of opinion that the Cervide originated in Asia, and from there spread east and west. Of the two divisions into which true deer are divided, viz., the Plesiometacarpalia and the Telemetacarpalia, the former is almost confined to the Old and the latter to the New World. The only North American species belonging to the first division is the Canadian Red Deer, which fact clearly indicates its recent immigration to that continent.

There were probably two distinct migrations of the Red Deer into Europe. An older one coming from Asia Minor into Greece, which stocked Sardinia, Corsica, Malta, and North Africa in the first place, when these were still connected with one another. This same migration likewise affected western continental Europe, the Irish Red Deer being probably the descendant of this very ancient stock. The latter entered the island when it was still part of the Continent. The later migration of a larger form came from Siberia and spread mainly over Eastern and Central Europe, but it appears that it also reached England, although there is no evidence of any of these Siberian deer having ever inhabited Ireland. 
The range of this deer, therefore, to some extent corresponds to that of another described on p. 153 . We found then that two races of Reindeer had migrated to the British Islands-one from the Arctic Regions, and the other from Siberia, but that only the former had reached Ireland.

The so-called Irish Elk (Cervus giganteus) has been referred to the Oriental migration, but, as stated below, it has some claims to be regarded as a European. Unfortunately it is now extinct; it seems not unlikely, however, that it inhabited Ireland when man had already made his appearance on the island. Although its remains are found in such extraordinary abundance in Ireland, it certainly did not originate there. It lived also in England and Scotland, and in the Isle of Man, in France, Denmark, Germany, Austria, North Italy, and Russia. Its remains have been discovered even in Siberia. It must either have originated in Europe and then migrated to Asia, or have had its birthplace in Asia and wandered to Europe. There is nothing to lead any one to assert positively that either of these two continents was the one in which the original home of the Irish Elk was situated, and we can only be guided in this case by the history of its nearest relatives. These are the Fallow Deer (Cervus dama). There are two very closely allied species, the Persian and the European, but several others have been discovered in the Forest-Bed and the pliocene deposits of the Auvergne. As no 
remains of the Fallow Deer are known from Asia, it seems probable that it and also the Irish Elk originated in Southern Europe, and only invaded Asia in early pleistocene times.

The Mammoth (Elephas primigenius) is a familiar example among a large number of mammals which have come to us about the same time from Asia by the Asia Minor route. It had a much wider range than the Irish Elk, since its remains have been discovered in a large number of European localities as far west as Ireland, also in Siberia, and even North America. Though we have had Proboscidea in Europe from the Middle Miocene onwards, Mr. Lydekker ( $d$, p. viii.) holds that "our comparatively full knowledge of Lower Miocene and Upper Eocene mammalian faunas of the greater part of Europe and North America, renders it almost ccrtain that neither of those regions was the home of the direct ancestors of the Elephantide; and we must therefore look forward to the discovery of mammaliferous Lower Miocene or Upper Eocene strata in some other region of the (probably old) world which may yield these missing forms."

The genus Elephas makes its first appearance in the Upper Miocene of India. Our European $E$. antiquus is, according to Professor Zittel, probably identical with $E$. armeniacus of Asia Minor, while E. meridionalis agrees in all essential characters with the Indian E. hysudricus. The Indian and European species of fossil elephants altogether are 
very closely related, and the supposition that they all have had their original home in the Oriental Region offers, I think, no serious obstacle. The vicw of the European origin of the mammoth especially is open to very serious objections. It does not occur in any European pliocene deposits, and could not therefore hare originated in our Continent until pleistocene times. That it should then have commenced its travels through Europe and Siberia to the New Siberian Islands and North America seems almost an impossibility. But if we suppose the mammoth to have had its home in India in pliocene times, it could then easily have migrated to all the parts of the world where its remains have been discovered.

Of the Asiatic mammals still living, some have only just crossed the borders of Europe and then died out again. Similar cases have been referred to in discussing the Siberian migration. Thus remains of the camel have been found in Roumania and in Southern Russia in pleistocene deposits. Others have lingered on to the present day. Crocidura etrusca, for instance, still lives in Southern France, Italy, Sicily, and North-western Africa. All its nearest relations are typically Oriental species. In spite of the fact that a Crocidura is known from French and German miocene deposits, the general range of the genus suggests an Oriental origin. In early Tertiary times a section spread into African territory and another castward as far as the island of Timor. This may possibly have happened in miocene times, when 
a few species likewise found their way into Europe. Many other mammals have wandered still farther west, and now form an important percentage of the European fauna.

Of Birds, too, a large number might be mentioned which had their home in Asia and have found their way to Europe with the Oriental migrants. A few instances have already been alluded to, and some additional ones may be specified at random, without attempting to give a complete list.

Some of the Wagtails (Motacilla), as I mentioned in the last chapter, have certainly come to us with the Siberian migration; but others seem to be Oriental, such as Motacilla melanope, which is resident in Southern Europe and migratory in the North. $M$. campestris - the Yellow Wagtail-has a most peculiar discontinuous range. One colony breeds in the British Isles and Western Europe generally, where it is known as a summer visitor, retiring to West Africa during winter; another is found from South-east Russia to Turkestan in summer, and winters in Southern Africa. This fact may possibly be due to two distinct migrations from Asia having taken place: an earlier one from the South-east-that is to say, an Oriental one-and a Siberian one more recently. In this case the members of the two migrations have not become sufficiently differentiated to be regarded as distinct varieties. Though most of the Wagtails have a somewhat northern range, none (except perhaps $M$. 
borealis) are truly Arctic; and indeed, as almost all of them pass the winter in southern latitudes, it may be assumed that they are of southern and not of northern origin.

The Dippers (Cinclus) are practically unknown in the Central European plain, but they occur in Western Europe as far north as Scandinavia, also in the Alps, Carpathians, and Southern Europe, including Sicily and Sardinia. Some authorities distinguish three species, others only one. As a matter of fact, the difference between the three forms is very slight, and their nests and eggs are undistinguishable. Eight other species have been recognised, and all these are either Asiatic or American. As one of the American forms is peculiar to Peru and another to Ecuador and Columbia, and since the genus as a whole is a mountain-genus, it probably is an ancient one. Its European range alone, however, implies that it has inhabited our continent for a considerable time and is no new-comer. We may look upon it as of Asiatic origin. The ancestors have spread east and west, the European species having arrived with the earlier Oriental migrants, and wandered along the Mediterranean at a time when the geographical conditions of that sea were vastly different from what they are to-day.

Not quite so ancient as the Dippers, but likewise Asiatic in their origin, are the Bullfinches (Pyrrhula). The closely allied Pine-Grosbeak (Pinicola enucleator) has already been referred to (p. I9I) 
as a member of the Siberian migration. The distribution of the European Bullinch ( $P$. europaa) is very interesting, as it occurs in two distinct forms, by some authorities regarded as races, by others as species. In all probability these two races owe their origin to two different migrations from the same ancestral stock. We may suppose that $P$. europea came to Europe along with the Oriental migration, spreading chiefly over the south and west, while another branch developed in Siberia into the larger and more brilliant race ( $P$. major), which subsequently entered the neighbouring continent with the Siberian fauna. The latter race inhabits, according to $\mathrm{Mr}$ Saunders, Northern and Eastern Europe, and also Siberia. All the other species-there are eight more-except one, are found in Asia. This one species, which inhabits the Azores, appears to be more closely related to one of the Siberian bullfinches than to the European. It stands isolated, and is an extraordinary instance of discontinuous distribution, as no Bullfinch inhabits either Madeira or the Canary Islands. We must assume that the form connecting it with the Asiatic probably lived in Southern Europe, and has become extinct.

One of the most typically Oriental genera of birds is Placianus, to which our Common Pheasant belongs. Out of twenty species, nineteen are found exclusively in Asia, most of them being confined to the central plateaux of that continent. Only one species passes 
the confines of Asia into Greece, Turkey, and Southern Russia. This is Phasianus colchicus. Formerly, however, the Pheasant appears to have had a wider range in Europe, for three species are known fossil from France. Altogether, it is not quite certain whether the Pheasant is not really an indigenous bird in the British Islands, having survived from preglacial times. It is belicved that the Romans brought it to England, but there is no record of an introduction at that time.

Among the older Oriental bird migrants might be mentioned the Fire-crested Wren(Regulus ignicapillus), which has even occasionally visited England. It becomes commoner as we go south-eastward. In Asia Minor it is more abundant than the Gold-crest; and throughout the ycar it is resident in Southern Europe, where it occurs in Turkey, Greece, Italy, Spain, Sardinia, and Malta. On the opposite shore, in North-west Africa, it again makes its appearance, and its range extends westward to the Canaries (R. teneriff $a$ ) and Madeira ( $R$. maderensis).

The genus to which our common Goldfinch belongs, viz., Carduelis, is also probably of Oriental origin, and may be looked upon as one of the earlier migrants. That species (C. elegans) breeds throughout Europe, except in the extreme north, but it is especially abundant in Southern Europe and North-west Africa. It is also resident in Madeira and the Canaries. Eastward its range extends to Persia. A larger race (C. major) inhabits Western Siberia and crosses 
the European border into Russia. It interbreeds in Siberia with $C$. caniceps, an East Siberian form.

A few instances of Reptiles and Amphibia with a similar range will show that the Oriental migration was not confined to the higher vertebrates.

Two species of the genus Eremias (Podarcis) occur in South-eastern Europe. This is a genus of Lizards with rather a wide distribution, ranging from Central Asia to South Africa southward and China eastward. Altogether there are twenty-four species, two of which just enter Europe; and of the rest half are Asiatic and half African. Even if the genus were of African origin, it is extremely unlikely that the Asiatic species came by way of Europe. We may assume, therefore, with a fair degree of probability that the two European species wandered westward along with the Oriental migrants.

The genus Ablepharus belongs to a family of Lizards in which the legs are either very fully developed, or quite absent as in the Slow-worm (Anguis fragilis). It is an ancient genus, having a wide range from Central Asia to Australia on the one hand, and to South Africa on the other. One species of this Scink-like Lizard, viz., Ablepharus pannonicus, enters Europe in the south-east, inhabiting Greece as far north as Southern Hungary. In Asia it is found in Syria and North Arabia. This clearly signifies that the Lizard is an Oriental migrant.

Among the Snakes which participated in the 
Oriental migration might be mentioned Eryx jaculus, whose home is probably in Western Asia. It is known in Europe from the Greek islands of Tinos and Naxos, from Turkey and Southern Russia. Another, a peculiar worm-like form, lives underground in damp earth and under stones-Typhlops lumbricalis. This species inhabits the mainland of Greece as well as the Greek islands, and Asia Minor as far as the Caucasus.

A most interesting case of distribution is that of the pretty little Toad so well known on the Continent under the name of "fire-toad" (Bombinator igneus). Though some authorities, such as Boulenger, recognise only one form of Bombinator, ${ }^{1}$ others are of opinion that two well-marked varieties exist in Europe. These are looked upon by Dr. von Bedriaga as good species, but he acknowledges that they are rather critical and difficult to identify. No other species of Bombinator occur in Europe. Bombinator pachypus, the western race,-or if we choose to call it species,-occurs in France, Germany, Switzerland, Austria, Sicily, and Greece. B. igneus-the eastern race-is found in Southern Sweden, Denmark, Germany, Austria, and Russia. The latter has therefore a more northerly and easterly range. The species is not known from Siberia, but makes its appearance again in China in a form which, according to Dr. von

1 Since writing the above account, Mr. Boulenger, in his new work on the Batrachia of Europe, has accepted the specific distinctions between the two fire-toads. 
Bedriaga, does not quite agree with either of the two European races.

Now if we supposed Bombinator to have originated in Europe, its absence from the British Islands, most of the Mediterrancan islands, and the greater part of Scandinavia would not be easy of explanation, while as an Asiatic migrant the European range is more readily understood. Its apparent absence from Western Asia might quite likely be due to the fact that the zoology of that part of the Continent is only now being investigated. The latter has, moreover, undergone great physical changes in recent geological times. The supposition that one migration of Bombinator from the south-east has taken place, and then another from the east, seems to explain this case of distribution, as other similar ones, in a most satisfactory manner.

The Tree-Frog (Hyla arborea) must be an ancient species, but it is not of European origin. Few genera of Amphibia have a wider distribution than Hyla. There are only three species in Asia, Europe, and Africa, the remaining 129 being confined to America and Australia. Two of the three Old World Treefrogs are so closely allied that until recently they were regarded as mere varieties of one another. These are Hyla arborea and H. chinensis. The former is found in Asia Minor, Persia, China and Japan, and in most of the Mediterranean islands and Southern Europe generally. It does not occur in the British Islands, Norway, or North Russia, but in 
South Sweden, Germany, France, and Spain. It is also known from North Africa and from Madeira, the Canaries, and the Salvages. The occurrence of the Tree-Frog on so many of the Mediterranean islands is of particular interest, especially as four well-marked varieties have been distinguished by our leading herpetologists, so that the more minute features of the various forms can be traced from island to island, adding one more proof-if proof were needed-of their former continuity. Of course, that Hyic arborea must be considered an Oriental migrant scems so evident that it scarcely needs further comment.

A number of mollusca might be mentioned whose range indicates that they have migrated to Europe from Asia Minor. Buliminus pupa is one of these. It is known from Asia Minor, Greece, South Italy, Sicily, and Algeria. Buliminus detritus is perhaps better known, being common in some parts of Germany. From there its range spreads east as far as Asia Minor. Many closely allied species inhabit Western Asia, to which they are confined, while others enter on European territory in some of the Greek islands. B. fasciolatus occurs on the islands of Crete, Rhodes, Cyprus, and in Greece and Syria. Most of the species of Buliminus have a very restricted range, but Buliminus obscurus is found almost all over Europe, from Ireland in the west to the Crimea and Transcaucasia in the east.

Whether the sub-genus Pomatia of the genus Ifelix - to which the so-called Roman Snail belongs- 
is of Asiatic origin, or whether some of the species have migrated from Europe to Asia, I am not prepared to say; but there can be no doubt that Helix pomatia has reached Western Europe from the east.

On the whole, the number of mollusca which we might point to as having migrated to Europe is not large, the great majority being indigenous to our continent. However, some of the other groups of invertebrates differ very materially in that respect from the mollusca. I cannot leave the consideration of the mollusca without referring to the fact that there appears to be a very important centre of distribution in South-eastern Europe. It is from this centre that many species have spread north and south, east and west. Take, for example, the genus Clausilia, a small land-shell shaped like a pointed round tower, and abundant on old walls and tree trunks. In England we have four species of Clausilia, in Ireland only two. In the greater part of Spain only our common Cl. bidentata occurs. As we go east the number of species rapidly increases. A maximum is reached in South-eastern Europe, where hundreds of different kinds are found. Towards Northern Europe a similar decrease of species takes place. So far the history of the Clausilice seems perfectly simple. An active centre of origin appears to exist in South-eastern Europe, from which the species radiate out in all directions. But when we come to look more closely into the extra-European distribution of the genus, and 
especially when we examine its past history, we find that its origin is extremely complex, and dates back to a much more remote period than would have been imagined, had we merely taken into account its present range in our own continent. Professor Boettger, who is the highest authority on Clausilia, tells us that the genus is known from the earliest deposits of the Tertiary Era. About 700 species are now known, and these have been sub-divided by Professor Boettger and others into a number of sub-genera. Some of these are extinct, but the great majority are still living. The sub-genus Phadusa occurs in the eocene and oligocene of Southern Europe, but it is extinct as far as our continent is concerned. Close upon a hundred species, however, still inhabit India, the Malayan Islands, China, Ceylon, and Japan. Then again, the sub-genus Laminifera occurs in the oligocene and miocene of Central Europe, and survives in a single species, Cl. Pauli, in Southwestern France. The groups Garnieria of China, Macroptychia of East Africa, Boettgeria of Madeira, and Nenia of South America, have no fossil representatives. We have here some very remarkable cases of discontinuous distribution which testify to the antiquity of the genus, and this is certainly confirmed by the fossil evidence. However, it is hardly likely that the headquarters, as it were, of Clausilia have always been in South-eastern Europe. Most of that part of the Continent has been sub- 
merged since eocene times more than once. The peculiar distribution of the genus might be explained, I think, if we supposed the original home of Clausilic to have been in Southern Asia, that from this centre Southern Europe was colonised, where a new centre developed in oligocene and miocene times, sending colonies off to Madeira and across the old landconnection which united Northern Africa and South America about that time. The most active centre of development then gradually shifted eastward again, while the older centres were perhaps submerged during the physical changes in the distribution of land and water.

I should have mentioned that the species wandering westward and northward from this South-European centre of distribution, would naturally have joined the migrants which came from beyond the borders of our continent. They might thus appear to be true Oriental migrants, and on a previous occasion I grouped all these together under the term of "Southern Fauna," as I assumed the observer to be stationed in the British Islands. All new-comers from the southeast, south, or south-west of Europe would be to him southerners quite irrespective of their original home, which might be in Southern Europe, Asia, or Africa.

The Swallow-tail is well known to all collectors of Butterflics in England, though it has of late years become very rare and is now confined to a 
few localities in the east of England. The members of the family Papilionida, to which it belongs, are mostly large and striking species, and their distribution is therefore more accurately known than that of the smaller and less conspicuous butterflies. Only four different kinds of Swallow-tail Butterflies inhabit Europe, but in Southern Asia and the Malay peninsula they attain their maximum as regards numbers; and there we find a great many species of this genus Papilio. Of the four European species only one, viz., Papilio hospiton, is peculiar to Europe; all the others range into Asia. It would seem, therefore, as if this genus was an Asiatic one and had migrated to Europe, and that the route taken was the one from Asia Minor across to Greece. We have a similar case in the closely allied genus Thais two of the three European species living also in Asia Minor. Thais cerisyi inhabits some of the Greek islands, as well as the mainland of Turkey and Greece.

Another genus of the great family Papilionida with which most lepidopterists are well acquainted is Parnassius. What butterfly-hunter has been in Switzerland without hearing of, or seeing, the famous Parnassius Apollo? We have four European species of Parnassius, only one of which is peculiar to our continent, but the locality where it occurs, the Caucasus, is on the borders of Asia. Almost all the other species are Asiatic, none however range to the south. Its headquarters, and I think its original home, are the mountains of Central Asia. From there it 
has spread-some species to the Himalayas, and a few to Europe and North America. But these migrations are not of very recent date. Parncissius no doubt arrived accompanied by a large number of other Central Asiatic mountain insects and plants. I shall refer to the latter again when dealing with the origin of the Alpine fauna, but meanwhile it might be mentioned that the famous Swiss "Edelweiss" (Leontopodium alpinum), which we are accustomed to regard as a typical Alpine plant, is certainly of Asiatic origin. In some parts of Southern Siberia it is one of the common meadowflowers, and ranges from there south into Kashmere, but not northward. Like the Apollo, it does not occur in Scandinavia or Northern Siberia. Both plant and insect evidently migrated from Central Asia, directly westward along the southern border of the sea, which extended from that region as far as the European Alps in early Tertiary times. At that time the Caucasus was possibly still connected with the Balkan Mountains, across what is now the Black Sea, and that may have been the highway on which they travelled west.

Some of the Clouded-Yellows-butterflies appertaining to the genus Colias-formed part of the Oriental migration. The genus is undoubtedly of Asiatic origin, and while many of the species have turned northward, ranging across Siberia and North America, others have taken a southern and westward turn and thus reached Europe. We have two 
Clouded-Yellows in Western Europe, and both of them must have come with this migration.

A very good example of an Oriental migrant is Danais chrysippus, a magnificent butterfly found in Greece and Southern Italy. In Asia it is known from Syria, Persia, and from the whole of the southern portion of the Continent. The genus Danais (in its wide sense) is a large one, and principally occurs in the warmer regions of Asia. Three species are found in North America and only one in Europe.

Among the beetles belonging to this migration, there is one of very considerable interest from a distributional point of view, for all the species of the genus-even the whole family to which the genus belongs-are what is known by zoologists as "Commensalists." These are animals habitually associating and living in close connection with others with which they are not tied by any family relations or kinship. Such a state of close and permanent friendship is called "commensalism." Now it appears as if the members of this family of beetles (Clavigeride) had of their own free will formed such a close connection with colonies of ants-sometimes with one species, sometimes another. They are the permanent guests of the ants, and in return they secrete a fluid which is apparently highly prized by them. All of the Clavigers are provided with peculiar club-shaped antennæ, with which they ungraciously beat their hosts, when they are in want of food. According to some authori- 
ties, they even occasionally gnaw at the pupæ and larvæ of the ant with which they live.

Such beetles naturally can only have extremely limited means of distribution, and they are comparable in that respect with the woodlice of the genus Platyarthrus, to which I have already had occasion to refer. All the species of Claviger are confined to Europe, chiefly to the south, but one species, $\mathrm{Cl}$. testaceus, has wandered farther north and occurs in the nest of the ant Lasius flavus in the south of England, Ireland, and Scotland. Though none of the Clavigers can be claimed as Oriental migrants, the centre of distribution of the genera belonging to the Clavigeride is in Southern Asia, and it is probable that the ancestors of the European Clavigers have spread westward from that region to Europe, eastward to Australia and Japan, and southward to Madagascar and South Africa. The genus Hopatroides, belonging to the same family as the so-called Spanish-fly (Tenebrionide), has twelve species in Western Asia and Greece. One only, H. thoracicus-an instance of discontinuous distribution-occurs in Andalusia. Amphicoma is represented in Western Asia and the Balkan peninsula by fifteen species, while three others are met with in North-west Africa and Southern Spain.

A genus of Dragon-fly, Onychogomphus, has in Europe a somewhat similar distribution to Claviger, but it has besides a very extensive foreign range. There are altogether thirty-five species; of these ten are Holarctic, twelve Oriental, five Mascarene, and 
eight Ethiopian. The centre of distribution is therefore in the Oriental region, and we may assume that in all probability the genus has originated there, the European specics having travelled west with the Oriental migration at an early date of the Tertiary Era.

Ryothemis, another genus of Dragon-flies, has originated perhaps somewhat farther east than the last,. for no less than thirteen species are found in Australia, a like number in India, five in Madagascar and Africa, and five in the Holarctic region. Both of these genera are entirely absent from America, and they have possibly travelled to Europe together.

Among the European Orthoptera-the group to which our Earwigs and Grasshoppers belong-there are also a good many instances of Oriental migrants. One of the most striking of these is the curious "praying insect" (Mantis religiosa). It occurs all over Southern Europe, and ranges as far north as the north of France. It is also found in Southern Germany and in Austria, and has a vast extra-European range. There are even rccords of its occurrence from all parts of Southern Asia and Java and a great part of Africa. That it belongs to an extremely ancient genus is testified by the fact of its presence in Mauritius, Japan, Australia, New Zealand, South America, and Madagascar. The genus Bacillus-to which the typical Stick-insects belong-has a somewhat similar geographical distribution. But no less 
than four species of Bacillus are known from Europe, according to our great authority Mr. Brunner von Wattenwyl-all from the south; and some of these also range into North Africa. There are thirty-two other species distributed over Southern Asia, Africa, Australia, New Zealand, and the Sandwich Islands.

Volumes, indeed, might be filled with lists of species and genera of terrestrial invertebrates of Oriental origin, but I will not weary the reader with further enumeration of such instances. Just two more, however, before concluding, as I have not alluded to the large group of the Arachnida.

Two peculiar spider-like genera, viz., Galeodes and Rhax, are found in Southern Europe. Both occur also in North Africa, and in Western and a portion of Southern Asia. As the whole family altogether has an Asiatic character, I cannot agree with Mr. Pocock, who considers them of European origin and believes that they are migrating eastward.

But not only terrestrial forms migrated to Europe from Western and Southern Asia. Freshwater species also took part in this great Oriental migration. I need only refer to the freshwater Crab (Thelphusa fluviatilis), with which Southern Europeans are familiar. It is the sole representative of a large genus which ranges east as far as Australia and southward to Madagascar and the Cape of Good Hope. The European species is found in Turkey, Cyprus, Greece, Southern Italy, Sicily, North Africa, Southern Spain, Syria, and Persia. 
There is a corresponding flora with a range exactly similar to that of some of the animals quoted. Thus the Balkan Rhododendron (Rhododendron ponticum) is again met with in the western Mediterranean region in Southern Spain. The Cedar occurs in local varieties in the Himalayan Mountains, in the Lebanon, and the Atlas Mountains. Both of these are instances of discontinuous distribution, a proof of their antiquity; but a large number of plants have a continuous range between Asia Minor and Spain.

On looking through these few instances of what have been called Oriental migrants, one cannot help being struck by the fact that the species after their entry into Europe evidently did not all follow the same path during their westward advance. We have scen that a good many seem to have travelled either due west or north-west on entering our continent from Asia Minor. They may now perhaps be found in Greece, Southern Italy, Algiers, and Spain, also probably on some of the intervening islands in the Greek Archipelago, in Sicily, Sardinia, and Corsica, or they may have travelled north-east and occur in the Alps. This distribution indicates undoubtedly, as I have already set forth in another memoir ( $c$, p. 459), that land extended from Asia Minor across Greece to Southern Italy, that the latter again was disconnected with Central Italy, but united with Sicily, Sardinia, and Tunis, and that the Straits of Gibraltar did not exist at the time when these species migrated westward. Some species are only to be found as far west as Southern Italy, 
while others occur in Central and Northern Europe, scarcely in the South, and not at all in the larger Mediterranean islands or in North Africa. This appears to me to indicate that the late comers from the east found that geographical changes had taken place in Southern Europe which prevented them from following the same track as the older immigrants. They were now obliged to turn directly northward and then westward. It may be asked, why should not the earlier migrants have taken the same route? This question will be answered immediately. Meanwhile it should be clearly understood that there probably was an older and a newer migration from the east. The Oriental genera-from whose general range we know that they must be very ancient indeed, such as Mantis and Bacillusare almost invariably confined to Southern Europe. There they are frequently found on some of the Mediterranean islands. The earlier migrants therefore went westward and the later ones northward.

Let us now inquire a little into the reasons why such different courses were pursued by the migrants -why the Oriental migration divided into two streams, an older and a newer.

During early Tertiary times, and probably throughout the Miocene and Pliocene Epochs, the Agean Sea did not exist. From the island of Crete to the Peloponnesus, and from Asia Minor to Thessaly and Macedonia, stretched a vast and fertile plain 
dotted over with numerous freshwater lakes. Gradually the sea encroached upon this land from the south, owing chiefly to extensive subsidences having taken place. Only very recently, says Professor Suess, did the whole of the Egean continent subside (i., p. 437). Huge cliffs of levantine freshwater deposits now mark the new coast-line, and the Medi-. terranean advances steadily towards the Black Sea and the Sea of Asov. A new order of things is now established, continues the famous author of Das Antlitz der Erde; where there were high mountains we now behold a deep sea, in some places many thousand feet deep. All this took place quite recently,-geologically speaking,-certainly in postglacial times; and man may even have witnessed these imposing events. Most geologists admit the correctness of these views. They are, moreover, built upon such solid geological evidence, that even if the science of zoogeography had not yet taught us anything, naturalists would not hesitate in accepting them.

Animals and plants were free to migrate from Central and Southern Asia to Greece by land for untold ages. The vast accumulation of mammalian bones which have been discovered at Pikermi, and so ably described by Gaudry, are probably to a large extent the remains of Asiatic immigrants to Europe. Many of these resemble forms still living in South Africa, which implies that a highway existed also at that time between Asia and Africa. Among these is 
a giraffe and antelopes closely allied to African species, and other most interesting mammals.

In still earlier European deposits-the Miocenewe find the ancestors of modern Elephants, which are probably of Asiatic origin. The remains of several kinds of monkeys occur, whose nearest relations are now confined to Southern Asia. Altogether the fauna bears a strong Asiatic facies. Many of our European terrestrial invertebrates probably arrived about this time from Asia. The struggle for existence being keener and the facility for migration much greater in the higher vertebrates, they-or at any rate the mammalian faunas-were subjected to more rapid changes than the invertebrates. I have repeatedly expressed my belief that a great number of our familiar insects and mollusca inhabited Europe long before our present mammals came into existence. ${ }^{1}$

Let us now follow one of the miocene Oriental migrants starting from Central Asia on its way to Europe. Very soon after leaving its home, it must have encountered a sea which extended at that time from the Eastern Mediterranean to the borders of Afghanistan. In following a westward course, the emigrant was compelled to keep along the northern shore of it. We do not know the state of the physical geography of the region between the Black

1 In some cases the accuracy of this view is proved by fossil evidence, Helix rotundata, a common and widely spread British species, having been found in miocene strata near Bordeaux. 
Sea and the Tianshan Mountains, but it seems certain that a considerable extent of dry land enabled a wanderer from Central or Southern Asia to reach the Balkan peninsula by skirting the northern shore of that large miocene sea. No miocene deposits occur north of Teheran or of the Upper Euphrates, nor are they known from the islands of the Egean Sea or the lands surrounding it. From the Balkan peninsula it was possible for our migrant to reach the European Alps, which were then slowly rising as a peninsula out of the western portion of the great miocene sea. What are now the Alps was then hilly ground, which was being raised from the bottom of the sea. It was no doubt connected with the Balkan peninsula, so that an intercourse of species could take place between this newly-formed peninsula and Central Asia. I say peninsula, because the miocene sea almost completely surrounded it. From the Western Mediterranean a wide gulf extended up the Rhone valley into that of the Rhine as far north as Maintz. Then skirting along the northern outliers of the Tyrol, the gulf can be followed as far east as Transylvania. It is quite probable that it extended much farther east still, but there is as yet no geological evidence forthcoming. At any rate, our Asiatic migrant turning northward from the Balkan peninsula found its farther progress barred once more by an arm of the same sea which in its earlier peregrinations had stopped it from going south (cf. Suess, i., p. 406). 
In later miocene times the sea does not secm to have surrounded the Alps to the same extent as it did before, but it certainly extended from the Eastern Alps to the shores of the Sea of Asov, so that the direct northward passage was still more or less barred to the Oriental immigrants. At the same time Alpine species were now able to emigrate to the North European provinces. During the last stages of this epoch, the same sea increased its area very considcrably in an eastward direction. One continuous expanse of water now stretched from the Alps as far as the Sea of Aral in Central Asia, perhaps even farther.

During pliocene times especially, the northern parts of the Balkan peninsula werc occupied by a series of freshwater lakes, while Greece was joined to Southern Italy, Sicily, and Tunis. Central and Northern Italy were represented by a long narrow peninsula connected in the north with the Alps. Corsica and Sardinia were joined to Sicily, and the Straits of Gibraltar did not exist. When I first published my views regarding these geographical conditions of the Mediterranean area, Professor Depéret was good enough to send me his criticisms from a purely geological standpoint. $\mathrm{He}$ is of opinion that though Sicily and Sardinia might at this time have still been connected with Tunis, the Straits of Messina must already have been formed-in other words, Southern Italy and Sicily could no longer have been connected with one another. This opinion is based upon the 
fact that in the upper strata of the enormously thick Sicilian pliocene deposits are found a number of arctic or subarctic species of mollusca which are entirely foreign to the Mediterranean fauna. It is generally supposed that these reached the Meditcrranean area by the newly opened Straits of Gibraltar in later pliocene times, and that the lower Sicilian deposits must therefore have been laid down earlier. So far the deductions are perfectly correct, if we assume the northern mollusca to have arrived in the Atlantic at the time stated. However, they must have reached the Atlantic much later-not till pleistocene timesif we adopt the above-stated suggestions as to the age of the Forest-Bed (cf. p. 125). Moreover, the great similarity between the faunas of Southern Spain and North-western Africa indicate that the formation of the Straits of Gibraltar is of very recent date. The northern mollusca, of course, could not have reached Sicily till later. To suppose that the Sicilian deposits have been uplifted 7000 feet since then is no doubt contrary to all our geological teaching, but we must remember that this is altogether an exceptional case. The area in question has probably ever since been in the immediate neighbourhood of an active volcano, and the rate of the uplift has therefore been immeasurably greater than at other localities with which this one might be compared. The disconnection between Tunis, Sicily, and Southern Italy was evidently produced by a subsidence of the tract of land uniting these countries. If we suppose 
that this happened in early pliocene times, we have either to take for granted that the terrestrial fauna and flora of these countries are of miocene origin, or that they were joined again during the Pleistocene Epoch. The range of a very large number of animals and plants is such as can only be explained by assuming that Tunis, Sicily, Sardinia, Corsica, and Southern Italy were connected with one another. Of such extensive land-connections subsequent to the arrival of the northern marine mollusca we possess, however, no geological evidence whatsoever; and it is extremely improbable that the land-areas which had sunk were once more raised before again subsiding. The many animals whose presence in the Mediterranean Region bears witness to these ancient landconnections could not have arrived there in miocene times-in fact, they could hardly have lived there before the end of the Pliocene Epoch. On the other hand, it seems difficult to believe, once the Straits of Gibraltar were open and the waters of the Atlantic able to enter the Mediterranean, that the sunken parts between Sicily, Italy, and Tunis could have been raised without affecting the entire area of that sea. Nor is it likely that the junction between these countries could have then been brought about by a general lowering of the Mediterranean waters. As it may be asked what evidences we possess at all for the supposition of such land-connections as I have indicated, also that Southern Italy and Greece were connected, a few of the more salient instances 
of distribution bearing on this problem may be of interest.

I have already referred to the occurrence of the remains of a small race of Red Deer in the caves of Malta, similar to those still living in Northwest Africa, Corsica, and Sardinia. The Blackmouthed Weasel (Mustela boccamela) inhabits Persia, Asia Minor, Greece, South Italy, Sicily, and Sardinia, while Mustela africana is found in Malta and Algiers. The European Porcupine inhabits Asia Minor, the island of Rhodos, Greece, Southern Italy, Sicily, North Africa, and Spain. Then we have the Wild Sheep of Asia Minor, Cyprus, Sardinia, and Corsica, all of which are closely allied. The small shrew-like Crocidura etrusca occurs in South France, Italy, Sicily, and North Africa. Many other mammalia might be quoted, but these are sufficient for our purpose.

There are a good many reptiles and amphibians with a similar distribution. The European Chamæleon (Chameleon vulgaris) has been found in South Spain, North Africa, and Sicily. The Snake Periops hippocrepis is confined to Spain, Sardinia, and Greece. The worm-like Lizard Blanus cinereus inhabits some of the Greek islands, North Africa, and Spain. Another Lizard belonging to the Scincide has also been found in some of the Greek islands, Sicily, Sardinia, Southern Spain, and the Canary Islands. Discoglossus pictus-a toad-occurs in Spain, Northwest Africa, Malta, Sicily, Sardinia, and Corsica. 
A varicty of the Tree Frog (Hyla arborea Savignyi) is found in Europe only in Corsica, Sardinia, and the Greek Archipelago.

Eight species of Reptiles and Amphibia-some of which I have just referred to-are enumerated by Dr. Forsyth Major as occurring eastward and westward of the Italian peninsula (and almost all also in North Africa) without being known on the mainland of Italy. And in order to show that Sardinia and Corsica are more closely related to North Africa than to Italy, he indicates the general range of the Reptiles and Amphibians found in these islands. Of the twentyone species, only twelve inhabit Italy, but at least sixtcen North Africa and seventeen Spain. Indeed, he shows that Corsica, Sardinia, Sicily, and Northwest Africa form a zoogeographical province, from which Italy, with the exception of a few localities on its west coast, is excluded. It is a remarkable fact that there are a few localities on the west coast of Italy which in their fauna and flora exhibit closer relationship with Corsica and Sardinia than with the mainland. Thus Dr. Major pointed out that the Catena Mettalifera, the Monte Argentario, and Monte Circeo all belong to what we may call the former Tyrrhenian continent. They are to be regarded as its eastern limits, which remained standing, while the central portion-now occupied by the Tyrrhenian Sea-subsided, and is at present covered by deep sea. Subsequently these remnants of the old continent became joined with 
the newly-formed Italian peninsula, but the plants and animals belonging to the older flora and fauna were mostly destroyed by newer and more vigorous immigrants. A few of the more hardy ones survived, and are a standing testimony of the geographical revolutions of that part of Southern Europe.

That the Mediterranean area has undergone such profound geographical changes as I have endeavoured to indicate is no new theory. Many zoologists who have investigated the fauna of that region, and have attempted to explain the faunistic relations, had to acknowledge that the migrations must have taken place under geographical conditions entirely different from those obtaining at present. Rütimeyer long ago remarked that it seemed to him much more probable that Morocco, Algeria, and Tunis were peopled by way of Gibraltar, and perhaps also by Sicily and Malta from Europe, than Southern Europe from Africa. After careful conchological researches in the Western Mediterranean region, Dr. Kobelt came to the conclusion that formerly Southern Spain and Morocco must have been united by a broad land-connection. Sicily and Algeria do not apparently show any very intimate relationship conchologically, but farther west-in the mountains of Tetuan-Dr. Kobelt discovered a colony of Sicilian forms. ${ }^{1}$

1 There are a great many instances of discontinuous distribution among Oriental Invertebrates. Thus the Freshwater Crab (Telphusa fuviatilis) occurs in Southern Italy, Greece, Turkey, Cyprus, and 
"The close relationship," remarks Dr. Major ( $a$, p. I06), "shown in the fauna of Corsica and Sardinia to Africa, permits the supposition that the connection with these islands had persisted to a much more recent date than that with Europe."

Many other authors have pointed out the close similarity existing between the faunas of Southern Europe and North Africa. We need only refer to the writings of Professor Suess, Milne-Edwards, and Boyd Dawkins. Mr. Blanchard went even so far as to say, "a comparer les plantes et les animaux de la Sicile et de la Tunésie, on se croirait sur le même terrain" (p. 1047).

No less than II 3 species of phanerogamic plants are enumerated by Professor Engler (p. 53) as occurring in the Mediterranean coast region east and west of Italy without being found in that peninsula, or at least only in the extreme south of it., But he tells us that these species represent only a portion of such plants, which are extremely numerous.

In taking a general survey of these plants, Professor Engler is of opinion that their range implies that a large number of the Mediterranean species have migrated along a line which can be drawn between North Africa, Sicily, Greece, Crete, and Asia Minor, and that from this line the distribution started northward again.

Asia Minor. Another crustacean-a Freshwater Crayfish-(Hemicaridina Desmaresti) inhabits Spain, Corsica, Sardinia, Sicily, and Asia Minor. 
Many of these plants then, and also some of the animals I have referred to, formed part of the older stream of migration which entered Europe from Asia Minor (vide Fig. 5, p. II7). There were only two courses open to them as they arrived on our continent during earlier Tertiary times. They could either go straight west towards Greece, or in a more northward direction to the newly-formed Alps. As the latter were raised, some of the immigrants were modified so as to adapt themselves to the new surroundings. Others became extinct; but a great many have persisted in the Alps to the present day and exhibit discontinuous distribution, having meanwhile disappeared in the intermediate tract between the latter and their original home in Asia. The lowlands of Eastern and Central Europe were either occupied by the sea or by large freshwater lakes, so as effectually to prevent a direct migration northward.

When the newer migrants arrived from Asia not only had the Alps risen to a lofty, mountain chain acting as an effectual barrier, but Southern Italy and Greece had become disconnected. Some time after, Sicily and Southern Italy also became separated. Meanwhile the stream of migrants which consisted less and less of typically southern forms, emigrants from Central Asia and even Southern Siberia, mingled with the southern forms on their way to Europe, and these now poured across the newly opened plain of Central and Northern Europe. But it was not until some time after this that the Mediter- 
ranean Sea broke across the Ægean region, and that the Northern Sea retired from the plains of Eastern Russia to admit the typical Siberian fauna and flora into our continent (vide pp. I89-24I).

I cannot close this chapter without referring to the active distributional centre-or I might say, centre of origin-of species situated in South-eastern Europe. No group of animals is more instructive in elucidating the paths of migration from this centre than the terrestrial mollusca. Wherever the original home of the genus Clausilia may have been in early Tertiary times, it is certain that the most active centre of origin is now, and has been for a considerable time past, in South-eastern Europe. One of the earliest migrants from that modern centre of this interesting genus is Clausilia bidentata, which is the only species found in Southern Spain, and one of the two met with in Ireland, and which has been observed in high altitudes in the Alps and in Scandinavia. As we go eastward from Western Europe the number of species of Clausilia, as we have seen, increases until we reach a maximum in the Balkan peninsula and the region of the Caucasus. Limax, Agriolimax, and Amalia, three genera of slugs, likewise appear to have originated in the same region and spread over Europe from there. Some species like Limax maximus and L. marginatus are very ancient, and probably commenced their wanderings in early Tertiary times. In this manner many animals of European origin have joined the Oriental 
migrants in their westward and also in their later northward travels. In a similar way species of plants and animals of Alpine origin might have joined these migrants in their northward course, and it is only when we come to carefully analyse the constituent parts of all these members which have come to us in England from the south, that we realise the complexity of their origin. Finally, even the Siberian migrants mingled with the later Oriental ones, and in some cases the decision as to whether a certain species belongs to the former or to the latter migration becomes a matter of great difficulty.

SUMMARY OF CHAPTER VI.

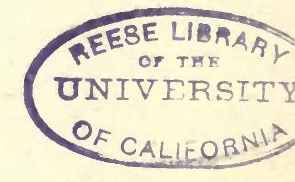

LIKE the last chapter, this deals with the Asiatic migrants. But while the former described the history of the northern invasion, those animals which entered Europe from the southeast are here more particularly referred to. They originated in Central, Southern, and Western Asia. It is not easy to discriminate in all cases between this Oriental migration and the Siberian. To a certain extent, even an entry of Northern Asiatic species has taken place by the southern route, and vice vers $\hat{a}$. On the other hand, southern species might have come to Europe by the southern route-that is to say, to the south of the Caspian-and also by the northern, which lay to the north of that great inland sea. The Red Deer is a good example. It arrived on our continent by both routes. However, there is a racial difference in the members of the two migrations. The small race now found in Corsica, Sardinia, North-west Africa, and Western Europe, is probably the older 
of the two, while the larger one-resembling the American Wapiti Deer-arrived very much later from Siberia.

The Mammoth, Wild Boar, Badger, the Dippers and Pheasants, are all Oriental species which have come to us from the south-east; but there are also Reptiles and Amphibians, and a host of Invertebrates. Not all the animals, for instance, which have reached us in England from the south-east are of Asiatic origin. There is an active centre of distribution in Southeastern Europe itself, from which species radiate out in all directions. This fact is well illustrated by the genus Clausilia. Species from this centre, and also from the Alps, joined the Oriental stream in their northward course.

In reviewing a number of instances of Oriental species in Europe, one is struck by the peculiarity of their having apparently followed two distinct routes. All entered from Asia Minor, which is proved to have been connected with Greece until recent geological times. From here some seem to have proceeded straight west, others northward. Further study reveals the fact that the first route was followed by a much older set of migrants at a time when the Mediterranean area was greatly different from what it is at the present day. Greece was then joined to Southern Italy, Sicily, and Tunis. The latter was also connected with Sardinia and Corsica, and the Straits of Gibraltar did not exist. Under such geographical conditions a direct migration on land from Southern Greece to Spain was not only possible, but was actually undertaken by a very large number of Oriental species. 


\section{CHAPTER VII.}

THE LUSITANIAN FAUNA.

UNDER the Roman Emperor Augustus, the Spanish peninsula was divided into three provinces, one of which-namely Lusitania-occupied a large portion of the present area of Portugal. The term "Lusitanian" is therefore almost synonymous with Portuguese, but it has frequently been applied by zoologists and botanists in a much wider sense, so as to vaguely include the extreme south-west of Europe without any definite limits. Neither do I propose to restrict the term to everything found within the borders of Portugal. For the sake of convenience, we may designate as Lusitanian forms those animals and plants which have migrated to Central, Southern, or Northern Europe from South-western Europe. They may really be North-west African species, or they may have originated on land which lay to the west of Portugal, and which is now mostly buried beneath a deep sea. Nevertheless, we have received them from the extreme south-western portion of our continent -they have come to greater Europe from that direction.

In discussing the component elements of the British 287 
fauna and flora in the third chapter, I have alrcady referred to the distinguishing characters of the Lusitanian migrants and to their distribution. I need only repeat, therefore, that these are now principally confined to the south-western portions of the British Islands. The late Edward Forbes was the first to trace the Lusitanian flora to its native home. In his classical memoir on the geological relations of the existing fauna and flora of the British Isles, he laid the foundations of a new method of research. We are as yet only beginning to realise the far-reaching conclusions obtainable by a careful study of the geographical distribution of animals and plants, though the lines of investigation were indicated by him more than fifty years ago. Forbes was of opinion that the Lusitanian element in the British flora was of miocene age, and that it survived the Glacial period on a now'sunken land to the southwest of Ireland. Mr. Carpenter and myself agree in so far that we are both inclined to look upon this Lusitanian flora and the accompanying fauna in Ireland as of pre-glacial origin. But I am not quite satisfied that the Lusitanian migration ceased to come north then. It may have received a temporary check; but the presence, for instance, of the Dartford Warbler (Melizophilus undatus) in the south-east of England would seem to indicate that its northward migration took place in very recent times. It is possible also that the very restricted occurrence of the Dartford Warbler may 
imply that it is gradually withdrawing towards its centre of origin from a former wider range. Such an eventuality, as we have seen, has actually taken place in a great number of instances.

It is not only in the British Islands that we perceive the influence of the Lusitanian element. Scandinavia, Russia - indeed almost every part of Europe-can boast of some migrants which have originated in South-western Europe or on the mysterious lands which lay beyond it. As a rule, however, we notice a marked decrease of Lusitanian species as we travel eastward from Western Europe. Nevertheless, certain forms have travelled far beyond the confines of our continent, and we certainly meet with them in Asia and Northern Africa.

It is remarkable that we are apt to mistake sometimes for Lusitanian migrants species which are of Oriental origin. In a previous paper I classed such animals which had apparently originated in Southwestern Europe, but had really come from Asia by a circuitous southern route, with the Lusitanians. However, there is really no reason why the two should not be kept apart, provided we can discriminate between the pseudo-Lusitanians and the true ones. I have already indicated in the last chapter how these pseudo-Lusitanian migrants originated.

Supposing an Oriental species had left Asia for Europe in miocene times, it would on its arrival in Greece have had to decide between two courses. It could either advance into the newly-formed Alpine 
peninsula and there remain, or at once push on westward into Southern Italy, Sicily, and Tunis, by means of the old land-connections, and thence into Southern Spain. The Atlantic communicated at that time with the Mediterranean across the valley of the Guadalquivir; but that connection ceased to exist towards the end of the Miocene Epoch, when the Oriental migrants were free to ramble through Spain and the whole of the North European plain. I have indicated on a previous occasion ( $a$, p. 484 ) that the earliest members of the Red Deer migration, which have left their traces in the caves of Malta, and whose descendants still live in Corsica, Sardinia, and North Africa, may have found their way to Northern Europe in this manner. Many other Asiatic mammals probably reached the British Islands in a similar way.

I cannot call to mind any large species of mammal which we might reasonably suppose to have originated in South-western Europe. Even among the smaller ones, few give us any definite clue in this respect. For instance, the present range of the genus Myogale-a small Insectivore belonging to the Mole family (Talpida) - teaches us nothing. The two living species show discontinuous distribution, and are almost confined to Europe. Myogale occurs fossil in French miocene deposits, but is unknown beyond the confines of our continent. It is therefore probably of West European origin. The gap between the South Russian M. moschata and the Spanish $M$.pyrenaica is bridged over in so far as we 
know from fossil evidence that the former had a much wider range in pleistocene times, being then found in England, Belgium, and Germany. Talpa, too,- to which genus our common Mole belongs,seems to be a West European genus, since it occurs in French miocene deposits. However, it would be difficult to name many more recent genera which could be included in the area which I propose to investigate in this chapter. The genus Lepus is probably not of Lusitanian origin, but the sub-genus Oryctolagus-to which our common Rabbit belongs-has no doubt had its original home in that region. Only two species of Lepus (Oryctolagus) are known, one of which-Lepus lacostei-has been met with in French pliocene deposits. The other is the Rabbit (L. cuniculus). Though generally considered to have been introduced into the British Islands, no reason can be brought forward in favour of such a supposition, especially as it is known to have spread into Germany in pleistocene times from South-western Europe. It occurs in France, the Spanish peninsula, North-western Africa, and on some of the Mediterranean islands. Its nearest living relatives, as we should almost expect, are found in South America.

Of the Lusitanian Birds I have already mentioned the so-called Dartford Warbler (Melizophilus undatus), which ranges from the south of England to the extreme south-west of Europe. A second species occurs on the Balearic Islands and on Corsica, Sardinia, and Sicily. The Andalusian Bush-quail 
(Turnix sylvatica) is probably of North African origin, and has subsequently spread into Southern Spain and Portugal, and eastward as far as Sicily. It is an instance of a migrant utilising the old Mediterranean land-connections in the opposite direction from that described in the last chapter.

Two of our British Wagtails are very closely related, so much so that it requires a very critical eye to distinguish them even at close range. They also frequently interbreed. In their distribution, however, there is a considerable difference between the White Wagtail (Motacilla alba) and the Pied Wagtail (M. lugubris). While the former ranges almost all over Europe and Asia, the latter is a local form resident in the British Islands, Southern Scandinavia, and France, and a winter visitor to Spain and North-west Africa. The genus Motacilla is probably Oriental in its origin, but it seems as if the Pied Wagtail was a Lusitanian species which had gradually spread northward, only to return to South-western Europe in severe weather for shelter.

The Bearded Titmouse (Panurus biarmicus)-the only representative of the family Panurida-may possibly be a Lusitanian bird. The fact of its being absent from Scandinavia and Northern Russia is suggestive of a southern origin. It is doubtful whether the bird occurs on the south side of the Mediterranean, but it is common in the south of France and Spain, and has also been observed in Sicily, Greece, and Asia Minor. In Central Europe 
it is found sparingly, and eastward its range extends as far as Turkestan.

The genus Fringillat, which belongs to the great family of the Finches, appears to be not only of European origin, but, if the range of the species counts for anything, I should feel inclined to locate their home in the south-west. Altogether, five species are known. One of them, viz., Fringilla teydea, is confined to the Island of Teneriffe; another, $F$. madeirensis, is found in Madeira, the Canaries, and the Azores; a third, $F$. spodiogenys, inhabits North-west Africa. The two remaining species have a much wider range. $F$. colebs - the common Chaffinch-occurs in Europe, while its range extends eastward to Western Siberia, Persia, and Turkestan. The other $-F$. montifringilla, known as the Brambling-is more common in Northern Europe, and generally frequents the more northern latitudes of Asia as far as Japan.

It might be urged that the peculiar little blue Magpie of Spain-Cyanopolius Cooki-should find a place among the Lusitanian species, since there is no bird like it anywhere else in Europe. But in Eastern Siberia there lives a bird so closely allied as to be barely distinguishable from it. Nevertheless, since there are some distinguishing characters, it has received a distinct name-C. cyanus. This is a most interesting and remarkable case of discontinuous distribution, which may perhaps be explained by the supposition that the genus is of Oriental origin, and 
has died out at its former headquarters in Southern Asia and all along the line of migration, except at the extreme limits of the range in both directionseast and west.

As we go down in the scale of life-among the lower vertebrates and invertebrates - we meet with a greater number of prominent members of the Lusitanian migration. The Bullfinch, Dipper, and Chough, which might be thought to be of Lusitanian origin, are, as I have shown in the last chapter, Asiatic.

The European snakes seem to be all of eastern origin, unless Tropidonotus viperinus might be claimed as a Lusitanian form. Of very great interest from a zoogeographical point of view is our only European member of the South American and African family Amphisbanida. This species-Blanus cinereus-is of the size and shape of an ordinary earth-worm, from which, however, it may be distinguished by its snake-like wriggling motions. It lives under stones in Spain and Portugal, North-west Africa, and Greece. It has, therefore, a somewhat similar distribution to that of many of the animals and plants referred to in the last chapter. But here we have an animal which has evidently utilised the old Mediterranean route described on p. 27I, from west to east. Two other species of Blanus inhabit Asia Minor and Syria, but most of its nearest relations either live in South America or tropical Africa. In migrating to North and West Africa, its ancestors probably made use of the land-bridge which spanned 
the Atlantic in early Tertiary times. Another Lusitanian Lizard-belonging not to an aberrant group, but to the typical Lacertidæ-is Psammodromus hispanicus. It is rather variable in colourgenerally of a brown or green-and grows to a length of about four or five inches. It occurs throughout the Spanish peninsula and also in Southern France. One of the handsomest European Lizards, which reaches almost a foot in length,-of an olive colour with greenish or mother-of-pearl reflection, and with two yellow stripes along each side of the body,-is an allied species ( $P$. algirus). From the Spanish peninsula it passes into Southern France and North Africa. Two other species of the genus are confined to North-west Africa.

It is quite possible that the genus Pelobates is of south-western origin. Of the two known species of this genus of Toads, one is found in the Central European plain and the other on the Spanish peninsula and in France. The closely allied Pelodytes punctatus, too, is confined to this south-western district, and their nearest relations are found in Mexico. Similarly, the genus to which the Midwife Toad (Alytes obstetricans) belongs may have its original home in that part of Europe. Of the two species, one is confined to France, Switzerland, Belgium, and Western Germany, and the other, viz., Alytes cisternasii, to Spain. Discoglossus pictus-a well-known and conspicuous Toad in Southern Europe-inhabits Spain, Algiers, and Tunis, the 
islands of Malta, Sicily, Sardinia, and Corsica. From the general range of the family Discoglosside, as given in Mr. Boulenger's excellent catalogue, it appears that nowhere in the vast space between China and New Zealand has any member of the family been discovered. The peculiar genus of Salamander-Chioglossa - is quite confined to the Spanish peninsula.

The Butterflies Nemeobius lucina and Charaxes jasius may also have had their home in that southwestern district. To this migration also seems to belong the genus Gonepteryx, which has so peculiar a range in the British Islands. The only British species, known as the Brimstone Butterfly (Gonepieryx rhamni), occurs in the south of England and in the south and west of Ireland. It is met with over the greater part of Europe, and its range extends into Asia Minor and Northern India, and then it reappears again in distinct varieties in Japan and the Amur district. Three other species of Gonepteryx are known from Tibet and India, and one ( $G$. cleopatra) from Solithern Europe and Northern Africa. All the remaining species inhabit the west, viz., Brazil, Mexico, and Venezucla. That the genus has migrated from America eastward to Europe appears to be more probable than a migration in the opposite direction. At any rate, that an exchange of species between the south-western portion of the Holarctic Region and the Neotropical area took place is indicated by the fact, not only that a variety of $G$. cleopatra has 
been found in Madeira, but also that the Canary Islands possess a distinct form of Goneptery.x, viz., G. cleobule.

Dr. Kobelt has given us such an exhaustive memoir on the characteristic Mollusca of the different zoogeographical provinces of Europe, that we are particularly well informed as regards that group of Invertebrates. He tells us that the group Torquilla of the genus $P u p a$ - which is a small chrysalis-like snail-is especially characteristic of the Pyrenees, Spain, and Portugal. In a certain measure they replace there the Clausilice which, as we have seen in the last chapter, have come from the east and are almost entirely absent in the south-west of Europe. Of about seventy species of Torquilla, the larger number are confined to this district, and some, which like Pupa (Torquilla) granum, range eastward, have travelled along the old Mediterranean highway, vi $\hat{a}$ Algiers, Sicily and Greece, to Asia Minor. They are still found along the whole of this route.

Similarly, we are told by the same author, that Gonostoma-a group of the large genus Helix-has a number of species in the same south-western district, while only one, viz., Helix obvoluta, occurs in England and Germany, and two in the Alps. Southward we again find many representatives crossing over to North Africa, among which Helix lenticula has a similar range to Pupa granum, which I have just referred to. The Alpine sub-genus Campyicea is quite absent in the Lusitanian district. 
298 HISTORY OF THE EUROPEAN FAUNA.

Among our own British testaceous Land Mollusca, several Helices, viz., Helix pisana, ericetorum, virgata, acuta, fusca, rotundata, aculeata, and probably many others, have come to us from the south-west. The species of Hyalinia are undoubtedly of very remote origin, and it would be futile at the present state of our knowledge to speculate as to their home. Some of our species may possibly be of British origin. Balea perversa is probably a south-western species, and certainly Pupa anglica, which is quite confined to Western Europe.

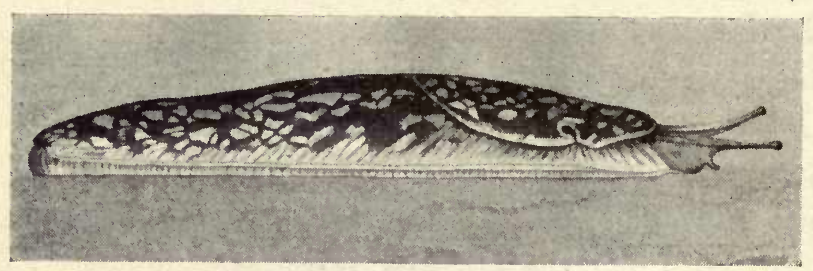

FIG. 18.-The Spotted Slug (Geomalacus maculosus).

Much more characteristic of South-western Europe, however, than these land-shells are some of the slugs. The peculiar genus Geomalacus is almost entirely confined to Portugal. One species, which I have had several occasions to refer to in illustration of the term "discontinuous distribution," ranges far beyond the confines of that country. This is Geomalacus maculosus (Fig. I8), first discovered in the southwest of Ireland, and more recently also in Portugal. Although careful search has been made for it in 
other parts of the British Islands, this slug has only been found in the portion of Ireland just indicated. Within the last few years I have taken it, up to a height of over a thousand feet, on the promontory north of the Kenmare River, also from sea-level up to a considerable height near Glengariff, and more recently Messrs. Praeger and Welch discovered it in abundance near the town of Kenmare. But beyond this rather circumscribed area in the counties of Cork and Kerry it does not occur (vide Fig. 19). Several Portuguese species of this interesting genus have since been added to science by Dr. Simroth and others. Dr. Simroth, too, has promulgated the view that the genus Arion-to which our common brown garden slug belongs-is of Lusitanian origin. Indeed, the number of species of Arion diminishes as we leave that province, though one extends beyond the borders of Europe into Siberia. The same number of species, viz. five, occur in Germany and in England. Testacella-a slug-like mollusc-which lives underground on earthworms, and of which genus three species, viz. T. maugei, T. haliotidea, 7 . scutulum, are known to inhabit the British. Islands, is another Lusitanian animal. All the species are confined to Western Europe and North Africa; they do not even reach Germany or Switzerland.

I have had occasion to mention once before an extremely interesting genus of blind Woodlouse, viz., Platyarthrus. Like Testacella, it lives underground, and also resembles it in its general range. Its distribu- 
tion is therefore of particular interest. It is difficult to conceive that Platyarthrus, from its peculiar mode of life, could have crossed any formidable barrier, such

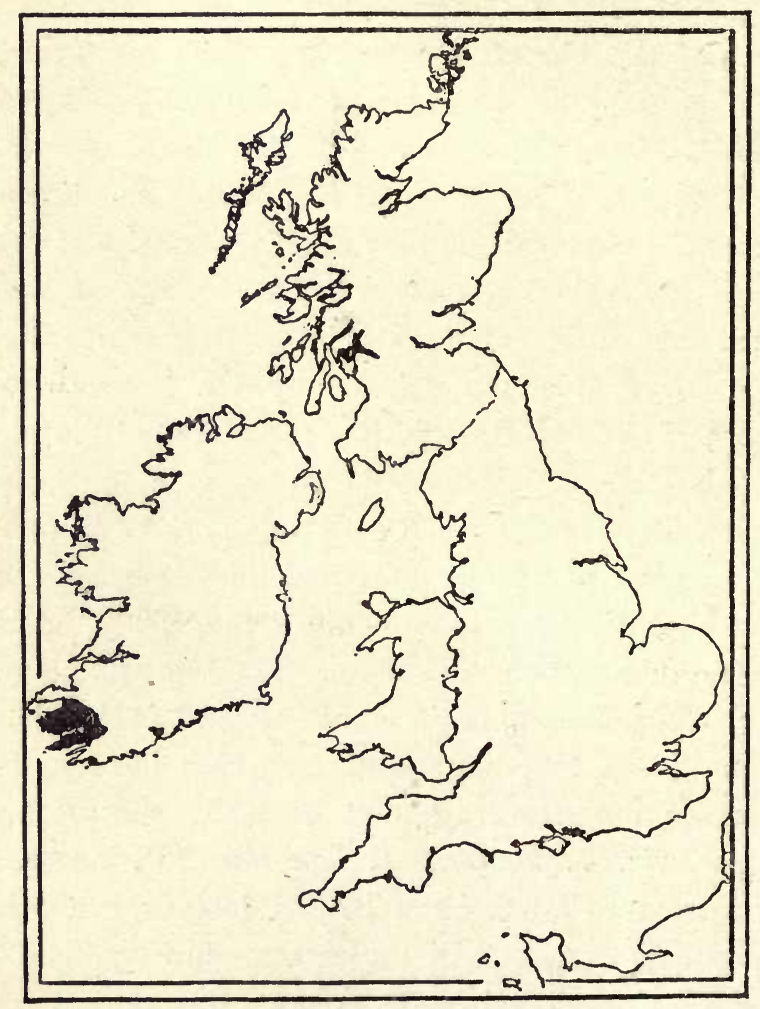

FIc. 19. - Map of the British Islands on which the geographical distribution of Geomalacus maculosus is indicated in black.

as even a narrow straits of sea. Its occurrence in Spain and North Africa indicates, therefore, that the Straits of Gibraltar did not exist at the time when 
it undertook the migration southward, just as the English Channel and the Irish Sea could not have been there when it wandered to England and Ircland. The species which occurs in the south of England has a wide range in Ireland, and reaches in Scotland its most northern European limit of distribution. Platyarthrus is only one of the Lusitanian genera of woodlice. In Ireland-chiefly on the west coast-we also find a brilliantly coloured Woodlouse, which is absent from Great Britain,viz. Metoponorthus cingendus. It reappears again on the Continent in the south of France. Its range is therefore suggestive of a Lusitanian origin; and indeed, when we examine the general distribution of the genus Metoponorthus, we find that out of the forty-four known species, fully one-half are confined to Western Europe and North Africa.

My friend and colleague, Mr. Carpenter, informs me that among the Irish Spiders he is acquainted with, the following are to be looked upon as Lusitanian species :-

Dysdera crocota.

Oonops pulcher.

Tegenaria hibernica.

Theridion aulicum.

Lasæola inornata.
Agroeca celans. do. gracilipes. Teutana grossa. Cnephalocotes curtus. Porrhomma myops.

Of the Coleoptera, the genera Trichis, Glycia, and Singilis, all belonging to the Running Beetles (Carabida), are almost confined to the Spanish peninsula. 
The beetles Rhopalomesites Tardyi, Eurynebria complanata, and Otiorrhynchus auropunctatus also belong to this fauna, as also the Earthworms Allolobophora veneta and $A$. Georgii, and the Millipede Polydesmus gallicus.

It will be evident to every one from these few instances of Lusitanian species, that somewhere in South-western Europe and. North-western Africa, and also, perhaps, in a larger now submerged western land-area, there existed an active centre of development, from which animals spread in all directions.

If the presence of Platyarthrus in North-west Africa proves that the Straits of Gibraltar had come into existence after its southward migration, it also suggests that the ancestral home of this woodlouse was in the Spanish peninsula. Whether this supposition is correct or not, does not affect the Straits of Gibraltar problem, for in a migration northward into Spain from Morocco a land-connection would be equally necessary. Almost every group of vertebrates and invertebrates furnishes instances of species which must have crossed the Straits on dry land. Many naturalists have come to this conclusion, and have clearly expressed their views on the subject. At the commencement of the present period, says $\mathrm{Mr}$. Bourguignat (p. 354), the north of Africa was a peninsula of Spain, the Straits of Gibraltar did not exist, and the Mediterranean communicated by the Sahara with the Atlantic.

The faunas of North-west Africa and the south- 
western portion of our continent are so closely related, that an uninterrupted intercourse by land must have existed for a very long period. The Mediterranean, however, throughout the Tertiary period-at any rate since miocene times-must have had almost constant communication with the Atlantic. According to Professor Suess, this was the case. The Atlantic was joined with the Mediterranean across the valley of the Guadalquivir during the Miocene Epoch, so that Andalusia must have belonged to North Africa in those days. The Straits of Gibraltar are supposed to have been formed in the next epoch. I have already expressed my disagreement with that theory from a zoogeographical point of view. The old Guadalquivir connection probably persisted much longer,-though interrupted by temporary periods of a partial retreat-so as to uncover sufficient land to allow of an interchange during miocene as well as pliocene times between the European and North African faunas. It is in this way, perhaps, that some of the members of the Alpine fauna have reached Spain by way of Corsica, Sardinia, and North-western Africa, and vice versâ. The Balearic Islands were then connected with Spain; and we find there many curious survivals which have long ago become extinct on the mainland.

That the Straits of Gibraltar are only of recent formation has been suggested on zoogeographical cvidence by Bourguignat, Simroth, Kobelt, and many others. Dr. Kobelt believes that the former land- 
connection between the south of Spain and Morocco was much wider than is gencrally assumed, and that the coast-line stretched from Oran in Algeria straight across to Cartagena in Spain (b, ii., p. 228).

$\mathrm{My}$ allusions to the lands lying beyond the Lusitanian province, refer chiefly to the Canary Islands and Madeira. Whatever doubts Dr. Wallace had on the subject of their former connection with Morocco, it cannot be denied that they used to be of much larger extent, especially in miocene and pliocene times. It seems extremely probable that these islands formed part of the mainland of North Africa until comparatively recently, and that they are the last traces of a sunken continent which united Africa and South America. A discussion of this problem, however, must be deferred, as it is a complicated one, and one which would lead me altogether outside the scope of this little volume. I hope I shall have an opportunity to publish my views on this subject before long, meanwhile the reader must content himself with this mere statement.

During the greater portion of the Miocene, and I think for part of the Pliocene Epoch too, the advance of the Lusitanian species eastward was barred on the continent of Europe by an arm of the sea. which stretched northward along the Rhone valley from the Mediterranean. The Lusitanian forms which originated in Southern Spain were able to travel east during these times by way of North-ivest Africa, 
306 HISTORY OF THE EUROPEAN FAUNA.

tanian centre was never a very active one compared with, for instance, the Oriental is indicated by many distributional facts. It is difficult to understand, however, why the Oriental species, on the whole, have migrated so far west, while few Lusitanians have gone very far east. This seems to have been noted

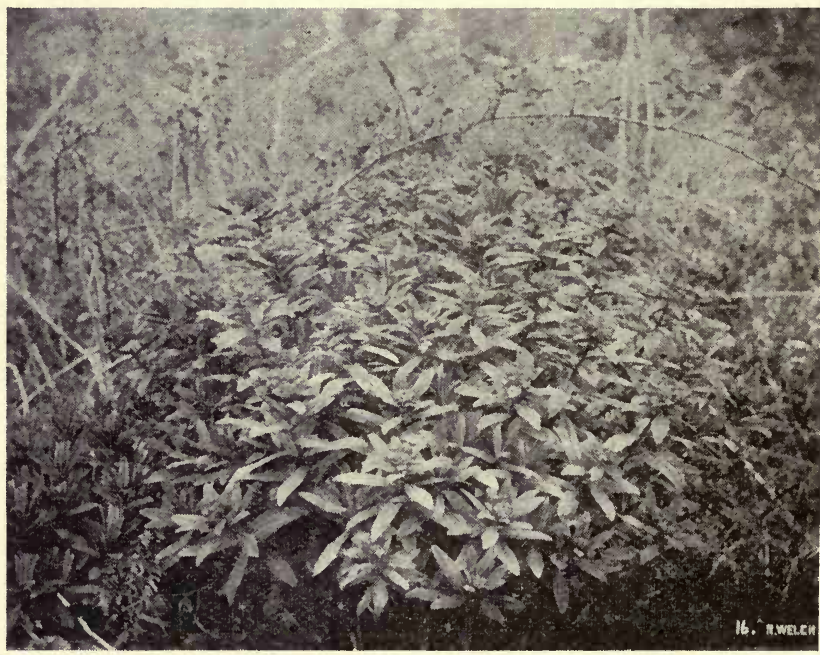

FIG. 21.-The Irish Spurge (Euphorbia hiberna) in its native habitat in the south of Ireland. (From a photograph by Robert Welch.)

particularly in the case of the flora. Mr. Bonnet drew attention to the fact that in Tunis there are none of the absolutcly characteristic plants of Morocco and Spain, while the Oriental flora is represented by a good many species. Lusitanian species have spread chiefly southward into North Africa, and northward into France, the British Islands, and even Scandinavia. 
As I have mentioned in the third chapter, there are a good many species of Lusitanian origin in the British Islands. However, we have only a mere remnant of what we ought to have, had the climate been less trying. It is probable, too, that the submergence destroyed a good many plants and the insects dependent on them. That the Lusitanian fauna is very ancient in the British Islands is proved by the fact of the discontinuous distribution of so many species. A greater number survived in Ireland than in England.

Altogether-and this was strongly urged by Edward Forbes-the Lusitanian element is the oldest of the components of our fauna, and it must have poured into the British Islands for many geological periods almost without cessation. The same author, in his classic essay, refers especially to the Lusitanian flora, two prominent members of which are the British plants, Arbutus unedo (Fig. 20, p. 305) and Euphorbia hiberna (Fig. 2 I, p. 306). The former has a wide range in the Mediterranean region, and occurs in the British Islands only in the south-west of Ireland. The Spurge, on the other hand, is also found in the south-west of England, besides Ireland and Southern Europe.

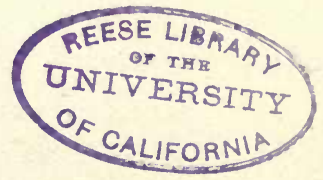




\section{SUMMARY OF CHAPTER VII.}

The term "Lusitanian" is in this chapter employed in the wide sense, as indicating the South-west of Europe and Northwestern Africa. From this centre, and probably also from a now sunken land which lay to the west of it, issued a fauna and flora of which we have abundant evidence in our own islands, especially in Ireland. Edward Forbes held that the Lusitanian element of the British flora was of miocene age, and that it survived the Glacial period in this country.

At the time when the Straits of Gibraltar did not exist, and when there was free land communication between Asia Minor, Greece, and Tunis, many Oriental species migrated westward by this ancient Mediterranean route as far as Spain. They would then have invaded the more central parts of Europe from the south-west, without however being of Lusitanian origin. Of the true Lusitanian mammals a typical example is the Rabbit. Then we have a few birds and several interesting reptiles and amphibians. The genus to which the Brimstone Butterfly belongs is also of south-western origin. A number of Mollusca are mentioned which from their range likewise indicate a Lusitanian origin. Most of our British Slugs and many of our larger Snails belong to this group.

All these are merely a small remnant of what we received from South-western Europe during the Miocene and Pliocene Epochs. But they spread into many parts of Europe, and a few even crossed into Asia. The antiquity of the Lusitanian element in our fauna is especially indicated by the frequent recurrence of "discontinuous distribution" among the species belonging to that section. 


\section{CHAPTER VIII.}

THE ALPINE FAUNA.

WE are told by Sir Archibald Geikie (p. 85I) that "from the Pyrenees eastwards, through the Alps and Apennines into Greece, and the southern side of the Mediterranean basin, through the Carpathian Mountains and the Balkan into Asia Minor, and thence through Persia and the heart of Asia to the shores of China and Japan, a series of massive limestones has been traced, which, from the abundance of their characteristic foraminifera, have been called the Nummulitic Limestone. Unlike the thin, soft, modern-looking, undisturbed beds of the AngloParisian area, these limestones attain a depth of sometimes several thousand feet of hard, compact, sometimes crystalline rock, passing even into marble, and they have been folded and fractured on such a colossal scale that their strata have been heaved up into lofty mountain crests sometimes 10,000, and in the Himalaya range more than 16,000 feet above the sea." "Nowhere in Europe," continues the same author (p. 860), "do oligocene strata play so important a part in the scenery of the land, or present on the whole so interesting and full a picture 
of the state of Europe when they were deposited, as in Switzerland. Rising into massive mountains, as in the well-known Rigi and Rossberg, they attain a thickness of more than 6000 feet." "By far the larger portion of these strata is of lacustrine origin. They must have been formed in a large lake, the area of which probably underwent gradual subsidence during the period of deposition, until in Miocene times the sea once more overflowed the area."

From these remarks by our most eminent British geologist, we gather that in early Tertiary times much of the present area of Switzerland was either a sea or a large freshwater lake. The Alps were then appearing in this sea, probably as a chain of islands, and in the beginning of the Miocene Epoch one large elongated island had made its appearance-the future European Alps. I have already mentioned that the Miocene Sea skirted the Alps from the Mediterranean up the valley of the Rhone and along its northern and eastern margin. Miocene marine deposits are also known from the Southern Alps and the east side of the Apennines, from Corsica, Sardinia, and Malta. No trace, however, of them has been noticed anywhere along the Egean Sea or on the Balkan peninsula. The Alps were therefore connected to the east with the outliers of the Balkan Mountains, and in this way with Asia, from which they received so large a proportion of their fauna and flora. In pliocene times the sea still washed the southern shore of the Alps, but to the north dry land gradually 
supplemented the sea, and the Alpine fauna and flora were able to pour into the plain. It was then that the Arctic species-which we have learned had migrated into Northern Europe from the north-found their way to the Alps. In a similar way Lusitanian forms-in fact, species from almost all parts of Europe-were now free to wander to the newly opened up peninsula which had become part of the mainland of Europe. The typical Siberian species had not entered our continent at that time, it was not till much later-not until the middle of the Pleistocene Epoch-that they made their appearance at the foot of the Alps, but, as we shall sce later on, it is doubtful whether many of these species ever reached the mountains.

The fauna of the Alps, and also the flora, is therefore made up of a number of component elements. In the first place we have the Oriental element -the migrants from Central and Southern Asia. When the nature and origin of the Oriental fauna in Europe was discussed, reference was made to the fact (p. 272) that we can distinguish an older from a newer Oriental migration. Both of these have entered the Alps. As we might anticipate, many of the older Oriental migrants have developed into new species, laying the foundation of an indigenous Alpine element. From the fact that they set foot on the Alpine peninsula, it miglit be expected that there could have existed no mountains to speak of. The climate was mild and damp. Now as the country 
rose, and a formidable mountain range took the place of a hilly island, the whole fauna was lifted up and transferred to entirely different conditions. A modification of their structure to suit the new surroundings was therefore to be anticipated, and that is exactly what occurred, though not in all cases.

Take, for example, the goats which are of Asiatic origin. Every one has heard of the "Steinbock," - the Alpine mountain goat (Capra ibex) - though very few have seen it in its native haunts, where it is now on the verge of extinction. A closely allied species (Capra sibirica) inhabits the Altai and Himalayan Mountains; a third species (Capra sinaitica) lives in Palestine, and has entered Egypt by way of the Sinaitic peninsula. Another ( $C$. agagrus) occurs in Asia Minor, Persia, the island of Crete, and some of the Cyclades. This exemplifies what I remarked in the last chapter about the former land-connection between Greece and the Asiatic continent. Finally, we have the Pyrenean Goat (Caprapyrenaica), which is found in the Pyrenees, the higher ranges of Central Spain, in Andalusia, and Portugal, thus indicating that it probably reached the Spanish peninsula from the south by means of the old Sicilo-Algerian highway, especially as remains of the species occur in the cave deposits of Gibraltar. The ancestors of the goat-like Antelope-known as the Chamois (Rupicapra tragus) - no doubt also came from Asia. The genus is not represented there, but Nemorhoedus and Budorcas are allied Asiatic genera, while the Rocky Mountain 
Goat (Haploceros montanus) also has certain affinities with the Chamois. Besides the Alps, the latter occurs in the Caucasus and the Pyrenees. The Alpine Marmot (Arctomys marmotta) is sometimes quoted as owing its origin to the Siberian pleistocene migration, but it does not occur in Siberia now, nor is there any palæontological evidence that it was ever found there. The genus Arctomys is an ancient Asiatic genus, to judge from its general range. Only two species occur in Europe, one of which, the true Siberian Marmot ( $A$. bobac), just enters our continent in the east-or rather, it is one of those species which came to us in pleistocene times and are now gradually retreating towards their native land. The genus, however, is probably not of Siberian origin. No less than seven other species occur in Asia, six of which are confined to Central Asia and the Himalayan Mountains, while four have wandered to North America. The sequence of events, therefore, was that the ancestor of Arctomys marmotta probably came to the Alps direct from Central Asia by way of Asia Minor in miocene or pliocene times. It has since become modified into a distinct species, and has spread to the European plain, where it occurs fossil in pleistocene strata, and to the Carpathian Mountains and the Pyrenees.

The great majority of species of the large genus Microtus (Arvicola) are Asiatic, and there can be little doubt that it has originated in that continent. There is one species of Vole (Microtus nivalis) which occurs 
in the high Alps, and which has been supposed to be a typical Alpine form. It is known, however, to occur also in North Italy and in Bohemia, while-Microtus leucurus of the Pyrenees is identical with this species. But its range is by no means confined to Europe, for it has also been discovered in Syria and Palestine, while a closely allied form exists in the Himalayan Mountains. This shows clearly that the species has migrated to the Alps from Asia Minor. That this migration may have taken place at an early period-at a time when Sardinia and Corsica were still connected with Southern Europeis indicated by the occurrence of an extinct Vole (Microtus brecciensis) in Sardinian and Corsican pleistocene (?) deposits.

All the Alpine species mentioned except the Chamois can be easily traced to their former Asiatic home. But even it has its nearest relations in Asia. I might also refer to another Vole (Evotomys Nageri) which is practically confined to the Alps and Northern Italy, and which has probably originated there, though most of its nearest relations are either Asiatic or North American species.

But besides these Asiatic immigrants and their modified descendants we have a small truly native Alpine mammalian fauna. Sorex alpinus-the Alpine Shrew-occurs only in the Alps, the Harz Mountains, Pyrenees, and Carpathians. The genus has been found in European cocene strata,-in vastly older deposits in our own continent than elsewhere,-so 
that it is extremely probable that it has originated there. It may then have developed a new centre of distribution in the newly-formed Alps, where both Sorex alpinus and S. mimutus (pygmaus) have their home. From there they again spread-perhaps already in miocene times-to Asia and North America, where a large number of new species originated. It seems to me even probable that one of these Asiatic species of Sorex, viz. S. araneus (vulgaris), subsequently migrated towards the old home of its forefathers, since we find it more or less confined to Central and Northern Asia and Northern Europe.

Though the origin of the Alpine Hare has already been referred to and fully discussed in a previous chapter (p. 148), the conclusions arrived at may be once more repeated. The Alpine Hare (Lepus variabilis) is of Arctic origin. It spread southward into Europe, North America, and Asia in early glacial times, and reached our continent from Spitsbergen by means of a direct land-connection with Lapland. The Scandinavian peninsula was then separated from Russia, but connected with Scotland and Ireland (Fig. 13, p. 170). Since England was then united to France, the Alpine Hare was able to invade western continental Europe and all the mountain ranges. Its range is very discontinuous, small colonies being scattered all over the mountainous parts of the Northern Hemisphere, while the European Harea closely allied species-occurs in the plain, and now 
occupies to some extent the former haunts of the Alpine Hare (cf. Fig. 8, p. 137). Might not the European Hare, as suggested, possess somie advantages which enabled it to drive the other into more inaccessible parts, thus producing the peculiarity of range? The present distribution of the Alpine and the European Hare (L. Europaus) appears to me to strongly support such an assumption. It is not the cold which has driven the Alpine Hare to the Alps; and its presence there is not, as is often supposed, a "standing testimony of a former arctic climate" in Europe, but merely the necessary consequence of the weaker species being thrust into less accessible regions by a stronger rival.

Muscardinus avellanarius, - the common Dormouse, -though by no means confined to the Alps, has probably originated there. It is found up to a height of nearly 5000 feet in these mountains, and is spread over Europe at nearly equal distances from the Alps in all directions. Being absent from Ireland, Scotland, Norway, and Northern Russia, it seems as if it had only diffused northward in more recent times.

The closely allied genus Myoxus is likewise of European extraction, some species being known from French eocene deposits.

There are only a few typically Alpine Birds. One of these is the Alpine Accentor (Accentor collaris), which on rare occasions visits England, and Northern Europe generally. It is, however, by no means 
peculiar to the European Alps; a variety of this species occurs in Central Asia, Eastern Siberia, and Japan. The only other Accentor inhabiting our continent is the Hedge Accentor (A. modularis), which is resident over the greater part of it, and also in North Africa and the Mediterranean Islands. It also extends its range across the Egean Sea to Asia Minor, so that really not a single Accentor is peculiar to Europe.

Both the European species are evidently old forms, and the genus, as might be expected, is certainly Asiatic. No less than ten other species of Accentor are known, all of which are confined to Central Asia and the Himalayan Mountains, and are therefore all Holarctic. I may mention that much difference of opinion still exists as to the true zoological position of this anomalous genus. It has been located in several different families by various ornithologists, but has not yet found a permanent resting-place. Another bird generally considered to be peculiar to Switzerland is the Alpine Chough (Pyrrhocorax alpinus), but its range extends across Asia Minor to the Himalayas. Whether the European Chough should not form a distinct genus is a matter of opinion. Some of our leading ornithologists, like Dr. B. Sharpe, are inclined to separate it from Pyrrhocorax; however, there is no doubt that it is closely related to the Alpine Chough, whatever view we may take of the generic distinctness. It inhabits principally Western and Southern Europe, also 
North Africa; and its range extends eastward to the Himalayas, China, and Eastern Siberia. If any doubt still existed as to the Asiatic origin of the Choughs, it may be noted that the only two other closely allied genera, viz., Corcorax and Podoces, live in Australia and Central Asia respectively.

There are two other birds to which I should like to refer. These are the Rock Sparrow and the Alpine Snow Finch. The first of these (Petronia stulta) is by no means peculiar to the Alps. It is the only species of the genus inhabiting Europe; and besides the Alps it occurs in Southern Europe generally, and ranges as far west as the Canaries and Madeira. Eastward it is not found beyond Central Asia. Of the remaining five species of Petronia, two occur in Asia (including India) and three in Africa. Whether the genus is African or Asiatic is immaterial for our purpose, since, in any case, the only European species came to us from the east with the Oriental migration. The distribution of the Alpine Snow Finch (Montifringilla nivalis) is very similar to that of the birds we have just been considering. It inhabits the Alps up to a great height, but occurs also on the Pyrenees and other South European mountain ranges as far east as Palestine, where again it is found in the Lebanon. The genus Montifringilla has seventeen other species. Twelve of these live in Central Asia and Japan, extending as far north as Kamtchatka, while five inhabit Western North America right down to Mexico. There is every probability that in this case 
also we have to deal with an Asiatic genus which spread eastward to America, and westward to Europe. As regards the Reptiles, there are no peculiar Alpine forms, but among the Amphibia some species deserve to be mentioned. $U p$ to an elevation of I0,000 feet we find in the Alps the Black Salamander (Salamandra atra); and it is apparently quite peculiar to them, never having been observed in the plains. The handsome black and ycllow Salamander (Salamandra maculosa)-so well known as a terrarium specimen-likewise occurs in the Alps, and it has besides a fairly wide distribution in Europe. It is known from Southern Germany, the Pyrences, Spain, Portugal, Sardinia, Corsica, Greece, Syria, and Algiers. A third species ( $S$. caucasica) inhabits the Caucasus. The evidence of distribution here points emphatically to an Alpine origin of the genus Salamandra. We cannot tell where the ancestors of Salamandra may have come from, but several other genera of Salamandrida are certainly Asiatic. Our common Newt (Molge vulgaris) belongs to a genus with nineteen species, several of which are peculiar to Europe. The general range of the genus, howevcr, extends to North America, and it is more probable therefore that it originated in Asia. If so, it certainly must have passed into Europe at a very early date. Let us assume the first Molges to have traversed the Ægean Sea on terra firma to Greece in miocene times, they might thus have been able to travel straight on to the old Tyrrhenian continent of which Corsica and 
Sardinia now form the remains, and also on to Northwest Africa. Indeed, we find high up in the Corsican mountains an interesting large brownish-grey Newt (Molge montana), and another in Sardinia (Molge Rusconii). Again, in Algiers there are two species, viz., Molge Poireti and $M$. Hagenmiilleri, while the Moroccan $M$. Waltlii passes into the south of Spain. Here Molge bosca, $M$. aspera, and $M$. marmorata originated, the latter passing into France.

Another branch of the Molge tribe turned northward from Greece towards the newly forming Alps; and there originated Molge alpesiris and $M$. palmata, which more recently have spread into England (one at least), Germany, France, Austria, and Southern Italy. Molge vulgaris is an Asiatic species which wandered northward after entering Europe, covering a large area, but never reached the extreme south or southwest. $M$. cristata-the large Water Newt-has a similar but not quite so extended a range, while $M$. vittata never managed to cross the borders of Asia Minor. Some of the other species occur in China, Japan, and North America.

None of the tailless Batrachians-the Frogs and Toads-are peculiar to the Alps, but one, viz. Rana temporaria, ascends to the height of no less than I0,000 feet. It is our common British Frog. No other Frog probably ranges so far north or to such heights.

Let us now inquire what the invertebrate fauna of the Alps teaches us. We are told by Dr. Kobelt, 
the great authority on Europcan land shells, that a uniformity of character marks the Alpine Molluscan fauna $(b, i .$, p. $25 \mathrm{I})$. One of the characteristic genera Campylaea-often looked upon as a sub-genus of Helix - is a group containing somewhat flattened conspicuous snails of large size. These are found everywhere in the Alps, and wherever they occur beyond the confines of these mountains, remarks Dr. Kobelt, their origin from the main stock is easily traced. They have been gathered in the Apennines in Sicily, and even beyond the Mediterranean in Algeria. On the Balkan peninsula they occur right down to the most southern point of Greece, but are not met with either in Crete or Asia Minor. One species has been found sub-fossil in Thuringia in Northern Germany.

Another truly Alpine genus, says Dr. Kobelt, is the operculate Pomatias, which in its geographical distribution offers some interesting modifications from that of Campylaea. Less limited to high elevations, it has spread over a greater part of the plains. This has happened especially in France, while in Germany one species advanccs almost as far north as Heidelberg. In other directions also the genus has travelled beyond the limits of range of Campylaea. Pomatias occurs in the Pyrences and Northern Spain, in Sardinia and Crete, and may, according to the same author, be expected in Asia Minor, although no species has as yet been met with there. In Greece, again, it has been observed, and numerous species 
inhabit Tunis and Algeria. Dr. Kobelt connects the wider range of Pomatias with the geological history of the genus (b, i., p. 253). He tells us that species of Pomatias have been found in eocene deposits differing but little from our present forms, while undoubted Campylaece are not met with till we reach the upper Miocene.

Zonites is, according to Dr. Kobelt, a third Alpine genus, whose range scarcely differs from the other two (b, i., p. 254). The centre of distribution lies at present in one of the branches of the most southern Alpine chain which help to form a large portion of the Balkan peninsula. The bulk of the species inhabit that peninsula, the Greek Islands (except Crete) and Asia Minor. Neither in the Tyrol nor in Switzerland do we find any Zonites, and the few species that do occur in the south-eastern Alps only just cross the outliers of these mountains. Between the south-western Alps and the Rhone we again find a Zonites - a remarkable case of discontinuous distribution, since the nearest other habitat of the genus is Monte Gargano in South-eastern Italy, which is known to harbour a good many interesting geographical puzzles.

We still have a good deal to learn as regards the molluscan fauna of Sicily, Sardinia, and Corsica. These islands have scarcely been more than skimmed by conchologists, and Zonites may inhabit one or all of these, which might indicate to us the manner in which this genus travelled from Southern Italy to 
Provence in the south of France. The distribution of Zonites certainly does not seem to imply an Alpine origin, because it is almost completely absent from the Alps proper. But I do not think my views differ materially from those of Dr. Kobelt, since the Alps, in the wide sense, include the mountains of the Balkan peninsula, where I should feel inclined to locate the ancestral home of the genus.

The small operculate genus Acme is a similar case. Dr. Kobelt places the centre of distribution on the southern slope of the Alps, but scarcely any of the species inhabit the Alps proper. Some occur in France, others in North Africa, Sicily, Southern Italy, and the Caucasus. It is evidently a very ancient genus. The species live in moss or underground, and are not likely to be transported across the sea by accidental or occasional means of distribution.

Still another genus, which resembles Acme in its geographical distribution, is Daudebardia-a small slug-like mollusc with a tiny shell. It does not, however, range nearly so far north or west as Acme, for it occurs neither in the British Islands nor in Spain or the Pyrenees.

I shall not be able to refer to more than a few of the most typical Alpine species of Lepidoptera, but they may be taken as fair examples of the geographical distribution of the rest of the group.

Even those visitors to Switzerland who do not claim to be naturalists have heard of the remarkably 
handsome and stately Butterfly known as Apollo. To the ardent entomologist, the first sight of this typical Alpine species is a never-to-be-forgotten delight, and he generally brings home with him a rich harvest of specimens. The more experienced Butterfly hunter knows that there are no less than three different kinds of Apollo-or, as we should say more correctly, of Parnassius-in Switzerland. There is first the common Apollo (Parnassius Apollo), then the rarer and more local $P$ delius, which inhabits more elevated regions, and finally the still scarcer $P$. mnemosyne, which is only known from the highest mountain ranges. It may be a surprise to those who have accustomed themselves to connect Apollo with the Alps, and who think the two belong together and cannot do without one another, to hear that it is by no means confined to them. It is also found in Scandinavia, France, Spain, Russia, and in Siberia. Parnassius delius is confined to the European Alps and the mountains of Central Asia, while $P$. mnemosyne is known from the Pyrenees, Sweden, Hungary, Sicily, Russia, and Western Asia. One other Parnassius inhabits Europe, viz., $P$. Nordmanni of the Caucasus, but all the remaining species of the genus -and there arc nearly thirty more-are confined to Central Asia. A few, as we have seen, have reached Europe, some have travelled to the Himalayan Mountains, and others to Western North America. The centre of distribution is certainly in Central Asia, and we have no reason to suppose that the 
original home in this case does not agree with that centre.

Melitea, a genus to which some of our British Fritillaries belong, has also some typically Alpine members. Two of these, viz. $M$. cynthia and $M$. asteria, are peculiar to the Alps, the latter being only found at considerable elevations. Most of the remaining fourteen European species are also found in Central Asia. Thus the isolated M. maturna, which in Europe is confined to Lapland, is also known from the Altai Mountains, which again are near the centre of distribution, since some species of Melitea range across the Northern Pacific to Western North America.

The small British Mountain Ringlet, and also the Scotch Argus, belong to a genus of butterflies which is very characteristic of the European Alps. But owing to its enormous geographical distribution, its probable home is somewhat difficult to ascertain. Nevertheless it is a noteworthy genus, especially so from the fact that the two British species Erebia epiphron and $E$. athiops are taken at first sight for true Arctic migrants. As neither of them, however, occurs in Scandinavia, Greenland, or Arctic America, this supposition must be abandoned. They must be looked upon as species which once had a wider range in the southern parts of the British Islands, and which have survived in a few isolated localities, where they are apparently on the verge of extinction. 
About sixty species of Erebia are known to science, half of which are found in Europe, the remainder in Siberia, the Himalayas, Arctic America, Chili, Patagonia, South Africa, and Madagascar. Though a few do range into these outlying regions of the earth, Ceritral Asia seems to lie near the centre of distribution of the genus, and the probability is that it also was its original home. Most of the European species are high Alpine forms $-E$. glacialis being met with at a height of 10,000 feet-and these are generally quite peculiar to the Alps, showing that their ancestors came from Asia at an early date, probably by way of Asia Minor and Greece. A few, as for instance $E$. lappona, range right across to the Altail Mountains from the Alps, and at least one-E. melas-is found in Greece. Erebia migrations seem therefore to have taken place by the Southern or Oriental route at different geological periods. But some of the European species which are more or less confined to the plain, and are either absent from Switzerland or do not reach the higher elevations, appear to me to have come by the more direct northern or Siberian highway, at a still more recent period. These are Erebia athiops, medusa, ligea, and ambla.

Only one species of the well-known Polar genus Eneis, viz. EE. aëilo, occurs in the Alps. It has always been taken at very high elevations near the verge of the snow-line on the most lofty parts of the Simplon Pass, and other similar situations. 
Altogether about a dozen species of this genus of butterfly are known, most of which are confined to the polar regions of the Old World and the New, though some have found their way to the extreme south end of South America, in what manner is still a mystery. Like the preceding genera, this also appears to have emerged from Central Asia. The genus, too, is closely allied to the last, and though its range is not quite so extensive, it resembles it in many respects. The Alpine species of Eneis came to Europe by the Oriental route. But the Lapland species-at any rate $E$. jutta and $E$. bore-have taken a somewhat circuitous route to reach our continent. They first migrated from Asia to North America, and then by the old land-connections by way of Greenland to Lapland. It is noteworthy that Professor Engler felt convinced (cf. p. I7I) that the occurrence of many of the Arctic plants in North Scandinavia and Siberia could be best explained by the assumption of such a migration from Asia viâ North America to Europe rather than by the shorter route.

There are far more Alpine bectles than butterflies, but their geographical distribution is less well known, and it is therefore not at all safe to base important conclusions as to the origin of a fauna on that group alone; however, as far as my limited knowledge of the Coleoptera of the Alps goes, their general range seems to agree perfectly with other orders of insects. Many can also be traced to an Asiatic home, and 
the route they came by is the Oriental and not what I have called the Siberian.

Take, for instance, the genus Nebria, of which we have one species in England-a black insect with a bright reddish-yellow border and long light legsknown as $N$. livida. There are about eighty European species, most of which are confined to the Alps, the Caucasus, the Pyrenees, Spain, and Greece. The genus, however, ranges all over the Holarctic Region, that is to say roughly, over Europe, Central and Northern Asia, and North America. The centre of distribution lies in Central Asia. If the genus had poured into Europe by the northern or Siberian route, we should probably now find many species in Northern Russia, Germany, and France; but this is not the case, and we may therefore assume with some justification that the Southern or Oriental route was the only one available at the time when the bulk of the species of Nebria wandered to Europe. Many of the Nebrias occur in Switzerland and in the Alps, generally on the margins of the snow-fields and glaciers, like $N$. Germari and Brunii. Others, for example, $N$. atrata, ascend to the highest limit of animal life, having been observed at a height of over Io,000 feet.

Of the remaining orders of insects we know as yet very little. Central Asia and even Siberia are only beginning to be explored, and their invertebrate fauna-except Lepidoptera and Coleoptera-is practically unknown. However, I cannot conclude this 
short summary of some of the more characteristic Alpine animals without referring to the Grasshoppers which are so conspicuous in the mountains. The mountain air simply rings during a bright summer's day with the loud and cheerful song of millions of these insects. It is one of the most vivid impressions a tourist brings back from Switzerland-this constant shrill sound issuing from an apparently invisible source.

Among these Grasshoppers there are some highly characteristic Alpine genera. Pezotettix-formerly known as Podisma-is one of these. P. alpinus is almost confined to the high Alps; with $P$. mendax it occurs in lower levels chiefly towards the southeast, that is to say, in the direction of Hungary, Servia, and Dalmatia. $P$. frigidus occurs not only in the high Alps, but also in Lapland. P. Schmidti and $P$. salamandra are found in Carinthia, Servia, and Transylvania; and one species also inhabits the Pyrenees and another the Italian Mountains. Finally, the only English species of Pezotettix, viz. $P$. pedestris, has been taken in Sweden, Denmark, and then again in Austria, Hungary, Servia, etc., as far east as the Volga, and also on the high Alps, in Sardinia and the Abruzzi Mountains in Italy.

Very little, as I remarked, is known of the Asiatic range of this genus, but either the same or a closely allied one has many representatives in North and South America. Whether Pezotettix is therefore 
of Asiatic origin we cannot positively affirm, but whatever view we take, the general range of the European species indicates that the migration took place from the Alps in a south-easterly direction, or to them in a north-westerly one. That is to say the Oriental route, and not the Siberian, was utilised by the migrants.

Fortunately, we know a little more about another Grasshopper genus, called Chrysochraon. There are only two species, one of which, Chr. dispar, has been found from Northern France to the mountains of Servia, but not in the Alps. The other, Chr. brachypterus, has a somewhat similar range in the plain; but, moreover, it inhabits the Alps up to a considerable height. It is interesting to note that both these Grasshoppers again turn up on the Amur in Eastern Siberia.

In conclusion, I might mention one more Grasshopper, viz. Tettix, because it includes a species- $T$. bipunctatus - which, though well known in the plain of Middle and North Europe, ascends the Alps to a height of nearly 10,000 feet. It is one of the few instances I know of an animal occurring in the same form in such an enormous range of altitude -from sea-level to the highest regions where animal life is known to exist. It is also known from Asia Minor and Siberia. T. subulatus has a similar distribution, but is more common in Southern Europe than the other. T. fuliginosus occurs in Lapland and Siberia, $T$. meridionalis and $T$. depressus all 
along the shores of the Mediterranean. There can be no doubt that here also we can trace migration to or from Siberia, and again, as on previous occasions, by the Oriental route.

We now possess a fair general idea of the fauna of the Alps. We have learned that a good many of the animals are indigenous, and that others have migrated to the Alps by various routes. The majority of these have come from Central and Southern Asia with what has been described as the Oriental migration. A much smaller number have reached the Alps from the north and the west, but none of the latter are among the high Alpine forms. What will be the most surprising revelation is that the eastern species, which arrived in Europe with the Siberian migration, are practically absent from the Alps proper. No doubt some of them still survive in the lowlands of Switzerland and the Tyrol, but none of the true Alpine fauna owes its origin to the Siberian migration. If we compare the Alpine mammals with the Siberian forms which reached England (vide p. 202), we at once perceive the difference. We should expect to find in the Alps-if not the Reindeer and the Glutton-the Arctic Fox, the little Pica, the Lemmings, and the pouched Marmots. It might be urged that some of the smaller Siberian carnivores and rodents do inhabit the Alps. So they do. The Stoat and Weasel have found such a congenial home in Europe, both in the, plain and mountains, that they have spread rapidly to the 
latter, and no doubt reached within a comparatively short time the great heights at which they now occur in the Alps. But the Voles (Arvicola) have scarcely spread beyond the region of fields and cultivated ground. A height of 5000 fect at the most marks their maximum altitude in the Alps.

The fauna which reached the Alps in miocene and pliocene times, as well as the indigenous element, must have survived the Glacial period in their mountain home. Though I think that the conditions of the climate at that time and the size of the Scandinavian glaciers have been greatly exaggerated, there can be no doubt at all about the enormous size of many of the Alpine glaciers at this period. The climate was probably much moister but not colder than what it is now, possibly warmer. The snowfall was therefore greater, so that glaciers filled many of the lower valleys of Switzerland which are now quite free from ice, and even invaded the plain. But there is no reason whatsoever why the Alps should not even then have supported a luxuriant fauna and flora as they do now. Possibly many of the miocene plants and animals became extinct then, but extinction of species occurs at the present day. We hear complaints that the Chamois and the Steinbock have nearly vanished; we know that the Marmot is now much scarcer than it used to be, and that the Edelweiss and many other plants are more and more difficult to find, and seem rapidly to disappear. No doubt all this is in a great measure 
due to the influence of man, but not altogether. There is a constant struggle for existence going on among the animals and plants themselves-the stronger and fitter species driving the less fit and weaker into a corner, where they finally succumb. This happens now just as it did in pliocene and pleistocene times, and need not imply change of climate.

As soon as the Miocene sea to the north of the mountains had retreated, a portion of the Alpine fauna poured into the plain, and many species have found their way to the British Islands, a few to Scandinavia and Russia. Westward too, the sea soon after retired and opened a way for those Alpine species which were vigorous enough to extend their range in that direction. South-eastward, of course, a highway had long ago been open, and Alpine forms which were able to migrate towards the incoming Oriental stream, had no difficulty in doing so. When they arrived in Greece, some turned westward again and populated Sicily, Southern Italy, Sardinia, Corsica, and Northern Africa, while others crossed over to Asia Minor, which was then connected with Greece, and wandered towards the Central Asiatic or the Himalayan Mountains.

But, as I remarked, few of the typical Alpine species reached Scandinavia and Lapland. I have already referred to the similarity between the Northern Scandinavian and the Alpine faunas in a previous chapter, and I have shown that this resemblance 
cannot altogether be explained by the supposition of an interchange in the faunas of the two regions. That this has taken place to some extent is probable, but the resemblance appears more especially due to the fact that the Alps and Scandinavia have been peopled from the same centres of distribution.

In order to make this matter quite clear, I will give a familiar example as an instance of the manner in which the present distribution can be explained without taking recourse to direct migration from the Alps to Scandinavia or vice versá. The example I will take is that of a family of birds, not only of extreme interest from the fact of its northern range, but also from the pleasure it gives to those addicted to sport. This is the grouse family, the Tetraonida.

Let us commence with our British Grouse (Lagopus scoticus), which is peculiar to the British Islands. In Norway we find a Grouse ( $L$. albus) which differs in habit, and in the fact of its turning white in winter; otherwise it is so closely allied to our Grouse that many ornithologists do not separate them specifically. No doubt the British Grouse is a descendant of this Scandinavian Willow-grouse. The latter is known also to inhabit Greenland and Arctic North America, and it is even found beyond Behring Straits in Northern Siberia. En route between Scandinavia and Asia, travelling in a westward direction, we meet with two other very local species of Grouse, which may be looked upon as offshoots of L. rupestris-viz., L. hyperboreus of Spitsbergen, 
and leucurus of Western North America. In Asia we then again find two kinds of Grouse, very closely related, and by some indeed regarded as belonging to the same species. These are $L$. rupestris and L. mutus. Mr. Ogilvie-Grant tells us of the former (p. 49), that it is merely a more northern rufous form of L. mutus, and that it goes through similar changes of plumage. In summer the males are readily distinguishable, but in winter it is impossible to tell one from the other. "L. rupestris taken as a whole," says Mr. Ogilvie-Grant, "appears to us barely specifically distinct from L. mutus." L. rupestris occurs not only in Northern Asia, but crosses the Behring Straits to Arctic America, being still found on the Aleutian Islands, which represent the last remains of the former land-bridge between Asia and North America, then eastward to Greenland and Iceland. However, while this form does not cross the confines of Asia in a westerly direction, its near relative L. mutus-better known as the Ptarmigan-does; and may perhaps have entered Europe as a Siberian and also as an Arctic migrant. It is still found in the Ural Mountains, in Finland, and the highlands of Scandinavia. It is gradually being driven out of the Alpine lowlands, while it has long ago disappeared from Germany, France, and Austria-in fact, from all the lowlands of Europe. It has also been met with in the Pyrenees and in some of the Spanish mountains. Similarly, the bird has become extinct in England and Ireland, while it is becoming 
more and more scarce in Scotland. The centre of distribution of the genus lies in Arctic America, and from there the genus has spread to Europe and Asia. L. albus and L. mutus appear in our continent chiefly as Arctic migrants.

The Black Grouse (Lyrurus tetrix) belongs to a closely allied genus, which has only two species. One of these is very local in distribution, being confined to the Caucasus, but the smallness of range is to some extent compensated for by the peculiarity of its name, which is L. mlokosiewiczi. The Black Grouse, on the contrary, is widely distributed. It inhabits Northern Asia from the Pacific to the Ural Mountains, and extends as far south as Pekin and the Tian Shan range. In Europe it is found from the extreme east to the Pyrenees, the Apennines on the south, and to Great Britain and Scandinavia in the north. It is important to note its absence from Spain, the Mediterranean islands, and Ireland; and we have learned that it is one of those Siberian migrants which have succeeded in establishing themselves in the Alps.

The Capercaillie (Tetrao urogallus)-another great favourite with sportsmen-is now generally separated generically from the Black Grouse, though they are of course near relations. Its range greatly resembles that of the Black Grouse, except that it does not go quite as far east in Siberia, not having been met with beyond Lake Baikal. From there it is found westward as far as the Pyrenees. It occurs also in 
the Carpathians and the Alps. In England, where it used to be known by the name Cock of the Wood, it became extinct at some remote period in history, while it lingered on in Scotland and Ireland until the end of the last century. In Scotland it has been reintroduced into several counties, and being protected, it appears to spread from these artificial centres of distribution.

Like the Black Cock, the Capercaillie is a Siberian migrant, and it is one of the few Siberian species which have reached Ireland, as I have had occasion to mention in dealing with the origin of the British fauna. Two other species of Capercaillie and an allied genus (Falcipennis) are met with in the extreme north-east of Siberia, and six other genera, all belonging to the grouse family, are confined to North America. We have therefore a very intimate relationship between the grouse of Asia and those of North America, some species even ranging right across the two continents.

The last genus of this very interesting family is Tetrastes. This grouse is not familiar to British ornithologists, since it is entirely absent from the British Islands. But sportsmen who have tramped over Scandinavia know it well by the name of Hazel Grouse. It is ashy grey in colour, barred and vermiculated with black. The Common Hazel Grouse (Tetrastes bonasia) is found from Northern Spain in the west right through the mountainous parts of Central and Northern Europe and Northern 
Asia to Kamtchatka and the Russian convict island of Saghalien in the Pacific. Besides the Common Hazel Grouse, two other species are known, one from Eastern Russia and the other from China.

Having now shortly reviewed the whole grouse family, we have seen that, although some species live within the Polar Circle, the majority are more or less confined to the more temperate or rather the less arctic parts of the Northern Hemisphere. They are quite absent from Southern Asia and even the southern parts of North America, and almost so from the Mediterranean basin. The whole range of the family is therefore suggestive of a northern origin, and this view agrees perfectly with all the details of distribution. The centre of distribution lies in Northern Asia, or in Arctic North America. From there the great genus Lagopus spread east and west, reaching Europe by these vastly divergent routes at a time when the physical geography was very different from what it is today. Several of the species common to the Alps and Scandinavia have migrated from Siberia direct to Eastern Europe. But we can now imagine how from a similar centre in Asia-perhaps at a rather more remote time-a species spread eastward across North America and Greenland to Scandinavia, and westward along the mountain ranges of the Tian Shan and the mountains of Asia Minor to Greece, and finally to the Alps. We should then have the same species in the Alps and in Scandinavia, not far 
removed from one another; but how different were their paths of migration! This, however, is not an imaginary instance. Such a migration must have actually taken place in a good number of instances among the terrestrial invertebrates and also among plants.

The view still current among many zoologists and botanists, that animals and plants were driven down into the plain from the mountains of Europe during the height of the Glacial period and there lived together till the return of a more genial temperature, when they retreated to their mountain homes, is a very plausible one. During their sojourn in the plain, the plants and animals-say from Scandinavia-intermingled with those from the Alps; and when the time of separation came, many Alpine forms retired northward with the Scandinavians, while many Scandinavians would go with the Alpines to their home. In this way the similarity between the Alpine and Scandinavian faunas and floras is assumed to have been brought about. These theories, first promulgated by Edward Forbes, were hailed with general satisfaction by the scientific world. Even Darwin says of them (p. 33I), that grounded as they are on the perfectly wellascertained occurrence of a former Glacial period, they seemed to him to explain in a satisfactory manner the present distribution of the Alpine and Arctic productions of Europe. To the present day this view meets with much favour among naturalists. 
It is somewhat similar to one which has recently been strongly supported by Professor Nehring and accepted by Professor Th. Studer and many others. They have never made it quite clear whether the pre-glacial fauna and flora are supposed to have been absolutely destroyed by the glacial climate, or whether part of them have been able to take refuge somewhere in the south; but the great mass of our Alpine plants and animals are believed to have been derived from the Siberian invasion, which I have fully described in the fifth chapter. This invasion spread over the European plain, and when the climate ameliorated, both animals and plants migrated north and south to the mountains. This view agrees with the earlier theory, except that the adaptation to Alpine conditions would, according to the former, have taken place since the close of the Glacial period, during which time no such modification or change of species seems to have been produced in other parts of the world. The characteristic fauna of the Alps, as has been gathered from the preceding pages, is mainly of Central Asiatic rather than of Siberian origin. Migration to the Alps took place by the Oriental route long before the Siberian invasion. Some of the species of the latter have penetrated to the Alps, but these Siberian species have not given to the fauna of the highest European mountain range the striking character with which we all associate it.

Before concluding this chapter, a few remarks on 
the botanical aspect of the Alpine problem might not be out of place. It will enable us to judge which of the views indicated is the more probable, and will add to the interest which may have been aroused by the perusal of this sketch of the fauna of the Alps. Very much the same train of argument was applied as to the course of events in the formation of the Alpine flora as in the case of the fauna. The plants were all supposed to have been killed or driven away by the arctic temperature of the Glacial period, and their place taken by new migrants from the north or east when the climate ameliorated.

Professor Engler, one of the highest living authorities on the geographical distribution of plants, is of opinion (p. 102) that a large number of the indigenous Alpine species did not originate till after the close of the Glacial period, because so many of them are absent from the Sierra Nevada in Spain, where the condition for their well-being exists, while many have evidently spread from the Alps to the Carpathian Mountains and to the Pyrenees. He does not believe that a glacial flora could have existed in the plain between the Sierra Nevada and the Pyrenees during the Glacial period (p. I09). In speaking of the Caucasus, Professor Engler informs us (p. I I 7 ) that a good many species which do not occur in the Alps reached these mountains from Siberia. Apart from the northern glacial plants, the Caucasus has only few species in common with the Alps, more with the Balkan moun- 
tains and Northern Persia. Turning to Afghanistan, our author mentions (p. I2I) a few Alpine plants as occurring in that country, and likewise in the Caucasus and the Himalayas. He considers it probable that the route of migration of some glacial plants from the east to the west, and vice versâ, lay across the Afghan mountains. Many of our Alpine plants occur in the Siberian mountains, but in the Altai and Eastern Siberia generally a considerable number of these are by no means confined to the mountains (p. 125). They are also met with in the lower regions, and the rare Alpine Edelweiss (Leontopodium alpinum) frequently covers wide tracts in the plain, and is passed by almost unnoticed by the Siberian botanist.

Special attention is drawn by Professor Engler to the fact (p. 130) that several of the Siberian plants inhabit the Alps and the Caucasus, but are not found in Scandinavia. And from this he deduces the conclusion that part of the Siberian flora migrated in a south-westerly direction towards the Caucasus and the mountains of the Mediterranean area, exactly in the manner indicated in respect to the fauna of the Alps. We learned that the migration to the Alps from Central and perhaps also parts of Northern Asia took a south-westerly course first, and was then followed by one in an easterly direction. I called the former the Oriental migration and the latter the Siberian. Later on Professor Engler states (p. 142) that the main mass of the Siberian forms of plants certainly wandered westward to 
the south of the Ural. This is proved by the numerous glacial plants found in the Caucasus, while the glacial flora of the Ural Mountains is poor. Finally, he expresses the opinion that the probability of most of the Alpine plants occurring in Arctic Siberia, having wandered from the Alps, by way of Scandinavia, Greenland, and North America, to North-eastern Siberia, is greater than the direct migration from Europe to Siberia (p. 143).

Another continental writer on the Alpine flora who deserves special mention is Dr. Christ. His observation that Alpine plants by no means suffer from a high temperature (p. 309), but solely from a drying up of the soil, seems to me to point to the correctness of the view I have expressed on several occasions, that these plants have originated long before the Glacial period at a time when the climate was warmer and moister than it is now. It seems quite natural to Dr. Christ that the Arcto-Alpine flora should have originated in Asia, but he excepts thirty species which are absent from Northern Asia, though occurring in America (p. 327). These he thinks have penetrated direct from America to the Alps by way of Scandinavia, since no less than twenty-three still occur in the latter country. In the human population of the Alps, he continues (p. 336), one can distinguish an indigenous Celtic race, a Germanic colder and more apathetic race, and a more lively Roman one. The flora is composed of quite a similar mixture. We find also an indigenous element-an Arctic and 
a Mediterranean one. The last element is a survival of the Tertiary flora of the Central European plateau (p. 532). The plants were driven down to the shores of the Mediterranean, and it is only after the retreat of the glaciers that a few of them have been able to regain their ancient territory. The incoming Asiatic and North American flora likewise retired at the end of the Glacial period to the Alps and the Arctic countries, and left isolated traces of its former abundance on the North European plain. The bulk of the Arctic or Alpine flora is held to be of Asiatic origin. Since Siberia shows little trace of having been glaciated, owing to the dryness of the climate, a rich flora was able to develop there, which spread into Europe as soon as the vanishing glaciers made room for it.

These are the views of Professor Engler and Dr. Christ. They agree in so far as both of them maintain that the bulk of the Alpine flora is post-glacial - that is to say, that it has developed quite recently, or migrated to the Alps after the glaciers had retreated from the plain to the mountain recesses. It is assumed by Dr. Christ that while Europe was practically uninhabitable, a rich flora survived in Northern Asia, because the climate there was too dry for the development of glaciers. Due consideration in this interesting speculation, however, is not given to the fact which he himself emphasised, that Alpine plants are particularly prone to suffer from a dry climate. Even a moderately dry cold 
kills most of them. How can we then reconcile this fact with the theory of their origin in a dry and intensely cold climate? I quite agree with the views as to the Asiatic origin of the bulk of the Alpine flora, while the dry state of the Siberian climate is certainly indicated by the extremely feeble development of the glaciers during a large part of the Glacial period. We know, however, that in Pliocene and even in early Glacial times the atmospheric conditions must have been very different in Siberia. A great slice of Central Asia was under water, and numerous freshwater lakes covered the lowlands in the north, so that the climate must have been damp though not cold enough for the formation of extensive glaciers. Everything, in fact, seems to indicate that the migration of the Asiatic Alpine flora took place at a very early date-probably long before the Glacial periodeither by the Oriental or by the Arctic route via North America, Greenland, and Scandinavia. But would this not necessitate a survival of the Alpine plants in the Alps themselves? That is the view which has already been expressed with regard to the fauna, and the flora probably followed a very similar course. This is by no means a novel theory, however, and though unfortunately an untimely death has removed one of our very best authorities on the Alpine flora before he had completed his life's work, we have some indications in the earlier writings of John Ball that his opinions on the origin of that flora did not coincide with those held by the leading continental 
authors. To quote the words of this distinguished botanist (p. 576): "Is it credible that in the short interval since the close of the Glacial period hundreds of very distinct species and several genera have been developed in the Alps, and-what is no less hard to conceive-that several of these non-Arctic species and genera should still more recently have been distributed at wide intervals throughout a discontinuous chain some I 500 miles in length, from the Pyrences to the Eastern Carpathians? Nor would the difficulties cease there. You would have left unexplained the fact that many of the non-Arctic types which are present in the Alps are represented in the mountains of distant regions, not by the same, but by allied species, which must have descended from a common ancestor; that one species of Wulfenia, for example, inhabits one small corner of the Alps, that another is found in Northern Syria, while a third allied species has its home in the Himalaya." Mr. Ball is of opinion (p. 584) that the effects of the Glacial period have been greatly overrated. "Even during the period of maximum cold the highest ridges of the Alps were not completely covered with snow and ice; for we still see by the appearance of the surface, the limit above which the ancient ice did not reach, and in the middle zone the slopes that rose above the ancient glaciers had a summer climate not very different from that which now prevails. In my opinion the effect of the Glacial period on the growth of plants in the Alps 
was to lower the vertical height of the zones of vegetation by from one to two thousand feet." He acknowledges that there was probably a moderate diminution of the mean temperature of Europe with an increased snowfall, so as to cause a great extension of glaciers on all the mountains of Northern Europe. "But that the climate of Middle Europe was such that the plants of the high Alps could spread across the plains seems to me an improbable supposition" (p. 584).

On the Continent, also, some botanists seem to feel that Forbes's theories of the origin of the Alpine flora, which were at first hailed with such delight, and accepted by almost every naturalist as the final verdict, must be modified in the light of rccent researches. Professor Krasan believes that many plants which now live in the high Alps flourished in pliocene times at sea-level (p. 37). "Especially the evergreen species exhibit the impression of an originally mild climate-of a climate without winter frosts-for otherwise the plants would have developed into species with deciduous leaves." To the favourable conditions, consisting in periodic snowfalls and high summer temperature, must be attributed the fact that in the highlands so many more species from Tertiary times have survived than in the plains. The temperature was probably much higher during the Glacial period than is generally believed. The climate was more moist, thus contributing to an abundant snowfall, while the 
survivors of ancient Tertiary times were able to repeople the parts which were temporarily devastated by the advancing glaciers.

In so short a chapter it is impossible to deal with the Alpine fauna in a manner more deserving of this theme. I have merely sought to give a sketch of the general outlines of the subject and to suggest another possible mode of origin of Alpine animals than that currently believed in by naturalists. It is to be hoped these suggestions will be useful to those intending to reinvestigate the problems raised in this chapter. When our knowledge of the fauna of Asia is more complete, it will be possible to give a more thorough and in many respects a more satisfactory history of the European fauna than at present.

\section{SUMMARY OF CHAPTER VIII.}

In early Tertiary times the area now covered by the European Alps was covered by the sea. Islands slowly rose above the surface of the waters, which finally coalesced to form a peninsula connected with the mainland in the east. Animals now began to invade the new territory which continued to rise, while the sea retired farther and farther to the north and south. During the Pliocene Epoch the sea ceased to wash the northern shores of the Alps, and both emigration and immigration became possible in that direction, and also from and to the west.

The Alpine fauna and also the flora are made up of a number of elements, the eastern one being the oldest. The latter is represented in the Alps by the older and newer Oriental migration. The general range of the Alpine Steinbock, Chamois, Marmot, Vole, Shrew, and Hare are specially referred to. The 
Alpine birds are few in number, and all of them are readily traceable to an Asiatic ancestry. Among the Amphibia, the Salamanders are considered of Alpine origin.

Dr. Kobelt tells us that a uniformity of character marks the Alpine molluscan fauna. Campylaea,-often considered a subgenus of Helix,-Pomatias, Zonites, are looked upon as truly Alpine genera. For very long periods the Alps seem to have received no addition to their molluscan fauna from other areas. The case is very different with the Lepidoptera, some of the most striking species being evidently Asiatic immigrants. Some examples of Coleoptera and Orthoptera are mentioned, and their origin discusser.

We find as the result of these considerations that the majority of the Alpine species are either indigenous or have come from Asia with the Oriental migration. None of the northern or western immigrants appear to be among the characteristic Alpine species, and it seems that the Siberian migrants have not retired to the Alps, as some naturalists have been led to suppose. It is evident that the fauna must have survived the Glacial period on the Alps, though according to geological evidence glaciers of enormous size originated on these mountains.

The identity of many Alpine species with Scandinavian ones appears at first sight due to a direct migration from the Alps to Scandinavia or vice versá. Perhaps such a migration has taken place to some extent, but it is probable that from a Central Asiatic centre some species spread across Arctic America into Northern Europe, and also westward to the Alps. The Grouse family forms an interesting example.

There are two older theories which explain the similarity between the Scandinavian and Alpine faunas. Forbes's view, which gained most adherents among naturalists, was that the Scandinavian and Alpine animals were driven into the plain by the cold during the Glacial period, and when they ultimately regained their homes, some individuals of the northern species 
moved southward, and a few of the southern ones northward. By the more recent theory of Nehring, the Siberian animals which invaded our continent from the east, and then spread northward to Scandinavia and southward to the Alps, formed the nucleus of the faunas of these two areas. The objections. to both of these views are fully set forth in this chapter.

A few remarks on the botanical aspect of the Alpine problem conclude the chapter. The origin of the flora has been explained in a very similar manner to that of the fauna. But already Ball and Krasan have raised their voices against the current theories, as the facts of distribution appear to them more satisfactorily explained on lines more consonant with those which I have used in discussing the origin of the Alpine fauna. One of the most important conclusions obtained by this study of the flora in conjunction with the fauna, is that I have emphasised in most of the preceding chapters-viz., that the Glacial period in Europe was not a time of extreme cold, and that its destructive effect on the animals and plants was by no means such as is currently believed.

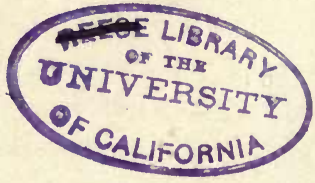




\section{BIBLIOGRAPHY.}

\section{(Titles of Works and Papers referred to in the Text.)}

Adams, A. Leith.-Report on the History of Irish Fossil Mammals, "Proc. Royal Irish Acad." (2nd series), vol. iii., 1878 .

Alston, E. R. - "The Fauna of Scotland," r880.

Ball, J.-On the Origin of the Flora of the European Alps, "Proc. Royal Geograph. Soc.," vol, i., 1879.

Barrett-Hamilton, G. E. H. (vide also Thomas and Barrett-Hamilton).- Notes on the Introduction of the Brown Hare in Ireland, " Irish Naturalist," vol. vii., 1898 .

Beddard, F. E.- "A Text-book of Zoogeography," I895.

Bell (vide Kendall and Bell).

Blanchard, E.-Preuves de la Formation Récente de la Méditerranée, "Comptes Rendus," vol. xciii., I88r.

Blanford, W. T.-Address delivered at the Anniversary Meeting of the Geological Society of London, I89o.

Blytt, A. - "Essay on the Immigration of the Norwegian Flora," I 876 .

Boettger, O.-a. System. Verzeich. d. lebenden Arten d. Landschneckengattung Clausilia, "Ber. Offenbach Ver. f. Naturkunde," I878. b. Entwicklung d. Pupa Arten d. Mittelrheingebiets, "Jahrbuch d. nass. Ver. f. Naturw.," vol. xlii.
Bogdanov, M. M.-Quelques mots sur l'bistoire de la faune de la Russie d'Europe, "Archives des Sciences physiques et naturelles" (N.S.), vol. lvi., 1876 .

Bonney, T. G. - "Ice-work, Present and Past," 1896.

Boulenger, G. A.-British Museum Catalogue (Amphibia), 1882.

Bourguignat, J. R. - Distribution géographique des Mollusques terrestres et fluviatiles en Algérie, "Annales des Sciences naturelles" (5th ser.), vol. v., 1864 .

Brandt, J. F. - Zoogeographische und Palæontologische Beiträge, "Verhandl. der Kais. russ. Mineral. Gesell." (2nd ser.), vol. ii., 1867.

Brauer, A.-Die Arktische Subregion, "Zool. Jahrbücher" (Abth. System.), I888.

Brehm, A. E. - "From North Pole to Equator," I896.

Brooke, Sir V.-On the Classification of the Cervidæ, "Proc. Zool. Soc. London," I878.

Bulman, G. W.-The Effect of the Glacial Period on the Fauna and Flora of the British Islands, "Natural Science," vol. iii., 1893.

Bunge, D. - La faune éteinte des bouches de la Léna et des îles de la Nouvelle Sibérie, "Congrès Intern. de Zoologie," vol. ii., Moscow, I892.

Carpenter, G. H.-Problems of the 
British Fauna, "Natural Science," vol. ii., I897.

Christ, H.- "Das Pflanzenleben der Schweiz," I879.

Cole, G. J.-Borderland, "Irish Naturalist," vol. vi., I897.

Credner, R. - Die Reliktenseen, "Petermann's Geog. Mitth.," 1887.

Croll, J._" Climate and Time," 1875 .

Darwin, C. - "Origin of Species," 6th ed., I878.

Dawkins, W. Boyd. - a. "Early Man in Britain," 1880. b. "The British Pleistocene Mammalia," part A, Preliminary Treatise, 1878. c. The Former Range of the Reindeer in Europe, "Popular Science Review," vol. vii., I868.

Drucle, O.-Betrachtungen ï. d. hypothetischen vegetationslosen Einöden im temperirten Klima der Nördlichen Hemisphäre zur Eiszeit, "Petermann's Geog. Mitth.," vol. xxxv., 1889.

Emery, C.-On the Origin of European and North American Ants, "Nature," vol. lii., 1895.

Engler, A.- "Versuch einer Entwicklungsgeschichte d. extratrop. Florengebiete d. Nördlichen Hemisphäre," 1879.

Falsan, A.- "La Période Glaciaire," I889.

Feilden, H. W. - a. Notes on the Glacial Geology of Arctic Europe and its Islands, part 2, "Quart. Journ. Geol. Soc.," vol. lii., 1896. b. Notes on a small Collection of Spitsbergen Plants, "Trans. Norfolk and Norwich Nat. Hist. Soc.," vol. vi., I894.

Fischer, P.-Faune malacologique de Cauterets, suivie d'une étude sur la répartition des Mollusques, "Journal de Conchyliologie" (3rd series), vol. xvi., I876.

Forbes, E. - The Geological Relations of the Fauna and Flora of the British Isles, etc., "Memoils Geol. Survey," vol. i., I846.

Geikie, Sir A. - "Text-book of Geology," I882.

Geikie, J. - a. "The Great Ice Age," r894. b. On Changes of Climate during the Glacial Period, "Geological Magazine," vol. ix., 1872.

Haacke, W.-Der Nordpol als Schöpfungs-zentrum der Landfauna, "Biologisches Centralblatt," vol. vi., I887.

Harlé, E.-Sur la succession de diverses faunes d̀ la fin du quaternaire, dans le sud-ouest de la France, "Societé d'Histoire Naturelle," Toulouse, 1893 .

Harmer, F. W.-On the Pliocene Deposits of Holland, and their relation to the English and Belgian Crags, "Quarterly Journal Geological Soc.," vol. lii., 1896.

Herdman, W. A., and Lomas, J.On the Floor Deposits of the Irish Sea, "Proc. Liverpool Geological Society," vol. viii., 1898.

Hofman, E.-Die Isoporien der Europäischen Tagfalter, "Inaugural Diss. d. Yhil. Fakultät in Jena," I873.

Hooker, J. D.-Outlines of the Distribution of Arctic Plants, "Trans. Linnean Soc.," vol. xxiii., 1862 .

Howorth, Sir H._"The Mam. moth and the Flood," I 887.

Ihering, H. von.-a. Die Ameisen von Rio Grande d. Sul, "Berliner Entomolog. Zeitschrift," vol. iii., I894. b. Najaden von São Paulo und die geographische Verbreitung d. Süsswasserfaunen von Sïd Amerika, "Archiv. f. Naturgesch.," I893.

Jordan, H. - Die Binnenmollusken der nördl. gemäss. Länder, "Nova Acta Acad. Carol.Leop.," vol. xlv., I883. 
Judd, J. W.-Address to the Geological Section, "British Association Report," Aberdeen, I885.

Karpinski, A.-Übersicht d. physiko-geograph. Verhältnisse d. Europ. Russlands, etc., "Beiträge z. Kenntniss d. Ruse, Reichs" (3 Folge), vol. iv., I 888.

Kendall, P. F., and Bell, A.-On the Pliocene Beds of St. Erth, "Quart. Jour. Geol. Soc.," vol. xlii., I886.

Kennard, A. S., and Woodward, B. B.-The Mollusca of the English Cave-Deposits, "Proc. Malacological Soc.," vol. ii., 1897.

Kew, H. W.- "The Dispersal of Shells," I893.

Kinahan, G. H.-On possible landconnections in recent geological times between Ireland and Great Britain, "Trans. Manchester Geol. Soc," vol. xxiv., I896.

Kobelt, W.-a. Das Verhältniss d. Europ. Landmoll. z. Westindien und Central Amerika, "Nachrichtsblatt d. deutschen Malak. Gesell.," I886. b. "Studien zur Zoogeographie," vols. i., ii,, I $897-98$.

Köppen, F. T.-Das Fehlen d. Eichhörnchens, etc., in der Krim, "Beiträge zur Kenntniss d. Russ. Reichs" (2 Folge), vol. vi., 1883.

Krasan, F. - Zur Abstammungsgesch. d. autochthonen Pflanzenarten, "Mitth. d. Naturw. Ver. Steiermark," I896.

Lamplugh, G. W.-The Glacial Period and the Irish Fauna, "Nature," vol. lvii., 1898.

Lomas (vide Herdman and Lomas). Lydekker, R. - a. "A Handbook of the British Mammalia," I895. b. "A Geographical History of Mammals," I896. c. "The Deer of all Lands," I898. d. Catalogue of the Fossil Mammalia of the British Museum, pt. 4, 1886.

Major, C. J. Forsyth.-a. Die Tyrrhenis, "Kosmos," 7 Jahrg.,
1883. b. Studien zur Geschichte der Wildschweine, "Zool. Anzeiger," vol. vi., 1883 .

Mallet, R.-Some Remarks upon the Movements of Post-tertiary and other Discontinuous Masses, "Journal Geol. Soc, Dublin," vol. v., I850-53.

Merriam, C. H.-The Geographic Distribution of Life in North America, "Proc. Biological Soc. Washington," vol. vii., 1892 .

Murray, Andrew.-_"The Geographical Distribution of Mammals," 1866.

Nathorst, A. G.-Kritische Bemerkungen über die Geschichte d. Vegetation Grönlands, "Botanische Jahrbücher," vol. xiv., I891.

Nehring, A._- "Tundren und Steppen der Jetzt und Vorzeit," 1890.

Neumayr, M. - "Erdgeschichte," vol. ii., 1887 .

Ogilvie, W. R. Grant._" Game Birds," I895.

Penck, A.-Die grosse Eiszeit, " Himmel und Erde."

Petersen, W.-Die Lepidopterenfauna d. arktisch. Gebiete von Europa, "Beiträge $z$. Kenntniss d. Russ. Reichs," vol. iv., I 888.

Pettersen, K.-Arktis, "Arch. f. Math. og Naturvid.," I882.

Pohlig, H.-Dentition und Kraniologie des Elephas antiquus (part 2), "Nova Acta Acad. Carol. Leop.," vol. liii., I889.

Reade, Mellard-a. The Present Aspects of Glacial Geology, "Geological Magazine," vol. iii., I896. b. High Level Shelly Sands and Gravels, "Natural Science," vol. iii., I893.

Reid, C. - The Pliocene Deposits of Britain, "Mem. Geol. Survey of the United Kingdom," I 890.

Rütimeyer, L. - "Die Herkunft unserer Thierwelt," 1867.

Sars, G. O.-Crustacea Caspica, "Bull. Acad. Imp. d. Sciences 
St. Petersburg," vol. xiii., I89394.

Scharff, R. F.-a. On the Origin of the European Fauna, "Proc. Royal Irish Acad." (3rd. ser.), vol. iv., I897. b. Some Remarks on the Distribution of British Land and Freshwater Mollusca, "Conchologist," vol. ii., I893. c. Étude sur les mammifères de la Région Holarctique, "Mém. de la Soc. Zool. de France," vol. viii., 1894 .

Schulz, A.-"Grundzïge einer Entwicklungsgeschichte d. Pflanzenwelt Mittel-europas," 1894.

Sharpe, R. Bowdler.-British Museum Catalogue (Birds).

Simroth, H. - Eine Bearbeitung d. Russischen Nacktschnecken fauna, "Ann. Musée Zool St. Petersburg," 1896.

Sjögren, H.-Ueber das diluviale Aralo-Kaspische Meer und die nord-europäische Vereisung, "Jahrb. d. Kais. K. Geol. Reichsanstalt," vol. xl., I890.

Sollas, W. J.-On the Origin of Freshwater Faunas, "Trans. Royal Dublin Soc." (2nd ser.), vol. iii., 1884 .

Speyer, A. and A. - "Die Geographische Verbreitung der Schmetterlinge Deutschlands und der Schweiz," vol. i., $185^{8}$.
Struckmann, C.-Ueber die Verbreitung d. Rennthiers, in d. Gegenwart, etc., "Zeitschr. d. deutsch. Geol. Gesell.," vol. iii., 1883.

Suess, E.- "Das Antlitz der Erde," vol. i., I892.

Tcherski, J. D.-Das Janaland und die Neusibirischen Inseln, "Mém. Acad. Imp. St. Petersburg," vol. xl., 1892 .

Thomas, O., and Barrett-Hamilton, G. E. H. - The Irish Stoat distinct from the British species, "Zoologist," I 895 .

Wallace, A. R.- "Island Life," 2nd edit., 1892 .

Warming, E.-Ueber Grönland's Vegetation, "Botanische Jahrbücher," vol. x., I888-89.

White, F. B.-Some Thoughts on the Distribution of the British Butterflies, "The Entomologist," vol. xiv., I88r.

Woodward, B. B. -On the Pleistocene (non-marine) Mollusca of the London District, "Proc. Geologists' Association," vol. ii. (vide also Kennard and Woodward).

Wright, J.-Boulder-clay a marine deposit, "Trans. Geol. Soc. Glasgow," vol. x., I 896. 


\section{INDEX.}

Ablepharus pannonicus, $25^{8}$

Accentor collaris, 316

modularis, $3 \mathrm{I} 7$

Accidental distribution, 12, 26

Acipenser ruthenus, 29

Acme, 323

Adams, Leith, I I2, I 50

Egean continent, subsidence of, 272-273

Agriolimax, 284

Alactaga jaculuıs, 204

Alca impennis, 92, 142

Alligator, accidental dispersal of, I4

Allolobophora Georgii, I1 5, 302 veneta, I I 5,302

Alpine Accentor, 316

Chough, 317

fauna, survival of, during Glacial period, 332

flora, 34I-348

flora, age of, 78,79

flora, suitable conditions for, 78 . 79

Hare, as a test of climate, $3 \mathrm{I} 6$

Snow-finch, 318

Alps, component elements of fauna, 3II-3I 2

Alston, E. R., 312

Alytes cisternasii, 295

obstetricans, 295

Amalia, 284

America, introductions from, 24

American beetles in the British Islands, 167

plants, origin of, in the British Islands, I 44

plants in Ireland, 166

sponges in Ireland, 166

Ampelis garrulus, 205
Amphibia of Europe, 193-194

dispersal of, 2 I

Amfhicoma, 268

Andalusian Bush-quail, 291-292

Anergates, 167

Anglo-Scotian fauna, 95

Animals as tests of climate, $7 \mathbf{I}-75$

Antelope, 39

Ants, European origin of, I6I

Apollo, 325

Apus glacialis, 94, 167

Aralo-Caspian Sea and Arctic Ocean, connection between, 219-23I

Arbutus unedo, I10, 307

Arctic animals in Caspian Sea, 238

flora in Europe, 238-24I

Hare, origin of, I48-149, 158-159

Hare, range of, I 36-138

Lepidoptera, 200

plant-beds at Bovey Tracy, 238

plants, I43-I44

plants, delicacy of, 185

mollusca in Red Crag, 235-236

Seal, I 74

sub-region, 132

Arctomys bobak, 204, 313

marmotta, 3I 3

Arion, 48, 299

subfuscus, 49

Arionida, origin of, 48, 299

Asiminea Grayana, 99

Aucapitaine, Baron, experiments by, 15

Autochthonous species, Io

Azores, remains of a continent, I9

Bacillus, 269-27o

Badger, distribution of, 43

Balea perversa, 298 
Ball, J., 77, 345.347

Baltic Sea, fauna of, 174

Baltic and White Seas, connection between, I75

Banded Lemming, range of, ${ }_{13} 8$

Barn Owl, 98

Barrett-Hamilton, G. E. H., 29, $90,139, \mathrm{I} 49$

Barriers to animal migration, 38

Barrington, R. M., I05

Bathyphantes nigrinus, 94

Baur, G., 19

Bearded Titmouse, 292

Beaver, 203

Beaver absent from Ireland, I 2 I

Beddard, F. E., I9, 58

Bedriaga, J. von, 259-260

Beetles common to North America and Europe, 161

American, in British Islands, 167

Bell (vide Kendall and Bell)

Black Cock, 143

Black Grouse, 336

Blanchard, E., 282

Blanus cinereus, 279, 294

Blethisa multipunctata, 93

Blytt, A., 34, 52, 79, 185, 239

Boar, distribution of, 44

Bobak Marmot, 204

Boetiger, O., 48, 263

Bogdanov, M. M., 53

Bombinator, 259-260

igneus, 259

pachypus, 259

Bonnet, 306

Bonney, T. G., 66, 70, 83, I80, 229

Boulenger, G. A., 259

Boulder-clay, foraminifera in, 84 origin of, 8I, I75, I80-18I, 229230

of Continental Europe, I80, 226 231

Bourguignat, J. R., 18, 47, 302

Bovey Tracy, arctic plant beds at, 238

Boyd, E., 104

Branchinecta palludosa, 167

Brandt, J. F., 51, 62, 107, 218, 222

Brauer, A., I32-133
Brehm, A. E., 139

Bristle-fern, II 5

British flora during Glacial period, 163

British Islands, Lusitanian flora in, 288, 306-307

submergence of, 127

Brooke, Sir V., 247, 250

Brunner von Wattenwyl, 270

Bufo calamita, 30

Buliminus detritus, 26I

fasciolatus, 26I

obscurus, 26I

pupa, 26I

Bullfinch, origin of, 191, 255-256

Bulman, G. W., II4

Bunge, D., 219

Bush-quail, Andalusian, 29I-292

Butterflies, Arctic distribution of, I 59-16I

origin of North European, 55

Caccabis rufa, 29

Campylaea, sub-genus of Helix, 49, 321

Canary Islands, origin of, I9

Canis lagopus, 135

Capercaillie, 28, I43, 336-337

Capra ibex, 312

agagrus, 61, 312

pyrenaica, 312

sibirica, 3 I 2

sinaitica, $3 \mathrm{I} 2$

Carabus, 199

Carduelis, 257

caniceps, 258

elegans, 257

major, 257

Carpenter, G. H., 64, 94-95, I04, I I 4, I 2 I-I 23, 288, 3 OI

Caspian Fishes, 224

post-pliocene deposits, 222, 226

Sea, Arctic animals in, 238

seal, 224

Castor fiber, 203

Cave deposits, mixture of Northern and Southern animals in, 54

Cenocosmic species, 24

Centre of distribution, 12, 43, 47 origin, shifting of, 202

Cervida, origin of, 248 
Cervus dama, 251 elaphus, 246-250 giganleus, 108, 25I

Chamaleon vulgaris, 279

Chamois, 312

Charrs, origin of, 124

-Chioglossa, 296

Chough, Alpine, 3 I 7

Christ, H. , 52, 343-344

Christy, Miller, 105

Chrysochraon, 330

Cicindela, 197-198

Cinclus, 255

Clarke, Eagle, 105

Clausilia, 47, 262-264, 284

bidentata, 47, 262, 284

biplicata, 47

laminata, 47

Pauli, 48, 263

Rolphii, 47

Claviger, 267-268

tesiaceus, 268

Climate in Glacial period, $658 \mathrm{I}$, I 27, I 49, 182-183

in Pleistocene Europe, 208-209

Close, Maxwell, I 29

Cod-fish, origin of, 143

Coecilianella, 17

Coenonympha typhon, 93

Cole, G. J., 83, I06-107

Coleoptera of Europe, origin of, I97

common to Europe and North America, I6I

Coiras, 266

Coregonus, 124

clupeoides, 124

pollan, 124

vandesius, 124

Cosmopolitan species, 24

Coltus, 92-93

bubalis, 93

gobio, 93

quadricornis, 175 scorpio, 93

Credner, R., I77-I78

Cricetus frumentarius, 190 vulgaris, 204

Crimea formerly an island, 35

Crimean fauna, 57

Croll, J., 66
Crocidura, 253

etrusca, 253, 279

Cuniculus torquatus, I 38

Current, Arctic, I72-173

Cyanopolius Cooki, 293

cyanus, 293

Cyclostoma elegans, 16

Danais chrysippus, 267

Dartford Warbler, 288

Darwin, C., 13-15, 17-19, 25, 3233, 339

Daudebartia, 323

Daulias luscined, 192

Dawkins, Boyd, 53, 62-63, 72-73, 107, I12-113, 120, 208, 222 223,282

Day, F., 29

Depéret, C., 44, 276

Dippers, origin of, 255

Discoglossus pictus, 279, 295-296

Dispersal of Amphibia, 59

of beetles (apterous), 59

of British butterflies, I 13

of earthworms, 58

of planarian worms, 59

of spiders, 59

of wood-lice, 59

Distribution, centres of, 12, 43, 47 discontinuous, I 14

Dormouse, 316

absent from Ireland, I2 I

Drapetisca socialis, 94

Dreyssensia polymorpha, 26, 230231

Drift, a marine deposit, I 29

Drude, O., 52, 77

Dryas octopetela, 79, 238

Dual origin, possibility of, 38

Dyer, Th., 79

Earth-worms, distribution of, 19, 23, 58

Edelweiss, 266, 342

Egean Continent, subsidence of, 272-273

Eider-duck, range of, I4I

Elephantida, origin of, 202, 252. 253

Elephas primigenius, 214, 252

Emery, C., I6I, I67 
Endemic species, Io

Engler, A., 52, 145, 17 1, I76, 282, 34 I -342

English Hare, 29

Ephydatia crateriformis, 94

Epoccus, 167

Erebia, $325-326$

athiops, $325 \cdot 326$

epiphron, 325

glacialis, 326

lappona, 326

Eremias, 258

Erratics, I8I-1 82

Eryx jaculus, 259

Euphorlia hiberna, 307

European beetles, origin of, 197 butterflies, origin of, 200

land and fresh-water mollusca, origin of, 196

mammals, origin of, 106, 193

Eurynebria complanata, 302

Evotomys Nageri, 3I4

Extension of range, mode of, 38

Fallow Deer, 25I

Falsan, A., 66, 68-69, 71, 73

Feilden, H. W., I3, 77, 84.85 , I64

Finmark, Greenland mollusca on coast of, I7 I

Fire-toads, origin of, 259

Fischer, P., 103

Fishes, Caspian, 224

"Flotsam and jetsam" theory, 20

Foraminifera in boulder-clay, 84

Forbes, E., 64, IOI, IIO, I I4-II5, I 7 I, 288, 339

Forest-Bed an inter-glacial deposit, 70

corresponding to continental inter-glacial deposits, 120

fauna of, 232-234

mollusca, 21 2-2 I 3

Fossil glaciers, 220

Fresh-water faunas, origin of, $\mathrm{I} 77$

Fringilla, 293

caelebs, 293

madeirensis, 293

montifringilla, 293

spodiogenys, 293

teydea, 293
Frog, introduction of, into Ireland, 30-3I

Gadow, H., I 39

Galapagos Islands, 19

Galeodes, 270

Gammaracanthus relictus, 179

Gardner, J. S., I45

Garnieria, sub-genus of Clausilia, 48

Gasterosteus aculeatus, 92

Gaudry, A., 73, 273

Geikie, Sir A., I I 6, 309

Geikie, J., 59, 66-67, 70, 75-76, $80-83$, I $16,129,163,181,216-$ $217,226-227,233,235,238$

Geographical changes, importance of, 64

Geomalacus maculosus, 5, 49, 99, I02, I I 5, 298.299

Gervais, E., I 50

Glacial climate in France, 150 period, climate of, 65-81, 127, I 49, I 82-183

period in Scandinavia, 176

period, survival of animals and plants during, 65

Glaciation of Ireland, I 29

Glutton, I 19, 203

Goldfinch, origin of, 257

Gonepteryx, 296-297

cleobule, 297

cleopatra, 296

rhamni, 296

Gould, J. E., 20

Great Auk, range of, 92, I 42

Greenland flora, I6I-162

flora, survival of, 163-164

miocene temperature in, 146

mollusca on coast of Finmark, 17 I

Tertiary plants, I 44 - I 45

Grouse, 9I, 334

black, 336

Gulo luscus, I I9, 203

Haacke, W., I47

Hamilton, John, I6 I

Hamster, I90, 204

Hanitsch, R., 94

Hare, 2, 29, 90

Arctic, 2, 90-91

English, 29 
Hare, Alpine, as a test of climate, 316

Harlé, E., I 50

Harmer, F. IV., I 82

Harvest-mouse, 3, 190

Harvie-Brown, J. A, 105

Haughton, W., 86

Hazel-grouse, 337

Hedge Accentor, 317

Hedley, C., 20

Heer, O., I44-145

Helix, 4

acuta, 102, 298

aculeata, 298

aspersa, 24, 195

ericetorum, 298

fusca, 298

lapicida, 4

olvoluta, 4, 297

pisana, เо2, 298

pomatia, 15, 32, 195, 262

revelata, 102

rotundata, 122, 274, 298

ruderata, $212-213$

Herdman, W. A., and Lomas, J., 236

Herring, origin of, 143

Heteromeyenia Ryderi, 94

Hofman, E., 54

Hooker, Sir J., 99, I6I

Hopatroides thoracicus, 268

Howorth, Sir H., 73

Hyalinia, antiquity of, 50

Hyla, 260

arborea, 260-261, 280

chinensis, 260

Ice-Age, climate of, 65, 8I

Ice-bridge, migration on, 108

Idotea entomon, I78, 224

Ihering, H. von, 19, 20, 24-25

Indigenous species, to

Inter-glacial deposit, the Forest-Bed an, 70

periods, climate of, 181,218

Introduced species, I0, 23, 27-29

Introduction by man, 32-33

Introductions from America, 24

Ireland, glaciation of, 129

Irish and Scotch Hare, I 36

Elk, 108, 251-252
Irish fauna, composition of, 63

Stoat, 136

Isle of Man, fauna of, 123

Isotoma littoralis, 94

Jeffreys, J. G., 27

Jerboa, 204

Jordan, H., 103

Judd, J. W., 6i

Karpinski, H., 222

Kendall, P. J., 125

Kendall, P. J., and Bell, A., I74

Kennard, A. S., 167

Kennard, A S., and Woodward, B. B., 4

Kessler, H., 222

Kew, H. W., I7, 23, 32

Killarney fern, i 5

Kinahan, G. H., I07-108, I 29

Kirkdale Cavern, remains in, 54

Kobelt, W., 49, 56, 58, 62, 75, 195-196, 212, 281, 297, 303, $32 \mathrm{I} \cdot 323$

Köppen, F. T., 51, 62, 222, 248

Krasan, F., 347

Lagomys, origin of, 4I, 203

Lagopus, 334

albus, 91, 142, 334

hyperboreus, 334

leucurus, 335

muutus, 9I, 142, 334

rupestris, 334

scoticus, 334

Laminifera, sub-genus of Clausilia, 48

Lamplugh, G. W., 107-108

Land-connection between America and Northern Europe, 6I

British Islands and France, 5960

British Islands and Scandinavia, $6 \mathrm{I}$

Europe and North Africa, 6r

Europe and North America, 6I, I68-1 72

Greece and Asia Minor, 61

Greenland and Europe, I 55, I 59

Ireland and Spain, 1 10

Land Mollusca, migrations of, 9 
Land shells, West Indian, 21

Lartet, E., 51, 73, 107, 150

Lemming, range of, I 38 - I 40

Leon'opodium alpinum, 266, 342

Lepus, 27, 29, 3I

alpinus, 136

cuniculus, 27, 3I, 29 $\mathrm{J}$

europecus, 29, 316

glacialis, 136

lacostei, 291

variabilis, 2, 29, I 36, 3I 5

Lepidoptera, range of, I 59-160

Arctic, 200

surviving Glacial period, 54

Leuckart, R. , I76

Lewis, Carvill, I 29

Limax, 284

marginatus, 284

maximus, 284

Limnocalanus macrurus, 179

Linyphia insignis, 94

"Loess" fauna, 75, 196

Lomas (vide Herdman and Lomas)

Lovén, S., 177

Lusitanian flora in British Islands, 288, 306-307

spiders, 3 o I

Lydekker, R., I4, 22, 32, 58, I 57 , $183,202,248,252$

Lyell, Sir C., I4, 22

Lyrurus tetrix, 336

Macroptychia, sub-genus of Clausilia, 48

Madeira, I9

molluscan fauna of, 25

remains of a continent, 19

Major, Forsyth, 45-46, 2So, 282

Mallet, R., 86

Mammoth in Siberia, 214-217 range of, 252-253

Mammals, dispersal of, 9, 2 I

Mantis religiosa, 269

Maps, general plan of, 8

Margaritana, 93

Marine connection between Caspian Sea and Arctic Ocean, 62, 219231

mollusca, distribution of, 236

origin of boulder-clay, $82-86,228$ 230
Marine shells above sea-level, I27I 28

transgression in Northern Russia, 172

Marmot, Alpine, 313

Bobak, 204

Marsh-ringlet, 93

Marshall, Rev., I 66

Martins, C., 68

Mediterranean land-connections, 276-282

Meles, 43

albogularis, 44

anakuma, 44

leucurus, 44

maraghanus, 44

polaki, 44

taxus, 43

Melitcea asteria, 325

cynthia, 325

maturna, 325

Melizophiluis undatus, 288

Merriam, C. H., 38

Metoponorthus cingendus, $30 \mathrm{I}$

Microtus, 31 3

brecciensis, 314

lezcurus, 314

nivalis, $3 \mathrm{I} 3$

Mid-wife Toad, 295

Migrations, 8-9

cause of, 208

of British shore-forms, 124

Migration from Asia to Europe by

North America, 327

Migration on ice-bridge, 108

waves of, 204-206

Miller's thumb, 93

Milne-Edwards, A., 282

Mingling of Southern and Northern Mammals, 72-75, 209

Miocene geography, 274-276 temperature in Greenland, 146

Miogale moschata, 290 pyrenaica, 290

Molge alpestris, 320

cristata, 320

montana, 320

palmata, 320

rusconii, 320

vulgaris, 319

Mollusca in Loess, 196 
Mollusca, distribution of marine, 236 Molluscan fauna, divisions of British, IO2

Madeira, 25

Porto Santo, 25

Molluscs, dispersal of, I7, 24

Mongoose, 28

Montifringilla nivalis, 318

More, A. G., 104

Möschler, E., 160

Motacilla, 254, 292

alba, 292

borealis, 255

campestris, 254

lugubris, 292

melanope, 254

Mountain Avens, 79

Mountain-ringlet, 325

Mouse, distribution of Harvest, 3

Mud-glaciers, 86

Murchison, R., 175, 230

Murray, Andrew, 32-33, 150, I54

Muscardinus avellanarius, 316

Musk-Ox, range of, II9, I34-135, 203

Mus minutus, 3, 95, 190

Mustela africana, 279

boccamela, 279

erminea, I35-136

putorizıs, 190

Myodus lemmus, 138

obensis, 138

Myoxus, 316

Mysis caspica, 223

necropihalma, 223

relicta, I 79, 223

Nathorst, A. G., I63, I69, 240241

Natterjack Toad, 30

Nebria atrata, 328

livida, 328

Nehring, A., 96, 107, I 19, 196, 208-21 I, 340

Nenia, sub-genus of Clausilia, 48

Neumayr, M., 19, 67

Newt, 319

New Siberian Islands, origin of bone-beds, 219

extinct fauna of, 218

Nightingale, 192
Nordquist, 179

North American marine mollusca in crag deposits, 173

North European Sea, 172

Ocean basins, permanence of, 18

Oceanic Islands, 18

Oeneis, 326-327

aëllo, 326

Onychogomphus, 268

Oriental nigration, old and new, 272

Oriental plants, $282-283$

Origin, centre of, shifting, 202

Otiorrhynchus auropunclatus, I15, 302

Ovibos moschatus, I 19, I 34-135, 203

Pacific Continent, 20

Painted-lady Butterfly, 98

Palincosmic species, 25

Pallas's Sandgrouse, 205

Panurus biarmicus, 292

Papilio hospiton, 265

Parmacella, 49

Parnassius, 265-266, 324

apolio, 265, 324

delines, 324

mnemosyne, 324

Nordmanni, 324

Partridge, 29

Pelias berus, 192

Pelobates, 295

Pelodytes punctatus, 295

Pelophila borealis, 93

Penck, A., 66

Perches, origin of, 143

Periops hippocrepis, 279

Peschel, O., I77

Petersen, W., 55, 1 54, 160, 200

Petronia stulta, $3 \mathrm{I} 8$

Pezotettix, 329-330

alpinus, 329

pedestris, 329

Phasianus, 256-257

colchicus, 3 I, 257

Pheasant, origin of, 256-257

Phoca annelata, 174

caspica, 224

Phadusa, sub-genus of Clausilia, 263 
Phylloxera vastatrix, 24

Pigs, origin of, $44-46$

Pika, 4I

Pine-Grosbeak, I9I

Pinicola enucleator, I9I

Planorbis dilatatus, 24 glaber, I67.

Plants, American, in Ireland, 166 as tests of climate, $75-80$ migration of, 34

Platyarthrus, 299-302

Plectrophenax nivalis, I40

Pleistocene climate of Asia, 210, 2I4-2 I 5

Europe, climate in, 208-209 fauna, northern and southern animals in, 72-75 mollusca, 2 I I-2 I 3

Pliocene deposits of Sicily, 277 geography, 276-277

Pohlig, H., I76

Polar Bear, I 34

Fox, range of, I35, I 49

origin of animals, 147

Pole-cat, 190

Polydesmus gallicus, I I 5, 302

Polynesian Islands, 20

Pomatias, 49, 321-322

Pontoporeia affinis, 179

Porto Sarto, molluscan fauna of, 25

Pouched Marmot, 4I

Praeger, R. L., 298

Praying insect, 269

Proboscidea, origin of, 252

Psammodromus aigirus, 295 hispanicus, 295

Ptarnigan, 9I, I42

Pufa, antiquity of, 50

Pupa, 297-298

anglica, 298

granum, 297

ringens, 102

Pyrrhocorax alpinus, 317

I'yrrhula, I9I, 255

europica, I9I, 256

major, I91, 256

Rabbit, introduction of, 27, 31, 29I

Rana temporaria, 194, 320

Range, extension of, $3^{8}$

Rangifer tarandus, I 33, I 50-1 58
Reade, Mellard, 127-129

Red Crag, Arctic mollusca in, 235. 236

Red Deer, 246-250

Red Grouse, 91, I42

Red-legged Partridge, 29

Regulus ignicapillus, 257 maderensis, 257

teneriffe, 257

Reid, Clement, 76,163

Reindeer, range and varieties of, 9I, I 33, I 49-I 58

Relict lakes, I76-I 79, 223

Reptiles, dispersal of, $\mathbf{2 I}$

Reptiles of Europe, 192-I93

Rhax, 270

Rhinoceros, distribution of, 214-216

Rhododendron ponticum, $27 \mathrm{I}$

Rhopalomesites Tardyi, 302

Rock Sparrow, 318

Route of migration of Siberian mammals, 2 Io

Rupicapra tragus, 312

Russia, marine transgression in, I 72

submergence of North, 155

Ritimeyer, L., 43, 57, 28I

Ryothemis, 269

Saiga Antelope, 39, 204

Saiga tartarica, 39, 204

Salamandra atra, 319

caucasica, 319

maculosa, 319

Salmonide, origin of, 92,143

Sandgrouse, migration of Pallas's, $4 \mathrm{I}, 205$

Sars, O.. I77, 223-224

Saunders, H., 256

Seal, Arctic, I74

Sea-urchin, I25

Sedgwick, A., 86

Scandinavia, absence of Oriental and Siberian mammals from, I76, 206

during Glacial period, I 76

Scandinavian boulders, origin of, I 72-173

butterflies in America, 167

flora, antiquity of, 162,185 glaciers, 172 
Scandinavian lepidopterous fauna, 55 Schulz, A., 52, 155

Sclater, P. L., 95

Scotch Argus, 325

Scotch and Irish Hare, 136

Siberia, climate of, during Glacial period, 217

Siberian birds in British Islands, 19I-I92

mammals absent from Scandinavia, 176,206

mammals absent from Southern Europe, 206

mammals in Great Britain, 95-96, 190, 202-204

migration, date of, 208

steppe-fauna, 39

Sicily, Pliocene deposits in, 277

Silurus glanis, 29

Simpson, C. T., 2 I

Simroth, H., 48, 299

Sjögren, H., 226

Slugs, dispersal of, I6-I7

Snails, dispersal of, 17

Snow-Bunting, range of, 9I, I40

Snow-Finch, 318

Sollas, W., I77

Somaleria mollissima, I4I

Sorex, 202, 3I4-3I 5

alpinus, 314-3I 5

araneus, 315

minutus, 3 I5

Southern mammals in Arctic Siberia, 21 3-2 6

Sparrow, introduction of, 28

Spermophilus, 4I

Speyer, A. and A., 55, 200

Spiders, Lusitanian, $30 \mathrm{I}$

Sponges, American, in Ireland, 166

St. Erth fauna, I74

Steinbock, 3I 2

Steppe-fauna, Siberian, 39

Sterlet, introduction of, 29

Stick-insect, 269

Stickleback, origin of, 92, I43, 166 . I67

Stoat, range of, 90-9I, I35-I36

Straits of Gibraltar, age of, 277 $278,28 \mathrm{I}$

Strix flammea, 98

Sironglyocentrotus lividus, 125
Struckmann, C., I 53

Studer, Th., $34^{\circ}$

Sub-marine plateau between Norway and Spitsbergen, I 54

Suess, E., 61, 273, 282, 303

Sus scrofa, 44-46

Swallow-tail Butterfly, 264-265

Syrrhaptes paradoxus, 4I, 205

Tailless Hare, 4I

Talpa, 29I

Taylor, J. W., 105

Tcherski, J. D., 214-21 5, 222

Tertiary plants in Greenland, I44145

Testacella, 17, 299

haliotidea, 299

maugei, 102, 299

scutulum, 299

Tetrao, 28

urogallus, 28, 143, 336-337

Tetrastes bonasia, 337

Tettix, 330

bipunctatus, 330

Thais cerisyi, 265

Theiphusa fluviatilis, 270, 28I

Thomas, O., 90

Thompson, W., 32

Time of disconnection between

Great Britain and Ireland, 63

Titmouse, bearded, 292

Toad, Natter-jack, 30

Tree-frog, 260, 280

Trichomanes radicans, I I 5

Tropidonolus viperinus, 294

Tubella pensylvanica, 94

Tundras in Northern Europe, 209. 210

Turnix sylvatica, 291-292

Tyndall, J., 68

Typhlops lumbricalis, 259

Tyrrhenian Continent, 280

Unio(Mar garitana) margaritifer, 93

Ursus maritimus, 134

Ussher, R. J., 92, I05

Vanessa cardui, 98

Vertigo alpestris, 93

Viper, range of, I92

Vole, range of, 3I3-3I4 
Wag-tails, origin and range of, 254, 292

Wallace, A. R., 12-13, 18-19, 23, 58,99, III, 304

Warming, E., 76, I63

Watson, H. C., 100

Wax-bill, migrations of, 205

Welch, R., 298

West-Indian land-shells, 2 I
White, Buchanan, I09, II3

Willow-grouse, 9I, I42

Woodward, B. B. (vide Kennard and Woodward)

Wright, J., 84

Zittel, 252

Zonites, 49, I95, 322.323

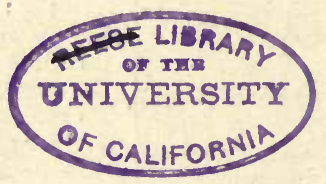

THE END. 
Crown Quarto, in specially designed Cover, Cloth, Price 6s.

"Wedding Present" Edition, in Silver Cloth, 7s. 6d., in Box. Also in Limp Morocco, in Box.

An Entirely New Edition. Revised Throughout.

With Twelve Full-Page Portraits of Celebrated Musicians.

\section{DEDICATED TO PADEREWSKI.}

\section{The Illisic of the lipoets:}

A MUSICIANS' BIRTHDAY BOOK.

COMPILED BY ELEONORE D'ESTERRE-KEELING.

This is an entirely new edition of this popular work. The size has been altered, the page having been made a little longer and narrower $(9 \times 6 \mathrm{y} / 2$ inches); thus allowing space for a larger number of autographs. The setting-up of the pages has also been improved, and a large number of names of composers, instrumentalists and singers, has been added to those which appeared in the previous edition. A special feature of the book consists in the reproduction in fac-simile of autographs, and autographic music, of living composers; among the many new autographs which have been added to the present edition being those of MM. Paderewski (to whom the book is dedicated), Mascagni, Eugen d'Albert, Sarasate, Hamish McCunn, and C. Hubert Parry. Merely as a volume of poetry about music, this book makes a charming anthology, the selections of verse extending from a period anterior to Chaucer to the present day.

Among the additional writers represented in the new edition are Alfred Austin, Arthur Christopher Benson, John Davidion, Norman Gale, Richard Le Gallienne, Nora Hopper, Jean Ingelow, George Meredith, Alice Meynell, Coventry Patmore, Mary Robinson, Francis Thompson, Dr. Todhunter, Katharine Tynan, William Watson, and W. B. Yeats. The new edition is illustrated with portraits of Handel, Beethoven, Bach, Gluck, Chopin, Wagner, Liszt, Rubinstein, and others. The compiler has taken the greatest pains to make the new edition of the work as complete as possible; and a new binding has been specially designed by an eminent artist.

London: WalTER SCOTT, LTD., Paternoster Square. 
Crown 8vo, about 350 pp. each, Cloth Cover, 2/6 per Vol.; Half-Polished Morocco, Gilt Top, $5 \mathrm{~s}$.

\section{Count Tolstoy's Works.}

The following Volumes are already issued-

A RUSSIAN PROPRIETOR.

THE COSSACKS.

IVAN ILYITCH, AND OTHER STORIES.

MY RELIGION.

LIFE.

MY CONFESSION.

CHILDHOOD, BOYHOOD, YOUTH.

THE PHYSIOLOGY OF WAR.

ANNA KARENINA. 3/6.

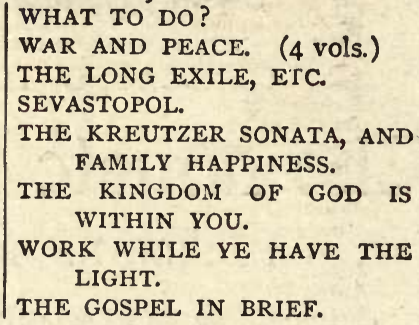

THE GOSPEL IN BRIEF.

IMPRESSIONS OF RUSSIA. By Dr. GEORG BRANDES. Post 4to, Cloth, Price Is.

PATRIOTISM AND CHRISTIANITY.

To which is appended a Reply to Criticisms of the Work. By Count Tolstoy.

\section{I/- Booklets by Count Tolstoy.}

Bound in White Grained Boards, with Gilt Lettering.

WHERE LOVE IS, THERE GOD $\mid$ THE GODSON.

IS ALSO.

THE TWO PILGRIMS.

WHAT MEN LIVE BY.

IF YOU NEGLECT THE FIRE, YOU DON'T PUT IT OUT. WHAT SHALL IT PROFIT A MAN?

\section{2/- Booklets by Count Tolstoy.}

NEW EDITIONS, REVISED.

Small I 2mo, Cloth, with Embossed Design on Cover, each containing

Two Stories by Count Tolstoy, and Two Drawings by H. R. Millar. In Box, Price 2s, each.

Volume I. containsWHERE LOVE IS, THERE GOD IS ALSO.

THE GODSON.

Volume II. contains-

WHAT MEN LIVE BY.

WHAT SHALL IT PROFIT A MAN?
Volume III. containsTHE TWO PILGRINIS.

IF YOU NEGLECT THE FIRE, YOU DON'T PUT IT OUT.

Volume IV. containsMASTER AND MAN.

Volume V. containsTOLSTOY'S PARABLES.

London: Walter ScotT, Limitrd. Paternoster Square. 


\section{The Emerald Library.}

Crown 8vo, Gilt Top, Half Bound in Dark Green Ribbed Cloth, with Light Green Cloth Sides, 2s. each.

Barnaby Rudge

Old Curiosity Shop

Pickwick Papers

Nicholas Nickleby

Oliver Twist

Martin Chuzzlewit

Sketches by $\mathrm{Boz}$

Olive

The Ogilvies

Ivanhoe

Kenilworth

Jacob Faithful

Peter Simple

Paul Clifford

Eugene Aram

Ernest Maltravers

Alice; or, The Mys. teries

Rienzi

Pelham

The Last Days of Pompeii

The Scottish Chiefs

Wilson's Tales

The Fair God

Miss Beresford's Mystery

A Mountain Daisy

Hazel; or, Perilpoint Lighthouse

Vicar of Wakefield

Prince of the House of David

Wide, Wide World

Village Tales

Ben-Hur

Uncle Tom's Cabin

Robinson Crusoe

The White Slave

Charles O'Malley

Midshipman Easy

Bride of Lammermoor

Heart of Midlothian

Last of the Barons

Old Mortality

Tom Cringle's Log

Cruise of the Midge

Colleen Bawn

Valentine Vox

Night and Morning

Bunyan

Foxe's Book of Mar. tyrs

Mansfleld Park

Last of the Mohicans

Poor Jack

The Lamplighter

Jane Eyre

Pillar of Fire

Throne of David

Dombey and Son

Vanity Fair

Infelice
Beulah

Harry Lorrequer

Essays of Elia

Sheridan's Plays

Waverley

Quentin Durward

Talisman

From Jest to Earnest

Knight of 19th Century

Caudle's Lectures

Jack Hinton

Bret Harte

Ingoldsby Legends

Handy Andy

Lewis Arundel

Guy Mannering

Rob Roy

Fortunes of Nigel

Man in the Iron Mask

Great Composers

Louise de la Valliere

Great Painters

Rory O'More

A rabian Nights

Swiss Family Robinson

Andersen's Fairy Tales

Three Musketeers

Twenty Years After

Vicomte de Bragelonne

Monte Cristo-Dantes Revengeof Dantes

The Newcomes

Life of Robert Moffat

Life of Gladstone

Cranford

North and South

Life of Gen. Gordon

Lincoln and Garfield

Great Modern Women

Henry Esmond

Alton Locke

Life of Livingstone

Life of Grace Darling

White's Selborne

Tales of the Covenan. ters

Barriers Burned A way

Opening a Chestnut Burr

Pendennis

David Copperfield

Luck of Barry Lyndon

St. Elmo

Son of Porthos

Stanley and Africa

Life of Wesley

Life of Spurgeon

For Lust of Gold

Wooing of Webster

At the Mercy of Tiberius

Countess of Rudol. stadt
Consuelo

Two Years before the Mast

Fair Mald of Perth

Peveril of the Peak

Shirley

Queechy

Naomi; or, the Last

Days of Jerusalem

Little Women and Good Wives

Hypatia

Villette

Ruth

Agatha's Husband

Head of the Family

Old Helmet

Bleak House

Cecil Dreeme

Melbourne House

Wuthering Heights

The Days of Bruce

The Vale of Cedars

Hunchback of Notre Dame

Vashti

The Caxtons

Harold, Last of the Saxon Kings

Toilers of the Sea

What Can She Do?

New Border Tales

Frank Fairlegh

Zanoni

Macaria

Inez

Conduct and Duty

Windsor Castle

Hard Times

Tower of London

John Halifax, Gentle. man

Westward Ho!

Lavengro

It is Never Too Late to Mend

Two Years Ago

In His Steps

Crucifixion of Phillip Strong

His Brother's Keeper

Robert Hardy's Seven Days, and Malcom Kirk (in 1 vol.)

Richard Bruce

The Twentieth Door

House of the Seven Gables

Elsie Venner

The Romany Rye

Little. Dorrit

The Scarlet Letter

Mary Barton

London: Walter Scotr, Limited, Paternoster Square. 


\section{NEW ENGLAND LIBRARY. GRAVURE EDITION.}

PRINTED ON ANTIQUE PAPER. 2s. 6d. PER VOL. Each Volume with a Frontispiece in Photogravure.

\section{BY NATHANIEL HAWTHORNE.}

THE SCARLET LETTER.

THE HOUSE OF THE SEVEN GABLES.

THE BLITHEDALE ROMANCE.

TANGLEWOOD TALES.

TWICE-TOLD TALES.

A WONDER-BOOK FOR GIRLS AND BOYS.

OUR OLD HOME.

MOSSES FROM AN OLD MANSE.

THE SNOW IMAGE.

TRUE STORIES FROM HISTORY AND BIOGRAPHY. THE NEW ADAM AND EVE.

LEGENDS OF THE PROVINCE HOUSE.

BY OLIVER WENDELL HOLMES.

THE AUTOCRAT OF THE BREAKFAST-TABLE. THE PROFESSOR AT THE BREAKFAST-TABLE. THE POET AT THE BREAKFAST-TABLE. ELSIE VENNER.

\section{BY HENRY THOREAU.}

ESSAYS AND OTHER WRITINGS. WALDEN; OR, LIFE IN THE WOODS. A WEEK ON THE CONCORD.

London: Walter Scott, Limited, Paternoster Square. 
Crown 8vo, Cloth Elegant, Price 5s. net.

\section{BIRDS OF THE BRITISH ISLES}

\section{Drawn and Described by JOHN DUNCAN.}

This volume contains about 400 drawings of birds by John Duncan, naturalist and artist. The drawings are accompanied by a concise description of each bird.

Mr. Chas. Dixon, in the Introduction to this work, says:- "Just a century ago, British naturalists and the British public were captivated by the first volume of Bewick's classic History of British Birds-a work, completed by the issue of the second volume seven years later, that gave more or less accurate pictures of all the species, and one that has retained a high place in the affections of ornithologists and artistic people generally down to the present time. To a certain extent, Mr. Duncan's volume very closely resembles the immortal engraver on wood; and in some respects, as those who have the pleasure of inspecting his remarkable series of drawings will find for themselves, it is superior. The present book, so far as British birds are concerned, is practically unique. For the first time, an up-to-date manual, containing an accurate and artistic picture of every species, is placed within the reach of the multitude by reason of its very modest price."

London: Walter Scott, Limited, Paternoster Square. 


\title{
THE CONTEMPORARY SCIENCE SERIES.
}

\author{
EDITED By HAVELOCK ELLIS.
}

NEW VOLUMES.

Crown 8vo, Cloth, Price 6s.; with a large number of Illustrations and Diagrams.

\section{The Natural History of Digestion.}

\section{By A. LOCKHART GILLESPIE,}

M.D., F.R.C.P. ED., F.R.S. ED.

Dr. Gillespie, who has long been known as an original investigator in this department of physiology, has in the present volume attempted to bring together all the facts and recent discoveries bearing on this subject of great scientific and practical importance. Dealing with the subject in much detail, as well as broadly and comprehensively, the book appeals both to medical specialist and general reader. The author shows that digestion is a process which occurs throughout animated nature, and beginning with digestion in plants, and describing many original and other experiments with carnivorous plants, he passes on to digestion in the lower animals, and then deals fully with the many complicated problems offered by digestion in the higher animals and man. The practical questions of diet are exanined in their various aspects, and the influence of alcohol, tea, and other stimulants discussed.

Crown 8vo, Cloth, Price 6s. With Illustrations.

\section{Degeneracy :}

\section{ITS CAUSES, SIGNS, AND RESULTS.}

By Professor EUGENE S. TALBOT, M.D., Chicago.

This volume presents, in a sinıle and comprehensive way, the basis of fact on which the speculations of Nordan and others have been founded. It is the first book written in English by a competent authority dealing broadly with this subject. The author deals with more especial fulness with the signs of degeneracy in the head and face-ears, jaws, teeth, etc. -as those which he has chiefly studied, and which are of most general interest; but be also discusses degeneracy in the body generally, as well as its mental forms. The chief causes tending to prodnce degeneracy in modern life are discnssed-heredity, climate, foods, alcohol, education, etc. -and the methods of combating them considered. 'The book is fully illustrated, chiefly from original photographs.

London: Walter Scotr, Limited, Paternoster Square. 


\section{Great Writers}

\section{A NEW SERIES OF CRITICAL BIOGRAPHIES.}

Edited by ERIC ROBERTSON ANd FRANK T. MARZIALS.

A Complete Bibliography to each Volume, by J. P. ANDERson, British Museum, London.

Cloth, Uncut Edges, Gilt Top. Price is. 6 d.

VOLUMES ALREADY ISSUED.

LIFE OF LONGFELLOW. By Professor Eric S. Robertson.

LIFE OF COLERIDGE. BY Hall CaINE.

LIFE OF DICKENS. BY FRANK T. MARZIALS.

LIFE OF DANTE GABRIEL ROSSETTI. BY J. KNIGHT.

LIFE OF SAMUEL JOHNSON. By Colonel F. GRANT.

LIFE OF DARWIN. By G. T. BeTTANY.

LIFE OF CHARLOTTE BRONTE. BY A. BIRRELL.

LIFE OF THOMAS CARLYLE. By R. GARNETT, LLD.

LIFE OF ADAM SMITH. By R. B. HALDANE, M.P.

LIFE OF KEATS. By W. M. RossetTI.

LIFE OF SHELLEY. By WILLIAM SHARP.

LIFE OF SMOLLETT. BY DAVID HanNaY.

LIFE OF GOLDSMITH. By AUSTIN DOBSON.

LIFE OF SCOTT. By Professor YONGE.

LIFE OF BURNS. By Professor BLACKIE.

LIFE OF VICTOR HUGO. BY FRANK T. MARZIALS.

LIFE OF EMERSON. BY RICHARD GARNETT, LL.D.

LIFE OF GOETHE. BY JAMES SIME.

LIFE OF CONGREVE. By EDMUND Gosse.

LIFE OF BUNYAN. By Canon Venables.

LIFE OF CRABBE. BY T. E. KEBBEL.

LIFE OF HEINE. By WILLIAM SHARP.

LIFE OF MILL. By W. L. COURT NEY.

LIFE OF SCHILLER. BY HENRY W. NEVINSON.

LIFE OF CAPTAIN MARRYAT. By David Hannar.

LIFE OF LESSING. By T. W. ROLLESTON.

LIFE OF MILTON. By R. GARNETT, LL.D.

LIFE OF BALZAC. BY FREDERICK WEDMORE.

LIFE OF GEORGE ELIOT. BY OSCAR BROWNING.

LIFE OF JANE AUSTEN. By Goldivin SMith.

LIFE OF BROWNING. By William Sharp.

LIFE OF BYRON. BY HON. RODEN NOEL.

LIFE OF HAWTHORNE. By MONCURE D. Conway.

LIFE OF SCHOPENHAUER. By Professor Wallace.

LIFE OF SHERIDAN. By LLOVD SANDERS.

LifE OF THACKERAY. By Herman Merivale and Frank T. MARZIALS.

LIFE OF CERVANTES. By H. E. WATTS.

LIFE OF VOLTAIRE. BY FRANCIS ESPINASSE.

LIFE OF LEIGH HUNT. By COSMO MONKHOUSE.

I.IFE OF WHITTIER. By W. J LINTON.

LIFE OF RENAN. BY FRANCIS ESPINASSE.

LIFE OF THOREAU. By H. S. SALT.

LIBRARY EDITION OF 'GREAT WRITERS,' Demy 8vo, 2s. 6d.

LONDON : WALTER Scotr, LTD., Paternoster Square. 


\section{Ibsen's Prose Dramas}

\section{EDITED by IVILLIAM ARCHER}

Complete in Five Vols. Crown 8vo, Cloth, Price 3s. 6d. each. Set of Five Vols., in Case, $175.6 d$. ; in Half Morocco, in Case, 32s. $6 d$.

- We seem at last to be shown men and women as they are; and at first it is more than we can endure. . . . All Ibsen's characters speak and act as if they were hypnotised, and under their creator's imperious demand to reveal themelves. There never was such a mirror held up to nature before; it is too terrible. . . Y Yet we must return to Ibsen, with his remorseless surgery, his remorseless electric-light, until we, too, have grown strong and learned to face the naked-if necessary, the flayed and bleeding-reality.'-SPEAKER (London).

Vol. I. 'A DOLL'S HOUSE,' 'THE LEAGUE OF YOUTH,' and 'THE PILLARS OF SOCIETY.' With Portrait of the Author, and Biographical Introduction by William Archer.

Vol. II. 'GHOSTS,' 'AN ENEMY OF THE PEOPLE,' and 'THE WILD DUCK.' With an Intro. ductory Note.

VoL. III. 'LADY INGER OF ÖSTRÅT,' 'THE

- VIKINGS AT HELGELAND,' 'THE PRETEND. ERS.' With an Introductory Note and Portrait of Ibsen.

Vol. IV. 'EMPEROR AND GALILEAN.' With an Introductory Note by WiLliam ARCHrR.

VoL. V. 'ROSMERSHOLM,' 'THE LADY FROM THE SEA,' 'HEDDA GABLER.' Translated by William ARChER. With an Introductory Note.

The sequence of the plays in each rolume is chronological; the complete set of volumes comprising the dramas presents them in chronological order.

LONDON : Walter ScotT, LtD., Paternoster Square. 


\section{Library of Humour}

Cloth Elegant, Large Crown 8vo, Price 3s. 6d. per Vol.

- The books are delightful in every way, and are notahle for the high standard of taste and the excellent judgment that characterise their editing, as well as for the brilliancy of the literature that they contain." -Boston (U.S.A) GazkTtr.

\section{VOLUMES ALREADY ISSUED.}

THE HUMOUR OF FRANCE. Translated, with an Introduction and Notes, by ElizabeTH LEE. With numerous Illustrations by PAUL FRÉNZENY.

THE HUMOUR OF GERMANY. Translated, with an Introduclion and Notes, by HANS MÜLLER-CASENOv. With numerous Illustrations by C. E. BROck.

THE HUMOUR OF ITALY. Translated, with an Introduction and Notes, by A. Werner. With 50 Illustrations and a Frontispiece by ARTURO FALDI.

THE HUMOUR OF AMERICA. Selected with a copious Biographical Index of American Humorists, by JAMES BARR.

THE HUMOUR OF HOLLAND. Translated, with an Introduction and Notes, by $A$. WERNER. With numerous Illustrations by DUDLEY HARDY.

THE HUMOUR OF IRELAND. Selected by D. J. O'DONOGHUE. With numerous Illustrations by OLIVER PAQUE.

THE HUMOUR OF SPAIN. Translated, with an Introduction and Notes, by SusETTE M. TAYLOR. With numerous Illustrations by $\mathrm{H}$. R. Millar.

THE HUMOUR OF RUSSIA. Translated, with Notes, by E. L. Boole, and an Introduction by STEPNIAK. With 50 Illustrations by PAUL FrénzenY.

THE HUMOUR OF JAPAN. Translated, with an Introduction by $A$. M. With Illustrations by GeORGE BIGOT (from drawings made in Japan). [In preparation.

LONDON : Walter Scott, Ltd., Paternoster Square. 
COMPACT AND PRACTICAL.

In Limp Cloth; for the Pocket. Price One Shilling.

\section{THE EUROPEAN}

\section{CONVERSATION BOOKS,}

\section{FRENCH \\ ITALIAN \\ SPANISH GERMAN \\ NORWEGIAN}

\section{CONTENTS.}

Hints to Travellers-Everyday Expressions-Arriving at and Leaving a Railway Station-Custom House Enquiries-In a Train-At a Buffet and Restaurant-At an Hotel-Paying an Hotel Bill-Enquiries in a Town-On Board Ship-Embarking and Disembarking-Excursion by Carriage-Enquiries as to Diligenses-Enquiries as to Boats-Engaging ApartmentsWashing List and Days of Week-Restaurant VocabularyIelegrams and Letters, etc., etc.

The contents of these little handbooks are so arranged as to permit direct and immediate reference. All dialogues or enquiries not considered absolutely essential have been purposely excluded, nothing being introduced which might confuse the traveller rather than assist him. A few hints are given in the introduction which will be found valuable to those unaccustomed to foreign travel.

London: Walter Scott, Limited, Paternuster Square. 


\section{EVERY-DAY HELP SERIES OF USEFUL HAND-BOOKS. Price 6d. each,}

\section{OR IN ROAN BINDING, PRICE 1s.}

Contributors-J. LANGDON DOWN, M.D., F.R.C.P.; HENRY POWER, M.B., F.R.C.S.; J. MORTIMER-GRANVILLE, M.D.; J. CRICHTON BROWNE, M.D., LL.D.; ROBERT FARQUHARSON, M.D. Edin.; W. S. GREENFIELD, M.D., F.R.C.P.; and others.

The Secret of a Clear Head.

Common Mind Troubles.

The Secret of a Good Memory.

The Heart and its Function.

Personal Appearances in Health and Disease.

The House and its Surroundings.

Alcohol: Its Use and Abuse.

Exercise and Training.

Baths and Bathing.

Health in Schools.

The Skin and its Troubles.

How to make the Best of Life.

Nerves and Nerve-Troubles.

The Sight, and How to Preserve it.

Premature Death: Its Promotion and Prevention.

Change, as a Mental Restorative.

Youth: Its Care and Culture.

The Gentle Art of Nursing the Sick.

The Care of Infants and Young Children.

Invalid Feeding, with Hints on Diet.

Every-day Ailments, and How to Treat Them.

Thrifty Housekeeping.

Home Cooking.

Flowers and Flower Culture.

How to do Business. A Guide to Success in Life.

How to Behave. Manual of Etiquette and Personal Habits. How to Write. A Manual of Composition and Letter Writing. How to Debate. With Hints on Public Speaking. Don't: Directions for avoiding Common Errors of Speech. The Parental Don't: Warnings to Parents. Why Smoke and Drink. By James Parton. Elocution. By T. R. W. Pearson, M.A., of St. Catharine's College, Cambridge, and F. W. Waithman, Lecturers on Elocution.

London: Walter Scott, Limited, Paternoster Square. 
Cloth, Uncut Edges, Gilt Top. Price Is. 6d. per Volume.

VOLUMES ALREADY ISSUED-

1 ROMANCE OF KING ARTHUR.

2 THOREAU'S WALDEN.

3 THOREAU'S "WEEK."

4 THOREAU'S ESSAYS.

5 ENGLISH OPIUM-EATER.

6 LANDOR'S CONVERSATIONS.

7 PLUTARCH'S LIVES.

8 RELIGIO MEDICI, \&c.

9 SHELLEY'S LETTERS.

10 PROSE WRITINGS OF SWIFT.

11 MY STUDY'WINDOWS.

12 THE ENGLISH POETS.

13 THE BIGLOW PAPERS.

14 GREAT ENGLISH PAINTERS.

15 LORD BYRON'S LETTERS.

16 ESSAYS BY LEIGH HUN'.

17 LONGFELLOW'S PROSE.

18 GREAT MUSICAL COMPOSERS.

19 MARCUS AURELIUS.

20 TEACHING OF EPIC'TETUS.

21 SENECA'S MORALS.

22 SPECIMEN DAYS IN A.IERICA.

23 DEMOCRATIC VISTAS.

24 WHITE'S SELBORNE.

25 DEFOE'S SINGLETON.

26 MAZZINI'S ESSAYS.

27 PROSE WRITINGS OF HEINE.

23 REYNOLDS' DISCOURSES.

29 PAPERS OF STEELE AND ADDISON.

30 BURNS'S LETTERS.

31 VOLSUNGA SAGA.

32 SARTOR RESAR'I'US.

33 WRITINGS OF EMERSON.

34 LIFE OF LORD HERBERT.

35 ENGLISH PROSE.

36 IBSEN'S PILLARS OF SOCIETY.

37 IRISH FAIRY AND FOLK TALES.

38 ESSAYS OF DR. JOHNSON.

39 ESSAYS OF WILLIAM HAZLITT.

40 LANDOR'S PENTAMERON, \&c.

41 POE'S TALES AND ESSAYS.

42 VICAR OF WAKEFIELD.

43 POLITICAL ORATIONS.

14 AUTOCRAT OF THE BREAKFAST-TABLE.

45 POET AT THE BREAKFAST-TABLE 46 PROFESSOR AT THE BREAKFAST-TABLE.

47 CHESTER FIELD'S LETTERS.

48 STORIES FROM CARLETON.

49 JANE EYRE.

50 ELIZABETHAN ENGLAND.

51 WRITINGS OF THOMAS DAVIS

52 SPENCE'S ANECDOTES.

May be had in the following Bindings:-Cloth, uncut edges, gilt top, Is. 6d. ; Half-Morocco, gilt top, antique ; Red Roan, gilt edges, etc.

53 MORE'S UTOPIA.

54 SADI'S GULISTAN.

55 ENGLISH FAIRY TALES.

56 NORTHERN STUDIES.

57 FAMOUS REVIEWS.

58 ARIS'TOTLE'S ETHICS.

59 PERICLES AND ASPASIA.

60 ANNALS OF TACITUS.

61 ESSAYS OF ELIA.

62 BALZAC.

63 DE MUSSET'S COMEDIES.

64 CORAL REEFS.

65 SHERIDAN'S PLAYS.

66 OUR VILLAGE.

67 MASTER HUMPHREY'S CLOCK

68 TALES FROM WONDERLAND.

69 JERROLD'S ESSAYS.

70 THE RIGHTS OF WOMAN.

71 "THE ATHENIAN ORACLE."

72 ESSAYS OF SAINTE-BEUVE.

73 SELECTIONS FROM PLA'IO.

74 HEINE'S TRAVEL SKETCHES.

75 MAID OF ORLEANS.

76 SYDNEY SMITH.

77 THE NEW SPIRIT.

78 MALORY'S BOOK OF MARVELLOUS ADVENTURES.

79 HELPS' ESSAYS \& APHORISMS.

80 ESSAYS OF MONTAIGNE.

81 THACKERAY's BARRY LYNDON.

82 SCHILLER'S WILLIAM TELL.

83 CARLYLE'S GERMAN ESSAYS.

84 LAMB'S ESSAYS.

85 WORDSWORTH'S PROSE.

86 LEOPARDI'S DIALOGUES.

87 THE INSPECTOR-GENERAL.

88 BACON'S ESSAYS.

89 PROSE OF MILTON.

90 PLATO'S REPUBLIC.

91 PASSAGES FROM FROISSART.

92 PROSE OF COLERIDGE.

93 HEINE IN ART AND LETTERS.

94 ESSAYS OF DE QUINCEY.

95 VASARI'S LIVES OF ITALIAN PAINTERS.

96 LESSING'S LAOCOON.

97 PLAYS OF MAETERLINCK.

98 WALTON'S COMPLETE ANGTER.

99 LESSING'S NATHAN THE WISE.

100 STUDIES BY RENAN.

101 MAXIMS OF GOETHE.

102 SCHOPENHAUER.

103 RENAN'S LIFE OF JESUS.

104 CONFESSIONS oF ST. AUGUSTINE

I05 PRINCIPLES OF SUCCESS IN LITERATURE.

LITERATURE.
106 WHA'I IS ART? (Tolstoy). 
Crown 8vo, Cloth, 3s. 6d. each; some vols., 6s.

THE

\section{Contemporary Science Series.}

EDITED BY HAVELOCK ELLIS.

Illustrated Volumes containing between 300 and 400 pp.

EVOLUTION OF SEX. By Prof. Geddes and Thomson. ELECTRICITY IN MODERN LIFE. By G. W. DE TUNZEL MANN.

THE ORIGIN OF THE ARYANS. By Dr. TAYLOR.

PHYSIOGNOMY AND EXPRESSION. BY P. MANTEGAZZA. EVOLUTION AND DISEASE. By J. B. SUTTON. THE VILLAGE COMMUNITY. By G. L. GOMME. THE CRIMINAL. By HAVELOCK ELLIS.

SANITY AND INSANITY. By Dr. C. MERCIER. HYPNOTISM. By Dr. AlBERT MOLL (Berlin).

MANUAL TRAINING. By Dr. WOODWARD (St. Louis). SCIENCE OF FAIRY TALES. By E. S. HARTLAND. PRIMITIVE FOLK. By ELIE RECLUS

EVOLUTION OF MARRIAGE. BY LETOURNEAU. BACTERIA AND THEIR PRODUCTS. Dr. WOODHEAD. EDUCATION AND HEREDITY. By J. M. GUYAU. THE MAN OF GENIUS. By Prof. LOMBROSO. THE GRAMMAR OF SCIENCE. By Prof. PEARSON. PROPERTY : ITS ORIGIN. BY $\mathrm{CH}$. LETOURNEAU. VOLCANOES PAST AND PRESENT. By Prof. HuLI. PUBLIC HEALTH PROBLEMS. By Dr. J. F. SYKES. MODERN METEOROLOGY. By FraNk WALdo, Ph.D. THE GERM-PLASM. By Professor WeismanN. 6s. THE INDUSTRIES OF ANIMALS. By F. HOUSSAY. MAN AND WOMAN. BY HAVELOCK ElLIS. 6s. MODERN CAPITALISM. By JOHN A. HOBSON, M.A. THOUGHT-TRANSFERENCE. By F. PODMORE, M.A. COMPARATIVE PSYCHOLOGY. By Prof. C. L. MORGAN. 6s. THE ORIGINS OF INVENTION. By O. T. MASON. THE GROWTH OF THE BRAIN. By H. H. DONALDSON. EVOLUTION IN ART. By Prof. A. C. HADDON. HALLUCINATIONS AND ILLUSIONS. By E. PARISH. 6s. PSYCHOLOGY OF THE EMOTIONS. By Prof. RiBot. 6s. THE NEW PSYCHOLOGY. By Dr. E. W. SCRIPTURE. $6 s$. SLEE : ITS Physiology, Pathology, Hygiene, aND PSYchology. By MaRie de MaNacÉĩne.

THE NATURAL HISTORY OF DIGESTION. By A. LOCKHART GillesPiE, M.D., F.R.C.P. ED., F.R.S. ED. 6s.

DEGENERACY : Its CAuses, Signs, aNd Results. By Prof. EUgene S. TAlbot, M.D., Chicago. $6 \mathrm{~s}$.

London: Walter Scott, Limited, Paternoster Square. 


\section{THE CANTERBURY POETS.}

Edtred by William Sharp. Cloth, Cut and Uncut Edges, Is. ; Red Roan, Gilt Edges, 2s. 6d.; Pad. Morocco, Gilt Edges, 5 s.

A Superior Edition Bound in Art Linen, with Photogravure Frontispiece, 25.

I CHRISTIAN YEAR

2 COLERIDGE

3 LONGFELLOW

4 CAMPBELL

5 SHELLEY

6 WORDSWORTII

7 BLAKE

8 WHITTIER

9 POE

IO CHATTERTON

II BURNS. Songs

12 BURNS. Poems

13 MARLOWE

14 KEATS

15 HERBERT

16 HUGO

17 COWPER

18 SHAKESPEARE'S POEMS, etc.

19 EMERSON

20 SONNETS OF THIS CENTURY

21 WHITMAN

22 SCOTT. Lady of the Lake, etc.

23 SCOTT. Marmion, etc.

24 PRAED

25 HOGG

26 GOLDSMITH

27 LOVE LETTERS, etc.

28 SPENSER

29 CHILDREN OF THE POETS 30 JONSON

31 BYRON. Miscellaneous.

32 BYRON. Don Juan.

33 THE SONNETS OF EUROPE

34 RAMSAY

35 DOBELL

36 POPE

37 HEINE

38 BEAUMONT \& FLETCHER

39 BOWLES, LAMB, etc.

40 SEA MUSIC

$4 I$ EARLY ENGLISH POETRY

42 HERRICK

43 BALLADES AND RONDEAUS

44 IRISH MINSTRELSY

45 MILTON'S PARADISE LOST

46 JACOBITE BALLADS

47 DAYS OF THE YEAR

48 AUSTRALIAN BALLADS

49 MOORE

50 BORDER BALLADS
51 SONG-TIDE

52 ODES OF HOKACE

53 OSSIAN

54 FAIRY MUSIC

55 SOUTHEY

56 CHAUCER

57 GOLDEN TREASURY

58 POEMS OF WILD LIFE

59 PARADISE REGAINED

60 CRABBE

6I DORA GREENWELL

62 FAUST

63 AMERICAN SONNETS

64 LANDOR'S POEMS

65 GREEK ANTHOLOGY

66 HUNT AND HOOD

67 HUMOROUS POEMS

68 LYTTON'S PLAYS

69 GRFAT ODES

70 MEREDITH'S POEMS

7 IMITATION OF CHRIST

72 UNCLE TOBY BIRTHDAY BK

73 PAINTER-POETS

74 WOMEN POETS

75 LOVE LYRICS

76 AMERICAN HUMOROUS VERSE.

77 MINOR SCOTCH LYRICS

78 CAVALIER LYRISTS

79 GERMAN BALLADS

80 SONGS OF BERANGER

8I RODEN NOEL'S POEMS

82 SONGS OF FREEDOM

83 CANADIAN POEMS

84 CONTEMPORARY SCOTTISH VERSB

85 POEMS OF NATURE.

86 CRADLE SONGS.

87 BALLADS OF SPORT.

88 MATTHEW ARNOLD.

89 CLOUGH'S BOTHIE.

90 BROWNING'S POEMS.

Pippa Passes, etc. Vol. 1.

9I BROWNING'S POEMS.

A Blot in the 'Scutcheon, etc. Vol. 2.

92 BROWNING'S POEMS.

Dramatic Lyrics. Vol. 3.

93 MACKAY'S LOVER'S MISSAL

94 HENRY KIRKE WHITE

95 LYRA NICOTIANA

96 AURORA LEIGH.

London: Walter Scott, Limited, Paternoster Square. 


\title{
The Canterbury Poets.
}

IMPORTANT ADDITIONS.

\section{WORKS BY ROBERT BROWNING.}

\author{
VOL. I.
}

Pippa Passes, and other Poetic Dramas, by Robert Browning. With an Introductory Note by Frank Rinder.

\section{VOL. II.}

A Blot in the 'Scutcheon, and other Poetic Dramas, by Robert Browning. With an Introductory Note by Frank Rinder.

VOL. III.

Dramatic Romances and Lyrics; and Sordello, by Robert Browning. To which is prefixed an Appreciation of Browning by Miss E. Dixon.

\section{BINDINGS.}

The ahove volumes are supplied in the following Bindings :-

IN GREEN ROAN, Boxed, with Frontispiece in Photogravure, 2s. 6d. net.

IN ART LINEN, with Frontispiece in Photogravure, 2s.

IN WHITE LINEN, with Frontispiece in Photogravure, $2 \mathrm{~s}$.

IN BROCADE, 2 Vols., in Shell Case to match (each vol. with Frontispiece), price $4 \mathrm{~s}$. per Set, or 3 vols. $6 \mathrm{~s}$. per Set.

And in the ordinary SHILLING BINDINGs, Green Cloth, Cut Edges, and Blue Cloth, Uncut Edges (without Photogravure).

The Three Volumes form an almirable and representative "Set," including a great part of Browning's best-known and most admired work, and (being each of about 400 pages) are among the largest yet issued in the CANTERBURY PoETs. The Frontispiece of Vol. I. consists of a reproduction of one of Browning's last portraits; Mr. Rudolf LeHManN has kindly given permission for his poitrait of Browning to be reproduced as a Frontispiece of Vol. II. ; while a reproduction of a drawing of a View of Asolo forms the Frontispiece of the third Volume.

LONDON : Walter ScotT, LTd., Paternoster Square. 


\section{The World's Great Novels.}

\section{Large Crown 8vo, Illustrated, 3s. 6d. each.}

Uniform with the New Edition of "Anna Karénina"

A series of acknowledged masterpieces by the most eminent writers of fiction.

THE COUNT OF MONTE-CRISTO. By Alexandre Dumas. With Sixteen Full-page Illustrations drawn by Frank T. MERRILL, and over I100 pages of letterpress, set in large clear type.

THE THREE MUSKETEERS. By AlexandRe Dumas. With Twelve Full-page Illustrations by T. EYRE MACKLIN, a Photogravure Frontispiece Portrait of the Author, and over 600 pages of letterpress, printed from large clear type.

TWENTY YEARS AFTER. BY ALEXANDRE DUMAs. With Sixteen Full-page Illustrations by FrANK T. MERRILL, and 800 pages of letterpress, set from new type.

LES MISÉRABLES. By VICTOR Hugo. With Eleven Full-page Illustrations, and 1384 pages of letterpress.

NOTRE DAME. By Victor Hugo. With numerous Illustrations.

JANE EYRE. By CharlotTe Brontë. With Sixteen Full-page Illustrations, and Thirty-two Illustrations in the Text, by EDMUND H. GARRETT, and Photogravure Portrait of Charlotte Brontë. Printed in large clear type; 660 pages of letterpress.

Tolstoy's Great Masterpiece. New Edition of Anna Karénina. ANNA KARÉNINA: A NOVEL. By COUNT TolsToy. With Ten Illustrations drawn by PAUL FrénzenY, and a Frontispiece Portrait of Count Tolstoy in Photogravure.

"Other novels one can afford to leave unread, but Anna Karénina never; it stands eternally one of the peaks of all fiction."-Revierw of Revierws.

London: WALTER SCOTT; LtD., Paternoster Square. 

THIS BOOK IS DUE ON THE IAST DATE STAMPED BELOW

AN INITIAL FINE OF 25 CENTS WILL BE ASSESSED FOR FAILURE TO RETURN THIS BOOK ON THE DATE DUE. THE PENALTY WILL INCREASE TO 50 CENTS ON THE FOURTH DAY AND TO $\$ 1.00$ ON THE SEVENTH DAY OVERDUE.

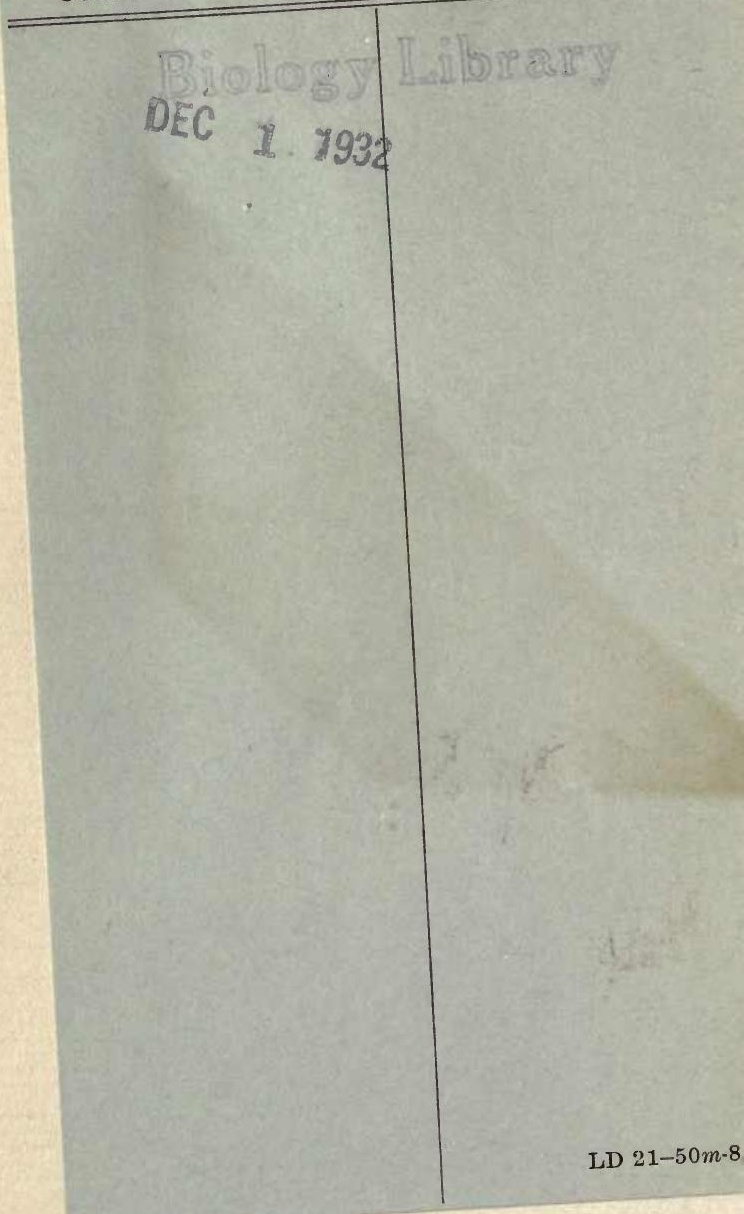




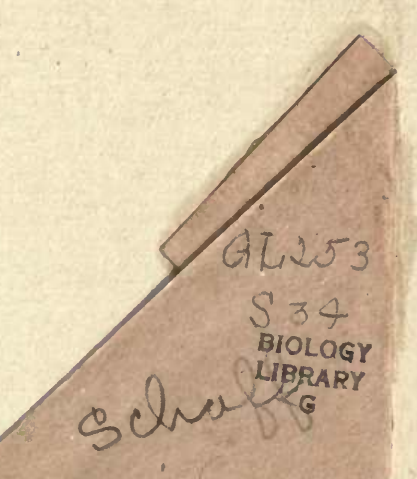
86461 
, 